\title{
ESTRATEGIAS DE INTERNACIONALIZACIÓN EN EL SECTOR DEL E-LEARNING PARA INSTITUCIONES DE EDUCACIÓN SUPERIOR
}

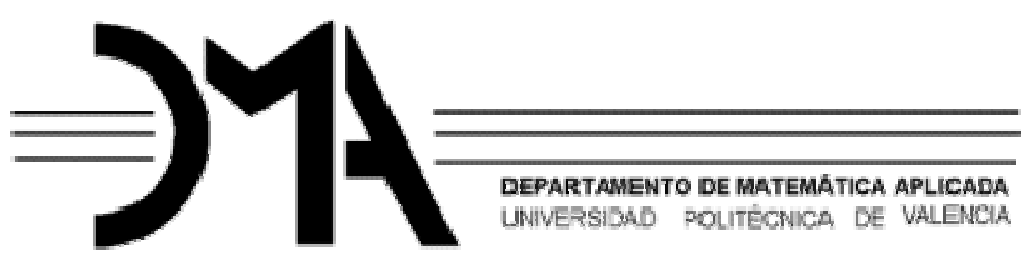

David Roldán Martínez

Dirigida por Dr. Antonio Hervás Jorge

Departamento de Matemática Aplicada

Universidad Politécnica de Valencia

España, 2007 
Este trabajo plantea un estudio de la internacionalización de la Educación Superior desde el punto de vista de las Universidades y del e-learning como estrategia competitiva, proponiendo un proceso de construcción de dicha estrategia competitiva a partir del análisis estratégico del sector que, además, pretende plantear opciones que puedan servir de base para futuros estudios relacionadas con este sector de actividad en el ámbito de la Educación Superior.

A este fin, en primer lugar se analiza el entorno en que se hallan inmersas las Universidades y que se caracteriza por una clara tendencia a la internacionalización de la Educación Superior cuya muestra en Europa es el desarrollo del Espacio Europeo de Educación Superior. Seguidamente, y como quiera que las TIC son uno de los habilitadores de este proceso transformador, se describe el proceso de incorporación de las Tecnologías de la Informática y las Comunicaciones a todos los ámbitos de la actividad universitaria (docencia, investigación y gestión) y en sus consecuencias, para pasar a profundizar en su aplicación al proceso de enseñanza-aprendizaje. Posteriormente, y siguiendo las directrices de diseño de estrategias de aprendizaje flexible propuesto por la Australian National Training Autority, se propone un método de análisis estratégico del sector del e-learning en el ámbito de la Educación Superior a partir del cual se concluye con la identificación de las bases para la construcción de una estrategia competitiva en un mercado internacionalizado de Educación Superior, dejando la puerta abierta a estudios más avanzados y profundos de las líneas generales planteadas.

En este trabajo se pretende introducir un procedimiento sistemático de análisis que asista a las instituciones de Educación Superior en la elaboración de sus planes estratégicos y tácticos en cuanto a la formación on-line se refiere, siempre con el objetivo de conseguir una posición y una ventaja competitivas sólidas y estables. 
Aquest treball planteja un estudi de la internacionalització de l'Educació Superior des del punt de vista de les Universitats i de l'e-learning com estratègia competitiva, proposant un procés de construcció d'aquesta estratègia competitiva a partir de l'anàlisi estratègica del sector que, a més, pretén plantejar opcions que puguen servir de base per a futurs estudis i que estiguen relacionades amb aquest sector d'activitat en l'àmbit de l'Educació Superior.

A aquest fi, en primer lloc s'analitza l'entorn en que es troben immerses les Universitats i que es caracteritza per una clara tendència a la internacionalització de l'Educació Superior, la mostra de la qual a Europa és el desenvolupament de l'Espai Europeu d'Educació Superior. Seguidament, i com que les TIC són un dels habilitadors d'aquest procés transformador, es descriu el procés d'incorporació de les Tecnologies de la Informàtica i les Comunicacions a tots els àmbits de l'activitat universitària (docència, investigació $\mathbf{i}$ gestió) $\mathbf{i}$ en les seues conseqüències, per a passar a aprofundir en la seua aplicació al procés d'ensenyament-aprenentatge. Posteriorment, i seguint les directrius de disseny d'estratègies d'aprenentatge flexible proposat per l'Australian National Training Autority, es proposa un mètode d'anàlisi estratègica del sector de l'e-learning en l'àmbit de l'Educació Superior a partir del qual es conclou amb la identificació de les bases per a la construcció d'una estratègia competitiva en un mercat internacionalitzat d'Educació Superior, deixant la porta oberta a estudis més avançats i profunds de les línies generals plantejades.

En aquest treball es pretén introduir un procediment sistemàtic d'anàlisi que assistisca a les institucions d'Educació Superior en l'elaboració dels seus plans estratègics i tàctics respecte a la formació on-line, sempre amb l'objectiu d'aconseguir un posicionament $i$ un avantatge competitius sòlids i estables. 
This work is a study about Higher Education internationalization analyzed from the point of view of Universities and e-learning as a competitive strategic tool, proposing a construction process of such a strategy through the strategic analysis of the sector which, besides, pretends to identify options that will be the foundation for future studies about this sector of activity in the Higher Education scope.

First of all, the context where the Higher Education institutions are living in is analysed. This environment is characterized by a clear trend to the internationalization and the European Higher Education Space is only an example.

Then, because of the TIC are one of the drivers of this transforming process, it is described how Communication and Information Technologies (CIT) are introduced in all the aspects of the

University activity (teaching, research and management) and its consequences, going through a deeper study about how CIT can be applied for teaching and learning.

Afterwards, following the guidelines from flexible learning planning of the Australian National Training Authority, it is proposed a strategic analysis method for the e-learning sector in to Higher Education context which use allows to identify critical issues for the building of a competitive strategy in the Higher Education internationalized market, trying to establish the basis for further and future research and work in this area.

To summarize, this work has tried to introduce a systematic analysis process useful when the Higher Education institutions want to elaborate their strategy and tactic plans related with on-line education. 
A MI MUJER Y A MI HIJA,

"There are two great clichés about the university. One pictures it as a radical institution, when in fact it is most conservative in its institutional conduct. The other pictures it as autonomous, a cloister, when the historical fact is that it has always responded, but seldom so quickly as today, to the desires and demands of external groups -sometimes for love, sometimes for gain, increasingly willingly, and, in some cases, too eagerly. The external view is that the university is radical; the internal reality is that it is conservative. The internal illusion is that it is a law unto itself; the external reality is that it is governed by history."

Clark Kerr, The Uses of the University, 1963. 


\section{AGRADECIMIENTOS}

A Dios Gracias, muchas gracias, porque me ha permitido terminar un proyecto más y me ha dado la fuerza y el valor necesarios para lograrlo y continuar adelante.

A mi hija, Natalia, y mi mujer, Clara, a quienes mucho debo por toda la fuerza que me infundaron y por todo el tiempo que estuve lejos de ellas investigando, pensando y escribiendo este trabajo. A mis padres, hermano y familiares por todo el apoyo recibido, que ha sido mucho y muy sustancial.

A Antonio Hervás, por guiarme en mi desarrollo personal dentro de éste área de conocimiento que tanto me gusta y llena. También por su sinceridad y sabios consejos que me han sido de utilidad en éste y otros ámbitos de mi vida.

A Mar Monsoriu, por sus ánimos y orientaciones y por esas horas de animada conversación de las que han surgido muchas de las ideas de este trabajo.

También me gustaría dedicar unas palabras de agradecimientos a aquellos que han colaborado en la recopilación de información y que me han proporcionado datos, ánimo y ayuda desinteresada. Espero no olvidarme de nadie: José Manuel Huidobro, Julio Alba, Mariate GómezMascaraque, Alberto Ramos, Carla Martín, José Canabate, Arturo Azcorra, Luis Moltó, Andrés López, David Plá, Pascual Muñoz, Roberto Romero, Xavier Illana, Miguel González y al IL3.

Finalmente, a todos aquellos que algún día se cruzaron en mi camino y confiaron en mí por la seguridad y el ánimo que me proporcionaron, y a todos aquellos que me pusieron algún obstáculo, porque el reto de superarlo me hizo crecer y hacerme más fuerte.

A todos,

MUCHAS GRACIAS 


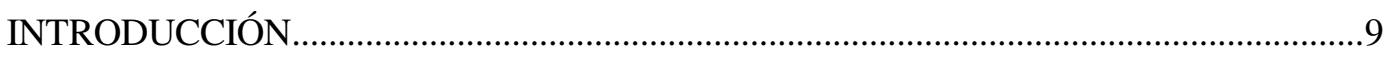

Capítulo 1 Introducción ..............................................................................................11

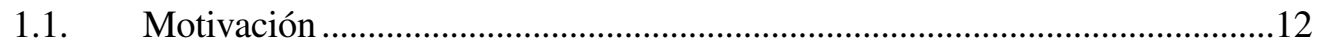

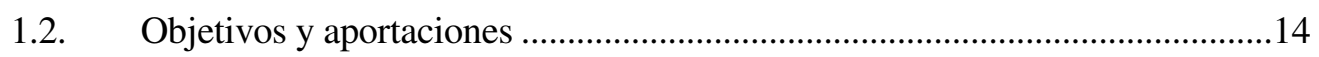

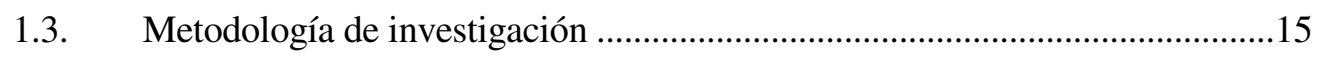

1.3.1. Diagrama base: el FLBPF de ANTA ........................................................16

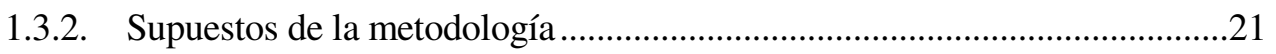

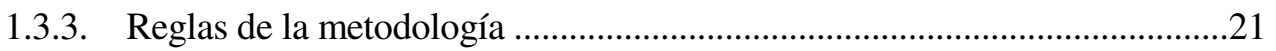

1.3.4. Recopilación de datos................................................................................21

1.3.5. Limitaciones del estudio.............................................................................22

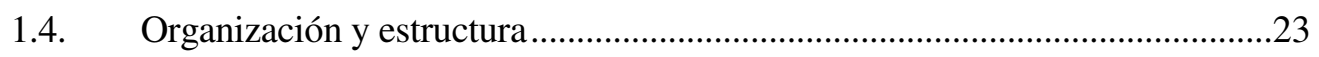

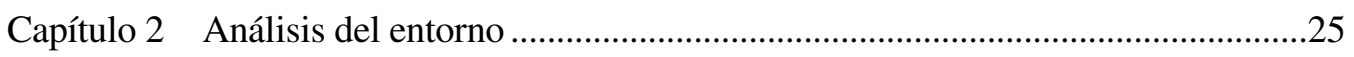

2.1. La Universidad en la Sociedad de la Información y el Conocimiento .............25

2.2. Internacionalización y globalización de la Educación Superior........................29

2.3. Impulsores de la transformación universitaria ..................................................32

2.3.1. Evolución de la demanda de enseñanza universitaria ...................................33

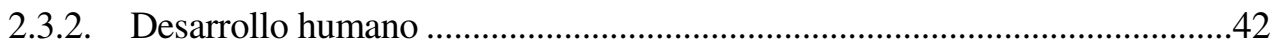

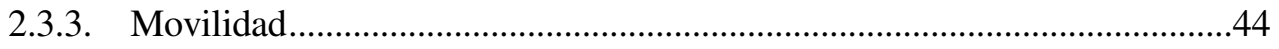

2.3.4. Innovación y tecnología .........................................................................46

2.3.5. Demanda de resultados de la actividad universitaria .....................................47

2.3.6. Cambios en el control del sistema educativo...................................................48

2.3.7. Evolución de la financiación........................................................................49

2.3.8. Comercialización de servicios de información y conocimiento.....................51

2.4. Principales manifestaciones del cambio organizativo ........................................55

2.4.1. Adopción de parámetros de mercado..........................................................55

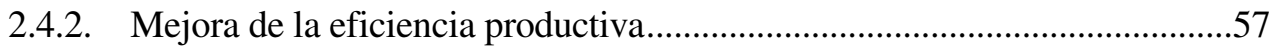

2.4.3. Reducción de estructuras y descentralización ................................................59

2.4.4. Comunicación y transparencia informativa ...................................................63

2.5. Europeización de la Educación Superior: el EEES ..........................................64

Capítulo 3 Las TIC en la Universidad..........................................................................69

3.1. Introducción de las TIC en las Universidades españolas..................................70

3.2. Actitud frente la incorporación de las TIC......................................................74 


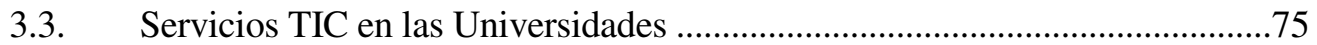

3.4. Obstáculos a la implantación de las TIC ...........................................................77

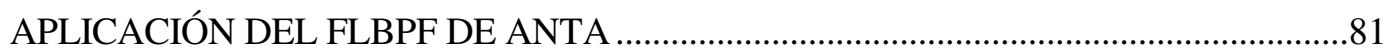

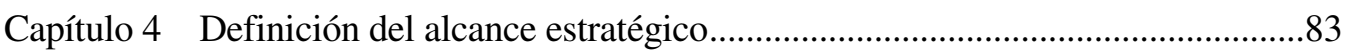

4.1. Estrategia y planificación de la introducción de las TIC en la Universidad ...84

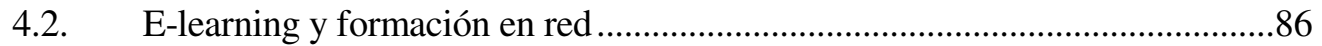

4.3. Estrategias de utilización del e-learning...........................................................91

4.4. Modelos organizativos en Universidades Virtuales .........................................97

4.5. Incidencia del e-learning en la estructura organizativa de la Universidad......99

Capítulo 5 Análisis del sector ......................................................................................101

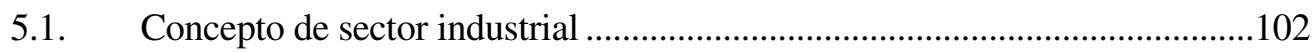

5.2. Selección de un modelo de análisis sectorial ....................................................103

5.3. Análisis estructural .....................................................................................107

5.3.1. Rivalidad e identificación del competidor ..................................................108

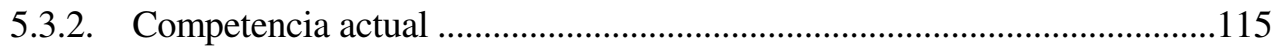

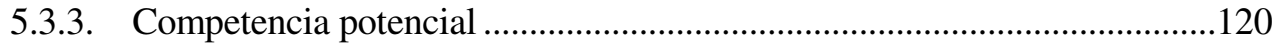

5.3.4. Negociación con los proveedores ...............................................................123

5.3.5. Negociación con los clientes ........................................................................124

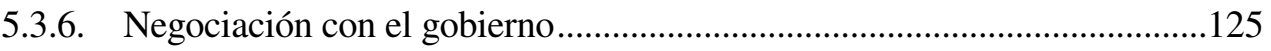

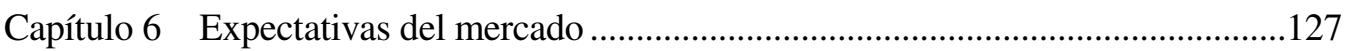

6.1. Análisis de la demanda ..............................................................................127

6.2. Perfil sociodemográfico del consumidor de formación on-line ......................133

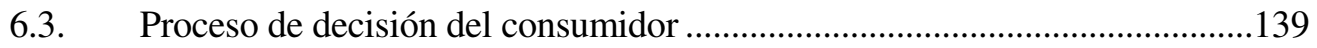

Capítulo 7 Análisis interno y capacidad proveedora ......................................................143

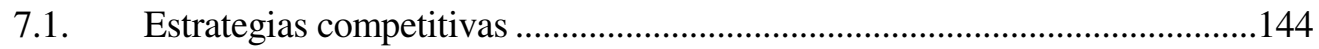

7.2. Cadena de valor del e-learning .......................................................................144

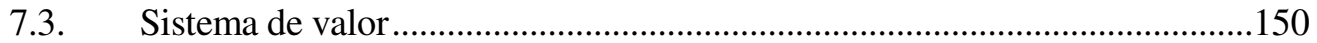

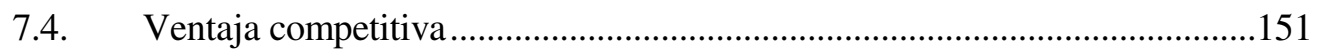

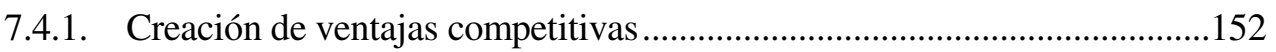

Capítulo 8 Viabilidad económica ...............................................................................157

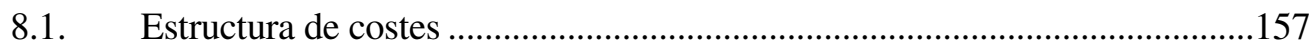

8.1.1. Planificación y producción de materiales ......................................................161

8.1.2. Realización del curso..................................................................................163

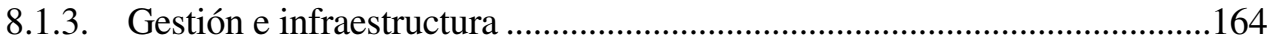

8.1.4. Número de matrículas...............................................................................165

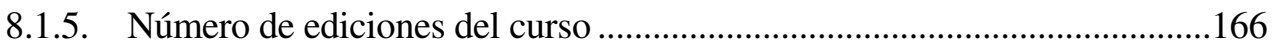


8.2. Activos intangibles asociados al e-learning ..................................................167

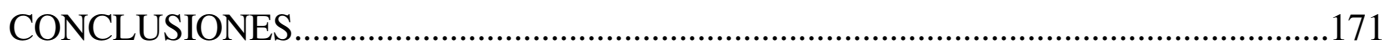

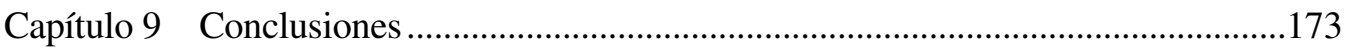

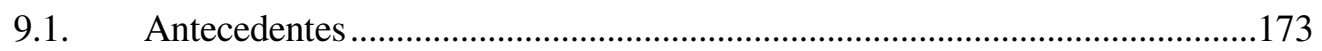

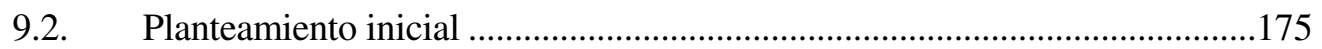

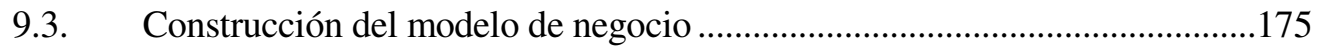

9.3.1. Análisis estratégico del sector ...................................................................176

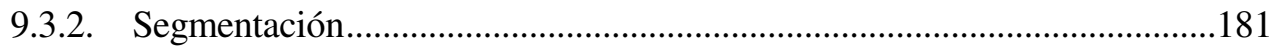

9.3.3. Identificación del competidor........................................................................183

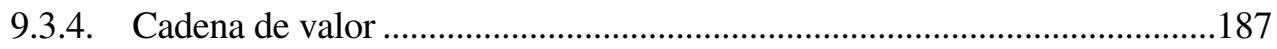

9.3.5. Estructura de costes ...............................................................................189

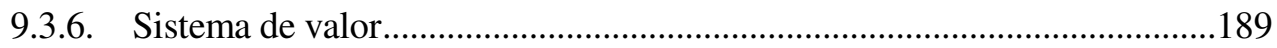

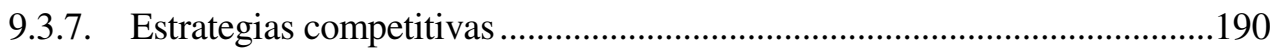

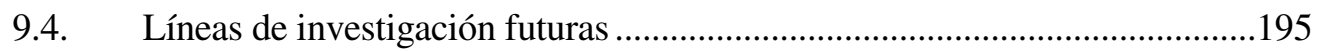

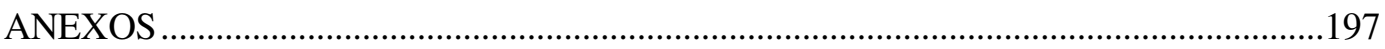

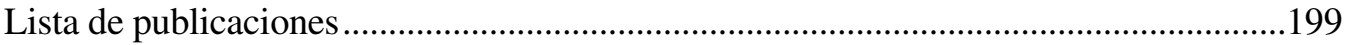

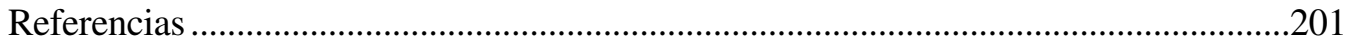




\section{INTRODUCCIÓN}




\section{CAPÍTULO 1 INTRODUCCIÓN}

La tesis que se presenta se refiere a investigar los efectos de los cambios en los paradigmas sociales y económicos sufridos en los últimos años en la Educación Superior, consecuencia, sobre todo, de la globalización, desde una perspectiva empresial, siempre sin dejar de lado la labor social de las Universidades. Sin embargo, ello obliga a trasladar conceptos propios del mundo empresarial al académico y emplear una terminología más propia del mundo de los negocios que del educativo.

Tal y como aseguró recientemente el director general de Universidad y Formación Superior en la III Jornada del Sistema Universitario Público Valenciano, el contexto socioeconómico actual exige promover la actividad empresarial en la Universidad (Capilla, 2007).

"Hoy ya no basta con formar buenos profesionales como se ha hecho desde siempre en nuestras aulas. [...] Hay que promover el conocimiento de la actividad empresarial y se debe proporcionar a los estudiantes las capacidades necesarias para la creación y gestión de nuevos proyectos empresariales".

Ya en 2002, Skilbeck (citado en Brunner y Uribe, 2007) advertía que:

"La Universidad ya no es más un lugar tranquilo para enseñar, realizar trabajo académico a un ritmo pausado y contemplar el universo como ocurría en siglos pasados. Es ahora un potente negocio, complejo, demandante y competitivo que requiere inversiones continuas y de gran escala".

Esta afirmación no hace sino poner de manifiesto el creciente interés de la investigación y la literatura especializada sobre la Educación Superior en la orientación a mercado de la misma, que constituye una de las tendencias actuales, tal y como confirman innumerables informes nacionales e internacionales sobre el tema, así como la creciente preocupación de los Gobiernos y su actitud favorecedora de iniciativas y proyectos relacionados con este campo de actividad.

En esta misma línea, en este trabajo se pretenden formular propuestas y aportar ideas que amplíen el conocimiento en dicho terreno y que, además, sirvan de referencia para futuros estudios adicionales en el propio sector y en sectores afines. Para ello, se propone un proceso de construcción de modelos de negocio a partir del análisis estratégico del sector del e-learning en la Educación Superior española que complementa las directrices de planificación, diseño, implantación y explotación de soluciones de aprendizaje flexible propuestas por la Australian National Training Autority ${ }^{1}$ (2003).9

\footnotetext{
${ }^{1}$ En adelante, nos referiremos a esta entidad por su acrónimo: ANTA.
} 


\subsection{MOTIVACIÓN}

La evolución social de la formación durante el último siglo, medida a través del nivel de formación de los individuos ha experimentado una importante mejora. La constatación de una incidencia recíproca entre la formación y la actividad económica ha permitido delimitar la existencia de interrelaciones significativas entre Educación y Economía. De hecho, en la Sociedad de la Información y el Conocimiento, existe un estrecho vínculo entre el desarrollo económico y la acumulación de conocimiento (Langlois, 2003). La consecuencia principal es que la demanda formativa por parte de los diferentes sectores de dicha Sociedad sea continua, e incluso se incremente, a lo largo de la vida de las personas.

Por esta razón, los Gobiernos de los países desarrollados están prestando una atención especial a la formación de los ciudadanos, no sólo durante sus etapas escolares tradicionales y universitarias, sino también una vez que el individuo se incorpora a la vida laboral, pues cada vez resulta más frecuente el libre movimiento de personal cualificado entre diferentes países. Una muestra de esta preocupación es que, por ejemplo, en la Unión Europea se ha puesto como objetivo desarrollar la economía de conocimiento más competitiva del mundo fijándose un horizonte en el 2010 (Estrategia de Lisboa, 2000). Todo ello lleva a que, en general, se estén lanzando numerosos programas e instrumentos de optimización de los sistemas y políticas de educación y formación en la práctica mayoría de los países del mundo desarrollado y sus zonas de influencia. En un panorama como éste, la utilización de las nuevas tecnologías como catalizadoras de la eficiencia y la eficacia de los programas formativos resulta obvia y es, precisamente, en este punto en donde entra el juego el e-learning.

El e-learning ha surgido, por tanto, como una respuesta a la demanda del medio externo, inserto en una sociedad marcada fuertemente por el impacto de las Tecnologías de la Información y de las Comunicaciones (TIC) en todo el quehacer de las personas, tanto en el ámbito personal como el profesional. En el caso particular de España, durante las últimas décadas las fuerzas económicas y tecnológicas han hecho evolucionar la economía desde una economía productiva a una economía de servicios. Por otra parte, en un entorno socioeconómico caracterizado por la globalización y la revolución tecnológica, el aprendizaje a lo largo de toda la vida es imperativo ya que la vida del conocimiento es reducida y éste queda caduco a pasos agigantados.

En este contexto, desde la década de los 1990, las Universidades se han enfrentado a numerosos cambios, tanto internos como externos: incorporación de las TIC a todos los ámbitos de la actividad universitaria, cambios sociales y demográficos de los estudiantes, adopción de parámetros de mercado, exigencia de transparencia en los resultados de su actividad y disminución de la financiación pública (Ryan et al., 2000; Alexander, 2001). El sector empresarial tampoco ha sido ajeno a esta evolución del entorno socioeconómico. La globalización ha tenido como principal consecuencia la apertura a nuevos mercados gracias a la reducción de las barreras espaciales que implica Internet, aunque también supone la entrada en el mercado de otras empresas que hasta ahora competían en un ámbito más localizado. También los avances tecnológicos han contribuido a esta vorágine de cambios: aumento del ancho de banda, incremento de la capacidad de almacenamiento, disponibilidad de banda ancha en prácticamente cualquier ubicación y con una amplia variedad de tecnologías de acceso, abaratamiento de los costes de las TIC, etc.

En definitiva, la expansión de Internet en todos los ámbitos del negocio y el entretenimiento, tiene su consecuencia lógica en el sector de la Educación Superior. Sin embargo, aunque, en general, las Universidades presentan una actitud favorable y de cierto compromiso con el empleo de las TIC (muestra de ello, como se verá más adelante, es la consolidación de dotación presupuestaria para este apartado), demasiado frecuentemente se trata de iniciativas proactivas e improvisadas y son muy pocas las que disponen de una verdadera estrategia institucional en este sentido (CRUE, 2004). Este hecho es debido a la escasa competencia que las Universidades han tenido en su sector de actividad, en el que tradicionalmente han venido disfrutando de una posición cuasi-hegemónica en su zona de influencia. Sin embargo, la globalización fruto de la 
expansión de Internet ha permitido la entrada de nuevos actores y la creación de un entorno competitivo mucho más voraz (Watson, 2000). Pero, al contrario de lo que ocurre con las empresas, las Universidades en general no están orientadas al negocio y no están acostumbradas a regirse por parámetros de mercado (Collis y Moonen, 2001). Por ello, son necesarios estudios que sirvan a las Universidades de guía a la hora de entrar a competir en el sector del e-learning.

Por otra parte, en los últimos años, se ha producido una serie de alteraciones en el entorno social y económico que permiten explicar las principales líneas de transformación de las Universidades de las economías desarrolladas. Estas transformaciones han tenido un carácter holístico y universal (Lam, 2001) y han incidido en la forma de organizar y gestionar la actividad universitaria, introduciendo una serie de alteraciones que deben entenderse en el contexto de la adaptación de la institución universitaria a la nueva realidad económica y social (Tugores y Pont Clemente, 1999, Burton-Jones, 1999; Ohmae, 2000). Como señala Scott (1998), todas las Universidades están sometidas al mismo proceso de globalización en tanto en cuanto víctimas de dicho proceso como en cuanto agentes de la propia globalización.

La búsqueda de instrumentos para dar respuesta a los nuevos requerimientos del contexto universitario ha acarreado un efecto imitación de las experiencias exitosas de la industria privada y, por tanto, una adaptación en muchos casos de los parámetros económicos consolidados en el ámbito empresarial (Michael, 1997). En efecto, hoy observamos cómo la transferencia de conocimiento procedente del mundo empresarial respecto a la introducción de innovaciones tecnológicas empieza a tener eco en el sector universitario, lo cual no deja de ser beneficioso, siempre y cuando la institución universitaria siempre sepa trasladar adecuadamente, y sin dejar a un lado su misión social, dichos conocimientos (Duart y Lupiáñez, 2005).

La principal consecuencia de este escenario es la adopción de una nueva visión del sector universitario como una industria del conocimiento (Duderstadt, 1997), es decir, la consideración de la existencia de un sector de valor añadido que tiene en el conocimiento su principal materia prima y su mercancía (GATS, 1995). Desde esta perspectiva de industria de valor añadido, los resultados e incluso la supervivencia de las Universidades dependen en gran parte de su capacidad de crear valor a partir de la adopción de nuevas formas de realizar y de organizar sus propias actividades. En este sentido, en el sector universitario se han empezado a definir los productos de la formación como commodities, los estudiantes como clientes y el rol del personal académico como la base del proceso de generación de valor para el estudiante (Agre, 2002).

Así, la evolución del contexto económico y social ha llevado a muchas instituciones universitarias a considerar la adopción de este modelo de commodity como una estrategia aceptable y adecuada para afrontar un proceso necesario de adaptación a su entorno más inmediato. En muchas ocasiones, sin embargo, la implantación de estos sistemas ha acarreado numerosos problemas asociados con el propio funcionamiento de la Universidad, que en muchos aspectos no opera bajo criterios económicos empresariales (Birnbaum, 1988).

Por todas estas razones, la comprensión del impacto del e-learning y su inclusión en el proceso de planificación estratégica y táctica de las Universidades resulta imprescindible si se desea analizar el mercado actual de la Formación Superior. Para facilitar dicho análisis, esta tesis pretende ofrecer una visión útil del comportamiento actual del mercado del $e$-learning y establecer un método de construcción de modelos de negocio a partir del análisis estratégico de dicho sector. Asimismo se pretende formular una propuesta y aportar ideas que amplíen el conocimiento en dicho terreno y que, además, sirvan referencia para estudios futuros, tanto en el propio sector como en sectores afines. Por supuesto, dada la naturaleza dinámica del sector, las conclusiones de cualquier estudio o análisis deberán revisarse periódicamente (Rosenberg, 2001; Lerner, 1999).

Por este motivo, y con el objetivo de aportar más elementos a la comprensión del complejo fenómeno de las relaciones entre la tecnología, la economía y la Universidad, creemos conveniente comenzar esta tesis doctoral con una exposición de la evolución, en las últimas 
décadas, de las relaciones entre la formación ${ }^{2}$ y la economía, con el objetivo de ubicar mejor el papel y los retos de futuro de las Universidades. Para ello, la investigación que se plantea en este trabajo analiza algunos aspectos económicos y estratégicos de la actividad de un determinado segmento de Universidades. La situación, el comportamiento y la evolución de estas Universidades, así como las decisiones adoptadas sobre su propia actividad, dependen en gran medida de un amplio conjunto de variables ubicadas en su contexto económico y social.

\subsection{OBJETIVOS Y APORTACIONES}

En este punto, y siguiendo el marco de análisis de la actividad empresarial, cabe destacar que se detecta una carencia de un análisis general y estructurado de la incidencia de las TIC en la actividad universitaria en general y del e-learning en particular evidenciadas por la literatura internacional (Teare, Davies y Sandelands, 1998; Bates, 1995). Es decir, cabe profundizar en el estudio de cómo las TIC están haciendo posible el surgimiento de elementos intangibles específicos asociados a la propia integración tecnológica, a la metodología y a la organización de la actividad universitaria, cómo se interrelacionan y cuáles son las implicaciones de esta interacción en la estrategia competitiva de las Universidades (Castillo, 2004).

Por otra parte, dentro de la literatura, el e-learning ha sido analizado teórica y empíricamente más de la perspectiva pedagógica y tecnológica que a partir de cuestiones estratégicas, si bien es posible encontrar algunos trabajos sobre modelos de negocio (Sangrá, 2001; Hoppe y Breitner, 2003). Por lo tanto, se requiere una investigación profunda que contribuya a analizar estratégicamente este sector, explicando su evolución, que dé una pauta para iniciar investigaciones futuras y que pueda servir como marco de referencia para estudios similares, abordando dicho análisis desde una perspectiva más amplia.

Este trabajo puede contribuir a explicar de una manera más precisa la naturaleza del comportamiento empresarial del sector del e-learning en el entorno de la Educación Superior, así como los factores que subyacen a la decisión de las instituciones de competir en dicho sector, con un especial énfasis en proporcionar un marco de referencia para el análisis estratégico del sector y para el diseño de modelos de negocio, introduciendo, por otra parte, un grado de detalle infrecuente en los escasos estudios realizados hasta la fecha.

Con este enfoque, este trabajo nace con los siguientes objetivos:

- Diferenciar, desde la perspectiva del marketing estratégico, los diversos factores que pueden ser críticos en la obtención de una ventaja competitiva sostenible dentro del sector del e-learning y, más concretamente, en el ámbito de la formación on-line superior.

- Proponer un marco teórico y conceptual que sirva de enlace entre las teorías de estudio del mercado, las fuentes de ventaja competitiva y la excelencia empresarial.

- Ampliar el conocimiento acerca del sector del e-learning en el ámbito de la formación superior, revisando las condiciones y tendencias de la industria, las condiciones en que operan las instituciones, sus servicios y tecnologías, bajo un esquema de intenso crecimiento y competitividad.

${ }^{2}$ En la literatura internacional se emplea muy habitualmente el término anglosajón education para referirse a la enseñanza tanto preuniversitaria como universitaria, es decir, a la formación a la persona, por oposición al training que define la formación directamente relacionada con la profesión del individuo asociada al puesto de trabajo. Etimológicamente, educación se refiere a la preparación del carácter y la inteligencia de los menores para que vivan en Sociedad mientras que la formación se define, en una de sus múltiples acepciones, como el entrenamiento en una determinada materia o actividad. Por tanto, la educación está más enfocada al modelo de las capacidades innatas de los individuos y la formación a la incorporación de conocimiento y de habilidades en materias o actividad concretas. Por este motivo, se considera más adecuado el empleo del término formación en este trabajo de tesis, ya que su semántica es más adecuada al contenido de la enseñanza superior, la cual es objeto de estudio. 
- Analizar el comportamiento de las instituciones de formación superior del sector observando cómo compiten entre ellas, estudiando sus modelos de rivalidad y dinámica competitiva.

\subsection{METODOLOGÍA DE INVESTIGACIÓN}

La dimensión del universo objeto de análisis y, especialmente, el número de variables de las que se dispone información, determina la opción metodológica que se debe adoptar.

El primer paso a la hora de seleccionar una opción metodológica de investigación es acotar la prentensión y el propósito de la misma.

Tal y como se ha expuesto en el apartado anterior, esta tesis pretende arrojar luz sobre la investigación centrada en mercado de la Educación Superior, proponiendo unas directrices generales útiles en el diseño de modelos de negocio para Universidades en un entorno educativo internacionalizado que puedan resultar útiles para investigaciones posteriores.

El concepto de modelo de negocio unifica decisiones importantes en el ámbito empresarial desde los puntos de vista económico, operacional y estratégico. Constituye una unidad de análisis muy útil que facilita el desarrollo teórico de la puesta en marcha de una idea empresarial. Sin embargo, aunque las raíces de la teoría de modelos de negocio son están claras, no ocurre lo mismo con la definición de modelo de negocio, en donde no existe un acuerdo unánime. No obstante, en lo que sí existe cierto consenso en la literatura internacional (Stewart y Zao, 2000; Afuah y Tucci, 2001; Amit y Zott, 2001; Mahadevan, 2000; Ethiraj, Guler y Singh, 2000), es en la importancia de identificar los actores participantes en un modelo de negocio y sus relaciones entre ellos.

Por todo ello, en lugar de centrar la tesis en el concepto de modelo de negocio, se ha preferido enfocarla hacia la utilidad práctica de dicho concepto, en la línea de lo sugerido en los trabajos de Standing Stones (2000), Canzer (2003) o Turban et al. (2004), de manera que los resultados de esta tesis puedan aplicarse con relativa facilidad a situaciones reales. El objetivo principal de la investigación llevada a cabo en esta tesis ha sido, por tanto, recopilar la información necesaria para:

1. Articular la proposición de valor, esto es, el valor creado para los usuarios del modelo por el producto (bien y/o servicio) ofrecido usando la tecnología.

2. Identificar un segmento del mercado, para dichos usuarios el uso de la tecnología debe ser útil y la empresa debe obtener ingresos por el ofrecimiento de la misma.

3. Definir la estructura de la cadena de valor que la empresa necesita para crear y distribuir su producto y determinar los activos complementarios necesarios para apoyar la posición de la empresa

4. Estimar la estructura de costes y los beneficios potenciales para ofrecer su producto, teniendo en cuenta la proposición de valor y la estructura de la cadena de valor elegida.

5. Describir la posición de la empresa dentro del sistema de valor, relacionando proveedores y clientes.

6. Formular la estrategia competitiva a través de la cual la empresa innovadora será más competitiva y obtendrá una ventaja sostenible.

Para lograr estos objetivos, se sugiere partir del análisis estratégico del sector y de la propia institución, empleando como guía el marco de trabajo propuesto por la Australian National Training Autority (2003) y que se describirá con más detalle en un epígrafe de este apartado.

Bajo estos supuestos, el estudio se abordará siguiendo una estrategia de indicios (Brunner y Uribe, 2007), según la cual es posible estudiar un campo de análisis dado empleando como indicios o señales las aportaciones de los expertos más prestigiosos en el campo de análisis bajo estudio. No obstante, aunque Brunner y Uribe (2007) indican que no es necesario el estudio del 
campo de análisis por "medios exhaustivos o mediante una minuciosa reconstrucción de sus diversos aspectos (estructura teórica, paradigmas o escuelas de pensamiento, programas de investigación, conceptos matrices y derivados, técnicas de recolección y análisis de datos, métodos heurísticos puestos en juego, estados del arte sobre los conocimientos adquiridos, etc.)", con el fin de completar y reforzar los indicios se incluirán, cuando estén disponibles, datos cualitativos y cuantitativos útiles a este efecto.

\subsubsection{Diagrama base: el FLBPF de ANTA}

Con el fin de ordenar el análisis, Brunner y Uribe (2007) proponen emplear un diagrama base en el que aparezcan las líneas de investigación que lo constituirán. En nuestro caso, se empleará el marco de trabajo FLBPF (Flexible Learning Business Planning Framework) propuesto por ANTA para la planificación estratégica de proyectos de aprendizaje flexible, independientemente de las tecnologías de soporte, y que presenta un enfoque orientado al mercado y a la organización.

Según ANTA (2003), el aprendizaje flexible es una aproximación a la formación que se caracteriza por estar centrada en el estudiante, siendo independiente, por otra parte, de los mecanismos de entrega (educación a distancia, blended learning, e-learning, etc.). Sin embargo, a efectos de este trabajo, se considerará como aprendizaje flexible cualquier manifestación de la formación en red (ver apartado 4.1).

En su sentido más amplio, el FLBPF persigue los siguientes objetivos (ANTA, 2003):

- Reforzar el aprendizaje flexible como opción tanto para estudiantes como para docentes.

- Construir la capacidad necesaria (por ejemplo, conocimiento, habilidades y sistemas) para desarrollar el aprendizaje flexible.

- Desarrollar una aproximación al aprendizaje flexible orientada al cliente/mercado.

- Favorecer los mecanismos de colaboración entre los actores del sector. 
El FLBPF se divide en cuatro áreas o secciones, tal y como muestra la Figura 1:

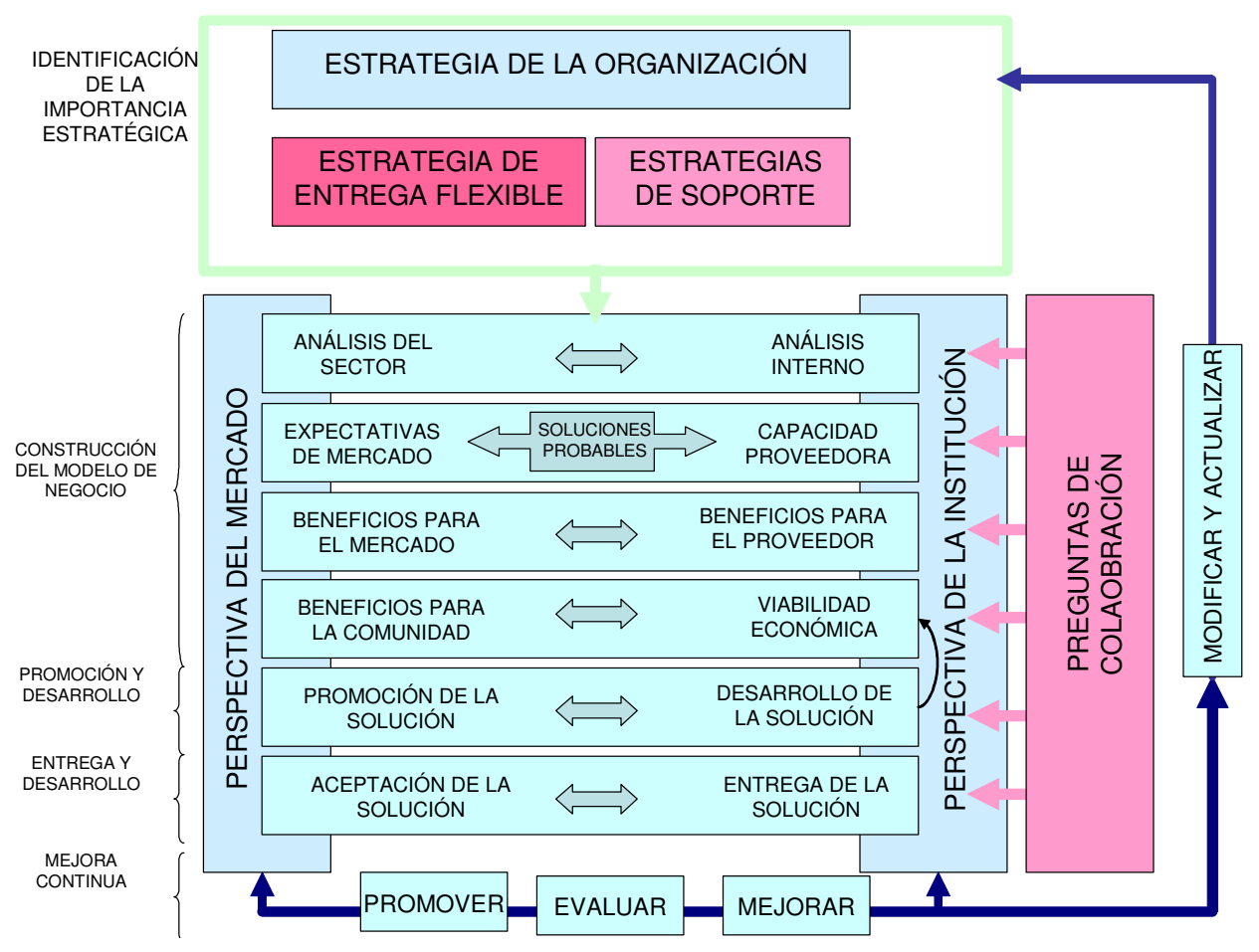

Fuente: adaptado de ANTA (2003).

Figura 1. Modelo FLBPF de ANTA.

1. Identificación de la importancia estratégica

El primer paso consiste en la identificación de la importancia estratégica del e-learning para la institución. Esto implica la participación de todas las unidades universitarias, desde las facultades hasta los departamentos e institutos de investigación.

La estrategia de e-learninig debe ser coherente con la misión, visión y valores de la organización y estar integrada dentro del Plan Estratégico General. Además, en esta sección deben concretarse el tipo de institución virtual que se desea ser y los modos de suministro de servicios educativos que se contemplarán, tal y como se observa en las secciones 2.3 .8 y 4.4 , respectivamente.

2. Construcción del caso de negocio

Esta sección del FLBPF pretende evaluar la probabilidad de que una idea estratégicamente relevante para la institución sea, efectivamente viable antes de la asignación de recursos para la materialización de la misma. ANTA (2003) propone estructurar la recopilación de la información necesaria para construir el caso de negocio en las siguientes actividades:

- Actividades orientadas al mercado

- Análisis del mercado: definición del mercado objetivo y evaluación de su atractivo para la institución.

- Expectativas del mercado: una vez definido el mercado objetivo, el paso siguiente consiste en identificar qué variables influyen en el comportamiento de los consumidores potenciales (en este caso, estudiantes potenciales). Además, conviene realizar un estudio de la demanda con el fin de conocer la evolución del mercado objetivo a lo largo del tiempo y ser capaces de predecir, en la medida de lo posible, su evolución futura y las tendencias de dicho mercado. 
- Beneficios del mercado: el producto o servicio ofertado por la institución (su oferta formativa) debe aportar valor para los estudiantes que conforman el mercado objetivo. Se tratará, pues, de identificar qué factores aportan valor en el sector del elearning y de describir las ventajas e inconvenientes potenciales que el desarrollo de una iniciativa de formación on-line aportará a dicho mercado objetivo.

- Beneficios para la comunidad: cualquier organización tiene una responsabilidad social con la que cumplir. En el caso de las Universidades esta responsabilidad se acentúa y surgen algunos peligros o alertas que será necesario tener en cuenta (el incremento de la brecha digital, la mercantilización ${ }^{3}$ de la Educación, etc.).

- Actividades orientadas a la institución

- Análisis interno: este punto se centra en la evaluación de la cadena de valor de la formación on-line con el fin de identificar qué actividades de dicha cadena de valor son susceptibles de convertirse en fuente de ventaja competitiva.

- Capacidad proveedora: hace referencia a la capacidad de la institución para cubrir, por ella misma, las necesidades del mercado objetivo. En ocasiones será necesaria la colaboración de una entidad externa con las que se establecerá una alianza estratégica en los términos más adecuados.

- Beneficios para el proveedor: para que la iniciativa resulte viable para la institución, es necesario que le aporte algún tipo de ventaja en la actividad universitaria.

- Viabilidad económica: en esta fase se debe efectuar un análisis de la estructura de costes, así como de los diversos factores que influyen en la rentabilidad de la formación on-line. El gran escollo, tal y como señala Duart (2002), es que en la valoración del e-learning confluyen gran cantidad de aspectos intangibles que complican el tratamiento de la rentabilidad a nivel genérico.

Es, precisamente, en esta sección del diagrama base en donde se centra la investigación realizada en este trabajo. Al no especificar el FLBPF un proceso concreto de realización de todas estas actividades, una de las aportaciones más importantes de esta tesis es, donde proceda, la propuesta de un método sistemático y concreto de realización de las mismas y se proporcionará información relevante cuya estructura puede servir de guía a la hora de abordar la realización de la actividad concreta de que se trate. Todos estos aspectos se tratarán con más detalle en capítulos posteriores.

3. Resto de etapas del FLBPF

El diagrama base muestra (ver Figura 1) que tras la construcción del modelo de negocio deben abordarse tras fases: promoción y desarrollo, entrega y evaluación y mejora continua. Estas fases quedan fuera del ámbito de la tesis, centrada, tal y como se ha manifestado, en la identificación de directrices generales obtenidas a partir del análisis estratégico del sector que permitan a las Universidades diseñar el modelo de negocio que más se adecúe a las características de su mercado objetivo y a su casuística interna como organización proveedora. Sin embargo, sí que es propósito del investigador mencionar brevemente el resto de fases, puesto que se considera que el disponer de una visión completa ayudará a entender la utilidad de las aportaciones dentro de la política y estrategias institucionales.

Hecha esta aclaración, el marco de trabajo propuesto por el FLBPF se completa con las siguientes secciones (ANTA, 2003):

- Promoción y desarrollo

Esta sección pone especial énfasis en los aspectos relacionados con la promoción y el desarrollo de la iniciativa on-line de la institución.

\footnotetext{
${ }^{3}$ Se ha optado por traducir así el término anglosajón marketization.
} 
La promoción hace referencia a la difusión de la innovación, tanto interna como externamente y se remite a la abundante literatura existente al respecto, donde destacan los trabajos de Rogers (1995) y Bates (2001). Internamente, no se debe olvidar que lo que realmente se encuentra detrás de las unidades universitarias son las personas: el personal docente y de investigación (PDI) y el personal de administración y servicios (PAS). Es necesario tener claro lo que se espera de ellos, sólo así podrán adoptarse decisiones tácticas: mejorar la capacidad pedagógica y el grado de motivación del personal, introducir incentivos (económicos y curriculares) para fomentar el buen uso de las TIC y del e-learning y proporcionar cursos de formación. El personal debe tener claro que no va a ser reemplazado por las nuevas tecnologías, al contrario, va a ser más imprescindible, pero se le va a exigir una mayor formación. Concienciarlo de este hecho supone la eliminación de una de las barreras más importantes para el uso de las TIC en las universidades. En cuanto a la promoción externa, se trata de emplear las herramientas de marketing más adecuadas en el segmento del mercado en que se ha decidido competir. En la actualidad, la tendencia, sobre todo en el caso de la formación no reglada, es conseguir la fidelización del cliente e intentar que aporte el mayor valor posible para la organización empleando para ello técnicas de marketing one-to-one y otras herramientas de marketing.

En cuanto al desarrollo, el objetivo es asegurarse de que la gestión del proyecto se realiza de la manera adecuada, para lo que se recomienda la realización de un concienzudo Plan de Proyecto en el que se recojan, al menos los siguientes aspectos:

- Descripción breve del proyecto

En uno o dos párrafos, se explicará breve y claramente el problema que se ha detectado y que se pretende resolver.

- Descripción del entorno

En este apartado, se incluyen todos los factores relevantes que pueden determinar en el éxito o fracaso del proyecto (características de la organización, resultados de experiencias anteriores, etc.) así como las limitaciones externas que se considere de influencia (presupuesto, factores políticos, etc.). Se trata de indicar, en términos generales, qué es necesario tener en cuenta para resolver el problema identificado.

- Objetivos del proyecto

Emplear un máximo de siete viñetas para establecer qué objetivos trata de alcanzar la solución propuesta. Es importante que los objetivos seleccionados y sus prioridades representen el punto de vista estratégico de la organización.

Los objetivos deben ser claros, concisos y concretos. Algunos ejemplos podrían ser:

* Captación de estudiantes de otros países.

* Captación de estudiantes con problemas de agenda.

* Captación de empresas como clientes.

* Reducción de costes operativos.

* Cambio de la imagen institucional.

* Etc.

- Estado actual

Identificar los procesos de la organización que pueden verse afectados por la solución propuesta por el proyecto. 
- Requisitos

Realizar una lista de los recursos necesarios para completar el proyecto.

- Alternativas

La solución propuesta se comparará con al menos dos o tres alternativas, explicando las razones de que la decisión por la elegida y haciendo hincapié en sus ventajas e inconvenientes (análisis DAFO).

- Plan de acción

En este apartado, se establecen los hitos del proyecto y los requisitos que deben cumplirse para alcanzarlos, a la vez que se indican las desviaciones potenciales respecto de la evolución esperada $\mathrm{y}$, en la medida de lo posible, las acciones correctoras que intentarán corregir estas desviaciones. Es importante que las metas que se fijen sean fácilmente medibles, por ejemplo, "aumentar el $10 \%$ el número de estudiantes procedentes de empresas", en el caso de una institución educativa.

- Resumen ejecutivo

Finalmente, se resumirán, en una sola página, las conclusiones de los apartados anteriores.

En realidad, la gestión de proyectos no es más que una exposición formal del sentido común aunque, sin embargo, dependiendo del tamaño y el ámbito de esta tarea, la enunciación de unos principios básicos resulta esencial.

- Entrega y aceptación

La etapa de entrega y aceptación hace referencia a la estrategia de implementación de la solución, es decir, a cómo se va materializar la explotación de la solución de aprendizaje flexible finalmente escogida.

- Mejora continua

Como ya se verá en el capítulo 2 uno de los impulsores del cambio organizativo en las Universidades es la necesidad de disponer de información objetiva y unificada acerca de los procesos y servicios académicos, siguiendo las directrices de convergencia en el Espacio Europeo de Educación Superior (Bolonia, 1999; Praga, 2001; Berlín, 2003; Bergen, 2005) y del Plan de Calidad de las Universidades.

La disponibilidad de estos datos, además de reducir el riesgo de fracaso en que se incurre en la toma de decisiones, permitirá habilitar los mecanismos necesarios para detectar posibles desviaciones respecto de la situación planificada y ejecutar las acciones correctoras oportunas de una manera racional y razonada.

Para cada sección se sugieren un número variable de aspectos relevantes que debe plantearse una institución (y en general, cualquier organización) que pretenda desplegar una estrategia o proyecto relacionado con el aprendizaje flexible y que en este trabajo se contextualizarán y particularizarán para el campo de análisis que nos ocupa: la Educación Superior.

Llegados a este punto, es necesario destacar que la dificultad y complejidad de la tarea que se propone este trabajo justifican la adopción de una estrategia de indicios puesto que si, como se pretende, se desea ofrecer una visión de conjunto del campo de análisis, debe procederse obligatoriamente de manera que el lector pueda ubicarse en cualquier lugar del diagrama base sin perderse gracias a las señales y referencias ofrecidas en el desarrollo del propio trabajo (Brunner y Uribe, 2007). 


\subsubsection{Supuestos de la metodología}

La primera pregunta que cabe plantearse es si el modelo base abarca la extensión completa del campo de análisis objeto de estudio. Esta pregunta que, a priori puede resultar relevante, en realidad carece de sentido, según Brunner y Uribe (2007), ya que, según los mismos autores los límites del campo de análisis se irán definiendo a medida que avance la investigación por lo que concluyen, citando a Rorty (2000), que el objetivo de la estrategia de indicios no es sino presentar la situación ordenada de manera más útil que el modo en que se hacía hasta el momento.

Por otra parte, si la metodología se basa en el estudio de las aportaciones de expertos de reconocido prestigio, inmediatamente surge la cuestión de los criterios de identificación y selección que deben considerarse en dicho estudio. La identificación de los autores cuyas aportaciones han sido consideradas dignas de mención en este trabajo se ha llevado a cabo bajo criterios eminentemente productivos y de relevancia, escogiendo aquellos autores y textos cuyas conclusiones han tenido mayor impacto y relevancia en su ámbito.

Finalmente, incluir todo trabajo relacionado con el campo de análisis resulta inviable, además de carecer de fundamento teórico (Brunner y Uribe, 2007). Por lo tanto, y aunque parezca obvio, conviene resaltar que se incluirán únicamente aquellos útiles para la consecución de los objetivos de la investigación.

\subsubsection{Reglas de la metodología}

Brunner y Uribe (2007) establecen que la aplicación de una estrategia de indicios exige el cumplimiento escrupuloso de tres reglas básicas:

1. Los textos y autores incluidos en este trabajo se evaluarán únicamente en función de utilidad para los propósitos de esta tesis (regla de neutralidad).

2. Si dos autores estuvieran en posiciones contrapuestas y ambas fueran relevantes para la investigación, debe reflejarse este hecho, puesto que ambos forman parte del campo de análisis (regla de oposición).

3. Este trabajo de investigación perseguirá relacionar textos y autores de distinta prodecencia y experiencia (regla de conexión).

\subsubsection{Recopilación de datos}

Los tipos de datos empleados en la investigación se muestran en la Figura 2:

1. Recopilación de datos primarios

Para la recopilación de datos primarios se acudió a una gran cantidad de fuentes. La literatura correspondiente a asuntos de gestión universitaria y empresarial es muy amplia, por lo que se eligieron cuidadosamente los artículos y las publicaciones que contuvieran aportaciones, ideas y contenidos interesantes e importantes para los objetivos de esta investigación. La mayoría de la literatura revisada corresponde al periodo comprendido entre 1995 y 2006, dentro de las que se encuentran:

- Para la conformación del marco téorico subyacente y la metodología se revisaron:

- Artículos y papeles de trabajo elaborados por diversos especialistas, así como de investigadores y profesores.

- Artículos procedentes de revistas científicas como European Business Review o Hardvard Business Review.

- Libros relacionados con la investigación.

- Para cada uno de los casos de estudio de instituciones educativas, se recopiló una gran cantidad de información proveniente de diversas fuentes, conformadas como sigue:

- Artículos de revistas especializadas. 
- Casos de instituciones publicados en revistas, anuarios, libros, artículos, papeles de trabajo y portales web.

- Entrevistas, realizadas por terceros a expertos, ejecutivos y directores de las instituciones analizadas.

- Libros impresos concernientes con la administración de empresas, las nuevas tecnologías, la gestión empresarial y la metodología de la investigación.

- Publicaciones y artículos de empresas consultoras.

- Informes anuales de las instituciones analizadas.

- Informes anuales y estadísticas publicadas por asociaciones oficiales como la CRUE, el Consejo de Universidades, etc.

- Portales web de las instituciones relacionads por el sector.

2. Recopilación de datos secundarios

Comprenderán entrevistas semiestructuradas a través de correo electrónico a ejecutivos y directivos de organizaciones que desarrollen su actividad, de uno u otro modo, dentro del sector de e-learning. También se contempla la realización de entrevistas directas de ejecutivos y directivos de empresas distribuidoras o colaboradoras de las organizaciones seleccionadas.

La entrevista semiestructurada fue distribuida a un total de 7 personas relacionadas con las instituciones investigadas.

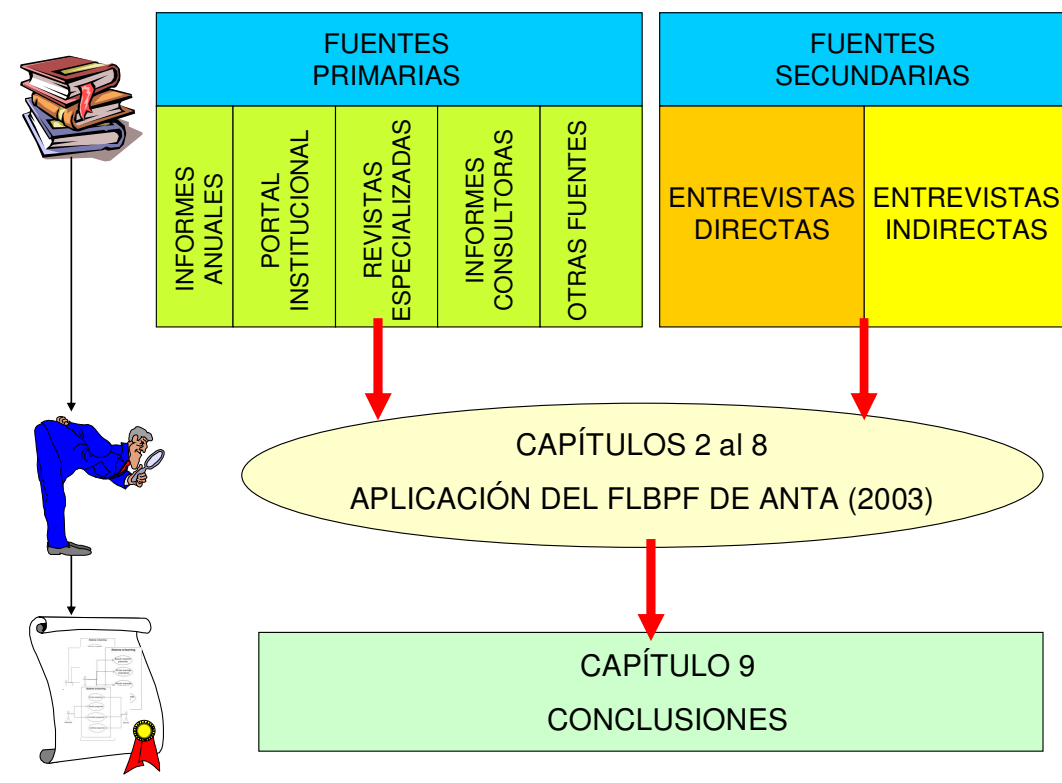

Fuente: elaboración propia.

Figura 2. Tipos de fuentes de información.

\subsubsection{Limitaciones del estudio}

Con este tipo de investigación cualitativa, difícilmente se pueden generalizar los descubrimientos sino que, como ya lo establecimos, el trabajo de esta tesis es de tipo exploratorio y puede servir de base para realizar un análisis más profundo a partir de los descubrimientos expuestos.

En primer lugar, la investigación se verá limitata por el sesgo introducido por el propio investigador durante la recopilación y el análisis de datos y, en segundo lugar, por el hecho de que, generalmente, las organizaciones sólo ofrecen una limitada cantidad de información que, muchas veces, puede ser incompleta, asimétrica, sesgada e interesada. 
Por otra parte, cabe notar que las limitaciones de la investigación también están relacionadas con cuestiones de tiempo y presupuesto. Es cierto que existen valiosos trabajos de investigación cualitativa y cuantitativa realizados, sobre todo, por consultoras de prestigio como Forrester Research, Gartner Research, IDC, etc., que podrían significar una excelente fuente primaria de datos pero su precio se sale del alcance del presupuesto para esta investigación. Así, aún cuando los datos provenientes de las fuentes seleccionadas sean válidos y confiables, carecerán de una triangulación adicional.

En relación con el tiempo, el dinamismo de la industria es tan grande que es probable que las características, los factores determinantes y las ventajas que podamos poner hoy de manifiesto, mañana se vean modificadas, disminuidas, quizá mejoradas o tal vez ocupen posiciones menos relevantes, por lo que no podremos asegurar que el conocimiento generado a partir de esta investigación sea atemporal. Por lo tanto, los descubrimientos y explicaciones producto de esta investigación, estarán limitados a un contexto y espacio de tiempo determinados.

Otros problemas que pueden surgir dentro del desarrollo de esta investigación radican en los siguientes aspectos:

- Las ventajas competitivas así como los factores críticos que las determinan son temporales y, a pesar de que se emplee un enfoque orientado a la dinámica competitiva, las conclusiones pueden verse afectadas por cambios intensos en el sector bajo estudio.

- Las estrategias que se estudiarán aquí serán de carácter global, por lo que puede ocurrir que no resulten adecuadas para cualquier combinación de variables país, mercado y cliente en particular.

\subsection{ORGANIZACIÓN Y ESTRUCTURA}

La organización del documento se corresponde, en gran medida, con la secuencia de actividades que ha seguido el investigador a la hora de elaborar este trabajo.

En los Capítulos 2 al 8 se recoge una revisión de la literatura subyacente dividida en siete bloques: 1) análisis del entorno que rodea a las instituciones de Educación Superior; 2) estudio del proceso de introducción de las TIC en las Universidades; 3) alternativas estratégicas de competitividad en el cuasi-mercado de la Educación Superior; 4) análisis estratégico del sector de la Educación Superior; 5) análisis de la demanda y características de los mercados universitarios; 6) análisis y interno y capacidad productora de las instituciones de Educación Superior; y, 7) aspectos a tener en cuenta en la evaluación de la rentabilidad de proyectos de e-learning en Educación Superior. Estos capítulos constituyen la base teórica sobre la que se sustenta la parte cuantitativa de este trabajo de tesis, eminentemente cualitativo y exploratorio.

El en Capítulo 9 se resumen y discuten las conclusiones obtenidas y, finalmente, se completa el trabajo con una amplia lista bibliográfica y de referencias que han servido de base para realizar este trabajo. 


\section{CAPÍTULO 2 ANÁLISIS DEL ENTORNO}

Este capítulo tiene como objetivo describir el entorno en que se encuentran sumergidas las Universidades y que, por sus características dinámicas, las obliga a adaptarse y cambiar. Se identificarán las fuerzas impulsoras del cambio en la Educación Superior y sus conscuencias en los ámbitos organizativos, económicos, sociales y de actividad, con el fin de ser capaces de comprender el posterior análisis que se llevará a cabo en capítulos posteriores.

\subsection{LA UNIVERSIDAD EN LA SOCIEDAD DE LA INFORMACIÓN Y EL CONOCIMIENTO}

En la Sociedad de la Información, el Conocimiento es el valor clave para el crecimiento económico, la innovación, la mayor competitividad en un mundo globalizado y el aumento de la productividad de las organizaciones. En estas circunstancias, la Universidad, en tanto que fuente creadora, transmisora y aplicadora del Conocimiento, debe tener un papel predominante en la construcción y viabilidad de la nueva Sociedad.

Las características de las Universidades y de su actividad condicionan la tipología y el ámbito de las transformaciones derivadas de la integración tecnológica. Por este motivo, queremos destacar a continuación los principios comunes a las instituciones universitarias de las economías desarrolladas en cuatro ámbitos (Castillo, 2004):

1. Objeto de la actividad universitaria

En el marco de la definición del objetivo de la actividad universitaria, cabe destacar la trascendencia social de la actividad de las Universidades. Independientemente de la forma jurídica que adopte la Universidad, este trasfondo social inherente a su actuación determina que la persecución de un beneficio mercantil se deba combinar con otros objetivos de carácter social (Hansmann, 1986).

Efectivamente, el hecho de que las Universidades no hayan actuado tradicionalmente según parámetros exclusivamente de mercado y que, por tanto, no hayan presentado un control externo ni interno equiparable al que se manifiesta en la industria privada sobre la dotación y asignación de recursos productivos, ha provocado la existencia de una presión relativamente reducida para que actúen de acuerdo con parámetros de eficiencia y eficacia.

Por otra parte, la importante utilidad social de la actividad universitaria ha comportado la introducción de medidas cualitativas asociadas al impacto y el beneficio social para aproximar la valoración de su actuación. En este ámbito social, las Universidades deben:

- Formar personas que sean capaces de experimentar y ser adaptables para la Sociedad.

- Educar personas en valores y con criterios propios que deben incorporar a su comportamiento individual y colectivo en una Sociedad que debe apostar por una serie de valores emergentes (paz, solidaridad, desarrollo humano, interculturalidad, etc.). 
Por tanto, la actividad universitaria se basa en dos pilares fundamentales: la voluntad de ofrecer un servicio a la sociedad y el modelo académico de la formación y la investigación. Este hecho determina que las variables empleadas para medir el resultado de actividad de las Universidades supongan la búsqueda de un equilibrio entre componentes económicos, sociales y educativos basado en parámetros como la excelencia educativa, las oportunidades de acceso de los estudiantes a la formación o la diversidad social y cultural (Bowen, 1980).

2. Modelo organizativo

La Universidad presenta una elevada complejidad organizativa, en cuanto que debe gestionarse y coordinarse un gran número de actividades distintas en las que están implicadas muchas personas con roles, profesiones, actividades y expectativas diferentes que se relacionan alrededor de la creación y transmisión del conocimiento. Todos estos individuos ocupan los diferentes puestos del organigrama funcional de la Universidad (estructura formal) y, al mismo tiempo, se integran y desarrollan entre ellos redes de relaciones interpersonales informales. Es decir, que en la organización universitaria conviven una dimensión formal (organigrama funcional) y una dimensión informal (redes de sociales).

Mintzberg (1991), en su tipología de organizaciones distingue entre burocracia maquinal y burocracia profesional y ubica a las Universidades en esta última categoría (ver Figura 3). Según este autor, la burocracia profesional se define como el tipo de estructura que se aplica a organizaciones que van a realizar trabajos de gran complejidad que requieren una formación importante del operario y que va a ser muy difícil controlar, supervisar, normalizar y medir en sus productos finales (Capacete, 2001).

La elevada capacitación y el grado de formación de los profesionales en que se basan estas organizaciones implican que tengan un gran nivel de autonomía y de autocontrol de su trabajo, lo que lleva a que buena parte del poder se encuentre en el núcleo de operaciones y que la jerarquía se apoye más en la destreza o la experiencia que en el puesto que se ocupe formalmente dentro del organigrama de la institución. Esta última circunstancia requiere un alto nivel de coordinación entre los distintos profesionales por medio de la formación de equipos de trabajo basados en sistemas democráticos de participación, pero que introducen muchas rigideces en el proceso de toma de decisiones. Por este motivo, las burocracias profesionales presentan una estructura plana con una línea de mandos intermedios reducida, una tecnoestructura minúscula, pero con un sistema de actividades de soporte ${ }^{4}$ muy elaborado.

La tabla de la Figura 3 compara los dos tipos de organizaciones propuestos por Mintzberg (1991). Como puede verse, el modelo organizativo de una Universidad, caracterizado por la existencia de un grado relativamente elevado de descentralización tanto en el control del contenido del trabajo como en la toma de decisiones de carácter operativo, puede ser calificado como una burocracia profesional.

${ }^{4}$ Forman parte de este staff de soporte, entre otros, los servicios de mantenimiento, reprografía, bibliotecas, editoriales, etc., que se configura como piezas de una máquina dentro del sistema de la organización profesional. 


\begin{tabular}{l|l}
\hline Burocracia maquinal & Burocracia profesional \\
\hline $\begin{array}{l}\text { Tareas sencillas y rutinarias. } \\
\begin{array}{l}\text { Autoridad centralizada en el nivel } \\
\text { superior. }\end{array}\end{array}$ & $\begin{array}{l}\text { Autoridad en el núcleo de operaciones } \\
\text { (descentralización vertical y horizontal) }\end{array}$ \\
\hline $\begin{array}{l}\text { Autoridad de tipo jerárquico según la } \\
\text { posición del organigrama. }\end{array}$ & $\begin{array}{l}\text { Autoridade naturaleza profesional basada } \\
\text { en la experiencia y la destreza. }\end{array}$ \\
\hline $\begin{array}{l}\text { Operario ligado a reglas formales } \\
\text { escritas. }\end{array}$ & Operario con gran autonomía. \\
\hline $\begin{array}{l}\text { Orientación burocrática hacia el } \\
\text { cumplimiento de procedimientos. }\end{array}$ & Orientación profesional hacia el servicio. \\
\hline $\begin{array}{l}\text { Alta regulación y normalización de las } \\
\text { tareas desde la tecnoestructura interna a } \\
\text { la organización. }\end{array}$ & $\begin{array}{l}\text { Gran dificultad de normalización de tareas } \\
\text { quele provenir del entorno externo a la } \\
\text { organización. }\end{array}$ \\
\hline $\begin{array}{l}\text { Control por supervisión directa. } \\
\text { Organización de rendimiento. }\end{array}$ & Gran dificultad de control directo. \\
\hline Difícil adaptación al mercado & Organización de solución de problemas. \\
\hline
\end{tabular}

Fuente: elaboración propia a partir de Capacete (2001).

\section{Figura 3. Burocracia maquinal vs. Burocracia profesional.}

3. La estructura de financiación

La estructura financiera de la Universidad se ha encontrado tradicionalmente en un rango limitado por dos extremos: una financiación basada fundamentalmente en recursos procedentes de subvenciones y donaciones, y una autofinanciación derivada de la venta sus productos en el mercado (Hansmann, 1986). Una implicación importante de esta consideración es el hecho de que el funcionamiento presupuestario de la Universidad se basa en la búsqueda de un equilibrio entre la realización de actividades económicas y la contraprestación y la percepción de aportaciones no lucrativas tanto del sector público como del sector privado; así, la generación de una parte de sus productos está subvencionada, de manera que su precio no debe cubrir el coste total de producción, pudiendo transferir este efecto a sus estudiantes a través de un subsidio que se concreta en la venta de productos a un precio inferior al del mercado.

La subvención de una parte de los recursos productivos de las Universidades determina que exista una relación positiva entre la política de distribución de recursos financieros y la calidad de la actividad universitaria (Falk y Gordon, 1977). Se produce así un círculo acumulativo en la disponibilidad de recursos, de manera que cuanto más recursos disponibles, mayor demanda, mayor posibilidad de seleccionar los mejores estudiantes potenciales, mayor calidad de los estudiantes, más calidad de la Universidad y mayor posibilidad de obtención de recursos adicionales, asumiendo que la calidad de los estudiantes universitarios es el principal indicador de calidad de la Universidad.

La principal implicación económica de este comportamiento es la existencia de un mercado universitario oligopólico y jerárquico (Hansmann, 1980, 1990), basado en las condiciones y el volumen de las subvenciones y no el número o dimensión de las Universidades que participan, de manera que se genera un efecto acumulativo a largo plazo (Castillo, 2004): las Universidades bien posicionadas en los términos señalados cada vez están mejor posicionadas. Se trata de un mercado de competencia imperfecta con una distribución condicionada por la cuota, en el que ganador puede terminar llevándoselo todo (Cook y Frank, 1993). 
4. Las características de sus productos y el proceso de generación

Los servicios de formación de las Universidades constituyen un claro exponente de lo que se denomina "bienes de experiencia", lo que significa que los consumidores de los mismos (los estudiantes) no pueden saber a priori la utilidad que se deriva de su uso, trasladando la determinación de su valor de uso hasta el momento de consumo. El beneficio atribuible a su uso habitualmente sólo se puede medir a largo plazo y, por tanto, no permite establecer acciones correctoras sobre las decisiones adoptadas. Esta circunstancia determina el hecho de que las Universidades actúen en mercados donde existen asimetrías significativas de información, de manera que los estudiantes no saben, a priori, qué están adquiriendo. Son dos las consecuencias de esta situación (Castillo, 2004):

- Las decisiones de inversión en formación Universitaria, dado el entorno de incertidumbre e incluso de conocimiento que caracteriza este tipo de decisiones, se basan en la certeza social de que la educación superior supone una importante inversión individual en conocimiento. Por tanto, el escenario del consumidor perfectamente informado no existe, de modo que la decisión de inversión se encuentra altamente vinculada con la consideración de indicadores de calidad, tanto formales como informales.

- Los productos intermedios que la Universidad ofrece a sus estudiantes tienen el carácter de servicio con un importante componente cualitativo. Este hecho confiere a los productos intermedios universitarios un grado relativamente elevado de intangibilidad, circunstancia que introduce dificultades significativas en su delimitación y medida y, consecuentemente, también complica el proceso de determinación de su precio (Harris y Jarrett, 1990) y de la comunicación de su contenido a sus estudiantes potenciales. Además, la naturaleza intangible de estos productos provoca que no sean susceptibles de ser almacenados, comportando un riesgo de inadecuación de la producción a las fluctuaciones de la demanda (Mazzarol y Soutar, 1999).

La formación de los estudiantes en las Universidades se produce a partir de la convergencia de una serie de servicios formativos basados en sus necesidades y requerimientos. Por tanto, la configuración de sus procesos y la determinación de las características de los productos universitarios se fundamentan principalmente en la utilidad educativa que tienen para sus estudiantes, de manera que se genera una integración muy elevada entre los procesos de producción y de consumo (Booms y Nyquist, 1981). Esta característica acarrea una serie de implicaciones productivas que deben destacarse (Castillo, 2004):

- La calidad de los servicios de formación que ofrece la Universidad depende, en gran medida, de la calidad de sus estudiantes.

- La participación de factores productivos muy heterogéneos y de carácter básicamente intangible en la capacidad de generar, transferir y formalizar conocimiento se convierte en una de las variables clave de la producción universitaria.

- La relación formal y continua entre productor y consumidor durante todo el proceso de conformación del servicio, cuestión que deriva en la posibilidad de adaptar de forma constante las especificidades de cada producto a las preferencias individuales de cada consumidor.

- La capacidad potencial de fidelizar a los consumidores de los servicios universitarios por medio a esta integración en su proceso de producción, genera la posibilidad teórica de incidir en el comportamiento de la demanda, condicionando su grado de fluctuación.

- La actividad de producción de las Universidades consiste fundamentalmente en la generación, transformación y difusión del conocimiento a través de las actividades de docencia e investigación. Así, la función de producción de las Universidades se caracteriza por incorporar conocimiento para la generación de conocimiento, siendo, por tanto, intensiva en recursos productivos basados en conocimiento. Una característica importante de esta función de producción es el hecho de que presenta una cierta inelasticidad del producto respecto a la dotación de factores productivos, debido a un 
comportamiento rígido de estos factores y a su elevado grado de independencia respecto al nivel de actividad.

\subsection{INTERNACIONALIZACIÓN Y GLOBALIZACIÓN DE LA EDUCACIÓN SUPERIOR}

Las Universidades están sumergidas en un entorno sujeto a cambios que llevan a estas organizaciones a un proceso de evolución constante (Malott, 2001) y dinámica (Fuentes, 2005). En la actualidad, los cambios se suceden a una velocidad elevada y los tiempos de respuesta son cada vez más cortos y ello está obligando a las instituciones educativas a convertirse en organizaciones mucho más flexibles. El entorno de cualquier organización es un campo de fuerzas, favorables o adversas, que requiere, en primer lugar, identificarlas $\mathrm{y}$, acto seguido, elaborar y aplicar estrategias y tácticas creativas y suficientemente eficaces para conseguir el objetivo de la acción (Costa, 1999). En la literatura internacional sobre Educación Superior, existe un amplio consenso acerca de que estas fuerzas motoras del entorno en que se desenvuelven las Universidades derivan de la internacionalización de la Educación Superior, a la que se está concediendo gran importancia, habida cuenta de que afecta a todos los participantes en el proceso (Fernández y Ruzo, 2004): estudiantes, profesores, Universidades, Administraciones Públicas y Sociedad en general.

La internacionalización en la Educación Superior surge como respuesta la globalización que caracteriza el entorno político, social y económico actual. Estos dos conceptos, internacionalización y globalización, pese que existe una marcada tendencia a emplearlos como sinónimos, hacen referencia a dos conceptos diferentes pero estrechamente relacionados:

1. Internacionalización

Según Thorsby (1998), la internacionalización de la Educación Superior engloba todos aquellos aspectos de los sistemas e instituciones educativas que traspasan las fronteras de un país o que se ven influidos por las relaciones de los agentes (estudiantes, profesores, gestores, etc.) en otros países.

Por su parte, la Asociación Internacional de Universidades (IAU) define la internacionalización de la Educación Superior como "un proceso que integra una dimensión o perspectiva internacional o intercultural en las funciones principales de las universidades",5.

2. Globalización

Yang (2002) define la globalización como un proceso social y económico de integración que transciende las fronteras nacionales, afectando al conocimiento, las personas, los valores y las ideas. Se trata, pues, de un proceso de compromiso y convergencia mundial que tiende a eliminar las barreras físicas entre países (Marginson y Rhoades, 2002), de modo que sea posible el libre intercambio de mercancías y servicios en un entorno de regulación mínima (Jones, 1998). Por lo tanto, la globalización es un proceso de transformación económica, cultural y política más drástico que la internacionalización.

La tabla de la Figura 4 recoge las principales diferencias entre internacionalización y globalización:

\footnotetext{
${ }^{5}$ http://www.unesco.org/iau/internationalization/i_definitions.html
} 


\begin{tabular}{|c|c|}
\hline Internacionalización & Globalización \\
\hline $\begin{array}{l}\text { Asume un mundo de naciones con } \\
\text { fronteras geopolíticas claras que se } \\
\text { pretenden superar con actividades como el } \\
\text { intercambio de estudiantes, profesores, } \\
\text { investigadores, etc. }\end{array}$ & $\begin{array}{l}\text { Es totalmente contraria a un mundo de } \\
\text { Estados. }\end{array}$ \\
\hline $\begin{array}{l}\text { Se apoya en las altas esferas de la } \\
\text { diplomacia y de la cultura. Por tanto, es } \\
\text { más fácil de controlar o regular. }\end{array}$ & Difícilmente controlable. \\
\hline $\begin{array}{l}\text { Tiende a reproducir, e incluso a legitimar, } \\
\text { la jerarquía y la hegemonía. Así, } \\
\text { determinados países que fueron centros de } \\
\text { imperios de siglos pasados atraen a los } \\
\text { alumnos procedentes de antiguas colonias. }\end{array}$ & $\begin{array}{l}\text { Ataca la jerarquía y la hegemonía } \\
\text { tradicionales. Por ejemplo, una } \\
\text { Universidad sin tradición internacional } \\
\text { y sin demasiados medios económicos } \\
\text { puede llegar a otros estudiantes a través } \\
\text { de la Red. }\end{array}$ \\
\hline $\begin{array}{l}\text { Su motor debería ser algo más altruista; la } \\
\text { expansión del conocimiento y la } \\
\text { investigación así como la crítica } \\
\text { constructiva a través de la cooperación. }\end{array}$ & $\begin{array}{l}\text { Su principal motor podría considerarse } \\
\text { el beneficio y la creencia en un } \\
\text { mercado global único que se consigue } \\
\text { fundamentalmente a través de la } \\
\text { competitividad. }\end{array}$ \\
\hline $\begin{array}{l}\text { No es algo nuevo, sino una faceta con la } \\
\text { que la Universidad se ha encontrado } \\
\text { tradicionalmente a gusto. }\end{array}$ & $\begin{array}{l}\text { Se trata de algo novedoso y dinámico. } \\
\text { Podríamos decir que surge a principios } \\
\text { del siglo XIX, o incluso antes, asociada } \\
\text { al nacimiento de la Revolución } \\
\text { Industrial. }\end{array}$ \\
\hline
\end{tabular}

Fuente: reproducido de Fernández y Ruzo (2004).

\section{Figura 4. Internacionalización vs Globalización.}

Fernández y Ruzo (2004) añaden a la discusión el término de regionalización, como el proceso de superación y eliminación de barreras entre distintas regiones e incluye dentro de este tipo de procesos la europeización de la Educación Superior materializada en el desarrollo del Espacio Europeo de Educación Superior. Los propios autores señalan que el establecimiento de una frontera clara entre estos tipos de procesos es una tarea muy compleja y que lo que realmente tiene importancia es el hecho de que se trata de procesos que se acelerarán en los próximos años.

Sin embargo, la influencia de la internacionalización en la Educación Superior no es, ni mucho menos, una tendencia novedosa. Ya en los tiempos de las primeras universidades, allá por el siglo XII, la avidez de conocimientos hacía a profesores y alumnos a moverse por Europa empleando el latín como lengua común e incluso resultaba bastante frecuente encontrarse con conflictos institucionales que tenían como resultado la escisión de importantes contingentes de estudiantes y profesores que acababan trasladándose de un país a otro (Tünnermann, 1996).

Durante el siglo XV, el descubrimiento de América y la colonización del Nuevo Mundo abrió las puertas a la instalación de Universidades diseñadas y construidas según los modelos de Europa vigentes en la Edad Media, concretamente, los de las universidades de Alcalá de Henares y Salamanca en las regiones de influencia española y el de la Universidad de Oxford en la zona británica (Yarzábal, 2004). Más tarde, a lo largo del siglo XIX y con la independencia de las colonias, se estimuló una reorientación de las universidades hacia los ámbitos nacionales. Fue entonces cuando se produjo el auge de las Universidades estadounidenses que combinaron el modelo de Inglaterra, la universidad de investigación concebida por Guillermo de Humboldt en Alemania y el concepto de servicio a la sociedad (Yarzábal, 2004). 
Más tarde, después de la II Guerrra Mundial, las circunstancias del entorno político y cultural impulsaron a los Gobiernos a favorecer iniciativas de internacionalización educativa. Sin embargo, la internacionalización de la Educación Superior evolucionó de manera diferente en Estados Unidos y en Europa (de Wit, 2002). Mientras que en el primer caso se asumió como un potente instrumento de política exterior y seguridad nacional (Aponte, 2003), en el segundo, Europa se comportó primero como un receptor pasivo de estudiantes extranjeros y luego utilizó la internacionalización de la Educación Superior como respuesta estratégica a los resto de la globalización (CRUE, 2003a, 2003b).

No obstante, lo que sí ha variado es la aplicación del concepto de internacionalización al contexto de la Educación Superior actual, impulsada por un conjunto de variables que se estudiarán a más adelante.

Por ejemplo, Knight (1993) definió la internacionalización de la Educación Superior como el proceso de dar a la actividad universitaria una dimensión internacional. Sin embargo, tal y como señala Yarzábal (2004), esta definición sugiere que la internacionalización es un proceso en sí misma, lo que contrasta con la visión de muchos países que la entienden más como una estrategia de desarrollo. En esta misma línea, van Der Wende (1997) propuso una definición alternativa, al considerar como internacionalización cualquier esfuerzo sistemático y sostenido dirigido a promover la respuesta de la Educación Superior a los retos planteados por la globalización en sus vertientes sociales, económicas y laborales.

Según se desprende de la literatura especializada (Marginson y Van Der Wende, 2006), la internacionalización ha generado cambios en la Educación en general y en la Educación Superior en particular (Carnoy, 1999, 2005; Brunner, 2001; Kwiek, 2003, Held et al., 1999). En las Sociedades del Conocimiento, las instituciones de educación superior adquieren una importancia y una relevancia fundamentales puesto que constituyen un medio de ampliación de la relaciones internacionales y de flujo continuo de personas, información, conocimiento, tecnologías, productos y capital (Marginson y van Der Wende, 2006).

Ya en 1998 la UNESCO instaba la las instituciones de educación superior a desarrollar políticas y programas institucionales de internacionalización claros como responsabilidad de su propio ser y de la función que les es propia en la sociedad. Esta dinámica académica debe estar soportada en un proceso estratégico de presencia institucional (Fuentes, 2005) en el que se establezcan las bases de identidad de la institución con el fin de conseguir una posición competitiva sólida y estable para poder aprovecharse de las ventajas de disponer de una imagen de marca positiva y generar una percepción de confianza en la demanda, tanto directa como indirecta. Un efecto derivado de esta necesidad de posicionarse es la aparición de ránkings mundiales de Universidades ${ }^{6}$.

En la misma línea, la Asociación Internacional de Universidades ${ }^{7}$ suscribió en 2004 un manifiesto en el que señala que las dos tendencias que caracterizarán el sector de la Educación Superior serán la necesidad de las instituciones de internacionalizar sus actividades con el fin de aumentar su excelencia académica y el crecimiento de la orientación a mercado estimulado, por un

${ }^{6}$ Los más conocidos son el del Institute of Higher Education Shanghai Jiao Tong University, cuya versión 2006 se encuentra disponible en: http://ed.sjtu.edu.cn/ranking.htm y The Times Higher Education Supplemente (THES) World University Rankings 2006, disponible en http://www.thes.co.uk/worldrankings/. La Wikipedia dedica una de sus entradas a esta nueva generación de rankings globales; ver en: http://en.wikipedia.org/wiki/Academic_Ranking_of_World_Universities. En España destaca el ránking universitario de Universia (http://universidades.universia.es/ranking/espanya.htm).

7 Ver el texto completo de la Declaración en: http://www.iesalc.unesco.org.ve/documentosinteres\%5Cotros\%5CCOMPARTIENDO\%20LA\%20CALIDA D\%20DE\%20LA\%20EDUCACI\%C3\%93N.pdf. 
parte, por el comportamiento de la demanda de Educación Superior a nivel mundial y, por otra, por la diversificación en los mecanismos de financiación.

En Europa la consecuencia ha sido la definición y puesta en marcha del Espacio Europeo de Educación Superior, que se estudia con mayor detalle en epígrafes posteriores.

Una vez establecida la definición de internacionalización de la Educación Superior, ya estamos en condiciones de manejar la complejidad de los elementos que la componen y de comprender los motivos que le confieren tanta importancia en el panorama socioeconómico actual.

\subsection{IMPULSORES DE LA TRANSFORMACIÓN UNIVERSITARIA}

En la literatura internacional es posible encontrar numerosos estudios que intentan explicar cuáles son los agentes de cambio que están llevando a la transformación de las Universidades y a la adopción de procesos de internacionalización en las mismas.

Warner (1992) agrupó estos agentes de cambio en tres grupos: motivos competitivos, es decir, la incorporación del contenido internacional a la actividad de la institución como medio para lograr una mayor posición competitiva en el mercado; motivos liberales, en cuanto a que la internacionalización se constituye como respuesta a las necesidades de desarrollo personal en el nuevo contexto social en que no encontramos; y, transformación social, en cuanto que pretende inculcar a los estudiantes un conocimiento y una cultura más amplias.

Por su parte, Davies (1992), ligó los cambios a razones derivadas de la reducción de la financiación pública y destacó el papel de la internacionalización como mecanismo de búsqueda de otras fuentes de recursos.

Finalmente, el estudio de Knight (1997), ordenó los motivos en cuatro grupos:

1. Motivaciones políticas

Están relacionadas con la política exterior de un país. Dentro de este marco se explican los programas de becas a estudiantes extranjeros con posibilidades de convertirse en futuros líderes y en promotores de relaciones diplomáticas y comerciales entre el país receptor y el país de origen del estudiante (Yarzábal, 2004).

2. Motivaciones económicas

Hace referencia a objetivos económicos a largo plazo, entre los que se encuentran la formación de capital humano altamente especialzado con el fin de mantener e incrementar la competitiva internacional del país, el reclutamiento de estudiantes extranjeros para que aporten ingresos directdos (pago de matrículas, por ejemplo) e indirectos (contribuciones al $\mathrm{I}+\mathrm{D}$, etc.) o la exportación de productos y servicios educativos.

3. Motivaciones académicas

Bajo esta denominación se incluyen todos los objetivos relacionados con las funciones de la Educación Superior, tales como el logro de estándares académicos aceptados a nivel internacional.

4. Motivaciones culturales y sociales

Contemplan la internacionalización como instrumento para la preparación de individuos con conocimientos y destrezas básicos en relaciones y comunicaciones interculturales (Yarzábal, 2004).

Sin embargo, en esta tesis adoptaremos una visión más orientada al marketing internacional de servicios como la propuesta por Lovelock (1999), quien a partir de valiosas contribuciones de diversos autores (Johansson y Yip, 1994; Lovelock y Yip, 1994; Yip, 1992), argumenta que en una estrategia de internacionalización conviene analizar el papel que juegan los impulsores del entorno que rodea a la organización, agrupándolos en cinco grupos: impulsores de mercado, impulsores tecnológicos, impulsores gubernamentales, impulsores de la competición e impulsores 
de costes. En la Figura 5 se indican cada uno de estos impulsores en el caso de la Educación Superior, que serán estudiados en los epígrafes siguientes. Evidentemente, algunos de estos impulsores pertenecen a varios de los ámbitos señalados, de hecho, resulta difícil encontrar alguno que no tenga un matiz económico (Fernández y Ruzo, 2004).

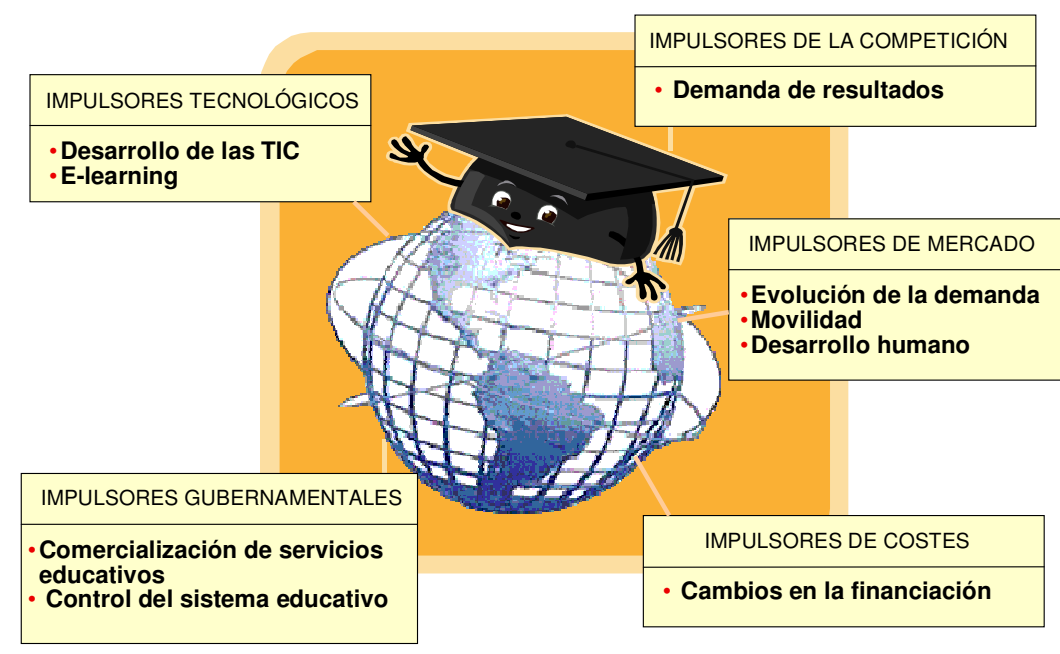

Fuente: elaboración propia.

Figura 5. Impulsores de la internacionalización de la Educación Superior.

En estas condiciones, las Universidades deben desarrollar vínculos estratégicos, lo que significa generar relaciones sólidas, fluidas y basadas en objetivos específicos que perduren en el tiempo y le permitan generar un espacio de intercambio con sus diferentes públicos (Manucci, 2004). Precisamente será este espacio de intercambio el que se convertirá en el elemento diferenciador de las Universidades en este nuevo entorno competitivo.

\subsubsection{Evolución de la demanda de enseñanza universitaria}

La evolución de la demanda de formación universitaria durante las últimas décadas en las economías desarrolladas se explica por el aumento de los requerimientos de capacidades y conocimientos de los trabajadores por parte de las empresas y de los gobiernos, unido a una voluntad política de democratizar el acceso a la Universidad y, por tanto, de incentivar la incorporación de todas las clases sociales (Geuna, 2000).

Por lo que respecta a la sociedad, ésta precisa de mano de obra con competencias, habilidades y conocimientos de mayor nivel y más especializada. Además, los estudiantes han de estar preparados para el nuevo entorno laboral que se avecina. Las habilidades adquiridas tendrán su reflejo en el desempeño de su futura actividad profesional. Hasta hace algunos años los modelos de organización laboral seguían unos esquemas claros y estables. Hoy en día, nos enfrentamos a profundos y continuos cambios que nos obligan a movernos sin modelos de referencia (Moreno, 2004):

1. Las empresas eran organizaciones que ofrecían estabilidad a sus profesionales. El desarrollo de la carrera se producía, sustancialmente, en una única organización. Hoy los niveles de rotación han roto los esquemas de "confianza mutua" que cohesionaban culturas empresariales. El nuevo contrato moral entre empresa y trabajador se sustenta en la ecuación "aportación de valor medible-mejora de empleabilidad". 
2. Los conocimientos que un trabajador tenía podían sustentar su actividad profesional durante toda la vida. Hoy las TIC, la modificación de procesos que introducen, la globalización, etc. nos sitúan ante una necesidad permanente de actualización de conocimientos y pone en la cresta de la ola a la formación continua, el e-learning y la gestión del conocimiento.

En un mercado globalizado, cada vez más competitivo, con una importancia creciente de las nuevas tecnologías y los rápidos cambios sociales, culturales y económicos que se propician, resulta imprescindible elevar el nivel del capital humano e ir actualizando y renovando conocimientos y especializarse en aquello que demanda la sociedad, para no quedar al margen del mercado laboral. No hay que olvidar que, como señala Bloom (2005), existe una fuerte correlación positiva entre la demanda de educación superior de una nación o región y su rendimiento competitivo en un entorno globalizado. Esta competencia global y la flexibilidad del mundo del trabajo requieren una educación que vaya más allá de obtener una titulación y conseguir un empleo con vistas a conservarlo durante toda la vida activa (Keegan, 2000).

Se necesitan prácticas de formación a lo largo de la vida para actualizar los conocimientos, así como oportunidades de aprendizaje adaptadas a las necesidades de cada individuo. De hecho, una de las mayores preocupaciones de los gobiernos e instituciones es la de la figura del estudiante adulto que dispone de menos tiempo para el aprendizaje presencial a causa de sus obligaciones laborales o familiares y que desea o necesita actualizar sus conocimientos, emprender una nueva carrera o postgrado, o ampliar su educación, para lo que no puede sufrir limitaciones de horarios, lugares geográficos o incurrir en los gastos de tiempo y dinero que significaría instalarse en la ciudad donde opera la universidad. Es, particularmente en este segmento del mercado (denominado lifelong learning) en donde existirá una competencia feroz en los próximos años y en donde el e-learning se posiciona como la alternativa idónea.

Este nuevo universo educativo es tomado muy en cuenta no sólo por gobiernos, sino por organizaciones internacionales: la Conferencia de la UNESCO sobre Educación Superior de 1998 (citado por Finquelievich y Prince, 2006) planteaba ya que la tarea central de la educación superior actual es proporcionar oportunidades de formación a lo largo de la vida, ofreciéndoles a los estudiantes un óptimo abanico de posibilidades y flexibilidad en cuanto a los puntos de entrada y de salida del sistema, así como facilidades para su desarrollo personal y su participación activa en la sociedad. Además de realzar estos dos ejes, la Conferencia también estipula que las instituciones de educación superior deberían proporcionar formación para el PAS y el PDI, asegurar equidad y acceso igualitario a esta formación, particularmente para las mujeres, y adoptar políticas explícitas con respecto al uso de TIC.

Por otra parte, la Comisión Europea en su informe "eEurope 2005, una Sociedad de la Información para todos" muestra su intención de reforma. Tal como lo plantea Bel Llodrá (2000), el motivo principal para la elaboración de este informe es la necesidad de llevar a cabo "actuaciones urgentes" para prepararse para la nueva economía. Los retos planteados son: proporcionar a todos los alumnos acceso a Internet; conectar gradualmente las escuelas a las redes de investigación; crear servicios de apoyo y recursos educativos en Internet; construir plataformas de aprendizaje electrónico para profesores, alumnos y padres; ofrecer incentivos a aquellos profesores que utilicen las tecnologías digitales en la enseñanza; y dotar a todos los alumnos de una cultura digital para el momento en el que dejen la escuela. Para todo ello se prevé utilizar la financiación procedente de fondos estructurales y del Programa IST (Information Society Technologies).

Por tanto, las instituciones de enseñanza superior deben volverse más flexibles y adoptar nuevos métodos para adaptarse a la satisfacción de estas nuevas necesidades.

El efecto conjunto de estos factores ha comportado un importante incremento de la demanda de formación universitaria y, por tanto, de un aumento del número de matrículas en programas y titulaciones de nivel universitario. Este incremento se ha traducido en una evolución creciente de la cifra de negocio del mercado mundial de la Educación. En este sentido, durante la 
segunda mitad de los años 1990, los ingresos derivados de la formación universitaria pasaron de los 85.000 millones de dólares en 1996 a los 105.000 millones en el 2000, con una previsión de que durante los primeros años del siglo XXI solamente los productos de formación virtual ofrecidos por las universidades generen un volumen de negocio de 50.000 millones de dólares (Serrano, 2002). Ahora bien, es importante apuntar que este resultado global es la consecuencia de la conjunción de dos elementos (Castillo, 2004): la evolución demográfica del conjunto tradicional de la enseñanza universitaria y la evolución del acceso de la población adulta a al formación universitaria y, consecuentemente, la evolución de la formación de los trabajadores.

A partir de comienzos de los años 1960 se inició en las economías desarrolladas un proceso de democratización del acceso a la enseñanza superior que supuso un incremento importante de la matriculación de estudiantes procedentes del bachillerato integrados en la cohorte tradicional de estudiantes de enseñanza superior. La evolución demográfica provocó que esta tendencia creciente se invirtiera durante la década de los 1980, iniciándose una disminución del número de matrículas en este grupo de estudiantes en prácticamente todos los países occidentales (Goodall, 1980). Esta evolución decreciente se ha mantenido en muchos casos durante la década de los 1990 y los primeros años del siglo XXI.

Efectivamente, si analizamos los datos disponibles para los diferentes países de la OECD recogidos en la Figura 6, podemos constatar que durante la segunda mitad de la década de los 1990 se produce un importante incremento de la matrícula universitaria en los países desarrollados a la vez que una reducción o estancamiento en la matrícula de los estudiantes pertenecientes a las cohortes tradicionales. Este hecho comporta, necesariamente, la consideración de otros factores a la hora de explicar el aumento de la demanda. La evolución demográfica de las cohortes tradicionales de la matrícula universitaria se configuró como uno de los principales factores desencadenantes del incremento de la competencia interinstitucional por la obtención de estudiantes, lo que explica la búsqueda de nuevas estrategias de captación, centradas en dos líneas principales: la ampliación del público potencial mediante la atracción de nuevos grupos sociales como la población adulta (población mayor de 25 años, entre la que se incluye la población ocupada), los grupos minoritarios y los inmigrantes; y la internacionalización de la oferta formativa. No obstante, es de destacar que existen excepciones destacables a esta tendencia generalizada del crecimiento de la demanda de enseñanza universitaria, como son los casos de Francia y Alemania, por la imposibilidad de compensar la caída de la matrícula tradicional con alumnos de otros orígenes, y de Canadá, donde la reducción de matrícula se debe, principalmente, a la caída de la matrícula correspondiente a estudiantes no integrados en las cohortes tradicionales. 


\begin{tabular}{|c|c|c|}
\hline & $\begin{array}{l}\text { Cambio en el total de } \\
\text { matrícula }(1995=100)\end{array}$ & $\begin{array}{c}\text { Cambios atribuibles a } \\
\text { la evolución } \\
\text { demográfica } \\
\end{array}$ \\
\hline Finlandia & 120 & 100 \\
\hline Australia & 111 & 108 \\
\hline Reino Unido & 114 & 97 \\
\hline Noruega & 105 & 98 \\
\hline Canadá & 98 & 100 \\
\hline Polonia & 184 & 111 \\
\hline Alemania & 98 & 85 \\
\hline Dinamarca & 116 & 93 \\
\hline Italia & 105 & 95 \\
\hline Corea & 154 & 85 \\
\hline Grecia & 161 & 96 \\
\hline Irlanda & 130 & 111 \\
\hline Francia & 99 & 93 \\
\hline Austria & 110 & 68 \\
\hline Bélgica & 112 & 94 \\
\hline Portugal & 129 & 98 \\
\hline España & 120 & 93 \\
\hline República Checa & 154 & 99 \\
\hline Hungría & 194 & 100 \\
\hline México & 134 & 107 \\
\hline Turquía & 125 & 104 \\
\hline Islandia & 140 & 104 \\
\hline Suecia & 125 & 95 \\
\hline UE 13 & 119 & 94 \\
\hline OECD 23 & 131 & 95 \\
\hline
\end{tabular}

Fuente: elaboración propia a partir ODCE. Education at a Glance (2000:2003).

Figura 6.Variación del número de matriculados en formación superior en la OECD y causas del cambio. 1995-2001

En el caso particular de España entre los cursos 1994-1995 y 2005-2006 (ver Figura 7) es posible distinguir una época de crecimiento que, va perdiendo fuerza paulatinamente hasta que comienza una etapa de disminución del número de estudiantes matriculados. 


\begin{tabular}{l|c|c}
\hline Curso & Universidades Públicas & Universidades Privadas \\
\hline $1994-1995$ & 1.394 .388 & 52.098 \\
\hline $1995-1996$ & 1.449 .967 & 58.875 \\
\hline $1996-1997$ & 1.480 .881 & 68.431 \\
\hline $1997-1998$ & 1.493 .927 & 81.718 \\
\hline $1998-1999$ & 1.489 .155 & 91.003 \\
\hline $1999-2000$ & 1.486 .912 & 100.143 \\
\hline $2000-2001$ & 1.438 .294 & 117.456 \\
\hline $2001-2002$ & 1.403 .390 & 123.517 \\
\hline $2002-2003$ & 1.363 .984 & 143.163 \\
\hline $2003-2004$ & 1.349 .224 & 139.350 \\
\hline $2004-2005$ & 1.317 .684 & 131.452 \\
\hline $2005-2006$ & 1.291 .542 & 131.019 \\
\hline
\end{tabular}

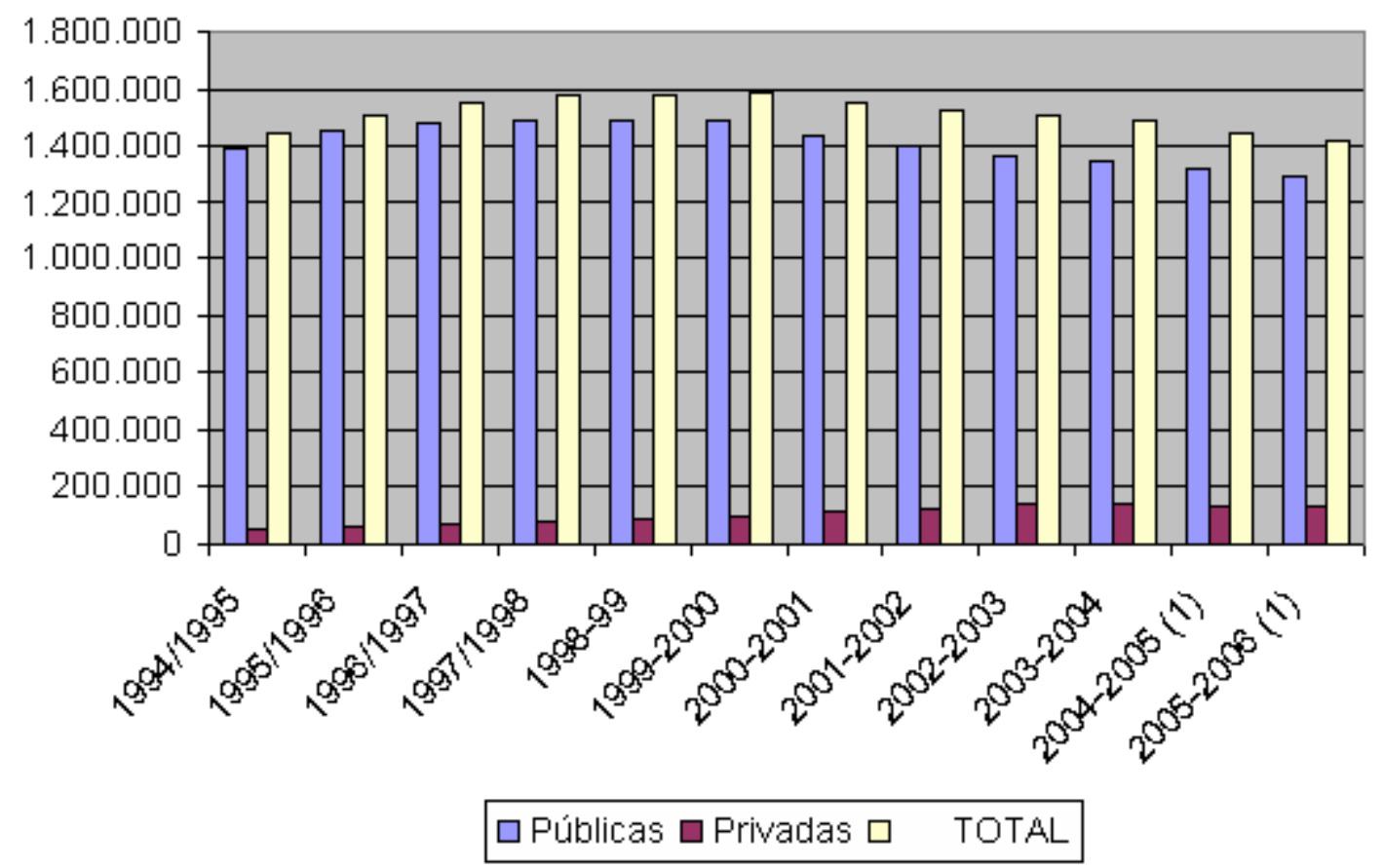

Fuente: Elaboración propia a partir de datos del Instituto Nacional de Estadística

Figura 7. Evolución de la matrícula en ler y $2^{\circ}$ ciclo y titularidad de la Universidad.

El último informe de la CRUE (2006) confirma esta tendencia bajista, cifrando en un 9,5\% el descenso de la matrícula de primer y segundo ciclo en el curso 2004-2005 respecto del 20002001, como recoge la Figura 8: 


\begin{tabular}{l|l|l}
\hline Universidades públicas presenciales & Curso 2004-2005 & Curso 2000-2001 \\
\hline Andalucía & 236.688 & 268.712 \\
\hline Aragón & 33.754 & 41.431 \\
\hline Asturias & 31.510 & 38.536 \\
\hline Baleares & 13.496 & 13.883 \\
\hline Canarias & 46.310 & 47.038 \\
\hline Cantabria & 11.550 & 13.474 \\
\hline Castilla-La Mancha & 28.440 & 32.230 \\
\hline Castilla y León & 80.257 & 91.593 \\
\hline Cataluña & 170.319 & 185.217 \\
\hline Comunidad Valenciana & 133.649 & 139.057 \\
\hline Extremadura & 24.281 & 28.050 \\
\hline Galicia & 80.555 & 95.863 \\
\hline Madrid & 203.843 & 213.488 \\
\hline Murcia & 33.666 & 35.936 \\
\hline Navarra & 7.595 & 9.427 \\
\hline País Vasco & 47.698 & 55.415 \\
\hline La Rioja & 6.750 & 7.237 \\
\hline España & 1.190 .361 & 1.316 .587 \\
\hline & & \\
\hline
\end{tabular}

Figura 8. Evolución de la matrícula de $1^{e r}$ y $2^{\circ}$ ciclo en España.

Una manera más ajustada de observar la evolución de la matrícula es analizar la demanda de nuevo ingreso, es decir, las cohortes que acceden por primera vez a la Universidad. Esta demanda, bajo el supuesto de que no hay restricciones en la oferta, viene condicionada fundamentalmente por la estructura demográfica, junto con una serie de factores de índole social, cultural, económica, etc., entre los que se pueden señalar la situación del mercado de trabajo, las expectativas de promoción social y económica de los titulados universitarios, el prestigio de los mismos y el coste de oportunidad de dichas enseñanzas (CRUE, 2006). Estos factores inciden directamente en la decisión de demandar estudios universitarios provocando movimientos al alza o a la baja de la tasa de escolarización. Sin embargo, el principal condicionante de la demanda de nuevo ingreso es la estructura demográfica que, por otra parte, no puede modificarse más que a largo plazo. En el informe de la CRUE (2006) se presentan las proyecciones para España a partir de datos del INE, según los cuales en el año 2000 la población española presenta claros síntomas de envejecimiento que no parecen desaparecer para los próximos años. Las bajas tasas de natalidad y el espectacular incremento de la esperanza de vida están detrás de la situación descrita. No obstante, las previsiones del INE, referidas a 2005 y 2010, corrigen algo esta tendencia que se presentaba en el año 2000 al contemplar los efectos de las migraciones. Además, predice una reducción continua hasta el año 2010 de la cohorte de edad de 18 a 22 años, lo que producirá un impacto negativo sobre el número de demandantes de plazas universitarias, tal y como muestra la Figura 9. 


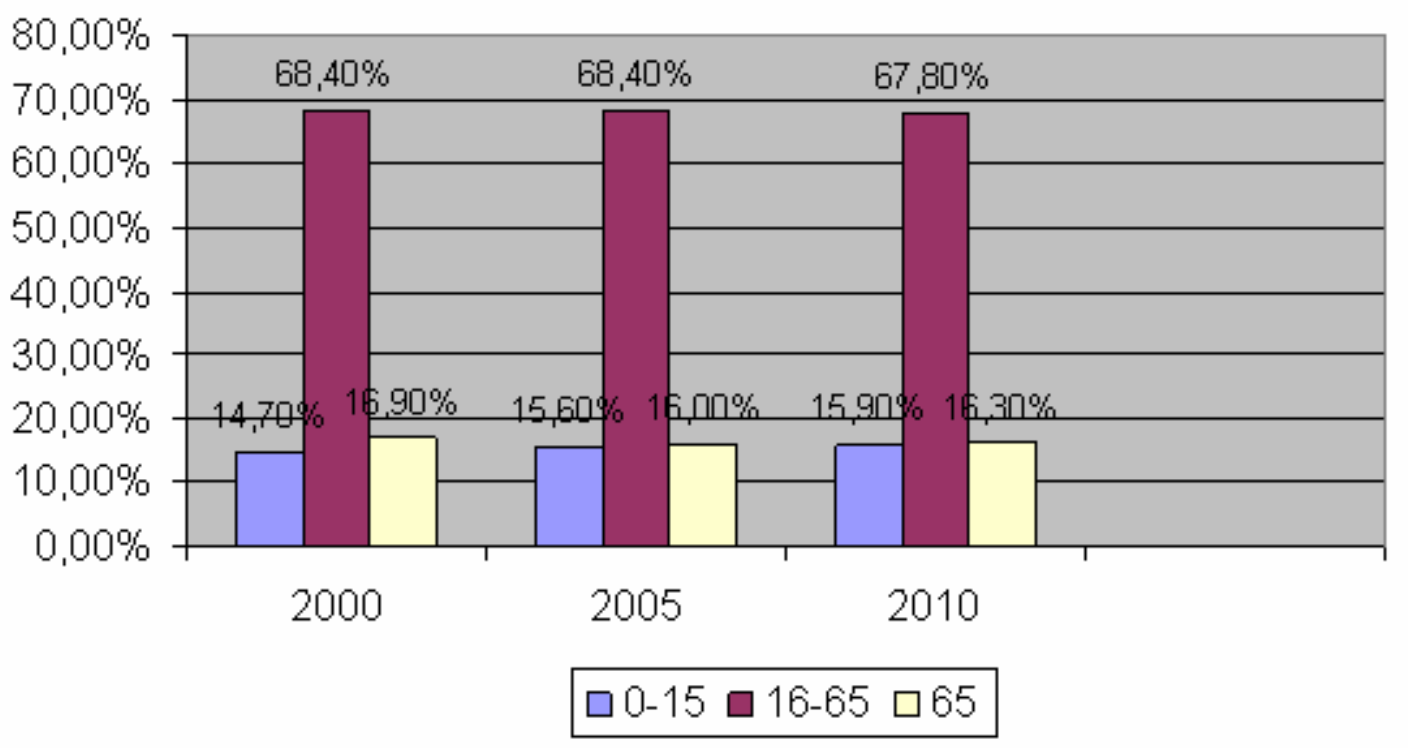

Fuente: CRUE (2006)

Figura 9. Estructura demográfica y proyecciones de población.

Con oscilaciones de un año a otro, observamos un estancamiento del nuevo acceso alrededor de 320.000 alumnos. No se observa aquí una tendencia a la baja, sino oscilaciones alrededor de un cierto volumen, como hemos señalado.

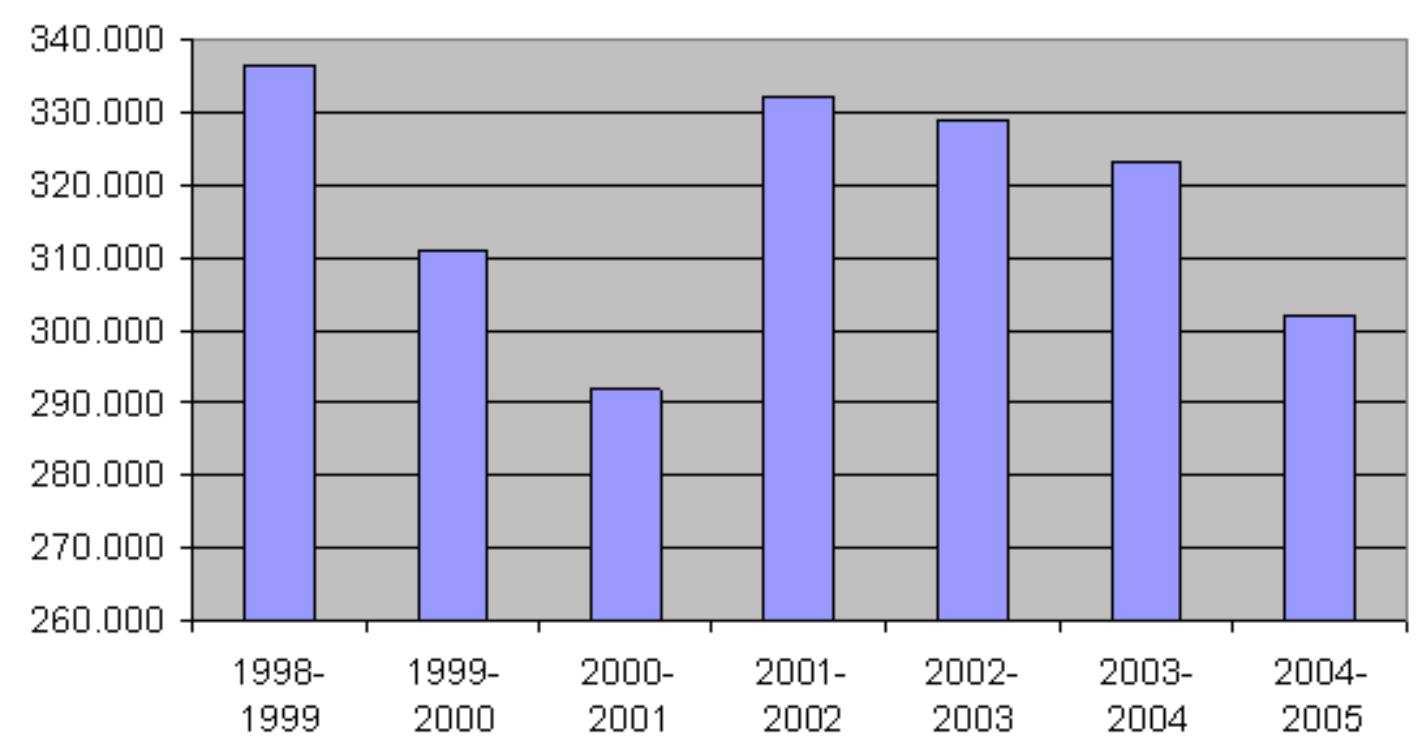

Fuente: Elaboración propia a partir de datos del INE (1994:2006).

Figura 10. Evolución del nuevo ingreso en la Universidad.

Podemos explicarnos este estancamiento del nuevo ingreso, no sólo por la llegada a la Universidad de las cohortes procedentes de la caída de la natalidad en la década de los 70 sino, también, por un cierto descenso de la tasa de estudiantes de bachillerato.

Sin embargo, un aspecto que llama la atención es el aumento de la demanda de formación de tercer ciclo, que en los últimos quince años ha crecido hasta doblar el número de alumnos. Es 
un nivel cuyo peso recae, prácticamente, en la Universidad pública con casi el 97\% del alumnado (ver Figura 11).

\begin{tabular}{l|l|l|l|l}
\hline & $\begin{array}{c}\text { Univ. } \\
\text { Públicas }\end{array}$ & $\begin{array}{c}\text { Univ. } \\
\text { Privadas }\end{array}$ & \multicolumn{1}{|c}{ Total } & \% Privadas \\
\hline $1998-1999$ & 61.897 & 2.575 & 64.472 & $3,99 \%$ \\
\hline $1999-2000$ & 61.648 & 2.645 & 64.293 & $4,11 \%$ \\
\hline $2000-2001$ & 60.166 & 2.364 & 62.530 & $3,78 \%$ \\
\hline $2001-2002$ & 62.873 & 2.817 & 65.690 & $4,29 \%$ \\
\hline $2002-2003$ & 69.693 & 3.280 & 72.973 & $4,49 \%$ \\
\hline $2003-2004$ & 73.740 & 3.699 & 77.439 & $4,78 \%$ \\
\hline $2004-2005$ & 72.484 & 3.767 & 76.251 & $4,94 \%$ \\
\hline
\end{tabular}

Fuente: Elaboración propia a partir de datos del INE (1998:2006)

Figura 11. Evolución de los alumnos matriculados en doctorado y titularidad del centro.

Asimismo, también puede constatarse el aumento del acceso a la formación universitaria por parte de la población adulta, lo que ha compensado también la caída de las cohortes tradicionales. Efectivamente, de los datos disponibles para los distintos países de la OECD (ver Figura 12), se desprende que en la práctica totalidad de las economías desarrolladas se ha producido un incremento de la obtención de un nivel universitario por parte de la población con edades comprendidas entre los 25 y los 64 años. Cabe destacar el caso de Alemania, que presenta un crecimiento muy reducido de esta tasa (de un $21 \%$ en 1991 a un $22 \%$ en 2001), hecho que puede explicar la reducción total de la matrícula universitaria en este país durante la década 19912001. También destacan, aunque en sentido contrario, España y Canadá, con unas tasas de crecimiento de este indicador en el periodo $1991-2001$ del $16 \%$ al $36 \%$ y del $32 \%$ al $51 \%$, respectivamente, que prácticamente triplican la media de los países 
considerados.

\begin{tabular}{|c|c|c|c|c|c|}
\hline & 1991 & 1993 & 1995 & 1997 & 1999 \\
\hline Australia & 23 & 23 & 25 & 26 & 29 \\
\hline Austria & 0 & & 9 & 12 & 13 \\
\hline Bélgica & 27 & 29 & 30 & 33 & 34 \\
\hline Canadá & 32 & 35 & 40 & 44 & 47 \\
\hline República Checa & nd & nd & 12 & 11 & 11 \\
\hline Dinamarca & nd & nd & nd & nd & 29 \\
\hline Finlandia & 33 & $\mathrm{Nd}$ & 235 & 36 & 37 \\
\hline Francia & 20 & 28 & 25 & 28 & 31 \\
\hline Alemania & 21 & $\mathrm{Nd}$ & 21 & 31 & 22 \\
\hline Grecia & nd & nd & 26 & 23 & 25 \\
\hline Hungría & $\mathrm{Nd}$ & nd & $\mathrm{Nd}$ & 12 & 14 \\
\hline Irlanda & 20 & $\mathrm{Nd}$ & 27 & 33 & 41 \\
\hline Italia & 7 & $\mathrm{Nd}$ & 8 & $\mathrm{Nd}$ & 10 \\
\hline Japón & $\mathrm{Nd}$ & nd & $\mathrm{Nd}$ & 45 & 45 \\
\hline Corea & $\mathrm{Nd}$ & nd & 29 & $\mathrm{Nd}$ & 35 \\
\hline Holanda & 22 & nd & 25 & $\mathrm{Nd}$ & 25 \\
\hline Nueva Zelanda & 23 & $\mathrm{Nd}$ & 24 & 25 & 26 \\
\hline Noruega & 27 & $\mathrm{Nd}$ & 32 & 30 & 35 \\
\hline Polonia & $\mathrm{Nd}$ & nd & 10 & 10 & 12 \\
\hline Portugal & 9 & nd & 14 & $\mathrm{Nd}$ & 11 \\
\hline Luxemburgo & $\mathrm{Nd}$ & nd & nd & nd & 21 \\
\hline España & 16 & $\mathrm{Nd}$ & 27 & 30 & 33 \\
\hline Suecia & 27 & $\mathrm{Nd}$ & 29 & 29 & 32 \\
\hline Suiza & 21 & $\mathrm{Nd}$ & 22 & 25 & 26 \\
\hline Reino Unido & 19 & $\mathrm{Nd}$ & 23 & 25 & 27 \\
\hline EEUU & 30 & nd & 34 & 36 & 37 \\
\hline UE 15 & 19 & $\mathrm{Nd}$ & 23 & 27 & 26 \\
\hline OECD 26 & 23 & $\mathrm{Nd}$ & 25 & 27 & 28 \\
\hline
\end{tabular}

Fuente: Elaboración propia a partir de OECD Education at a Glance (2000:2005)

Figura 12. Evolución del número de titulados en formación superior entre la población adulta en la OECD (porcentaje de población de entre 25 y 34 años que ha obtenido un título de educación superior).

Esta evolución del nivel de formación entre la población adulta se explica, en gran parte, por la demanda de formación asociada a trabajo, tanto por la necesidad de actualización y mejora 
de las habilidades de los trabajadores, como por el reciclaje de la población parada que pretende conseguir una capacitación que le permita la reinserción en el mercado laboral.

El incremento de la demanda de formación asociada al trabajo incluye, adicionalmente a la formación en el puesto de trabajo por competencias, la participación en programas de formación continua (cursos monográficos y de actualización no universitarios y formación de postgrado). Del análisis de los datos disponibles para el conjunto de países de la Unión Europea se puede concluir que la demanda de formación asociada al puesto de trabajo presenta una relación directa con el nivel formativo conseguido, de manera que los trabajadores con un nivel universitario presentan una tasa de participación en los programas de formación significativamente superior a los trabajadores de niveles formativos inferiores.

Se puede hacer referencia a la posición de España en relación a otros países de nuestro entorno, siguiendo la información recabada de Eurostat y la OECD. Según estos datos, un $31 \%$ de las personas altamente cualificadas en la UE-25 habían seguido en 2003 algún tipo de formación estructurada, intencional y planificada pero no reglada (educación no formal), mientras que el porcentaje equivalente para España era solamente del 21\%. Si la comparación se realiza no con la media de la Unión Europea sino con los países europeos con indicadores más elevados, como Dinamarca, Finlandia o Suecia, la diferencia ya pasa a ser de prácticamente 40 puntos. En una situación inferior a la española se encuentran países como Italia, Grecia, Holanda o algunos nuevos miembros como Hungría o Lituania. Es más, el porcentaje de población con un nivel de formación relativamente reducido que sigue estudios de formación continua en los países nórdicos antes mencionados es superior a la participación de la población con estudios superiores en España (ver Figura 13). Los datos de la OECD respecto de la educación no formal y relacionada con el lugar de trabajo ofrecen resultados similares y además permiten observar lo que ocurre también en otros países diferentes a los de la UE-25. Así, se constata que la participación en este tipo de formación de los estadounidenses con educación terciaria es similar a la de los países nórdicos (en torno al 60\%), e igual sucede en otro país no perteneciente a la UE-25 como Suiza.

También es destacable el hecho de que, nuevamente, son los países con una mayor incorporación de las TIC en la actividad empresarial (Finlandia, Suecia, Reino Unido, Dinamarca, Estados Unidos y Noruega, con la excepción de Irlanda) los que presentan un mayor porcentaje de trabajadores que participan en programas de formación, especialmente entre los trabajadores más cualificados, de manera que se refuerza la hipótesis de la existencia de una relación positiva entre la inversión y el uso de TIC y la demanda de habilidades especifícas de los trabajadores (Bresnahan, Brynjolfsson y Hitt, 2000).

\subsubsection{Desarrollo humano}

En las últimas décadas, las investigaciones en Economía Laboral permiten concluir que en la Sociedad de la Información el valor es producto del conocimiento y la información y que las empresas no pueden generar utilidades sin las ideas, las destrezas y el talento de los trabajadores del conocimiento, por lo que el reto para ellas es apostar por las personas (Moldoveanu, citado por Fuentes, 2005) y, en este sentido, la formación continua de los trabajadores se constituye como un elemento clave (Caparrós, Navarro y Rueda, 2005) para mantener actualizados los conocimientos de la fuerza de trabajo (Lynch, 1989) y facilitar a los empleados el acceso a trayectorias laborales ascendentes (Blau y Khan, 1996). Desde el punto de vista del empleador, por otra parte, permite contar con una fuerza de trabajo competitiva (Caparrós, Navarro y Rueda, 2005).

En efecto, el valor del talento humano como fuente crítica de ventaja competitiva es cada vez más reconocido por las empresas, no en vano las empresas que comparten los mayores estándares de satisfacción de los empleados son también las que mayores índices de rentabilidad presentan, según el Great Place to Work Institute (citado por Fuentes, 2005). Corresponderá a las instituciones educativas revisar sus programas formativos para garantizar que los estudiantes egresados disponen de las destrezas y el talento que el mercado de trabajo espera de ellos. 


\begin{tabular}{|c|c|c|c|}
\hline & Superior & Media & Baja \\
\hline Bélgica & 35 & 19 & 9 \\
\hline República Checa & 27 & 12 & 4 \\
\hline Dinamarca & 61 & 44 & 31 \\
\hline Alemania & 25 & 11 & 4 \\
\hline Estonia & 27 & 11 & n.d. \\
\hline Grecia & 13 & 5 & 1 \\
\hline España & 21 & 13 & 5 \\
\hline Francia & 35 & 20 & 11 \\
\hline Italia & 14 & 7 & 2 \\
\hline Irlanda & 24 & 14 & 7 \\
\hline Chipre & 45 & 17 & 4 \\
\hline Letonia & 33 & 11 & 3 \\
\hline Lituania & 20 & 5 & n.d. \\
\hline Luxemburgo & 36 & 16 & 5 \\
\hline Hungría & 10 & 5 & 2 \\
\hline Malta & 25 & 23 & 6 \\
\hline Holanda & 15 & 12 & 6 \\
\hline Austria & 45 & 26 & 9 \\
\hline Polonia & 32 & 8 & 2 \\
\hline Portugal & 30 & 18 & 5 \\
\hline Eslovenia & 49 & 22 & 7 \\
\hline Eslovaquia & 41 & 20 & 7 \\
\hline Finlandia & 60 & 37 & 24 \\
\hline Suecia & 64 & 45 & 30 \\
\hline Reino Unido & 56 & 34 & 11 \\
\hline UE 25 & 31 & 16 & 7 \\
\hline
\end{tabular}

Fuente: Fundación CYD (2006)

Figura 13. Tasa de participación en la educación no formal por nivel de formación, personas de 25 a 64 años.

Por otra parte, la desaparición del horizonte laboral del empleo continuo y estable en una misma empresa (Keegan, 2000), obliga a los empleados a prepararse para cambiar de trabajo, puestos y responsabilidades a lo largo de su vida laboral. Tanto es así, que hoy en día un contrato a largo plazo dentro de una misma organización, en general, es menos valorado que el conjunto de destrezas que el empleado va a adquirir durante su estancia en la misma y el grado en que éstas son demandas por el conjunto del sistema productivo. Entre este conjunto de destrezas y 
habilidades que determinan la empleabilidad de una organización, destacan el trabajo en equipo, la movilidad, la iniciativa y la formación continua. Como consecuencia, debe abandonarse la creencia tradicional que de que la educación universitaria tiene como fin preparar a los estudiantes para el desempeño de un trabajo concreto.

En su empeño por convertirse en la Sociedad del Conocimiento más competitiva para el año 2010, la Unión Europea ha puesto en marcha diversas actuaciones centradas en extender el concepto de aprendizaje más allá de los límites tradicionales de las escuelas, universidades e institutos (Comisión Europea, 2003). Esto es lo que se llama aprendizaje a lo largo de la vida (lifelong learning), formación continua o formación permanente. El e-learning constituye un soporte idóneo para este tipo de aprendizaje, dado que los estudiantes suelen serlo a tiempo parcial, compaginando los estudios con su actividad laboral $\mathrm{u}$ otras actividades. Por ello, es muy importante fomentar el despliegue y asimilación, por parte de la Sociedad, de las TIC ya que sólo así podrá garantizarse el acceso a la Educación.

\subsubsection{Movilidad}

La posibilidad de realizar una estancia (física o virtual) de duración variable en el extranjero para completar los estudios es cada vez más demandada por los estudiantes. En el caso particular de los países de la Unión Europea, esta posibilidad se vincula a la posibilidad de integrarse en la vida laboral, social y económica de cualquier país de la Unión. La Figura 14 muestra la evolución de estudiantes extranjeros para los países de la OECD entre 1998 y 2002, tomando como referencia el primero $(1998=100)$. Como puede observarse, excepto Reino Unido, Polonia y Turquía, en el resto de países se ha producido un aumento del número de estudiantes extranjeros.

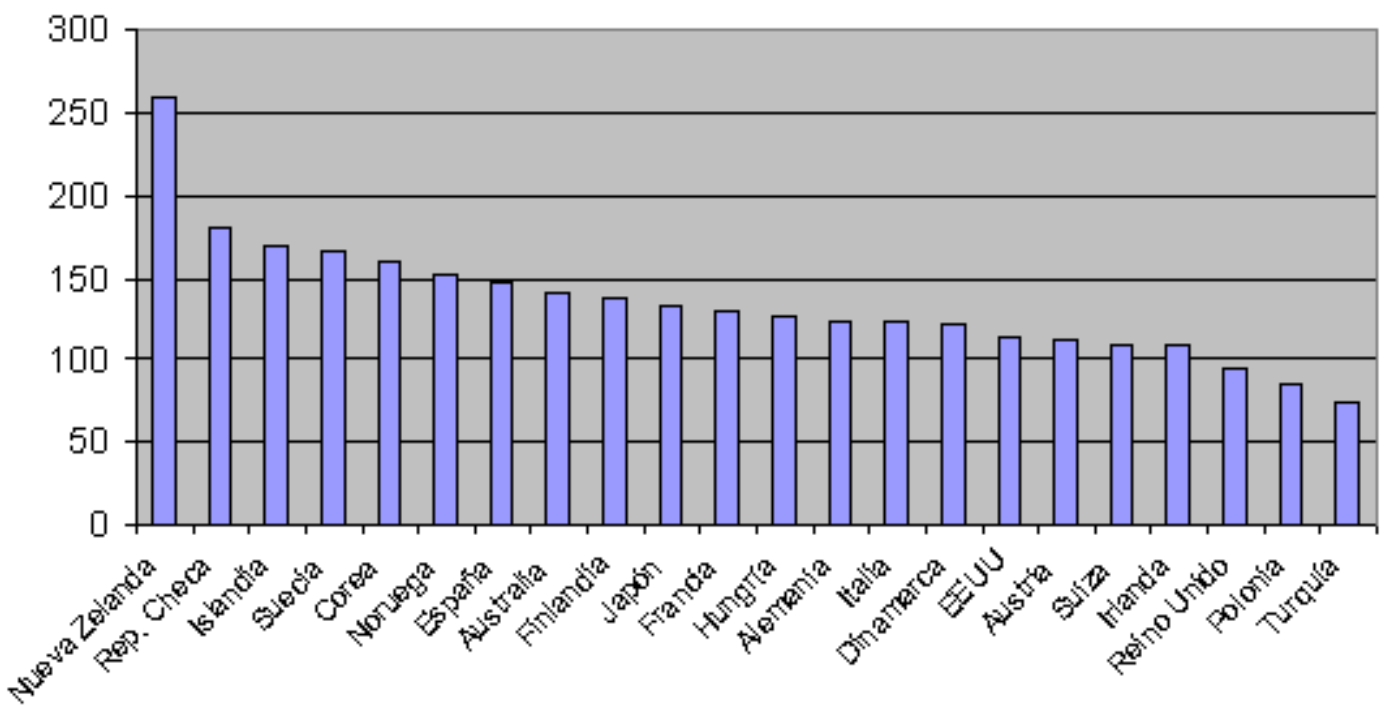

Fuente: elaboración propia a partir de datos de la OECD (1998:2002).

Figura 14. Evolución del porcentaje de estudiantes extrajeros en Educación Superior en los países de la OECD (1998-2002).

En la actualidad, existe una creciente movilidad de estudiantes, académicos e investigadores de distintas partes del mundo (CAPA, 2005; UNESCO, 2004) y una tendencia en los círculos políticos y académicos hacia una actitud favorable respecto la movilidad (Marginson y Van der Wende, 2007). 
En el contexto europeo, la Declaración de Bolonia (1999) anima los países a promover la libre circulación de estudiantes, profesores e investigadores. De hecho, las Universidades Europeas, en el contexto del Espacio Europeo de Educación Superior, están fomentando una mayor movilidad tanto horizontal como vertical a través de instrumentos como los créditos ECTS y el Suplemento al Título. Sin embargo, continua requiriéndose un enfoque común en materia de movilidad ficticia y de educación transnacional (García y Morant, 2005).

Fernández y Ruzo (2004) distinguen tres tipos de movilidad que contribuyen de forma diferente a la internacionalización de la Educación Superior, y que son (ver Figura 15):

1. Movilidad física

Supone el desplazamiento físico de los estudiantes al país en que reside la institución en la que cursarán sus estudios. Este tipo de iniciativas se ha venido favoreciendo a través de programas como ERASMUS o SÓCRATES.

2. Movilidad ficticia

En este caso, el estudiante cursa los estudios en una Universidad de su país de origen que ha llegado a algún acuerdo con la Universidad (o empresa) extranjera de tal manera que el título conseguido será homologado por esta última.

Según Jones (2001) y Machado (2002), es posible distinguir las siguientes modalidades:

- Campus satélites: la institución extranjera crea una sucursal en el país extranjero. Ejemplo: las universidades de Edimburgo, Birmingham y Manchester han establecido una Universidad Británica en Dubai que ofrece el título de master es varios campos.

- Franquicias: la institución extranjera reconoce a una entidad nacional como centro oficial de formación y homologa los títulos que esta última concede.

- Programas articulados: la institución extranjera convalida sistemáticamente los estudios ofertados por otra una nacional.

- Programas hermanados: oferta conjunta de programas entre instituciones de países diferentes que pueden exigir una estancia parcial del estudiante en el extranjero.

- Programas corporativos: se convalida la titulación de una institución extranjera previa superación de un examen.

3. Ausencia de movilidad

Este tipo de movilidad es la que más interesa a los efectos de esta tesis, ya que la interacción entre el estudiante y la Universidades se lleva a cabo desde su hogar, ya sea por correo postal, electrónico o Internet. También recibe el nombre de movilidad virtual y ha sido fuertemente impulsada por el desarrollo de las TIC. 

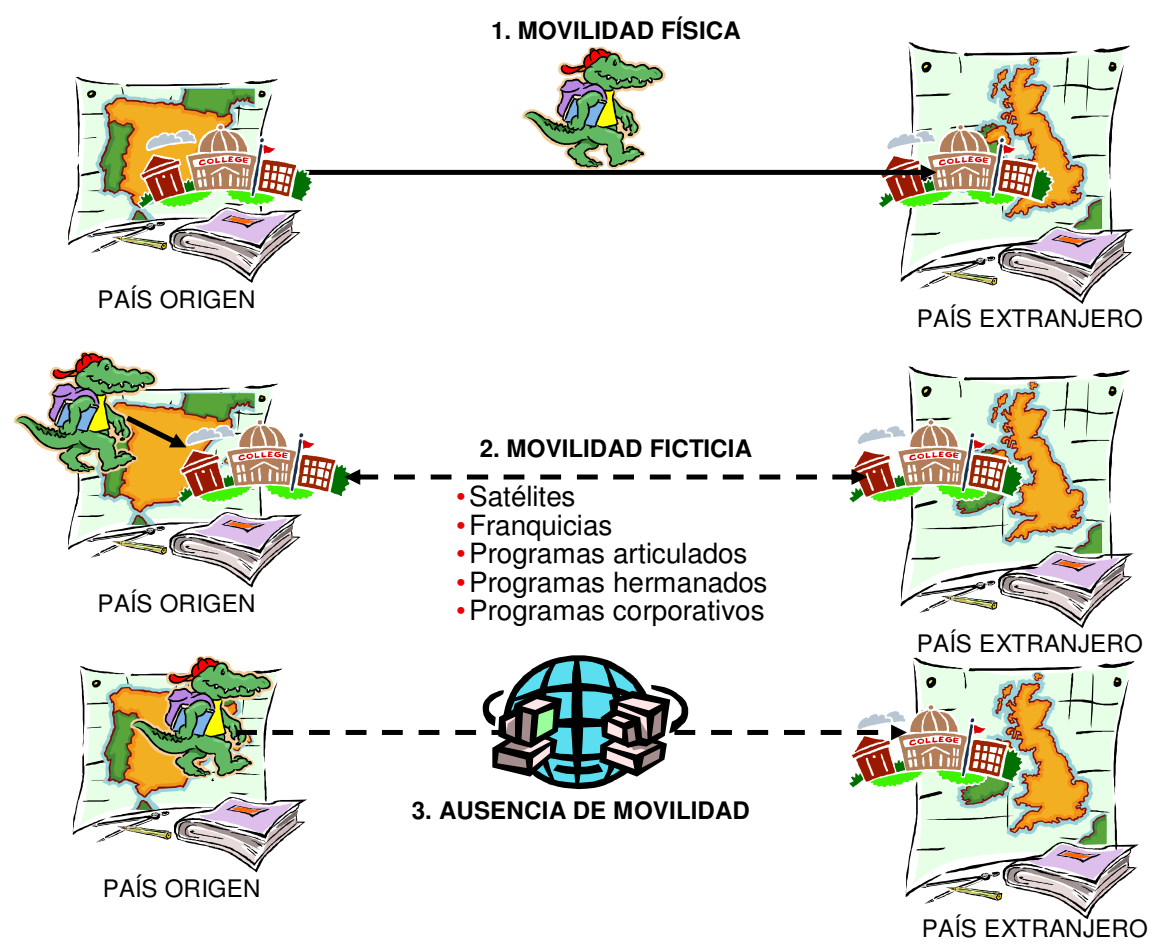

Figura 15. Distintos tipos de movilidad.

Fuente: elaboración propia.

Calvo (2007) señala que de los tres tipos de movilidad, los dos primeros presentan algunas deficiencias que pueden disminuir los beneficios que de ellas se derivan y que son:

- El porcentaje de estudiantes europeos que se desplazan para recibir formación internacional disminuye, debido a que la demanda de formación universitaria crece a mayor nivel, mientras que en valor absoluto el número de estudiantes demandantes de formación internacional se mantiene relativamente estable.

- La magnitud de los costes asociados a la movilidad y el hecho de que la mayor parte de ellos corre a cargo de los interesados, por lo que los principales beneficiarios de este tipo de iniciativas son las clases sociales medias y altas.

- La "fuga" de conocimiento en los centros emisores, puesto que la mayor parte de los estudiantes móviles proceden de los últimos años de carrera y ello hace peligrar el prestigio y la imagen de la institución.

Algunos de estos obstáculos pueden salvarse satisfactoriamente gracias a la ausencia de movilidad o movilidad virtual, caracterizada por el uso intensivo de las TIC en el mantenimiento de relaciones académicas.

\subsubsection{Innovación y tecnología}

El carácter dinámico del entorno exige a las Universidades fomentar una cultura de innovación que las convierta en más competitivas y productivas. En el entorno académico, la innovación incluye la renovación permanente de los procesos de investigación y la búsqueda constante de nuevos métodos y conceptos que mantengan la vigencia de los programas académicos frente al entorno cambiante. Sin embargo, lo relevante no es contar con una tecnología punta, sino tener unas organizaciones capaces de asimilar los cambios tecnológicos y adaptarlos a sus culturas: la tecnología es un medio más para potenciar la innovación, no una finalidad en sí misma. 
Éste es uno de los puntos más importantes de esta tesis y, por ello, se le ha dedicado un capítulo completo (capítulo 3) en el que se describe con suficiente nivel de detalle las implicaciones de la introducción de las TIC en las Universidades.

\subsubsection{Demanda de resultados de la actividad universitaria}

A lo largo de las dos últimas décadas del siglo XX se ha constatado un sensible aumento de las demanda social de mejora de resultados derivados de la gestión de la actividad universitaria (Macpherson, 1999), y, en consecuencia, de la disponibilidad de información periódica y con el objetivo de poder ejercer un control social sobre estos resultados y su evolución (Berzosa, 1988). En efecto, la Sociedad, cada vez más, exige una mayor rendición de cuentas a las Universidades y ello ha desembocado en la introducción de la evaluación en el sistema universitario que debe cumplir cinco objetivos básicos (Michavilla, 2005):

- Generar estrategias para la mejora de la docencia, la investigación y la gestión.

- Servir como mecanismo de rendición de cuentas a los gobiernos y a la sociedad.

- Servir como instrumento de información pública de lo que hace la institución.

- Servir para introducir sistemas de financiación diferencial, es decir, que una parte de la financiación esté vinculada a la consecución de resultados. Sin embargo, resulta evidente que este objetivo viene condicionado por el hecho de disponer de la financiación necesaria; si resulta insuficiente, este objetivo tendrá menos sentido.

- Servir de mecanismo de acreditación de los programas.

Esta demanda de adaptar la gestión de las Universidades a parámetros socialmente aceptados se ha concretado en un ámbito principal (Castillo, 2004): la mejora de la distribución y aplicación de los recursos productivos, es decir, la mejora de la eficiencia productiva de la Universidad como un instrumento para garantizar que sea económicamente sostenible y pueda continuar ejerciendo su función social. De esta manera, se ha producido una clara vinculación de la demanda de mejora de la administración y gobierno universitarios a la necesidad de incrementar la productividad de los recursos destinados a las actividades de docencia e investigación.

Esta percepción social de pérdida de productividad por parte de las Universidades y de deficiencia en la gestión de su actividad se ha atribuido a dos tipos de indicadores principales (Castillo, 2004):

- El empeoramiento de la situación de variables asociadas a la capacidad productiva de los profesores: la constante reducción de la capacitación docente del profesorado, una actividad investigadora inconsistente que han generado en muchos casos publicaciones controvertidas e irrelevantes (Michael, 1997), o la incapacidad del profesorado de ajustar el contenido de la formación universitaria a las nuevas demandas del mercado de trabajo, contribuyendo así a la generación de un desajuste entre la cualificación y la demanda de habilidades (Carnoy, 1994).

- Los costes elevados y crecientes de la actividad universitaria, caracterizados por un peso preponderante de los costes salariales y por la dificultad de vincularlos con indicadores de productividad. Como señalaban Burrup y Brimley (1982) para el caso de los EEUU, los agentes sociales comenzaban a ver las instituciones universitarias con financiación dependiente del sector público como una gran industria innecesaria, los costes elevados de la cual generan un efecto impositivo excesivo para la Sociedad y una constante tensión en las cuentas públicas.

La consolidación de esta demanda social de mejora del resultado productivo de la actividad universitaria ha puesto de manifiesto la necesidad de reorganizar la aplicación de los recursos de las Universidades a partir de una serie de líneas de acción principales (Michael, 1997):

- El análisis y la reordenación de los programas formativos ofrecidos con objetivos de eficiencia individual, evitando duplicidades en la aplicación de recursos y mejorando así los resultados de su uso, y de eficiencia social, ajustando su contenido a las necesidades sociales de formación. 
- El incremento del número de programas, tanto de proyectos de formación a la persona como de formación empresarial, con el objetivo de potenciar el acceso de la población a la formación y mejorar el rendimiento de las inversiones realizadas a través de la diversificación del uso de los recursos productivos.

- La reformulación de los programas de trabajo del profesorado, con una clara tendencia a incrementar el número de horas lectivas semanales con el fin de aumentar la productividad de este colectivo.

- La implantación del sistema de evaluación del rendimiento y la calidad de la actividad docente e investigadora.

\subsubsection{Cambios en el control del sistema educativo}

Los cambios que está sufriendo la Educación Superior como consecuencia de la globalización, no se limitan únicamente a un ámbito cultural y académico, sino que también existe una clara incidencia en aspectos económicos. De hecho, Teichler (2004) subraya que gran parte del debate acerca de la globalización de la Educación Superior se centra en su orientación al mercado, su competitividad y su gestión.

La prestigiosa revista The Economist publicó en 2005 un monográfico sobre Educación Superior $^{8}$ en el que se compara los modelos de Educación Superior pública, típicos de Europa, y los modelos de Educación Superior orientados al mercado, típicos de países anglosajones y cuyo máximo exponente es Estados Unidos. En este ensayo se subraya que la pérdida de competitividad del sistema universitario europeo se debe a un exceso de control estatal que impide a las Universidades regir su propio destino, mientras que, por el contrario, el éxito del modelo estadounidense se fundamenta en el limitado rol que juega el Estado Federal y el fomento de la competitividad en todos sus ámbitos (desde el puramente académico hasta el deportivo). Además, hace especial hincapié en el hecho de que los países que deseen establecer un sistema de Educación Superior exitoso deberán diversificar la financiación, dando más importancia a fuentes de financiación privadas.

Las características de estos modelos de Educación Superior han sido estudiadas por gran número de autores, entre los que destacan Clark (1983), Lindblom (2005) y Brunner y Uribe (2007), del que se reproduce la tabla de la Figura 16 que resume los resultados de comparación entre ambos.

Como se desprende de dicha tabla, en un modelo de sistema educativo coordinado por el Estado, los gobiernos rigen el comportamiento de dicho sistema a través de la regulación, limitando así la autonomía de las Universidades y controlándolas a través de los mecanismos de supervisión que se establezcan. Por el contrario, en un modelo de sistema educativo orientado al mercado, las normas las marca el comportamiento competitivo de sus integrantes y el gobierno únicamente atiende a un reducido conjunto de variables críticas (van Vught, 1999).

Una posición intermedia es la que se denomina mercado administrado (Shattock, 2003) o cuasi-mercado (Glennerster, 1991; Benczes, 1998; Dill, 1997), caracterizada por el hecho de que las Universidades (públicas) deben competir por la financiación, de manera que el resultado es parecido al de un mercado en el que las empresas compiten por un conjunto de recursos limitados. Esta situación de cuasi-mercado está muy relacionada con la demanda de resultados sobre la actividad universitaria estudiada en el epígrafe 2.3.5 y con la evaluación de la financiación examinada en el epígrafe siguiente.

\footnotetext{
${ }^{8}$ http://www.utsystem.edu/osm/files/planning/Economist-TheBrainsBusiness-091005.pdf
} 


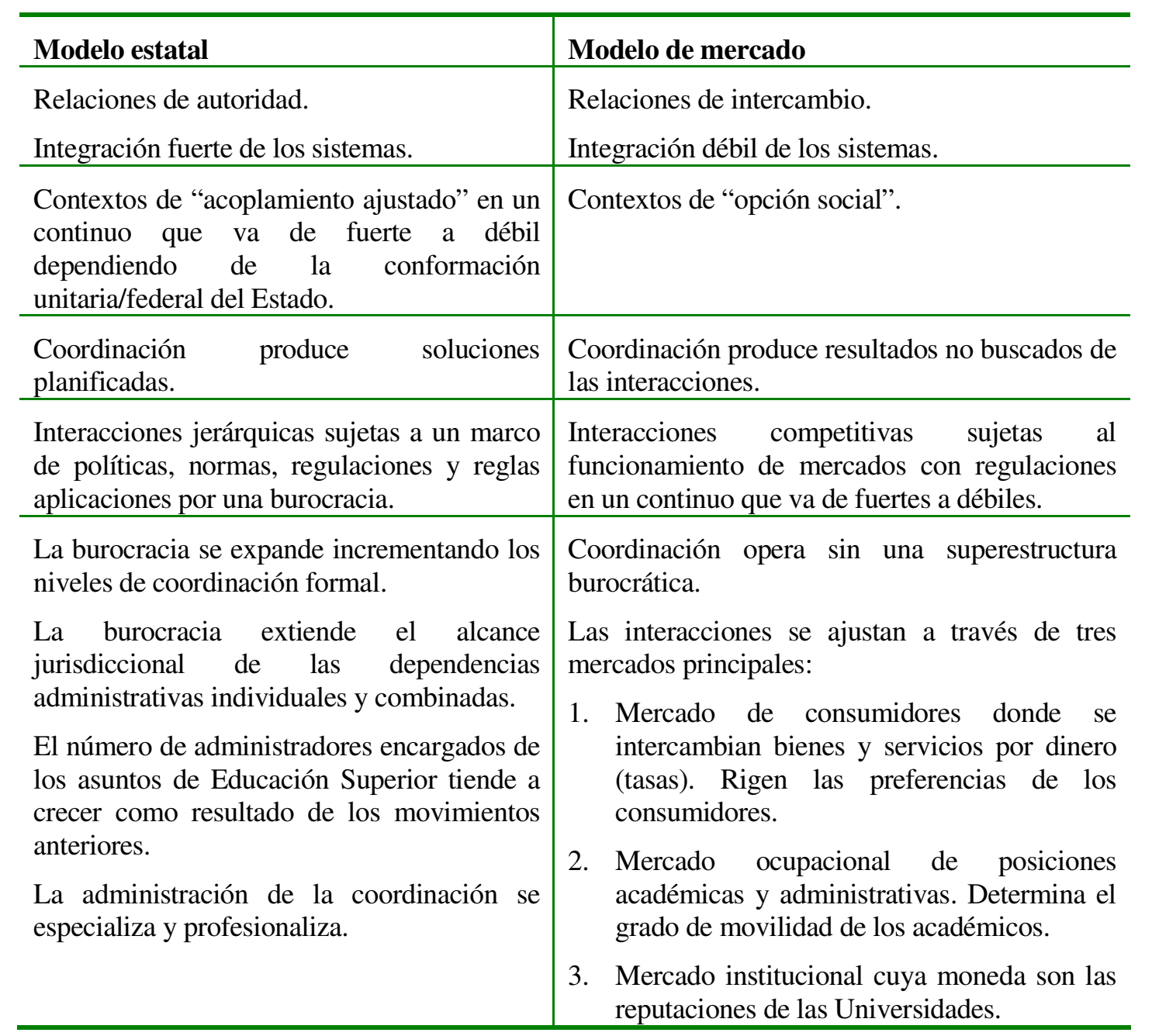

Fuente: reproducido de Brunner y Uribe (2007).

Figura 16. Comparación entre los modelos de Educación Superior.

\subsubsection{Evolución de la financiación}

La financiación de la Educación Superior es un debate cuyos orígenes se remontan a los tiempos de Adam Smith y The Wealth of Nations ${ }^{9}$ (1776), aunque actualmente la cuestion ha tomado un cariz mucho más complejo.

A mediados de las década de los 1980 se invirtió la tendencia alcista de la financiación pública iniciada después de la Segunda Guerra Mundial, de manera que la reducción de este origen de financiación afectó de manera generalizada a las Universidades de las economías desarrolladas, debido fundamentalmente a la reducción en los presupuestos de los gobiernos (Pickens, 1993), a la vez que a un desplazamiento de su distribución a aplicaciones alternativas a la financiación universitaria (Scannell, 1993; Plain, 1995). Esta fase reduccionista de los años 1980 se mantuvo durante la década de los 1990, convirtiéndose en una transformación estructural e independiente del ciclo económico (Michael, Holdaway y Small, 1993).

\footnotetext{
${ }^{9}$ Texto disponible en: http://www.econlib.org/library/Smith/smWN.html
} 
Una segunda etapa, iniciada alrededor del año 1995 y que se extiende hasta la actualidad, se caracteriza por un cierto estancamiento en términos generales de las cuantías destinadas a la financiación del sector universitario. Efectivamente, de los datos disponibles de algunos países de la OECD (ver Figura 17) se desprende que en la última década se han producido aumentos moderados de la financiación en algunos países (como es el caso de España) mientras que en otros se han producido pequeñas disminuciones (como es el caso de Australia).

\begin{tabular}{|c|c|c|c|}
\hline & \multicolumn{3}{|c|}{ Educación terciaria } \\
\hline & $\begin{array}{c}\text { Cambio en el } \\
\text { gasto }\end{array}$ & $\begin{array}{l}\text { Cambio en el } \\
\text { número de } \\
\text { estudiantes }\end{array}$ & $\begin{array}{c}\text { Cambio en el } \\
\text { gasto por } \\
\text { estudiante }\end{array}$ \\
\hline Austria & 108 & 94 & 114 \\
\hline Francia & 111 & 97 & 114 \\
\hline Alemania & 107 & 100 & 107 \\
\hline Japón & 118 & 102 & 116 \\
\hline Noruega & 124 & 104 & 119 \\
\hline Dinamarca & 136 & 105 & 129 \\
\hline Suiza & 148 & 106 & 140 \\
\hline Holanda & 110 & 107 & 104 \\
\hline Italia & 131 & 108 & 121 \\
\hline Turquía & $\mathrm{m}$ & 110 & $\mathrm{~m}$ \\
\hline Finlandia & 112 & 113 & 100 \\
\hline España & 154 & 115 & 134 \\
\hline EEUU & $\mathrm{m}$ & 117 & $\mathrm{~m}$ \\
\hline Reino Unido & 121 & 118 & 102 \\
\hline Irlanda & 180 & 131 & 138 \\
\hline Australia & 120 & 131 & 92 \\
\hline Portugal & 139 & 132 & 105 \\
\hline Suecia & 114 & 135 & 85 \\
\hline México & 172 & 142 & 121 \\
\hline Corea & $\mathrm{m}$ & 158 & $\mathrm{~m}$ \\
\hline Hungría & $\mathrm{m}$ & 161 & $\mathrm{~m}$ \\
\hline $\begin{array}{l}\text { República } \\
\text { Checa }\end{array}$ & 122 & 170 & 72 \\
\hline Eslovaquia & $\mathrm{m}$ & 177 & $\mathrm{~m}$ \\
\hline Grecia & 249 & 181 & 137 \\
\hline Polonia & 159 & 197 & 81 \\
\hline Bélgica & $\mathrm{m}$ & $\mathrm{m}$ & $\mathrm{m}$ \\
\hline Canadá & $\mathrm{m}$ & $\mathrm{m}$ & $\mathrm{m}$ \\
\hline Islandia & $\mathrm{m}$ & $\mathrm{m}$ & $\mathrm{m}$ \\
\hline Luxemburgo & $\mathrm{m}$ & $\mathrm{m}$ & $\mathrm{m}$ \\
\hline Nueva Zelanda & 107 & $\mathrm{~m}$ & $\mathrm{~m}$ \\
\hline
\end{tabular}

Fuente: Elaboración propia a partir de OECD Education at a Glance (1995:2005).

Figura 17. Cambio en el gasto de las instituciones educativas por estudiantes relativas a distintos factores, por nivel de educación (1995=100). 
De este hecho se derivan dos implicaciones principales (Castillo, 2004): la potenciación de políticas de obtención de recursos financieros privados y, consecuentemente, el fomento de la generación de actividad enfocadas al incremento de la autofinanciación; y, la presión encaminada a la reducción de las estructuras de costes operativos en el sector. La realidad es que prácticamente todas las Universidades del mundo han diversificado sus fuentes de financiación (Brunnel y Uribe, 2007). Los datos de la OECD (2006) muestran una distribución continua entre Universidades financiadas exclusivamente con recursos públicos y Universidades financiadas exclusivamente con recursos privados, con un creciente número de Universidades con financiación mixta (ver Figura 18).

Sin embargo, la búsqueda de financiación del sector privado para compensar la disminución de los recursos públicos ha comportado el incremento de partidas de coste no controlables ${ }^{10}$ asociados a la mejora de la imagen de la institución y a la concentración de sus programas formativos en el cumplimiento de determinados parámetros de excelencia por medio del gasto en el proceso de formación. Esta aplicación adicional de recursos (incremento de la capacidad de las bibliotecas, consecución de servicios académicos distinguidos o mayor dotación de infraestructuras tecnológicas, por ejemplo) ha implicado una generación adicional de gastos y el aumento de la cuantía de las inversiones.

La limitación en la disponibilidad de recursos del sector público ha provocado un incremento de la competencia universitaria por la obtención de recursos, induciendo una política de diversificación en el origen de la financiación a través de la captación de fondos procedentes del sector privado (Berzosa, 2000), a través de la comercialización de la investigación y de la entrada en segmentos del mercado no tradicionales como la formación continua (Brunner y Uribe, 2007).

\subsubsection{Comercialización de servicios de información y conocimiento}

Las políticas de soporte de cuasi-mercados y mercados comerciales en el ámbito de la Educación Superior se han expresado globalmente en las negociaciones de la Organización Mundial del Comercio (WTO, World Trade Organisation) dentro del acuerdo marco sobre la comercialización de servicios (GATS, Global Agreement on Trade in Services), que contempla la Educación como un servicio más susceptible de ser exportado globalmente.

El WTO/GATS, suscrito por 145 países, se firmó en 1995 y fue el primer intento de establecer un acuerdo global acerca del comercio de servicios con el objetivo principal de eliminar las barreras comerciales existentes hasta entonces, estableciendo los requisitos previos para la liberalización en alrededor de 12 sectores primarios, uno de los cuales es la Educación (Knight, 2003). Como parte del programa de trabajo incoporado en el GATS de 1995, se obligó a que los miembros de la WTO revisaran las negociaciones en 2000 con el fin de conseguir una mayor liberalización del comercio de servicios. Entonces se acordó como plazo de finalización enero de 2005, si bien, en diciembre de ese mismo año, tras la Reunión Ministerial de la WTO en Hong Kong, los países miembros mostraron un ambicioso plan para dar por concluidas las negociaciones definitivamente antes de finalizar 2006.

${ }^{10}$ En este sentido, Massy y Warner (1991) constataron que en las universidades de los Estados Unidos el aumento significativo de los costes de producción implicó un incremento importante de los precios de los productos universitarios, entre los que destacan los costes de imagen, que se definen como el resultado de las acciones que llevan a cabo organizaciones intensivas en mano de obra, como es el caso de las Universidades, para permanecer competitivas en el mercado laboral a través de mecanismo encaminados al mantenimiento de la calidad y al incremento de la competitividad (Castillo, 2004). 


\begin{tabular}{|c|c|c|c|}
\hline & $\begin{array}{l}\text { Gasto público directo } \\
\text { en instituciones } \\
\text { públicas }\end{array}$ & $\begin{array}{lr}\text { Gasto } & \text { público } \\
\text { directo } & \text { en } \\
\text { instituciones } & \\
\text { privadas } & \\
\end{array}$ & $\begin{array}{l}\text { Transferencias públicas } \\
\text { indirectas y pagos al } \\
\text { sector privado }\end{array}$ \\
\hline Australia & 65,0 & $\mathrm{~N}$ & 35,0 \\
\hline Austria & 81,3 & 0,7 & 18,0 \\
\hline Bélgica & 32,2 & 48,9 & 15,8 \\
\hline Canadá & 77,6 & 0,4 & 22,0 \\
\hline República Checa & 92,8 & 1,0 & 6,2 \\
\hline Dinamarca & 67,8 & $\mathrm{~N}$ & 32,2 \\
\hline Finlandia & 74,4 & 7,7 & 17,9 \\
\hline Francia & 86,6 & 5,2 & 8,2 \\
\hline Alemania & 81,6 & 1,2 & 17,2 \\
\hline Grecia & 94,0 & $\mathrm{Na}$ & 6,0 \\
\hline Hungría & 80,5 & 4,7 & 14,7 \\
\hline Islandia & 68,0 & 7,9 & 24,1 \\
\hline Irlanda & 86,2 & $\mathrm{~N}$ & 13,8 \\
\hline Italia & 81,2 & 1,8 & 17,0 \\
\hline Japón & 68,6 & 12,8 & 18,6 \\
\hline Corea & 61,9 & 33,5 & 4,6 \\
\hline México & 94,1 & $\mathrm{~N}$ & 5,9 \\
\hline Holanda & $\mathrm{Na}$ & 74,1 & 25,9 \\
\hline Nueva Zelanda & 55,1 & 1,5 & 43,4 \\
\hline Noruega & 59,4 & 3,7 & 36,7 \\
\hline Portugal & 97,4 & $\mathrm{Si}$ & 2,6 \\
\hline Eslovaquia & 91,5 & $\mathrm{Na}$ & 8,5 \\
\hline España & 90,1 & 2,0 & 7,9 \\
\hline Suecia & 66,9 & 4,7 & 28,4 \\
\hline Suiza & 93,6 & 4,5 & 2,0 \\
\hline Turquía & 86,7 & 0,1 & 13,2 \\
\hline Gran Bretaña & $\mathrm{Na}$ & 75,3 & 24,7 \\
\hline EEUU & 70,3 & 11,8 & 17,8 \\
\hline OECD & 71,7 & 11,2 & 17,4 \\
\hline Brasil & 88,0 & $\mathrm{Na}$ & 12,0 \\
\hline Chile & 34,6 & 30,7 & 34,6 \\
\hline Israel & 5,1 & 84,9 & 10,1 \\
\hline
\end{tabular}

Fuente: elaboración propia a partir de OECD (2006).

Figura 18. Distribución del gastos público total en Educación Superior en 2003 en los países de la OECD (en porcentaje). 
Por otra parte, el concepto de Educación Superior transnacional o transfronteriza (en inglés, cross-border) fue definida en un documento conjunto elaborado por la OECD y la UNESCO (2005), en el que se definía como las situaciones en que "un docente, estudiante, institución/proveedor o material didáctico cruza las fronteras jurisdiccionales de una nación”. De esta definición se deduce que la educación transnacional abarca un amplio espectro de modalidades, que van desde la formación presencial (como es el caso de los programas de intercambio) hasta los programas de e-learning.

Sin embargo, aunque los trabajos de Knight (2002, 2003), OECD (2000), Dryden (2001), Mallea (1998), Marginson (2003) y PSI/EI (2002), entre otros, coinciden en señalar que todavía es necesario un período de materialización en el que los términos del GATS se concreten en el sector de la Educación, el principio que subyace a este acuerdo es el desplazamiento hacia una liberalización total de los servicios educativos.

En el artículo 1, párrafo 2 del GATS se reconoce una clasificación de los servicios educativos desde el punto de vista del comercio internacional. Así, en el GATS se distinguen cuatro categorías o modos de servicios (Dryden 2001; PSI/EI, 2002; Knight, 2003):

1. Modo 1: Suministro transfronterizo

Son los servicios suministrados por un proveedor de un país miembro a una entidad de otro país. Este modo es el más similar al comercio de mercancías convencional, en el que podría decirse que es el servicio el que "viaja", mientras que el proveedor y el consumidor permanecen cada uno en su respectivo país de origen (Brunnel y Uribe, 2007).

En Educación, dos ejemplos son las iniciativas de educación a distancia y de e-learning que actualmente las universidades virtuales están ofertando fuera de sus fronteras (Knight, 2003). Por otra parte, el potencial de crecimiento de esta línea de actuación está ligada el desarrollo de Internet y de las infraestructuras de telecomunicaciones que dan acceso a la misma (PSI/EI, 2002).

2. Modo 2: Consumo en el extranjero

Se produce cuando el consumidor viaja a otro país y consume allí algún servicio de un proveedor de dicha nación, es decir, define los servicios suministrados en el territorio de un país miembro a un consumidor de otro país miembro.

Es lo que ocurre en los programas de intercambio (ERASMUS, SOCRATES, etc.) en los que el estudiante viaja a un país distinto del suyo para terminar o completar sus estudios allí.

3. Modo 3: Presencia comercial

Este modo se refiere a las situaciones en que se establece una sede comercial o de operaciones en el territorio de otro país miembro, de manera, que un proveedor de un país miembro suministra servicios directamente en el territorio de otro país miembro.

De acuerdo con la PSI/EI (2002), ésta es una de las tendencias más habituales en el sector de la Educación Superior, en donde resulta común que una Universidad establezca un campus en un país extranjero, de manera que las titulaciones emitidas son válidas en el país de origen de la institución (Knight, 2003). Un ejemplo de este tipo de Universidades en el campo del e-learning es la Open University del Reino Unido, que dispone de una oficina satélite en los Estados Unidos de América. También se incluyen dentro de este modo las franquicias y la adquisición o fusión con instituciones locales.

4. Modo 4: Movimiento de personas naturales

En este caso, una persona de un país miembro se desplaza físicamente, y de manera temporal, al territorio de otro país miembro y suministra servicios allí. En Educación, encontramos ejemplos en profesores e investigadores visitantes que trabajan en el exterior 
temporalmente o en los proyectos de consultoría realizados durante estancias en el extranjero (Knight, 2003).

El GATS es un acuerdo global que abarca todas las medidas públicas que afecten al comercio de servicios. Estas medidas son jurídicamente ejecutorias y pueden ser respaldadas por sanciones comerciales avaladas por la WTO. En este sentido, se distinguen tres grandes grupos de obligaciones:

1. Obligaciones generales

El WTO/GATS establece un conjunto de obligaciones generales que se aplican, por defecto, a todos los servicios, salvo que estos se excluyan explícitamente. El principio que rige estas obligaciones generales es el de la nación más favorecida, según el cual, el trato dado a proveedores de un país miembro en otro país miembro debe ser, al menos, igual de favorable que el dado a la nación más favorecida (artículo 2).

La única excepción a las obligaciones generales son los servicios públicos. Sin embargo, estos servicios tienen un alcance muy restringido ya que, si un servicio público se suministra en condiciones comerciales o existe algún otro proveedor además del Estado, dicho servicio estará sujeto al GATS.

2. Obligaciones específicas

Es posible negociar acuerdos específicos en determinados sectores que estarán sujetos a dos obligaciones principales:

- Acceso a mercados (artículo XVI): evita que los países miembros mantengan o adopten medidas que limiten la entrada de proveedores extranjeros en el mercado interior a través de la prohibición de cualquier medida que imponga restricciones cuantitativas sobre los servicios, limite la participación del capital extranjero y restrinja los tipos de entidad legal de un proveedor de servicios en un sector específico.

- Trato nacional (artículo XVII): queda prohibido dar a los proveedores nacionales un trato más favorable que a los proveedores de otro país miembro en los sectores que figuren en la lista de compromisos específicos.

3. Reglamentación nacional

El GATS insta a los Gobiernos de los países miembros que revisen sus leyes nacionales con el fin de eliminar los obstáculos al libre comercio de servicios.

Centrándonos en la Educación, el GATS distingue cinco subsectores: primaria, secundaria, superior y educación de adultos y formación contínua. En las negociaciones del GATS, los países miembros pueden contraer compromisos independientes en cada uno de estos subsectores. Actualmente, la Educación es uno de los servicios con menos compromisos en el GATS, aunque está aumentando la presión para que esta situación cambie (Internacional de la Educación, 2006), fruto de la influencia de países como Estados Unidos, Australia, Nueva Zelanda y Japón, sobre todo en el ámbito de la Educación Superior.

En general, las respuestas al propósito liberalizador de la WTO/GATS van desde la simple preocupación por la vulnerabilidad de los sistemas educativos en los países en vías de desarrollo, hasta los efectos de la competencia extranjera en los sistemas establecidos, pasando por la oposición al proceso globalizador. Por ejemplo, la respuesta de las Universidades a esta posibilidad ha sido, cuando menos, cautelosa (Brunner y Uribe, 2007), como se deduce de la declaración conjunta realizada por la AUCC (Association of Universities and Colleges of Canada), el ACE (American Council on Education), la EUA (European Universities Association) y el CHEA (Council for Higher Education Accreditation) en septiembre de $2001^{11}$, en donde afirman el carácter de servicio público de la Educación Superior y su oposición a tratarla como

${ }^{11}$ Disponible en: http://www.aucc.ca/_pdf/english/statements/2001/gats_10_25_e.pdf 
una mercancía más (Singh, 2001; Taskforce, 2000) y, aunque apoyan la eliminación de las barreras para el comercio internacional de servicios educativos, estiman que ésta debería hacerse a través de acuerdos elaborados al margen del régimen comercial.

A la hora de cuantificar, desde el punto de vista económico, la importancia y evolución del mercado de la educación superior como tal, Dryden (2001) señala que la información acerca del nivel y la magnitud del comercio de servicios educativos es escasa y difícil de evaluar, observación confirmada por otros autores como Mallea (1998) y Knight (2003). En efecto, existe muy poca información acerca de la comercialización de servicios educativos de los modos 1, 3 y 4, si bien, hay indicios que señalan que los modos 1 y 3 se encuentran en una fase de crecimiento rápido (Dean, 2004). En cualquier caso, un indicador del incremento de la demanda de internacionalización en el sector de la Educación Superior en los últimos años, son las cifras relativas al flujo de estudiantes que viajan a completar sus estudios a otros países (Dryden, 2001). Sin embargo, esta estimación está perdiendo exactitud con el auge de otras formas servicios educativos cuyo registro resulta mucho más difícil, como es el caso del e-learning o el e-training (formación continua on-line). De hecho, según Dryden (2001) se estima que la tasa de penetración del e-learning aumentará más rápidamente que el número de estudiantes que viajan el extranjero.

\subsection{PRINCIPALES MANIFESTACIONES DEL CAMBIO ORGANIZATIVO}

Una vez delimitado el marco general y los principales factores impulsores del cambio organizativo en las Universidades, abordaremos ahora el estudio de las manifestaciones más importantes de esta transformación. El hecho de que este proceso de cambio haya presentado unos ciclos y un ámbito similares en muchos países occidentales (Michael, 1997) y que haya tenido un carácter holístico y global, permite determinar una serie de patrones comunes útiles para el análisis general de las formas en que se han concretado las alteraciones de la organización de la Universidad y de las prácticas de gestión de su actividad.

Conceptualmente, el racionalismo económico que ha inspirado las transformaciones organizativas del sector ha comportado el inherente reconocimiento de una serie de principios de carácter económico centrados fundamentalmente en la eficiencia productiva de la actividad universitaria y, por tanto, con una atención especial al análisis de operaciones, la búsqueda de incrementos de productividad y la introducción de sistemas de responsabilidad.

Así, en coherencia con lo anterior, es posible establecer que los principales ejes del cambio organizativo y de la alteración de las prácticas de gestión se han materializado en los siguientes elementos (Castillo, 2004):

- Una introducción de parámetros de mercado en los procesos de gestión de la organización.

- Una búsqueda de la eficiencia en el empleo de los factores productivos que se han traducido en la introducción de medidas de productividad y de instrumentos de control de costes.

- Una tendencia a la reducción de estructuras centrales y al fomento de procesos de descentralización.

- La dotación de medios de comunicación y de provisión de información externa.

- El surgimiento de iniciativas de armonización de sistemas educativos a nivel regional e internacional, como es el caso del Espacio Europeo de la Educación Superior.

\subsubsection{Adopción de parámetros de mercado}

La potenciación del enfoque de mercado de la actividad universitaria, con la consideración del sector universitario como un sector productivo que opera en un mercado competitivo y que dispone de unos recursos escasos, ha tenido como consecuencia la búsqueda de variables competitivas en la adopción de sistemas e instrumentos organizativos y de gestión importados del 
mundo empresarial y relativos a la planificación estratégica, a políticas de diversificación del origen de los recursos y la autofinanciación y al control de la gestión (Dill, 1991).

Efectivamente, a lo largo de las dos últimas décadas se ha extendido la adopción de sistemas de planificación estratégica por parte de las Universidades. La nueva realidad caracterizada por una disminución progresiva de los recursos disponibles, un incremento de la competencia y al establecimiento de políticas institucionales centradas en la creación de una cultura de adaptación al entorno, ha llevado a las instituciones universitarias a sumarse al proceso de integración e implantación de este tipo de sistemas (Pedreño, 1998). Como muchos otros de los métodos, instrumentos y técnicas importadas por el sector universitario del ámbito empresarial privado, la planificación estratégica ha generado un cambio cultural importante en el sector, con una serie de implicaciones muy relevantes (Michael, 1997):

1. Ha comportado implícitamente un mensaje de necesidad de cambio rápido y ágil para poder garantizar la supervivencia de la institución en un entorno complejo y mutable.

2. Ha requerido el establecimiento de una misión institucional en la que se han de integrar las diferentes visiones de las distintas comunidades que integran la vida universitaria.

3. Ha llevado a una identificación de los agentes sociales interesados en el desarrollo de la institución y una respuesta a sus necesidades como medio de asegurar la atracción de los recursos financieros.

Es decir, desde una perspectiva general, los principales objetivos de la implantación de la cultura y de los métodos de la planificación estratégica han hecho posible que las Universidades incrementen su capacidad de analizar su situación y sus perspectivas de futuro, aumentar la eficiencia en la gestión y la aplicación de los recursos productivos y potenciar la adaptación permanente al cambio y a la praxis de su anticipación como base de la cultura institucional para dar respuesta a los retos derivados de las alteraciones del entorno en el que la Universidad está inmersa (Castillo, 2004). Conceptualmente, la gestión estratégica de la Universidad se configura como un proceso que incrementa el conocimiento de la institución y su contexto a través de un proceso cíclico que permite (Cheung y Cheng, 2000):

1. La planificación y estructuración de su actividad a partir del análisis de su entorno. Los resultados de este análisis contribuyen de manera importante como una fuente de información a posibilitar a los órganos de gobierno de la Universidad establecer las líneas directivas, las políticas, los programas, los diferentes presupuestos, la estructura organizativa adecuada y los procedimientos de trabajo adecuados.

2. La mejora de la eficiencia productiva del factor trabajo. Aquí se incluye tanto la selección como la formación inicial del nuevo personal, así como la definición de su progresión y carrera profesional en el seno de la organización para adquirir las habilidades y competencias necesarias para asumir eficientemente las tareas que tenga asignadas.

3. El control y la evaluación de los resultados obtenidos como un instrumento para poder adoptar nuevas medidas correctoras y/o potenciadoras.

Respecto a las políticas relativas a la financiación, el objetivo principal que ha conducido el conjunto de medidas adoptadas y los instrumentos aplicados ha sido la voluntad de diversificar las fuentes de financiación como medio de superar una situación condicionada por los recursos cautivos (procedentes principalmente del sector público) y tender hacia una ampliación de la autonomía de gestión. En este marco, cabe destacar tres manifestaciones fundamentales (Castillo, 2004):

1. La aproximación al sector empresarial privado para obtener fondos, situación que ha comportado principalmente, la mercantilización del conocimiento creado en las instituciones universitarias (la venta de los derechos de propiedad intelectual) y la potenciación de las líneas de investigación aplicada en función de su utilidad y viabilidad en el sector empresarial (Geuna, 2000).

2. La creación de grupos de presión (lobbies) sobre el poder político con el objetivo de poder influir en las decisiones gubernamentales que afecten a la financiación del sector universitario (Michael, 1997). 
3. La programación y realización de actividades y proyectos que comporten la obtención de recursos financieros incrementales derivados de las operaciones y que permitan evolucionar hacia un comportamiento creciente del grado de autofinanciación.

Esta nueva necesidad de gestionar la demanda de formación ha provocado la alteración de algunos conceptos consolidados en la organización de la Universidad. Los ejes vertebradores de estas modificaciones se concretan en dos aspectos fundamentales (Castillo, 2004):

1. La revisión de las estructuras de responsabilidad en el ámbito de las políticas institucionales de captación de estudiantes, tradicionalmente rígidas, ha llevado a la definición de unidades especializadas basadas en el conocimiento del mercado y con una dependencia directa de los órganos de gobierno y dirección de la Universidad.

2. La introducción del análisis del valor que los diferentes servicios universitarios aportan al estudiante en su proceso formativo ha llevado a asumir por parte de la Universidad el concepto de servicio integral al estudiante desde la óptica de su uso. Este concepto ha comportado la revisión, mejora y ampliación del contenido de los servicios que se ofrecen, desde el primer contacto oficial hasta la admisión, desde los servicios estrictamente docentes hasta los servicios generales a la comunidad universitaria, o desde las experiencias en el campus universitario hasta los contactos con antiguos alumnos. En definitiva, se ha pasado a considerar al estudiante como el principal destinatario de los servicios que presta la Universidad.

Otro de los ámbitos de la organización universitaria en donde más claramente se ha manifestado la introducción de instrumentos gerenciales ha sido en la aplicación de técnicas de control de la gestión. La integración de estas herramientas en la actuación de las Universidades se inició en la década de los 1980 y persigue, fundamentalmente, la creación de las condiciones necesarias para que estas instituciones asuman la necesidad de adaptar las variables internas de la organización a la evolución del entorno. Este aspecto ha implicado que los sistemas de gestión de las Universidades hayan experimentado un importante proceso de transformación, siguiendo los patrones y las aplicaciones consolidados en otras ramas productivas. Esta revisión se ha realizado a partir de una serie de principios generales que dibujan la filosofía y la finalidad del cambio (Gunn, 1995):

1. Principio de sinergia, que enfatiza la importancia de la coordinación de los diferentes agentes de la organización como sustitutos de los sistemas de subordinación, mediante el establecimiento de relaciones de igualdad de responsabilidad para el desarrollo de proyectos orientados a objetivos.

2. Principio de redundancia, que se centra en la potenciación de los procesos de integración de información a través del fomento del flujo libre de información en una red estructurada.

3. Principio de simbiosis, que fomenta la cooperación como una alternativa a la rivalidad, por medio de la aplicación de sistemas de comunicación y de control.

4. Principio de holismo, que quiere introducir una visión más global e integral en los procesos de toma de decisiones a partir de una visión más sistémica e interrelacionada de la organización.

\subsubsection{Mejora de la eficiencia productiva}

La contrastada relación entre calidad de la actividad universitaria y disponibilidad de recursos financieros ha provocado el florecimiento de importantes presiones internas para hacer posible el mantenimiento de los presupuestos expansivos, únicamente sujetos a la disponibilidad de fuentes y a restricciones de carácter externo impuestas por el entorno (Dunn, 1992). Esta ausencia de motivación interna en las Universidades por impulsar políticas de contención y reducción de los costes ha implicado el surgimiento de importantes tensiones ineficientes que se han ido realimentando con el transcurso del tiempo.

Así, el objetivo de eficiencia económica en la actividad universitaria, que ha experimentado un progresivo crecimiento en las dos últimas décadas (Aldrich, 1994; Harrold, 1994), no ha sido el resultado de un proceso endógeno de la asunción de la utilidad de su establecimiento, sino el fruto 
de una imposición (Brinkman, 1992) que se explica por las variables exógenas asociadas a la evolución de la demanda y del acceso a fuentes de financiación. Como resultado de este proceso, se ha constatado que el objetivo de medida de la eficiencia de la actividad docente e investigadora se ha ido integrando progresivamente en los objetivos de gestión universitaria (Cameron y Smart, 1998).

Las dificultades inherentes a la determinación y aplicación de este indicador han provocado que su aproximación se haya realizado a partir de dos dimensiones, la productividad y la rentabilidad, y mediante la comparación de los resultados derivados de diferentes estrategias, diferentes aplicaciones de recursos productivos y diferentes órdenes organizativos, llegando a una conclusión principal (Castillo, 2004): la consolidación de la idea de que la fuente de los incrementos de productividad se sitúa en la adaptación de los conceptos y los instrumentos empleados con éxito en la gestión empresarial. Esta perspectiva ha supuesto un cambio de tendencia clave en la conceptualización de la Universidad en cuanto a organización, que ha pasado de ser concebida como un sistema cerrado, orientado a los procesos y basado en la distribución de tareas de su personal, a configurarse como un sistema abierto, orientado a los clientes y a los productos, y basado en políticas de consecución de objetivos (Boyd, 1992).

Dos son los factores clave de la mejorar de la eficiencia universitaria (Pedreño, 1997):

1. La revisión del modelo organizativo y de la estructura financiera

La reestruturación organizativa y financiera está enfocada a la consecución de parámetros adecuados de coste-eficiencia (Odden y Clune, 1995). Bajo esta perspectiva, una serie de elementos se han constituido con unas variables objeto del control: la gestión de los recursos financieros, el análisis de resultados y la asignación de los recursos productivos y la gestión de costes. Relacionado con este último punto, cabe destacar que la reducción de costes operativos ha sido uno de los objetivos prioritarios establecidos en las políticas institucionales para conseguir las mejoras de eficiencia interna de los factores productivos. Estas acciones han sido en gran parte una respuesta a las presiones sociales porque las Universidades utilicen de forma eficiente los recursos disponibles y las restricciones crecientes en el acceso a recursos financieros. Las medidas adoptadas para conseguir estos objetivos se han centrado principalmente en los siguientes ámbitos: la reorganización y la informatización de sistemas y procesos; la reordenación de las cargas laborales y de la estructura salarial del factor trabajo; la cooperación y la financiación compartida de programas y proyectos por medio del establecimiento de alianzas y la firma de convenios con otras instituciones; la implantación de nuevos sistemas de gestión con el objetivo de eliminar el desaprovechamiento de recursos y la duplicidad de esfuerzos a través del análisis de las actividades de gestión.

2. La introducción del análisis de la calidad de los servicios que ofrece a la Sociedad

La atención por la calidad de las operaciones en la actividad empresarial en los países desarrollados a partir de los años 1980 se ha trasladado paulatinamente al sector universitario, poniendo de manifiesto una creciente presión evaluativa a las instituciones (Rhoades y. Slaughter, 2004).

Los principios establecidos para la creación de una cultura de la calidad en la empresa (Deming, 1986) han sido objeto de una progresiva adaptación a las particularidades de las Universidades (Messner y Ruhl, 1998; William, 1993; Rosa y Amaral, 2005). La adaptación de estos principios a los requisitos de los parámetros educativos se ha ido realizando durante la década de los 1990 a través de un proceso de depuración y de reducción de sus elementos, teniendo en cuenta los objetivos de los procesos formativos y bajo la premisa general de que las Universidades no presentan habitualmente una finalidad mercantil y que sus destinatarios son tanto los estudiantes, como las empresas e instituciones que conforman la demanda del mercado de trabajo.

De este modo, se han establecido tres principios generales de calidad aplicables a la actividad universitaria (Castillo, 2004): 
- La consideración de la calidad no como un estado obtenible sino como una meta que es necesario conseguir, que presenta una naturaleza dinámica y requiere de un proceso continuo.

- La mejora de la calidad centrada en el proceso por garantizar de forma eficaz la mejora de calidad de los productos.

- La adopción de una visión sistémica de la organización universitaria como una vía para poder mejorar su funcionamiento, de manera que los objetivos se establezcan de forma global e integradora.

Aunque el análisis de la calidad en el sector universitario es relativamente reciente, existe ya una cierta evidencia empírica de que la gestión de la calidad se está integrando adecuadamente en los sistemas de gestión de las Universidades porque sus fundamentos son compatibles con su estructura organizativa (Michael, 1997), ya que convergen con los intereses de la gestión universitaria en cuatro ámbitos principales (Castillo, 2004): la concentración en la misión y en los servicios a los usuarios, la aproximación sistemática al análisis de las operaciones, la perspectiva estratégica y el compromiso con los valores corporativos. De aquí se desprende que la atención por la gestión de la calidad en la enseñanza superior ha implicado un nuevo enfoque de la actividad universitaria (Castillo, 2004), centrado en el análisis del servicio prestado en términos de eficacia del proceso de aprendizaje de los estudiantes y de la mejora en la dotación y asignación de recursos productivos.

\subsubsection{Reducción de estructuras y descentralización}

La necesidad de adaptar la organización de los recursos productivos a una disposición limitada de fuentes financieras explica la tendencia de las últimas décadas a empezar procesos de reducción y atomización de las estructuras centrales de las Universidades (Appelbaum y Patton, 2002). En este sentido, algunos autores (Horn y Jerome, 1996; Dickman et al., 1996) defienden que las instituciones universitarias han estado influenciadas por el sector empresarial privado en la implantación de procesos de reestructuración, de manera que su ejecución se ha ido realizando de manera progresiva a través de la asunción de estas prácticas empresariales. En el caso de Estados Unidos, este tipo de actuaciones fue la respuesta a la crisis presupuestaria en que se sumió la Educación Superior durante la década de los 1990 (Cameron y Smart, 1998). El descontento social por la calidad de la Educación Superior y la percepción de otras prioridades como la salud pública, la seguridad ciudadana o la educación primaria y secundaria, provocaron una importante reducción de los recursos destinados a las Universidades (Hollins, 1992).

Así, la reducción de la estructura organizativa de las Universidades ha comportado un replanteamiento de los objetivos institucionales, la eliminación selectiva de actividades y el establecimiento de un proceso de planificación a largo plazo. Por tanto, la finalidad principal de la reducción de la dimensión organizativa de la Universidad ha estado en la reducción de la estructura de costes (Castillo, 2004). Esta circunstancia explica que los principales instrumentos empleados para hacer efectiva esta reducción en muchos casos hayan sido la congelación salarial, el recorte presupuestario sistemático a todos los niveles, la reducción de los servicios ofrecidos a los estudiantes y la eliminación de programas poco rentables y de bajo prestigio. En este sentido, cabe destacar que el hecho de que los costes de personal hayan sido tradicionalmente la principal partida de coste en la estructura de las Universidades, ha comportado la introducción de presiones para tomar medidas encaminadas a la reducción y la flexibilización de su peso en dichas estructuras de costes. Esta tipología de acciones no han sido, sin embargo, una opción habitual en las Universidades debido principalmente a la existencia en la actividad universitaria de una curva de experiencia muy acusada en la particular cultura institucional derivada de su estructura adhocrática basada en un modelo profesional y en la relevancia de los contratos implícitos o psicológicos con el personal. 
Por estos motivos, se han debido establecer sistemas alternativos para la reducción de estructuras basadas en acciones orientadas al análisis de las actividades que conforman los diferentes procesos de la Universidad. Este análisis ha llevado a centrar la política de reducción de los costes de estructura en acciones consistentes en la variabilización de otros factores productivos. Estas decisiones han implicado el surgimiento de una tendencia creciente a la subcontratación y también a la externalización de actividades inicialmente integradas en los procesos internos de las Universidades. El criterio más ampliamente empleado ha sido el coste, relativo a los precios de mercado, derivado de la producción interna y de la determinación de su contribución a la generación de los servicios que la Universidad ofrece a los estudiantes.

Si durante las décadas de los años 1970 y 1980 se iniciaron procesos de subcontratación económica, centrada principalmente en actividades de mantenimiento de infraestructuras siguiendo un análisis de costes de producción, durante la década de los años 1990, y con la progresiva incorporación de las TIC en el ámbito universitario, ha habido también un crecimiento de la externalización tecnológica. A pesar de que los servicios de información y comunicación asociados a la infraestructura digital son considerados como variables de importancia creciente para el desarrollo y la gestión de la actividad universitaria, la generación de costes fijos recurrentes derivados de su internalización debe constituir, en muchos casos, el argumento determinante para proceder a la externalización de muchas de las actividades que quedan dentro del ámbito de los departamentos de sistemas de información. La tabla de la Figura 19 muestra cómo se gestionan los servicios TIC de las Universidades españolas, indicando para cada uno de los servicios principales si se internalizan en el propio departamento de sistemas de información o en otro departamento de la Universidad o si se externalizan parcial o completamente. La tarea que ejerce un mayor porcentaje de universidades en el mismo servicio es el mantenimiento y gestión del correo electrónico, labor que tiene un carácter fundamental. A continuación estarían labores de tipo administrativo y de seguridad, en las que, generalmente, es importante mantener el control dentro del propio servicio. El análisis de aplicaciones externas, también es realizado habitualmente por el servicio. En la dirección de proyectos de TIC también resulta interesante intervenir de forma directa, ya que el propio servicio es quien conoce mejor las necesidades en materia de nuevas tecnologías de la universidad y, por tanto, de los proyectos que deben implementarse.

Por el contrario, el departamento TIC recibe una ayuda imprescindible de otros servicios de la universidad en lo que se refiere a la formación de personal y creación de páginas y contenidos web. Este hecho viene explicado, bien por la falta de conocimiento del propio departamento TIC, o bien por tratarse de actividades donde su tarea fundamental consiste en dar soporte, pero cuya responsabilidad pertenece a otros servicios (por ejemplo, los contenidos web).

Las labores en las cuales intervienen en mayor grado empresas externas son las de mantenimiento, tanto de microinformática como del hardware de ordenadores centrales. Otros servicios con una presencia superior de agentes externos, con porcentajes cercanos al 10\%, son la asesoría, control y auditoria de seguridad, el Help Desk y el Call Center, lo que puede indicar que existe un cierto grado de externalización de los mismos. 


\begin{tabular}{|c|c|c|c|c|}
\hline & $\begin{array}{c}\text { Se realiza } \\
\text { en el } \\
\text { servicio } \\
\end{array}$ & $\begin{array}{c}\text { Se realiza } \\
\text { en otro } \\
\text { servicio } \\
\end{array}$ & $\begin{array}{c}\text { Se realiza en } \\
\text { un empresa } \\
\text { externa }\end{array}$ & $\begin{array}{c}\text { Compartido con } \\
\text { otro servicio o } \\
\text { empresa externa }\end{array}$ \\
\hline Administración de antivirus & $93,75 \%$ & - & $6,26 \%$ & - \\
\hline Mantenimiento informático & $48,39 \%$ & - & $16,13 \%$ & $35,48 \%$ \\
\hline $\begin{array}{l}\text { Copias de seguridad } \\
\text { servidores corporativos }\end{array}$ & $93,33 \%$ & $3,33 \%$ & $3,33 \%$ & - \\
\hline $\begin{array}{l}\text { Dirección de proyectos de } \\
\text { nuevas tecnologías }\end{array}$ & $86,21 \%$ & $10,34 \%$ & $3,45 \%$ & - \\
\hline $\begin{array}{l}\text { Gestión de carnet } \\
\text { universitario }\end{array}$ & $51,72 \%$ & $27,59 \%$ & $6,90 \%$ & $13,79 \%$ \\
\hline $\begin{array}{l}\text { Análisis y dirección de } \\
\text { aplicaciones corporativas }\end{array}$ & $82,14 \%$ & $7,14 \%$ & - & $10,71 \%$ \\
\hline $\begin{array}{l}\text { Administración de aulas } \\
\text { informáticas }\end{array}$ & $82,14 \%$ & $10,71 \%$ & & $7,14 \%$ \\
\hline $\begin{array}{l}\text { Mantenimiento hardware de } \\
\text { ordenadores centrales }\end{array}$ & $28,57 \%$ & & $53,57 \%$ & $17,86 \%$ \\
\hline Correo electrónico & $96,3 \%$ & & $3,7 \%$ & - \\
\hline $\begin{array}{l}\text { Creación del contenido de la } \\
\text { web }\end{array}$ & $40,74 \%$ & $44,44 \%$ & - & $14,81 \%$ \\
\hline $\begin{array}{l}\text { Gestión de compra } \\
\text { centralizada de equipamiento } \\
\text { informático para el área de } \\
\text { gestión }\end{array}$ & $70,37 \%$ & $14,81 \%$ & $3,70 \%$ & $11,11 \%$ \\
\hline $\begin{array}{l}\text { Administración } \\
\text { ordenadores centrales }\end{array}$ & $96,15 \%$ & - & $3,85 \%$ & - \\
\hline Servidor web & $92,00 \%$ & $4,00 \%$ & - & $4,00 \%$ \\
\hline $\begin{array}{l}\text { Gestión de } \\
\text { centralizada de equipamiento } \\
\text { informático para todo el } \\
\text { campus }\end{array}$ & $56,00 \%$ & $20,00 \%$ & $4,00 \%$ & $20,00 \%$ \\
\hline Help Desk & $73,91 \%$ & & $13,04 \%$ & $13,04 \%$ \\
\hline Call Center & $72,73 \%$ & & $9,09 \%$ & $18,18 \%$ \\
\hline $\begin{array}{l}\text { Asesoría, control y auditoria } \\
\text { de seguridad }\end{array}$ & $72,73 \%$ & $13,64 \%$ & $9,09 \%$ & $4,55 \%$ \\
\hline $\begin{array}{l}\text { Copias de seguridad usuarios } \\
\text { microinformática }\end{array}$ & $85,00 \%$ & $5,00 \%$ & $5,00 \%$ & $5,00 \%$ \\
\hline Formación del PAS & $44,44 \%$ & $55,56 \%$ & & \\
\hline $\begin{array}{l}\text { Análisis y dirección de } \\
\text { aplicaciones externas }\end{array}$ & $86,67 \%$ & & & $13,33 \%$ \\
\hline Formación del PDI & $42,86 \%$ & $57,14 \%$ & & \\
\hline Formación de personal & $42,86 \%$ & $57,14 \%$ & & \\
\hline
\end{tabular}

Fuente: CRUE (2004).

Figura 19. Responsables de los servicios TIC en las Universidades españolas. 
En este sentido, en las Universidades españolas se revelan dos tipos de comportamiento en cuanto a la externalización se refiere y que explican el alcance y las motivaciones de su aplicación (Claver, González, Gascó y Llopis, 2002):

1. La externalización tecnológica realizada por las Universidades no se centra en la infraestructura tecnológica por medio de operaciones que sustituyen la adquisición de su control por sistemas de servicios exteriores, sino que compran las actividades asociadas a los servicios de información y comunicación.

2. La externalización de las actividades de sistemas de información tiene un comportamiento independiente del análisis económico de los costes de producción interna y de la transferencia pero muy condicionada por los recursos financieros disponibles por la organización, de manera que las instituciones de dimensión pequeña y mediana configuran la tipología de universidades con un mayor número de actividades de sistemas de información externalizadas.

Por otra parte, y por lo que respecta a los procesos de descentralización, cabe destacar que las características específicas inherentes al modelo profesional que define la organización de las Universidades, hace que exista en este modelo una importante descentralización de responsabilidades, en el que los centros y facultades, los departamentos y el profesorado constituyen las principales unidades organizativas. La facultad o escuela es el grupo dominante en una Universidad y el concepto de administración no es siempre considerado como una prioridad sino como una función más que está bajo la responsabilidad de personal especializado. En este sentido, las Universidades presentan una ausencia de los elementos de autoridad intrínsecos a las organizaciones empresariales aunque, sin embargo, sí que existe una cierta estructura jerárquica, pero sin una vinculación con los procesos del sistema y sin una sistematización del rol de los subordinados.

En este contexto, una de las líneas más importantes de profundización en el ámbito de la descentralización se ha construido sobre la base de heterogeneidad productiva de las Universidades (Castillo, 2004). Es decir, el hecho de que la actividad universitaria se haya caracterizado tradicionalmente por la generación de múltiples productos (titulaciones diferentes de distintos ciclos, proyectos de investigación, estudios, informes, congresos, seminarios, etc.) interrelacionados pero, a la vez, diferenciados, y que estos proyectos haya supuesto importantes diferencias en la cantidad, tipo y precios de los recursos productivos requeridos y de su nivel de utilización (Brinkman, 1992), ha implicado la aparición de una tendencia de refuerzo de la estructura descentralizada que caracteriza a las Universidades a través de la organización de los recursos de manera flexible y variable alrededor de este nivel de componentes (Pedreño, 1997).

Una de los principales elementos potenciadores de este proceso de descentralización ha sido la búsqueda, por parte de las Universidades, de una demanda de formación en el ámbito internacional. La internacionalización de la actividad de formación universitaria se ha realizado a través de diversos mecanismos, entre los que cabe destacar dos aplicaciones generales: los convenios y alianzas entre entidades ubicadas fuera del territorio nacional para cooperar y colaborar en distintos ámbitos de actuación y con una presencia importante de los intercambios de estudiantes a través del cruce de la oferta formativa; y la creación de una oferta de cursos y programas de educación a distancia basada en la utilización de las TIC, y principalmente, de Internet (Saffu y Mamman, 1999).

Las principales dificultades para su materialización se han centrado en el ámbito presupuestario (Castillo, 2004) y en el hecho de que la mayoría de Universidades no disponen de un control absoluto de sus recursos disponibles. Es decir, el origen público y de patrocinadores privados de una parte significativa de los fondos financieros de las Universidades provoca en muchos casos restricciones importantes en el proceso de decisión sobre la aplicación funcional de los recursos. Y, por otra parte, el hecho de que la política presupuestaria de las Universidades esté basada en las necesidades de las unidades organizativas y no en el enfoque integral de la institución también tiene consecuencias en esta línea. En efecto, la estructura descentralizada de 
las Universidades en centros de poder (facultades, departamentos, etc.) y el hecho de que la planificación financiera se realice a un nivel presupuestario, hace que el proceso presupuestario se fije de acuerdo con unas necesidades operativas de partes de la institución que muchas veces no tienen una perspectiva global de las necesidades de toda la institución ni persiguen optimizar el interés común, en lugar de establecerse en función de decisiones estratégicas centrales (Jones, 1993).

\subsubsection{Comunicación y transparencia informativa}

El principio de responsabilidad y de comunicación de los resultados de la actividad, consolidado en el sector empresarial, no se ha extendido a las Universidades hasta finales de la década de los 1990, dado que estas instituciones eran consideradas entidades socialmente aceptadas que no necesitaban justificar su funcionamiento (Lam, 2001).

La transformación organizativa de las Universidades que ha tenido lugar en las últimas décadas ha comportado la introducción de un proceso de transparencia y de comunicación de los resultados de la actividad universitaria a la Sociedad. El enfoque de los indicadores de responsabilidad y de los estándares de información ha sido objeto de múltiples propuestas. Para algunos autores, la responsabilidad se debe medir en términos de los objetivos conseguidos por los estudiantes (Luhm et al., 1998); para otros, tiene una connotación intrínsecamente relacionada con indicadores de resultados de la gestión (Kirst, 1990).

Sin embargo, han sido tres los parámetros básicos alrededor de los que se han canalizado las exigencias sociales, y son: equidad, eficacia y eficiencia (Castillo, 2004). Este hecho ha sido consecuencia de la consolidación de la idea de que las Universidades reciben fondos de la Sociedad (públicos o privados) por su capacidad de ofrecer determinados servicios socialmente necesarios. Los distintos agentes sociales, en consecuencia, demandan que estas instituciones demuestren y expliquen cómo los recursos otorgados son utilizados para conseguir los objetivos derivados de su tarea. Por tanto, los indicadores para la comunicación de los resultados de la actuación de las Universidades se han ido construyendo sobre la base de estos tres elementos: grado de penetración social de la actividad universitaria, cumplimiento de los objetivos establecidos a partir de los recursos disponibles y la relación de estos resultados con las decisiones de asignación de los recursos productivos.

El cumplimiento de estos objetivos de comunicación se ha encontrado con una serie de limitaciones asociadas a los fundamentos de la cultura universitaria y de la naturaleza de su actividad (Michael, 1997):

- Los centros universitarios que operan bajo un paradigma epistemológico son reticentes a la adopción de medidas de responsabilidad porque pueden mermar y condicionar su misión científica y humanística.

- Los resultados derivados de la actividad universitaria no son en muchas ocasiones susceptibles de ser medidos de una manera rápida y directa.

- Los miembros de un centro universitario desarrollan diversas actividades y, muchas veces, pueden ser excelentes en algunas áreas pero presentar deficiencias en otras. La determinación del peso y la importancia de cada una de estas parcelas de actividad en el cómputo global es visto como una acción con una gran carga de arbitrariedad y subjetividad.

- Consecuentemente, se manifiesta una falta de armonización en la utilidad de los indicadores aplicables, de modo que los criterios de medida deseables para los agentes no integrados en la esfera académica son, frecuentemente, indeseables para los miembros de la misma.

Por tanto, ha habido que arbitrar mecanismos que permiten un difícil equilibrio entre la autonomía universitaria y el condicionante de su actuación en los diferentes parámetros de la demanda social de responsabilidad. De entre estos instrumentos, cabe destacar por su universalidad y aceptación general, los procesos de evaluación interna y externa de la docencia y la investigación con el impulso y la mediación de organismos independientes. 


\subsection{EUROPEIZACIÓN DE LA EDUCACIÓN SUPERIOR: EL EEES}

En Europa se ha iniciado un proceso intenso y sin precedentes de armonización de sus estructuras de Educación Superior. De hecho, la internacionalización de la Educación Superior en Europa tiene su máximo exponente en el desarrollo del Espacio Europeo de Educación Superior, que nació con el objetivo de mejorar la competitividad de Europa (Van der Wende, 2004). La globalización y la internacionalización de la Educación Superior en Europa están diseñando las políticas de futuro de los países europeos. Tanto es así que en la Unión Europea en su conjunto, con la Comisión Europea siendo el mayor actor político, es posible distinguir diferentes fases y aproximaciones al problema (Huisman y Van der Wende, 2004), puesto que cada país ha respondido a los retos planteados de una manera particular.

Los orígenes de este proceso hay que buscarlos en tres raíces fundamentales (Margison y Van der Wende, 2006):

1. Aumento de la movilidad de personas e ideas.

2. Cooperación internacional a nivel económico, social y cultural entre los países de la Unión Europea.

3. Propósito de la Unión Europea de propiciar una zona de educación superior que facilite este tipo de actividades a nivel europeo.

Las primeras iniciativas de internacionalización de la Educación Superior en Europa datan de la segunda mitad de los 1970, cuando la Comisión Europea de la entonces Comunidad Económica Europea decidió tomar parte en la Educación Superior estimulando la cooperación y la movilidad entre sistemas educativos nacionales cerrados en los que el control estaba enteramente en manos de los estados miembros. Algunas experiencias en este sentido son fueron el proyecto ERASMUS o el proyecto SOCRATES, entre otros.

A medida que la Unión Europea creció, especialmente tras la primera ampliación en 1992, estas actividades sufrieron una notable expansión geográfica y se centraron en aspectos académicos y culturales, principalmente. Sin embargo, la agenda política se concentró en el proceso de integración europea, sobre la base del mercado interno común construido en 1992. Conscientes en estas necesidades de integración, en 1991 la Comisión Europea lanzó el Memorandum on Higher Education, en el que subrayaba el papel de la Educación Superior en la cohesión económica y social de los estados de la Unión Europea. Sin embargo, la respuesta de la comunidad universitaria fue particularmente negativa y crítica con el empleo de un final económico como justificación de un cambio en el paradigma académico. Fueron necesarios 10 años más para que la que Comisión Europea volviese con otro mensaje acerca de la influencia del desarrollo económico y la competitividad en la Educación Superior. De hecho, este rechazo a la mercantilización de la Educación Superior también fue corroborado en la Conferencia Mundial sobre Educación Superior de la UNESCO de 1998, en la que, además, se insistió en que la internacionalización de la Educación Superior debería sustentarse a través de la colaboración entre instituciones educativas con la participación y el control de los gobiernos de cada país.

A finales de la década de los 1990 la Educación Superior europea, tomó consciencia de su escasa competitividad a nivel mundial, si bien, las políticas de fomento de la internacionalización a nivel interno habían sido exitosas. Sin embargo, Europa había perdido el primer puesto en la lista de destinos preferidos por los estudiantes extranjeros, cuyo primer lugar ocupaban los Estados Unidos de América y, además, disponía de infraestructuras educativas menos eficientes derivadas del hecho de que sus estudiantes egresaban a una edad más tardía que los norteamericanos.

El 25 de mayo de 1998, en el aniversario de La Sorbona, los Ministros de Educación de Francia, Alemania, Italia y Reino Unido firmaron una Declaración conjunta a favor del desarrollo de un Espacio Europeo de Educación Superior. Sin embargo, no sería hasta el año siguiente (19 de 
Junio) cuando en la Declaración de Bolonia se sentaron las bases para la construcción del EEES sobre cuatro pilares fundamentales: calidad, movilidad, diversidad y competitividad.

La Declaración de Bolonia estableció seis objetivos fundamentales (García y Morant, 2005):

- La adopción de un sistema de títulos fácilmente legible y comparable, mediante la implantación, entre otras cuestiones, de un Suplemento al Título cuyo fin es promover la empleabilidad de los ciudadanos europeos y la competitividad del sistema de enseñanza superior a escala internacional.

- Las enseñanzas universitarias se organizarán en dos ciclos, según establecen los acuerdos derivados de la construcción del Espacio Europeo de Educación Superior (EEES). Estos dos ciclos se corresponden a tres niveles de cualificación universitaria que se denominarán Grado, Master y Doctor (permitiendo, en cada contexto nacional, la posibilidad de ciclos intermedios), cada uno de ellos descritos en términos de resultados de aprendizaje y competencias e incluyendo una recomendación sobre los créditos que se deben asignar los dos primeros ciclos, y la duración en años del Doctorado.

- El establecimiento de un sistema de créditos, como el sistema ECTS (European Credit Transfer System), como medio adecuado para promover la movilidad de los estudiantes. Los créditos podrán obtenerse también en contextos externos a la Educación Superior, incluyendo el aprendizaje a lo largo de la vida, en el supuesto de que fueran aceptados por las Universidades de acogida.

- La promoción de la cooperación Europea para asegurar un nivel de calidad para el desarrollo de criterios y metodologías comparables.

- La promoción de una necesaria dimensión Europea en la educación superior con particular énfasis en el desarrollo curricular, la elaboración de programas de estudio, la cooperación interinstitucional, los programas de movilidad y los programas integrados de estudio.

- La promoción de la movilidad y remoción de obstáculos para el ejercicio libre de la misma por los estudiantes, profesores y personal administrativo de las universidades y otras Instituciones de enseñanza superior europea.

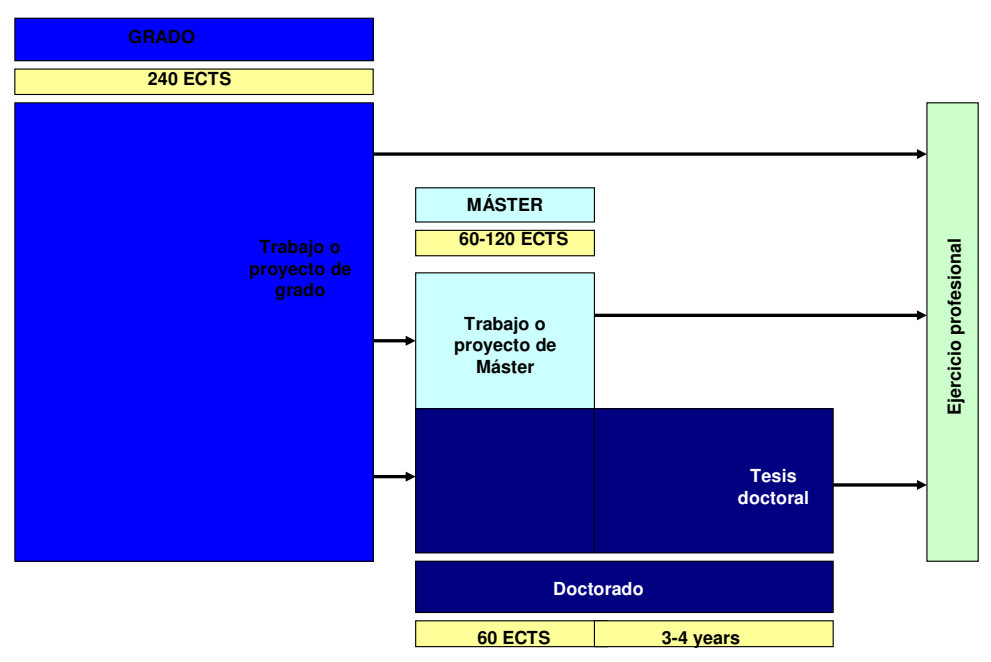

Fuente: elaboración propia.

Figura 20. Estructura de niveles de títulos universitarios. 
La Declaración de Bolonia tiene carácter no vinculante: enuncia una serie de objetivos y unos instrumentos para lograrlos, pero no fija unos deberes jurídicamente exigibles. No sería hasta el año 2000, cuando la Comisión Europea se sumó a esta iniciativa en una reunión de los ministros de educación de los países miembros de la Unión en Lisboa, cuando se promulgó una declaración que establece un plazo hasta 2010 para la realización del Espacio Europeo de Educación Superior, con fases bienales de realización, cada una de las cuales termina mediante la correspondiente Conferencia Ministerial que revisa lo conseguido y establece directrices para el futuro.

La primera conferencia de seguimiento del proceso de Bolonia tuvo lugar en Praga en mayo de 2001. En ella, los Ministros adoptaron un Comunicado que hacía hincapié en los siguientes temas (García y Morant, 2005):

- Aprendizaje a lo largo de la vida

Las estrategias de formación continua son necesarias para enfrentarse con los cambios de competitividad, el uso de las TIC y aumentar la cohesión social, la igualdad de oportunidades y la calidad de vida.

- Instituciones de Educación Superior y estudiantes

El proceso de europeización de la Educación exige la participación tanto de las instituciones educativas como de los estudiantes.

- Promoción del atractivo del área de Educación Superior Europea

Se incide en la importancia de mejorar el grado de atractivo del sistema educativo europeo con el fin de captar estudiantes de todo el mundo. Para ello, es necesario asegurar la calidad y la comparabilidad de las titulaciones así como fomentar la colaboración entre los países de la Unión.

Posteriormente, los Comunicados de Berlin (2003) y Bergen (2005), correspondientes a las reuniones de ministros, hacen balance de los progresos realizados hasta cada fecha, incorporando las conclusiones de los seminarios internacionales realizados y estableciendo directrices para la continuación del proceso.

La Figura 21 muestra el avance del proceso en los distintos países de la Unión Europea.

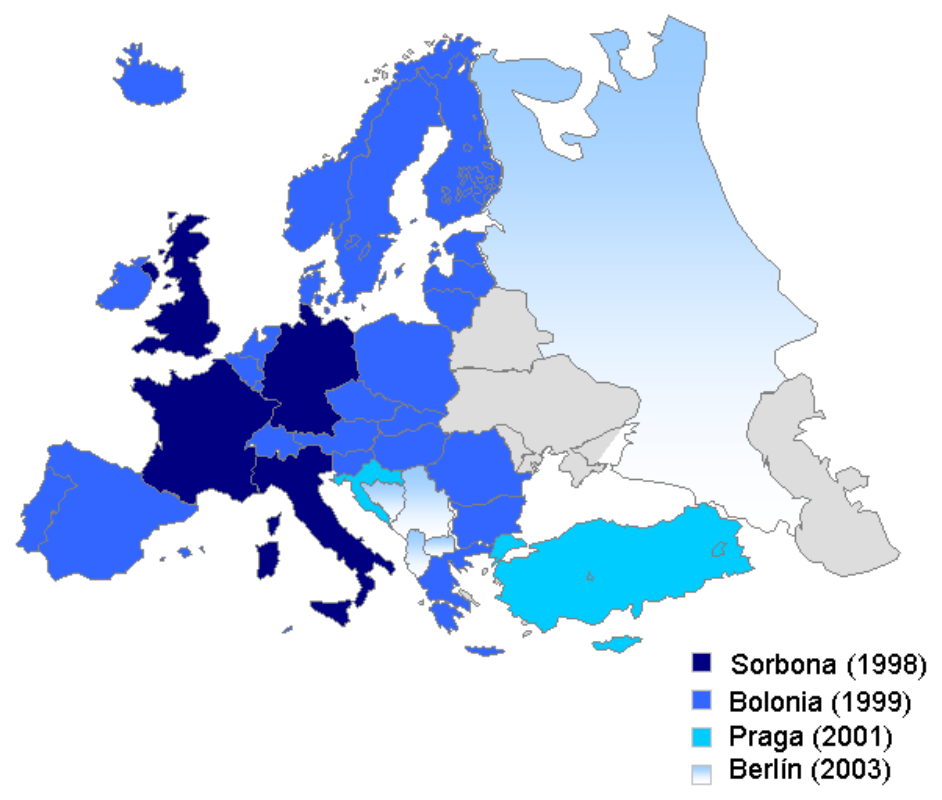

Fuente: reproducido de http://www.mec.es/universidades/eees/index.html

Figura 21. Países participantes en el EEES.

A pesar de logros como la convergencia en la estructura de la titulaciones y la introducción de criterios de calidad y calificación comunes, es cierto que continuan existiendo algunas 
tensiones entre la armonización y la diversidad (Marginson y Van der Wende, 2007). De hecho, algunos estudios en profundidad acerca de la marcha del proceso de cambio muestran que el grado de implantación de las nuevas estructuras varía notablemente de un país a otro. Por ejemplo, Lub et al. (2003) encontraron diferencias sustanciales en Holanda, donde el nuevo sistema de dos ciclos había reemplazado al de un solo ciclo largo previamente existente, y Alemania, donde el nuevo sistema se desarrolló paralelamente a los existentes y, a pesar del rápido crecimiento en el número de nuevos programas, únicamente una parte reducida de los estudiantes participaron en ellos. Según Alesi et al. (2005) la razón de esta divergencia es que el proceso de Bolonia no ha sido la causa de los cambios en la Educación Superior en cada país, sino que ha actuado como un elemento amplificador y habilitador de cambios producidos por intereses a nivel nacional, como las presiones para reducir la longitud de los estudios, lo que demuestra, por otra parte, que los cambios en el sistema educativo se producen cuando se alinean los intereses internacionales con los nacionales (Marginson y van der Wende, 2006).

El desarrollo del EEES implicará una reorganización conceptual de los sistemas educativos orientada hacia una formación académica integral, basada no sólo en conocimientos sino también en competencias, y en la que deberán tener cabida desde las tradicionales lecciones magistrales, exámenes y evaluaciones, hasta los trabajos prácticos, seminarios, tutorías, periodos de prácticas, trabajos de campo y trabajos personales. Se trata, pues, de contar con unas estructuras flexibles que posibiliten una mayor y mejor adaptación a los requisitos del mercado laboral. En este sentido, el EEES va unido a la utilización de las TIC como elemento vertebrador que permite desarrollar los aspectos clave de áquel, como son la transparencia en el aprendizaje, la autonomía de los estudiantes y la evaluación global del trabajo del alumno, incluyendo el realizado fuera del aula (Fernández, 2004).

Otra consecuencia de la europeización de la Educación Superior es que se abre la puerta a la llamada educación transnacional, es decir, a que estudiantes que se encuentren en un país diferente a aquel en que reside la institución, puedan cursar sus estudios en ella (Jones, 2001). De hecho, se empieza a observar cómo las Universidades, europeas, estadounidenses y australianas compiten entre sí por prestigio y por financiación (CRUE, 2004). 


\section{CAPÍTULO 3 LAS TIC EN LA UNIVERSIDAD}

Durante la década de los 1990 se produjo la incorporación generalizada de las TIC en las Universidades de los países desarrollados. Esta dotación de infraestructura tecnológica ha creado las condiciones adecuadas para el desarrollo progresivo de su utilización en la realización y la organización de la actividad universitaria. Así, la difusión de las tecnologías en el sector universitario se configura como un factor instrumental catalizador de las transformaciones que han experimentado las Universidades durante las dos últimas décadas, motivadas por la evolución de una serie de variables socioeconómicas, asociadas, fundamentalmente, a las alteraciones de la demanda de formación universitaria y de la asignación de fondos para la financiación de su actividad. Una de las manifestaciones de este proceso de transformación se encuentra en los cambios producidos en la forma de llevar a cabo y de gestionar la actividad docente. En este capítulo analizaremos el efecto de la implantación de las TIC en las Universidades y el proceso de cambio organizativo en las mismas como principal consecuencia de dicha implantación y las implicaciones del uso de las TIC en la docencia.

Al igual que el resto de las ramas productivas de las economías desarrolladas, las universidades han ido implantando las TIC en el conjunto de su actividad de forma generalizada a lo largo de la década de los 1990 con dos particularidades remarcables (Castillo, 2004): la existencia de una diferencia importante en la relación entre las TIC y la investigación y la docencia, y el hecho de que dicha introducción ha manifestado un cierto retardo respecto de la actividad empresarial y, además, se han incorporado a un ritmo más lento. En efecto, la Universidad, a pesar de estar en los mismos orígenes de Internet (Leiner, 2003), se está incorporando a este nuevo contexto no con pocas dificultades (Durderstadt, 1999; Jochems, 2004; Katz, 1999). Esta paradoja en el ritmo de integración tecnológica en las Universidades se explica por la proximidad de la investigación al origen de las TIC y porque su empleo precoz en la transferencia de conocimiento científico no ha comportado una dotación y un uso automáticos y generalizados de estas tecnologías en la docencia. En este sentido, las Universidades se enfrentan al reto de adaptarse a este nuevo paradigma socioeconómico. De este reto, y dado el papel que les toca desarrollar en nuestros tiempos, las instituciones de Educación Superior tendrán que salir especialmente airosas (Duart y Lupiáñez, 2005).

La aplicación exitosa de los descubrimientos científicos durante la Segunda Guerra Mundial provocó la consolidación de la confianza política en la aplicación directa de la investigación y, por tanto, el incremento de recursos financieros destinados a esta actividad. De este modo, se potenció el papel de las Universidades y de los centros de investigación como agentes creadores de conocimiento y la aproximación de la función de investigación universitaria al desarrollo tecnológico (Geuna, 2000). En el caso de las TIC, las principales aportaciones de la 
investigación universitaria las encontramos en EEUU, canalizadas principalmente por la aparición y el desarrollo del software y de Internet. Las sinergias que se crearon entre los proyectos de investigación militar y la investigación universitaria se sitúan aquí en la raíz explicativa del desarrollo de la ciencia informática en los EEUU (Castells, 2001). La participación de las Universidades investigadoras americanas en este proceso fue fundamental y el uso de las TIC en la actividad de investigación universitaria, iniciada a finales de la década de los 1960, fue anterior a su aplicación comercial y, por tanto, a su difusión en la actividad empresarial.

Esta proximidad a las causas y al origen de la evolución tecnológica por parte de una de las actividades principales de las Universidades, no se ha traducido en una rápida y paralela integración de las TIC para usos docentes y de gestión, como se pondrá de manifiesto a lo largo de este apartado.

No será hasta la década de los años 1990 cuando se produjo un impulso a la integración de la innovación tecnológica al conjunto de actividad universitaria, gracias al reconocimiento de una serie de beneficios derivados de esta política (Harris, 2000), que son, fundamentalmente, los siguientes (Castillo, 2004):

- La idea de que la clave del buen funcionamiento de las Universidades se sitúa en una adecuada gestión de la innovación tecnológica y en el desarrollo de estrategias coherentes con ella. Es decir, el reconocimiento de que una cultura de la innovación repercute positivamente en la mejora de la calidad universitaria y, consecuentemente, en la mejora de la actividad docente.

- La posibilidad de mejorar el valor aportado por la Universidad por medio de la aplicación de estándares de innovación generalmente aceptados a las prácticas organizativas y de gestión, como un instrumento para fomentar la mejora continua y la adaptación de la actividad universitaria a las alternaciones de la demanda social.

Este impulso ha comportado una apuesta por la introducción de las TIC en los distintos ámbitos de la actividad universitaria de las economías desarrolladas que se inició en la década de los 1990 y que ha supuesto un incremento significativo de la inversión y del gasto en infraestructura tecnológica.

No podría ser de otro modo si se quiere responder a las necesidades tanto internas como externas que plantea la Sociedad. No obstante, este proceso no resultará sencillo y ya han surgido obstáculos que entorpecen el camino (ver Figura 22).

\subsection{INTRODUCCIÓN DE LAS TIC EN LAS UNIVERSIDADES ESPAÑOLAS}

Las TIC no sólo están permitiendo a las universidades transformar sus procedimientos administrativos, innovar metodologías de enseñanza y aprendizaje o facilitar el acceso a nuevos grupos de personas (especialmente adultos), sino que, de forma especial, han propiciado una incipiente transformación en su sistema organizativo (VVAA, 2003).

Esta afirmación es respaldada también por Bricall (2000), quien señala que en el campo educativo las tecnologías auguran la progresiva desaparición de las restricciones de espacio y tiempo en la enseñanza y la adopción de un modelo de aprendizaje centrado en el estudiante (Huidobro y Roldán, 2005). Al mismo tiempo, favorecen la comercialización y la globalización de la educación superior, así como un nuevo modelo de gestión de la organización. Todo ello no hace sino poner de manifiesto una realidad existente: que las tecnologías no sólo entran en la universidad para transformar las acciones académicas, sino que especialmente lo hacen para catalizar cambios organizativos (Duart y Lupiáñez, 2005). En efecto, las TIC en la Universidad, como también en la empresa o en cualquier otro tipo de institución, no sólo afectan a sus procesos o a su cadena de valor, sino que de forma evidente afectan a la propia estructura de la organización (Carnoy, 2004). 


\section{Demanda}

Oferta

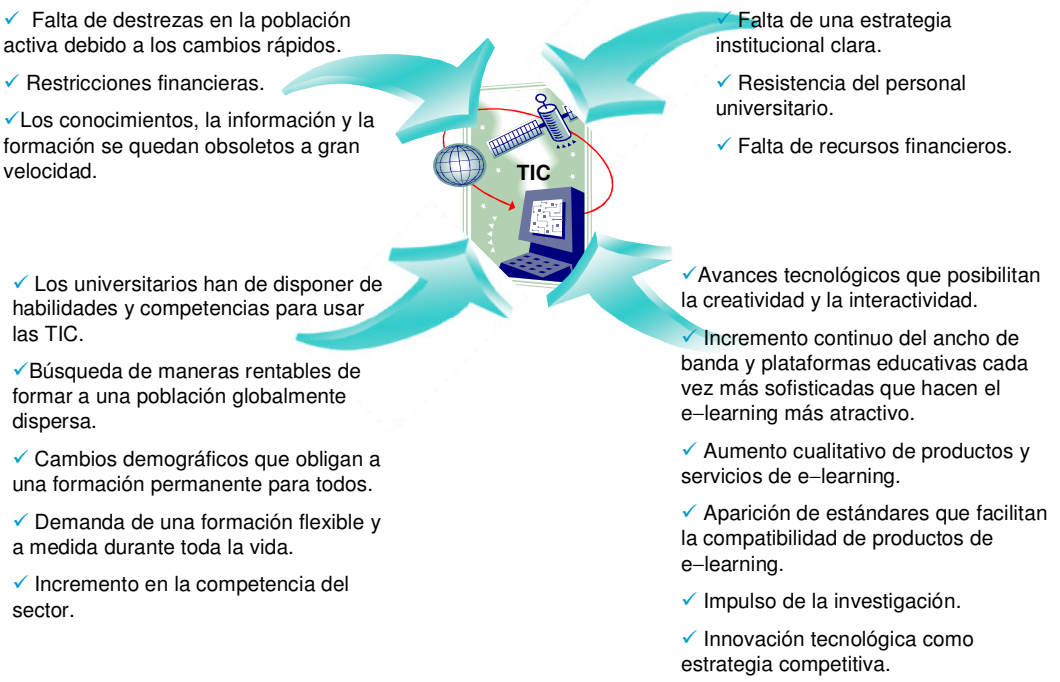

Fuente: elaboración propia a partir de CRUE (2004) y Roldán (2005).

Figura 22. Obstáculos y necesidades de la implantación de las TIC en las Universidades.

Un hecho constatable es que la incorporación de las TIC en las Universidades se ha realizado a un ritmo bien distinto en cada una de estas áreas. Si bien la investigación ha permanecido cercana a los orígenes y al desarrollo de las tecnologías digitales e incluso ha sido pionera en el empleo de las TIC para su realización (Geuna, 2000), la incorporación de dichas tecnologías en la docencia no se ha materializado con la misma fuerza. En efecto, los datos disponibles revelan que la dotación de infraestructura se ha generalizado en el sector universitario durante la segunda mitad de los $1990 \mathrm{y}$ principios del siglo actual, mientras que los usos de las TIC presentan un doble patrón de comportamiento: la aplicación de las tecnologías para la gestión administrativa de la actividad presenta una gran difusión mientras que su uso en la actividad docente ha sido minoritario hasta hace bien poco. Por ejemplo, en el sistema universitario español se puede observar un incremento medio anual en el presupuesto destinado a las TIC (CRUE, 2004), tal y como plasma la tabla de la Figura 23. En efecto, según los datos de este informe en el período 2000 a 2003 el prespuesto medio destinado a las TIC se ha incrementado en casi un $42 \%$.

\begin{tabular}{l|c|c|c|c}
\hline & \multicolumn{1}{|c|}{$\mathbf{2 0 0 0}$} & \multicolumn{1}{|c|}{$\mathbf{2 0 0 1}$} & \multicolumn{1}{c|}{$\mathbf{2 0 0 2}$} & $\mathbf{2 0 0 3}$ \\
\hline Presupuesto medio $(€)$ & 1.661 .259 & 1.795 .704 & 1.962 .383 & 2.357 .319 \\
\hline Incremento medio anual & - & $8,09 \%$ & $9,28 \%$ & $20,13 \%$ \\
\hline
\end{tabular}




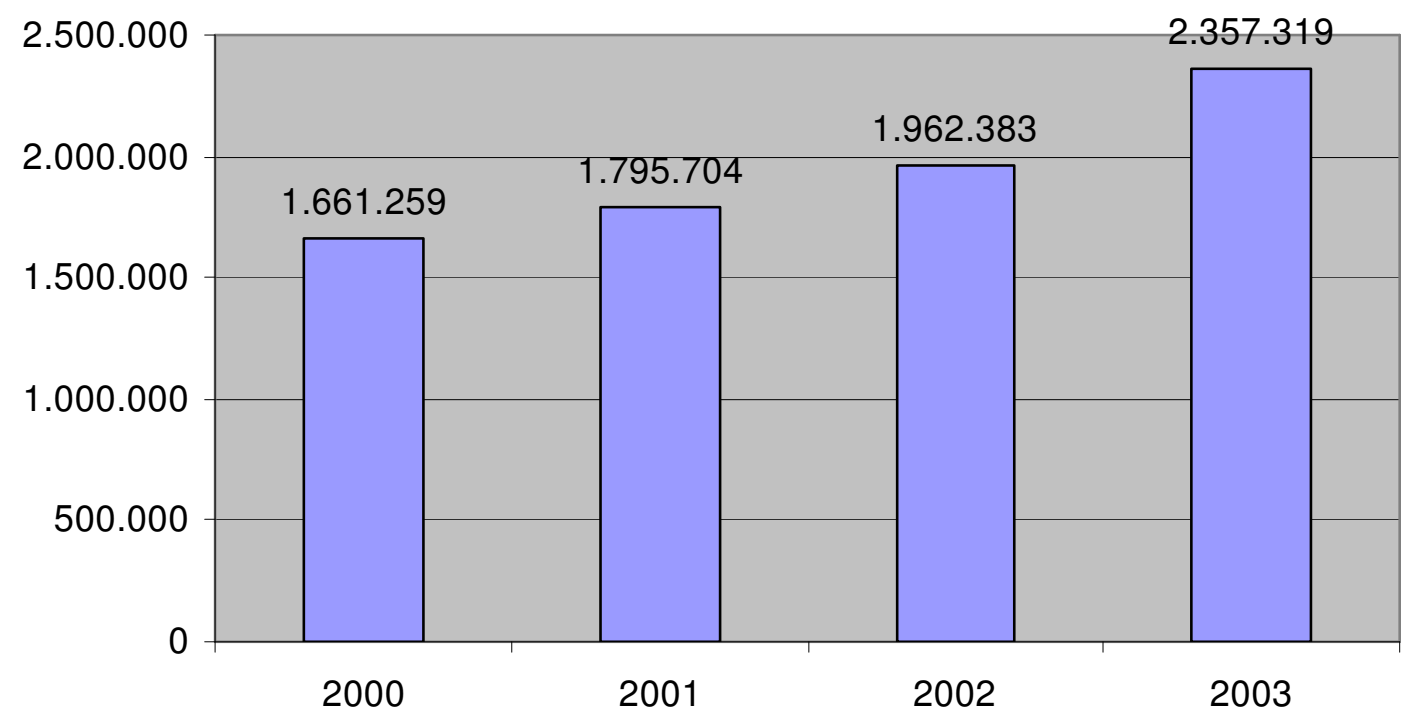

Fuente: reproducido de CRUE (2004).

Figura 23. Universidades que presentan presupuesto $T^{12} C^{2}$.

La creciente notoriedad económica de las TIC en el ámbito universitario se demuestra también a través de otras cifras, tal y como se indica el mismo informe (CRUE, 2004). En primer lugar, el porcentaje que representa el gasto en TIC sobre el presupuesto global de las universidades es, en término medio, el 2,57\%. No obstante, prácticamente la mitad de las universidades que aportaron datos sobre este aspecto reconocen que su presupuesto TIC representa menos del 1\% del presupuesto total de la universidad (ver Figura 24). Por tanto, el aumento constatado anteriormente no ha servido para alcanzar unas cifras representativas en el gasto total de las universidades. De hecho, sólo tres universidades destinan más del $5 \%$ de su presupuesto a TIC.

\begin{tabular}{l|l|l}
\hline & \multicolumn{1}{|c|}{$\begin{array}{c}\text { Número de } \\
\text { universidades }\end{array}$} & \multicolumn{1}{c}{ Porcentaje } \\
\hline$<1 \%$ & 9 & $47 \%$ \\
\hline $2 \%-4 \%$ & 7 & $37 \%$ \\
\hline$>4 \%$ & 3 & $16 \%$ \\
\hline
\end{tabular}

Fuente: reproducido de CRUE (2004).

Figura 24. Importancia de las TIC en el presupuesto total de las Universidades españolas.

En segundo lugar, si se toman las cantidades asignadas a TIC en función del capital humano, se aprecia la importancia económica que éstas pueden llegar a alcanzar (ver Figura 25). En relación con el número de alumnos el gasto medio es aproximadamente de 180 euros, realizando el 30\% de las universidades un gasto superior a 200 euros por estudiante. El gasto medio por PAS y PDI asciende a 3.963 y 2.200 euros, respectivamente, aunque existen diferencias

${ }^{12}$ En CRUE (2004) se considera que los datos presupuestarios presentados por las Universidades que formaron parte del estudio no computaban los gastos de personal asignados a actividades TIC. 
importantes entre las universidades, de tal modo que sólo una de cada cuatro se sitúa en un rango de $+/$ - el 25\% del valor medio (CRUE, 2004).

\begin{tabular}{l|l}
\hline Presupuesto por alumno & $177,33 €$ \\
\hline Presupuesto por PAS & $3.963,11 €$ \\
\hline Presupuesto por PDI & $2.199,48 €$ \\
\hline
\end{tabular}

Fuente: reproducido de CRUE (2004).

Figura 25. Presupuesto medio de TIC en función de la dotación de recursos humanos ${ }^{13}$.

Por otra parte, la literatura internacional sobre la administración universitaria evidencia que durante las últimas décadas se han producido una serie de alteraciones organizativas comunes a las Universidades de los países occidentales (Michael, 1997), que han estado encaminadas a la dotación de una mayor flexibilidad en la realización y gestión de su actividad. Estos cambios se han manifestado principalmente en la adopción de parámetros de eficiencia (Lam, 1998; Messner y Ruhl, 1998; Michael, 1997; Odden y Clune, 1995), en la reducción de las estructuras organizativas (Appelbaum y Patton, 2002; Horn y Jerome, 1996; Dickman et al., 1996) y en fomento de procesos de descentralización en la ejecución de la actividad (Saffu y Mamman, 1999). Los motivos de esta transformación se encuentran, fundamentalmente, en dos elementos (Castillo, 2004):

- La evolución de la demanda de enseñanza universitaria, que se concreta en la potenciación de la demanda social de ampliación del acceso a dicha formación, el incremento de la demanda de formación universitaria por parte de la población adulta y de adaptación de la oferta formativa a los nuevos requerimientos de capacidad y habilidades de los trabajadores. Es decir, un aumento de demanda de penetración social de la formación universitaria, de formación continua y de formación por competencias en el puesto de trabajo para atender las exigencias de actualización y reciclaje permanente de las habilidades de los trabajadores, características estas de la economía del conocimiento.

- La evolución de la financiación de las Universidades, caracterizada por una disminución de los recursos disponibles (Plain, 1995; Scannell, 1993; Pickens, 1993) y por una alteración de la composición de la estructura financiera con un incremento significativo de los recursos financieros privados y de la autofinanciación en detrimento de los fondos públicos.

En el caso de concreto de España (ver Figura 26), se comprueba, efectivamente, este comportamiento. Aunque la financiación de origen público es la predominante (con más de un $70 \%$ ), se observa una importancia creciente de los recursos de origen privado (en torno al 25 $\%)$, mientras que la autofinanciación tiene un carácter redisual.

${ }^{13}$ En CRUE (2004) se advierte de que los indicadores para el PAS y el PDI se obtuvieron dividiendo el presupuesto total entre el número de personal y de que, por ello, se debe ser cauto a la hora de interpretarlos por no tratarse de recursos destinados exclusivamente a PAS o PDI, respectivamente. 


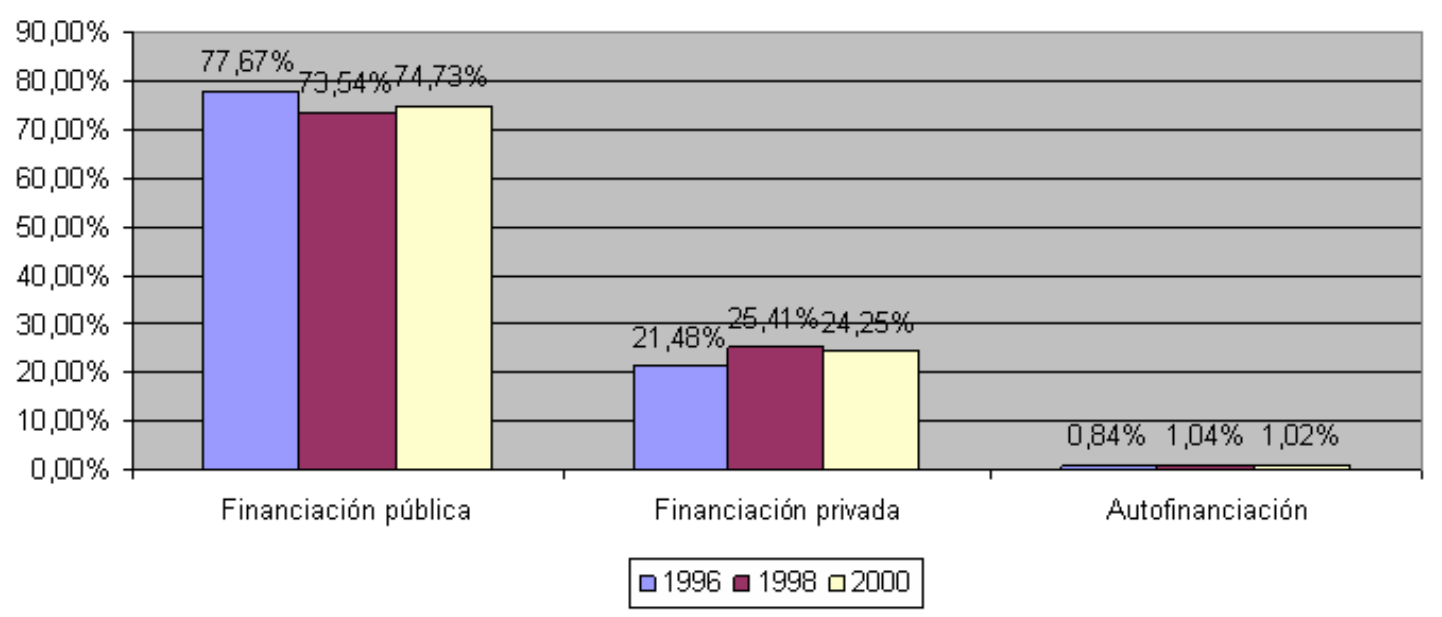

Fuente: elaboración propia a partir de Hernández (2003).

Figura 26. Evolución y origen de la financiación de las Universidades Públicas españolas (1996:2000).

En este contexto, el empleo de las TIC en la actividad universitaria se está convirtiendo en un elemento instrumental importante para conseguir los objetivos de atender una renovada demanda social de formación de una manera eficiente.

En el ámbito del análisis de la formación universitaria, la integración de las TIC en la actividad docente ha comportado importantes transformaciones, tanto de los métodos que enmarcan el desarrollo de la actividad como de los mecanismos y prácticas aplicables a su organización (Marcelo, Puente, Ballesteros y Palazón, 2002), introduciendo nuevas posibilidades de integración de recursos tecnológicos, de incorporación de elementos de flexibilidad y conectividad y de aumento de la interacción y la comunicación entre profesores y estudiantes. Así, la convergencia de estos elementos de transformación, la incorporación de las tecnologías digitales en la actividad universitaria y el cambio organizativo de la Universidad, tendente a la dotación de una mayor flexibilidad en la realización y la gestión de las actividades de su cadena de valor, explica la aparición de una nueva forma de realizar la actividad de formación basada en el uso intensivo de las TIC, el e-learning.

\subsection{ACTITUD FRENTE LA INCORPORACIÓN DE LAS TIC}

A pesar de que el incremento de las inversiones en TIC por parte de las Universidades, en general, es cada vez mayor (CRUE, 2004; Sánchez, 2005), la actitud de las mismas, a nivel institucional, no es igual de favorable. De hecho, según un estudio llevado a cabo por la consultora danesa PLS RAMBOLL Management para la Comisión Europea acerca de los modelos de universidades virtuales (2004), en relación con la actitud de las Universidades europeas con la introducción de las TIC en la actividad universitaria, es posible distinguir cuatro grandes grupos (ver Figura 27): 


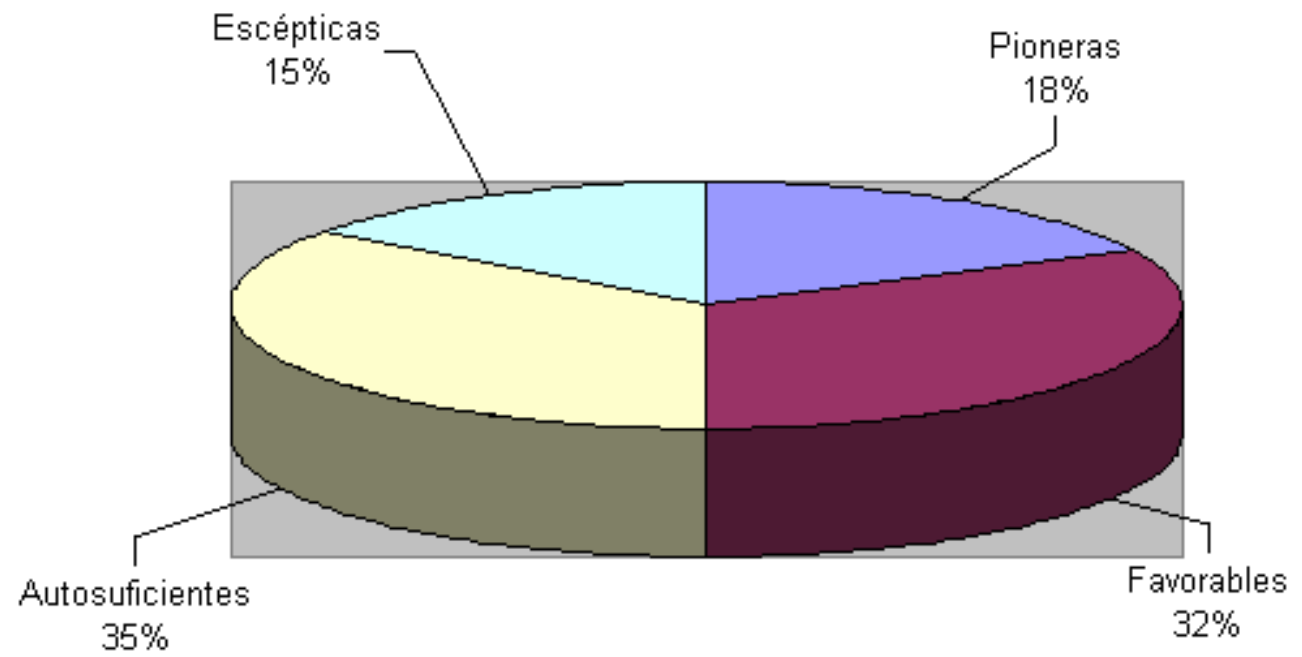

Figura 27. Aptitud de las Universidades europeas frente a la incorporación de las TIC.

El primer grupo de Universidades son instituciones que se encuentran al frente de la integración de las TIC en todos los ámbitos de la actividad universitaria y reciben la denominación de pioneras. De hecho, según el mismo informe, el $75 \%$ de las mismas ha formulado explícitamente una estrategia TIC y financia sustancialmente su puesta en marcha con recursos propios, lo cual da una idea de la importancia que le confieren. Sin embargo, el hecho que realmente las distingue es su actitud altamente positiva frente a las TIC. En el caso de España, podemos citar la Universitat Oberta de Catalunya (UOC), primera universidad española totalmente virtual, y la Universidad Nacional de Educación a Distancia (UNED), que ha potenciado fuertemente la introducción de elementos de virtualidad en su metodología docente (pese a que sigue ofreciendo formación a distancia en formato tradicional).

Por su parte, las Universidades del grupo de las favorables, a pesar de plantearse seriamente la incorporación de las TIC, no se encuentran en un estadio tan avanzado como las pioneras. Entre estas universidades, se encuentran la Universidad Politécnica de Valencia, la Universidad Complutense de Madrid o la Universidad de Barcelona.

El tercer grupo de Universidades son las autosuficientes, caracterizadas, por una actitud positiva a nivel institucional pero con un alto porcentaje de personal interno escéptico, por lo que el primer paso en su evolución será consolidar internamente la integración de las TIC en todos los niveles de la actividad universitaria. La mayoría de Universidades españolas se encuentran en este grupo.

Finalmente, las Universidades escépticas van a la cola en la integración TIC y solamente un porcentaje muy reducido de las mismas dispone de alguna estrategia en este sentido. No suelen dedicar recursos internos a financiar este tipo de proyectos, sino que recurren a fondos públicos. Un aspecto a destacar es que la mayoría de Universidades de este grupo tienen menos de 10.000 estudiantes, según el citado estudio.

\subsection{SERVICIOS TIC EN LAS UNIVERSIDADES}

La dotación de equipamiento tecnológico ha experimentado un crecimiento significativo en sector universitario a lo largo de la última década que se explica porque que éstas se han convertido en un elemento competitivo y no sólo por la mejora obvia en la gestión, la docencia y la investigación (Sánchez, 2005), sino porque permite aumentar el mercado objetivo de la Universidad que, hasta ahora, estaba prácticamente limitado al área geográfica de influencia de la 
misma. Por otra parte, la inversión en capital tecnológico por parte de las Universidades ha posibilitado el incremento y la mejora de los recursos disponibles, favoreciendo de esta manera la disponibilidad de instrumentos tecnológicos destinados a los diferentes miembros de la comunidad universitaria.

La Figura 28 muestra el catálogo de servicios TIC ofertados por las Universidades españolas (CRUE, 2004). Como puede verse, la mayoría de Universidades cuentan con servicios básicos de seguridad y mantenimiento informático, siendo este último el que mayor número de recursos humanos consume. En la parte inferior de la tabla se han agrupado los servicios menos extendidos y, en relación a ellos, cabe destacar, en primer lugar, que los servicios como el Help Desk y el Call Center, emplean un número relativamente elevado de trabajadores (3,8 y 3,3, respectivamente, frente a la media del total de servicios, situada en 2,7). Por otra parte, un hecho preocupante es la baja penetración de los servicios de formación del PAS y el PDI, algo que podría tener cierto impacto en la difusión de una estrategia de e-learning puesto que muchos usuarios se verán intimidados por el empleo de las TIC en su trabajo diario debido al desconocimiento de las mismas.

\begin{tabular}{|c|c|c|}
\hline & $\begin{array}{c}\% \\
\text { Universidades } \\
\text { que lo ofertan }\end{array}$ & $\begin{array}{l}\text { Número medio } \\
\text { de empleados }\end{array}$ \\
\hline Administración de antivirus & $97,0 \%$ & 1,3 \\
\hline Mantenimiento informático & $93,9 \%$ & 7,9 \\
\hline Copias de seguridad servidores corporativos & $90,9 \%$ & 1,9 \\
\hline Dirección de proyectos de nuevas tecnologías & $87,9 \%$ & 3,0 \\
\hline Gestión de carné universitario & $87,9 \%$ & 1,2 \\
\hline Análisis y dirección de aplicaciones corporativas & $84,8 \%$ & 3,4 \\
\hline Administración de aulas informáticas & $84,8 \%$ & 4,5 \\
\hline Mantenimiento hardware de ordenadores centrales & $84,8 \%$ & 1,6 \\
\hline Correo electrónico & $81,8 \%$ & 2,1 \\
\hline Creación del contenido de la web & $81,8 \%$ & 2,9 \\
\hline $\begin{array}{l}\text { Gestión de compra centralizada de equipamiento } \\
\text { informático para el área de gestión }\end{array}$ & $81,8 \%$ & 1,7 \\
\hline Administración de ordenadores & $78,8 \%$ & 3,1 \\
\hline Servidor web & $75,8 \%$ & 1,6 \\
\hline $\begin{array}{l}\text { Gestión de compra centralizada de equipamiento } \\
\text { informático para todo el campus }\end{array}$ & $75,8 \%$ & 1,6 \\
\hline Help Desk & $69,7 \%$ & 3,8 \\
\hline Call Center & $66,7 \%$ & 3,3 \\
\hline Asesoría, control y auditoria de seguridad & $66,7 \%$ & 1,4 \\
\hline Copias de seguridad usuarios microinformática & $60,6 \%$ & 1,7 \\
\hline Formación del PAS & $54,5 \%$ & - \\
\hline Análisis y dirección de aplicaciones externas & $45,5 \%$ & 3,3 \\
\hline Formación del PDI & $42,4 \%$ & - \\
\hline Formación de personal externo a la Universidad & $21,2 \%$ & - \\
\hline
\end{tabular}

Figura 28. Catálogo de servicios TIC y número medio de empleados. 


\subsection{OBSTÁCULOS A LA IMPLANTACIÓN DE LAS TIC}

La implantación de las TIC no está exenta de problemas. En el caso de la Sociedad española el uso de las TIC probablemente no esté suficientemente extendido entre los ciudadanos para que éstos puedan aprovechar plenamente los servicios telemáticos ofertados por la Universidad.

Según datos del Instituto Nacional de Estadística (INE), solamente la tercera parte de los hogares españoles dispone de acceso a Internet, si bien puede observarse un crecimiento sostenido en los últimos 5 años, tal y como muestra la Figura 29. En efecto, se ha pasado de 2.380 .800 hogares con conexión a Internet en 2002 a 5.637 .981 en 2006, aunque sobre el total de la población, el porcentaje de hogares con acceso a Internet sigue siendo relativamente bajo en comparación con otros países del entorno, principalmente los países nórdicos y los centroeuropeos.

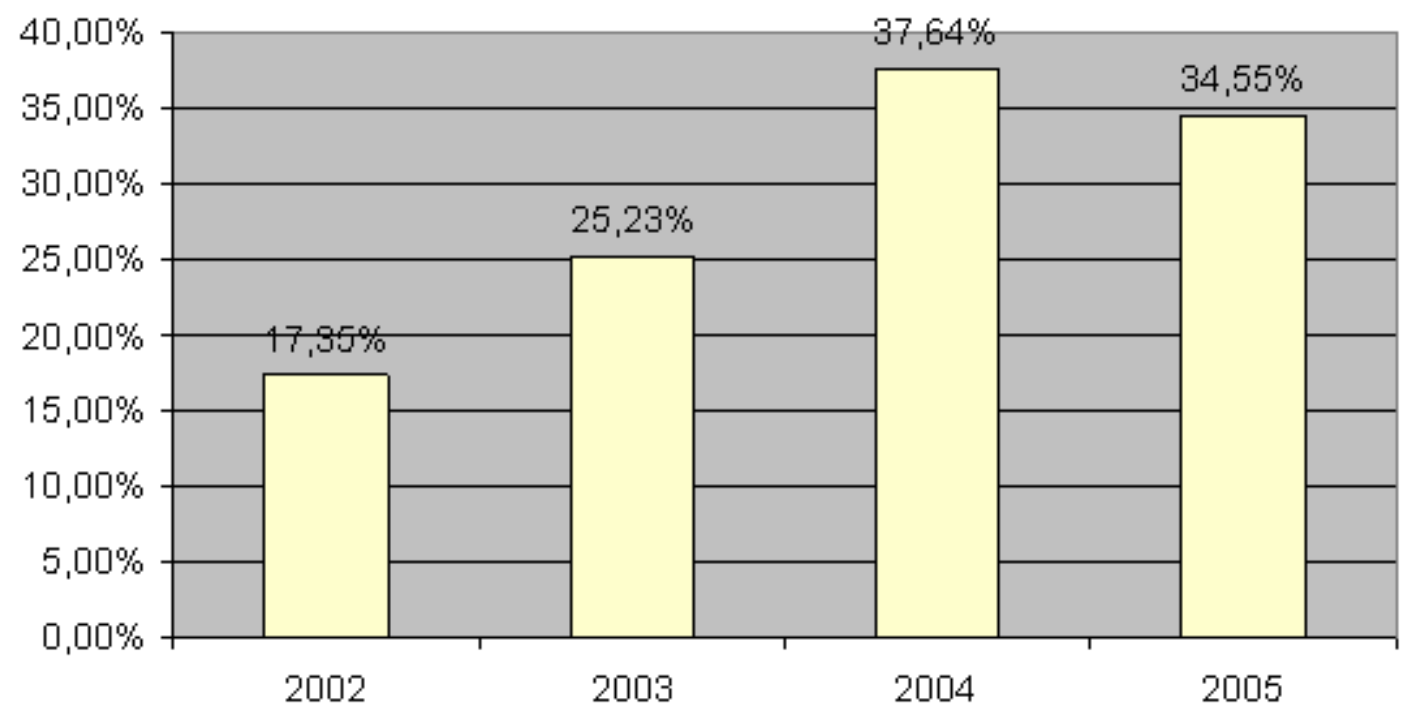

Fuente: elaboración propia a partir del datos del INE (2002:2006).

Figura 29. Porcentaje de hogares españoles con acceso a Internet.

En cuanto a la forma de conexión, puede observarse la migración de los accesos de banda estrecha (Red Telefónica Básica, RTB) hacia accesos de banda ancha (ADSL y cable, principalmente). 


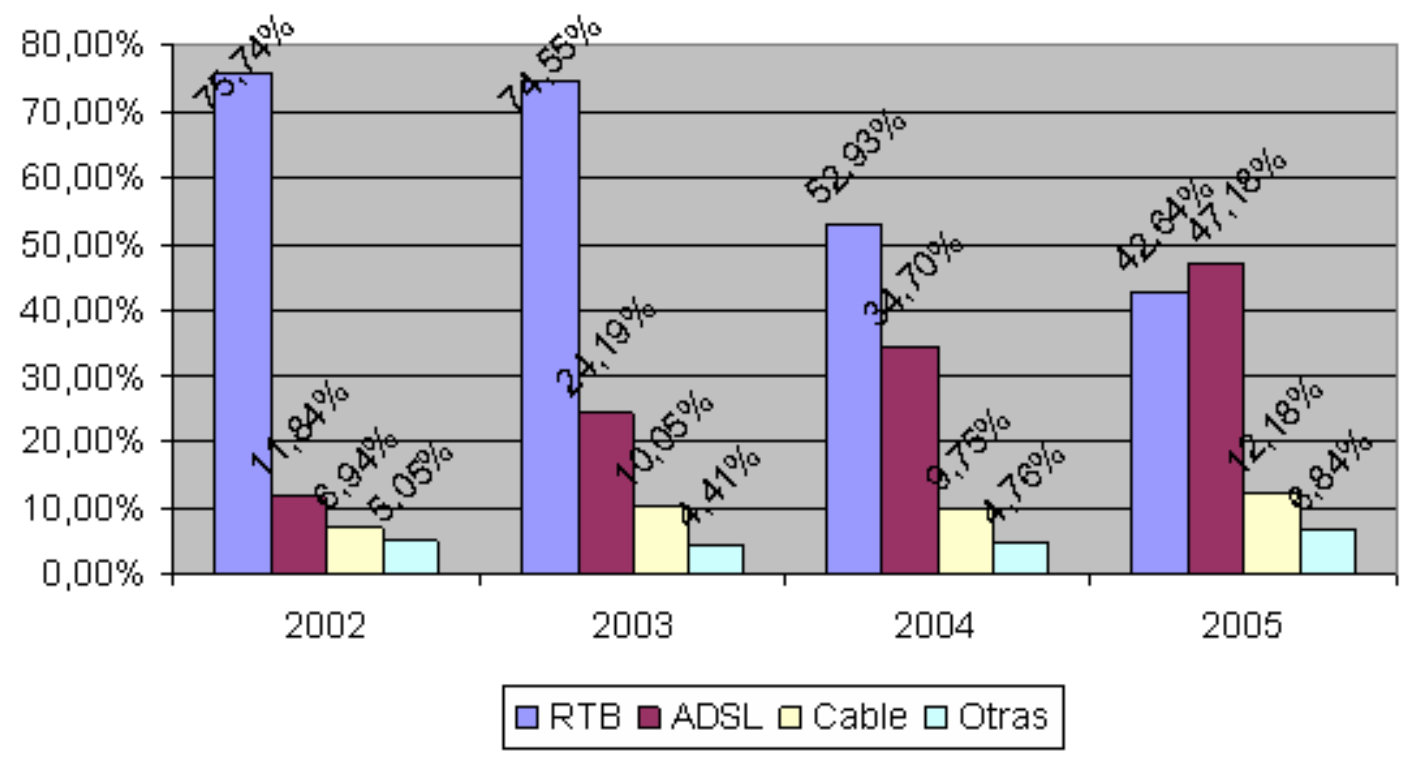

Fuente: elaboración propia a partir de datos del INE (2002:2005).

Figura 30. Evolución del tipo de acceso a Internet en los hogares españoles.

Respecto a los hogares que no disponen de conexión a Internet, las principales barreras detectadas en años anteriores se siguen manteniendo en el año 2005 (ver Figura 31). En este sentido, las razones que esgrimen los españoles para no disponer de conexión a Internet en casa son la falta de interés, la falta de conocimientos, el coste derivado de su uso o el acceso a Internet desde otros lugares distintos del hogar. Muchas de estas barreras podrían reducirse e incluso eliminarse a través de campañas informativas y de difusión de las Nuevas Tecnologías, como el Plan Avanza de Red.es. 


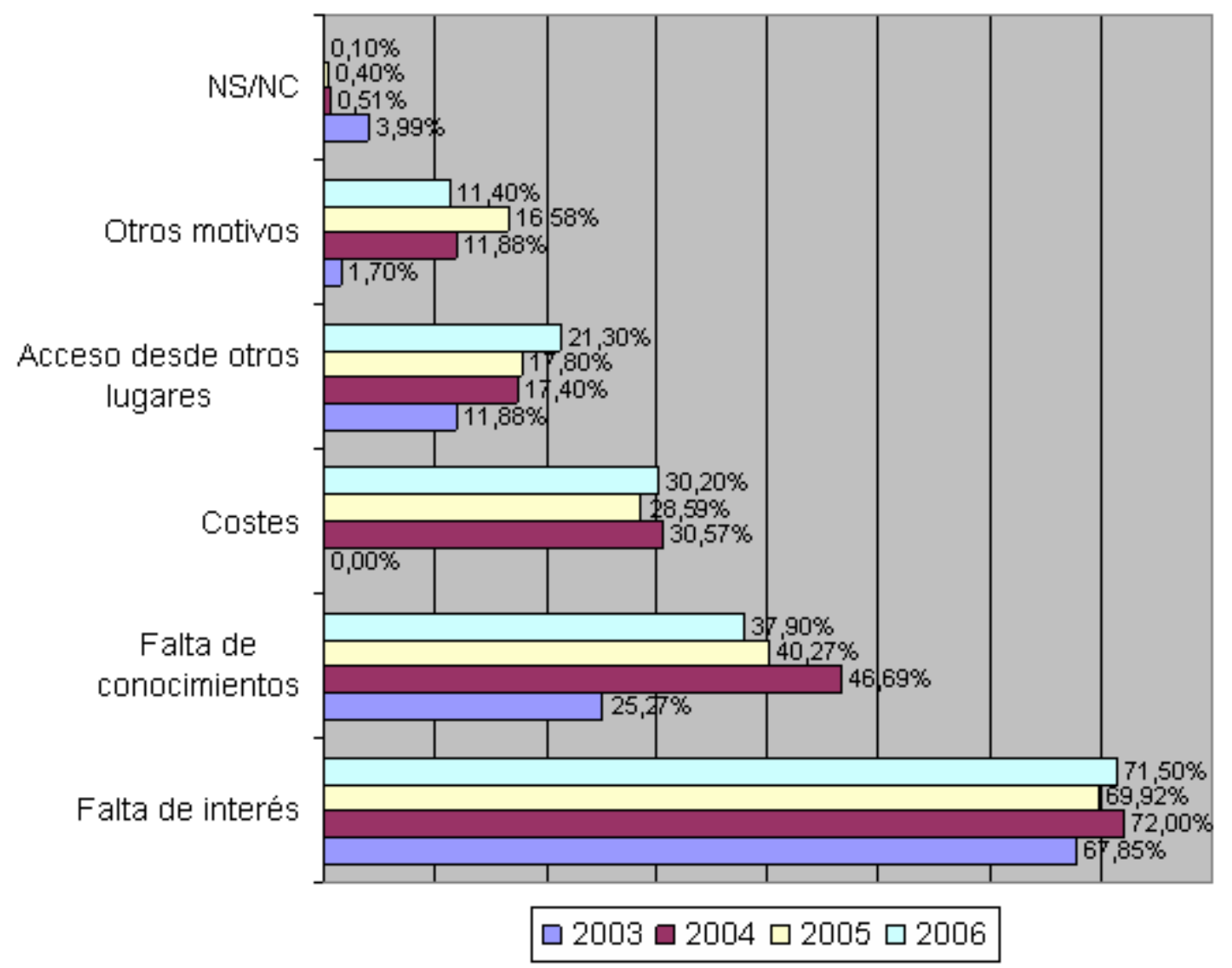

Fuente: elaboración propia a partir de datos del $\mathrm{INE}^{14}$.

Figura 31. Motivos para no disponer de conexión a Internet en el hogar.

A estos factores externos hay que añadir las limitaciones con las que cuenta la propia Universidad. En el caso de España estos obstáculos son, fundamentalmente, los siguientes (CRUE, 2004):

1. Falta de planificación estratégica

La ausencia en muchas universidades de una estrategia clara que diseñe un sistema de implementación integral de las nuevas tecnologías en los ámbitos de la gestión, docencia e investigación. El Informe Bricall (2000) constata que "aunque las universidades han desarrollado muchos proyectos, éstos acostumbran a ser acciones aisladas que no se encuadran en los objetivos estratégicos de la institución y cuya existencia suele autojustificarse como un fin en sí mismo".

2. La fuerte resistencia del personal, tanto académico como administrativo

Las resistencias a este tipo de iniciativas no han partido de las estructuras organizativas existentes, sino de las personas que sustentan dichas estructuras. La escasa flexibilidad de la carrera funcionarial dentro de la universidad no facilita los cambios necesarios en estos procesos (Duart y Lupiáñez, 2005). Esta resistencia es mayor en aquellas personas que se encuentran más próximas al final de su carrera.

Dentro del PDI (Personal Docente e Investigador), las tareas burocráticas de apoyo a sus procesos tanto docentes como investigadores son entendidas como ajenas a su tarea cotidiana y, en un primer momento, vieron el uso de estas aplicaciones como un trabajo extra que no repercutía directamente en su carrera profesional. No obstante, en la mayoría de los casos, el uso progresivo de estas herramientas los ha convencido de la eficacia y agilidad de

\footnotetext{
${ }^{14}$ Los porcentajes son sobre el total de hogares sin acceso a Internet.
} 
su funcionamiento. Por otra parte, el escaso peso que tiene la labor docente en la valoración del currículo del PDI dificulta su implicación en el uso de las TIC dentro de su oferta académica. Sin embargo, en el ámbito de la investigación, algunas universidades han desarrollado aplicaciones para su gestión. Este tipo de aplicaciones, que sí afectan directamente a la carrera profesional del PDI, son utilizadas y muy valoradas sin que sea necesario ningún tipo de acciones complementarias (Duart y Lupiáñez, 2005).

En cuanto al PAS (Personal de Administración y Servicios), la implementación de las nuevas herramientas de gestión supone un paso decisivo hacia la profesionalización y flexibilidad de sus funciones. No obstante, en la mayoría de los casos este hecho se ha percibido esto como una amenaza a su puesto de trabajo, si bien existe una clara diferencia entre las últimas incorporaciones, con un perfil profesional más adaptado al uso de las TIC, y aquéllos de mayor edad, que han desarrollado su carrera profesional dentro de la institución. Para superar estas barreras se ha optado por acciones de formación del PAS con cursos de reciclaje que permitan adaptar los perfiles profesionales a las nuevas demandas. Por otro lado, se ha visto en las TIC una oportunidad para generar nuevos puestos internos que puedan ser cubiertos por las personas mejor capacitadas y formadas que logren dar un impulso dentro de la institución. Finalmente, se han consolidado en puestos superiores aquellas personas que habían venido realizando tareas por encima de su escala funcionarial. Una vez superadas las reticencias iniciales al cambio, en la mayoría de las ocasiones las TIC se consideran una herramienta que claramente mejora la eficacia del trabajo y, lejos de amenazar el puesto de trabajo del PAS, constituye una oportunidad para la realización de tareas de mayor valor añadido y, por lo tanto, de mayor satisfacción personal.

La formación e incentivación del PAS resultan, al igual que en el caso del PDI y de los propios estudiantes, pieza clave en la consecución de los objetivos mencionados. En cualquier caso, es necesario llevar a cabo un enorme esfuerzo para formar e incentivar a todo el personal en el uso de las nuevas tecnologías y reconocer el esfuerzo invertido de algún modo, que no siempre tiene por qué ser exclusivamente económico.

3. La escasez de recursos financieros

Si bien es cierto que las nuevas tecnologías abaratan los costes de funcionamiento de las universidades (en general, el gasto corriente), es preciso inicialmente realizar un esfuerzo de inversión importante (gasto de capital). Además, este gasto inicial está sometido a una obsolescencia muy rápida, lo cual genera un elevado nivel de riesgo para este tipo de inversiones.

En definitiva, la incorporación de las TIC al trabajo diario de la Universidad resulta clave para responder a las demandas de la Sociedad. Ahora bien, debe realizarse de una forma planificada y meditada, para evitar o reducir en la medida de lo posible los problemas de esta implantación. 


\section{APLICACIÓN DEL FLBPF DE ANTA}




\section{CAPÍTULO 4 DEFINICIÓN DEL ALCANCE ESTRATÉGICO}

Esta sección de FLBPF (ANTA, 2003) se centra en considerar cómo la solución, el proyecto o la idea de aprendizaje flexible se relaciona con las prioridades estratégicas de la organización. En el caso de Universidades se tratará, por un lado, de verificar que el e-learning es coherente con las políticas definidas por los órganos de gobierno y con la misión, visión y valores de la institución y, por otro, de articular las acciones tácticas más adecuadas a cada caso.

Llegados a este punto, conviene hacer una distinción entre planificación estratégica y planificación táctica, puesto que la extensión del uso del e-learning requiere una planificación bastante detallada que debería iniciarse desde un plano estratégico y traducirse, posteriormente, a un plano táctico (CRUE, 2006). Examinaremos más detenidamente estos conceptos antes de proseguir:

1. Planificación estratégica

Desde un plano estratégico, la planificación requiere como condición anterior que las TIC sean consideradas un instrumento básico para la institución y como elemento articulador de la actividad universitaria en la docencia, la investigación, la gestión y la prestación de servicios.

\section{Planificación táctica}

Desde el punto de vista táctico, la planificación debe considerar la opinión de los propios expertos en TIC, procedentes del entorno interno y externo a la Universidad, así como de los órganos de gobierno, con el fin de evitar problemas de indefiniciones orgánicas o funcionales que acaben achacándose injustificadamente a las TIC.

Una vez que está diseñada la estrategia (planificación estratégica), se estará en condiciones de tomar las decisiones tácticas (planificación táctica) y, finalmente, las universidades estarán en condiciones de determinar los recursos necesarios para su ejecución. Éstos serán, fundamentalmente, recursos materiales, humanos y nuevas herramientas de enseñanza, investigación y gestión. Este paso permitirá a las instituciones cuantificar la inversión necesaria para poner en marcha su estrategia. Actuando de este modo, las universidades abandonarán la idea de los presupuestos marginales dedicados a TIC, esto es, la filosofía de que básicamente es el dinero que va quedando el que se destina a las nuevas tecnologías. Es preciso que éstas tengan asignada una dotación económica estable.

En la primera parte de este capítulo determinaremos cómo la interacción entre el empleo de las TIC por parte de las Universidades y el proceso de transformación del sector explica el 
surgimiento de una nueva forma de realizar la actividad docente a través del uso intensivo de las TIC y que recibe el nombre genérico de e-learning. A continuación, propondremos una clasificación de las Universidades en función del uso de las TIC en su actividad docente y explicaremos las características específicas de las universidades virtuales, relacionándolas con el entorno actual y los cambios sufridos en los últimos años.

\subsection{ESTRATEGIA Y PLANIFICACIÓN DE LA INTRODUCCIÓN DE LAS TIC EN LA UNIVERSIDAD}

A pesar de las ventajas que supone la incorporación de las TIC a la Universidad, su implantación también encierra un peligro. Un funcionamiento inadecuado en alguno de los servicios que los usuarios, tanto internos como externos, considere básico, puede repercutir negativamente en la imagen de la Universidad aunque se trate de un error puntual.

Por su parte, el establecimiento de una arquitectura tecnológica adecuada a las necesidades concretas de cada Universidad y, dentro de ésta, a cada unidad o función, es clave para garantizar el desarrollo de la actividad universitaria. Puesto que la Universidad es cada vez más dependiente de las TIC, es necesario que su proceso de implementación sea coordinado, con el fin de evitar desde un primer momento elementos que puedan crear incompatibilidades lógicas o físicas a la hora de conectar las distintas unidades.

Por último, insistir en la necesidad de realizar un esfuerzo adicional para formar adecuadamente tanto al personal, para que hagan uso de las TIC en sus puestos de trabajo, como a los alumnos, para que conozcan cuáles son las posibilidades que se le ofrecen y cómo pueden sacarle el máximo rendimiento.

Por tanto, la definición de la estrategia institucional es clave en cualquier proceso de introducción de una innovación. Las Universidades deben determinar qué es lo que van a implementar, cuándo, dónde, cómo y qué consecuencias esperan de estos desarrollos tecnológicos. La introducción no planificada de una innovación puede conducir su descrédito, además de resultar ineficaz, poco productiva y seguramente cara. Es interesante señalar que la Asociación Internacional de Universidades, institución que alerta sobre la importancia del uso de las TIC en la educación superior desde 1995, ha creado una Task Force on Universities and ICTs que, tras examinar los desafíos a que se enfrentan las Universidades en la Sociedad de la Información y el Conocimiento, ha publicado un Policy Statement on Universities and Information and Communication Technologies (Langlois, 1998). El mismo año, la European University Association (EUA) publicó una Guía para Universidades sobre Estrategias en TIC (CRE Guides, 1998), en la que figura una lista de criterios a considerar cuando se introducen las TIC en las universidades.

Este concepto de planificación no es nuevo en las instituciones educativas, ni mucho menos, ya que en todas estas instituciones se llevan a cabo, al menos, dos tipos de planificación (Kotler y Fox, 1995). En efecto, en todas las instituciones existe una planificación económica y presupuestaria que busca la optimización de los recursos de la institución y una planificación táctica cuyos objetivos son el aumento del número de matrículas, los cambios en el currículo, etc. Sin embargo, la mayoría adolecen de una falta de planificación estratégica. La Figura 32 muestra cuál debe ser la secuencia en el caso ideal (Kotler y Fox, 1995). Primeramente, se estudia el entorno y su funcionamiento y, en especial, qué oportunidades y amenazas presenta. A continuación se establecen los objetivos que describen qué posición desea alcanzarse en dicho entorno y se formula una estrategia institucional que persiga la consecución de dichos objetivos. Hecho esto, se construye una estructura organizacional capaz de dar soporte a la estrategia establecida. Finalmente, se diseñan los sistemas de análisis, planificación y control necesarios para implementar y controlar la estrategia institucional. 


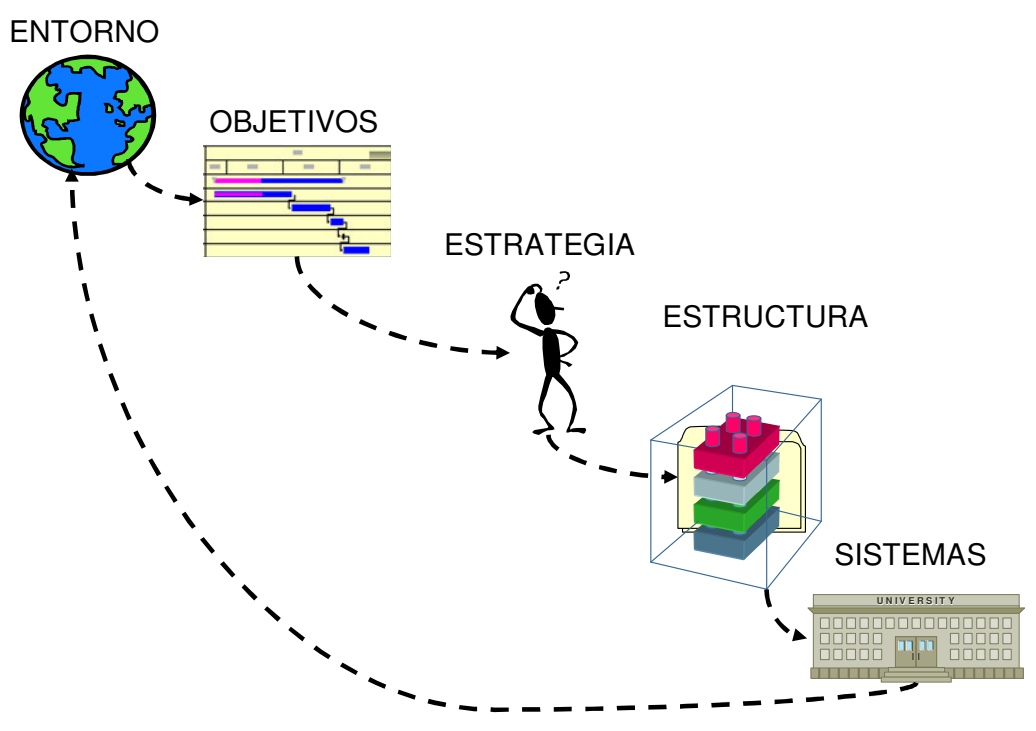

Fuente: elaboración propia a partir de Kotler y Fox (1995).

Figura 32. Papel del macroentorno en la dirección estratégica.

Sin embargo, la realidad es muy distinta ya que las instituciones educativas suelen operar en modo inverso al mostrado en la figura anterior. Es muy común encontrar instituciones que funcionen con sus sistemas y estructuras tradicionales porque, hasta el momento, les ha ido bien y, basándose en ellos, diseñe una estrategia y estudie el entorno actual sin ninguna visión de futuro.

Bates (2004) y otros insisten en que la planificación estratégica es clave para lograr la incorporación exitosa de las TIC, tanto en la administración, como en la implementación de nuevos programas. Salmi (2001) plantea que este éxito resulta de pensar detenidamente una estrategia que incluya el modelo de negocio de la gestión y gobierno de la Universidad, un mercado bien definido, un portafolio de programas orientado a satisfacer las necesidades de dicho mercado, el uso extensivo de las tecnologías educativas, y la confianza en docentes a tiempo parcial bien formados en el uso de tecnologías. Por el contrario, el fracaso en la puesta en marcha de proyectos TIC en las Universidades, según Salmi (2001), es el resultado de una carencia de planificación estratégica.

Por lo tanto, cuando se desea implementar un plan estratégico, es necesario reconocer la diversidad y la multiplicidad de intereses, a veces competitivos entre sí, de los diferentes actores en la institución en la que se plantea la innovación socio-tecnológica (Finquelievich y Prince, 2006). Ello hace que las estrategias institucionales necesiten de liderazgo fuerte para su implementación, de ahí que sea necesario contemplar sistemas de dirección específica para el desarrollo y la aplicación de las innovaciones en una organización (Duart y Lupiáñez, 2005). En efecto, cualquier innovación debe ser asumida y potenciada desde los órganos de gobierno de la institución para que pueda ser aplicada a toda la organización y, por otra parte, la puesta en marcha de la política institucional requiere gestores intermedios, direcciones operativas, que interpreten y ejecuten la misión institucional. Por tanto, también resulta imprescindible un liderazgo transversal. En definitiva, la estrategia que elaboren las Universidades y los centros de investigación deberá ganar la confianza de todos los implicados en la vida universitaria: órganos de gobierno, PDI, PAS y estudiantes.

De acuerdo con la Fundación Auna (2004), se podrían diferenciar las cuatro etapas que aparecen reflejadas en la Figura 33. 


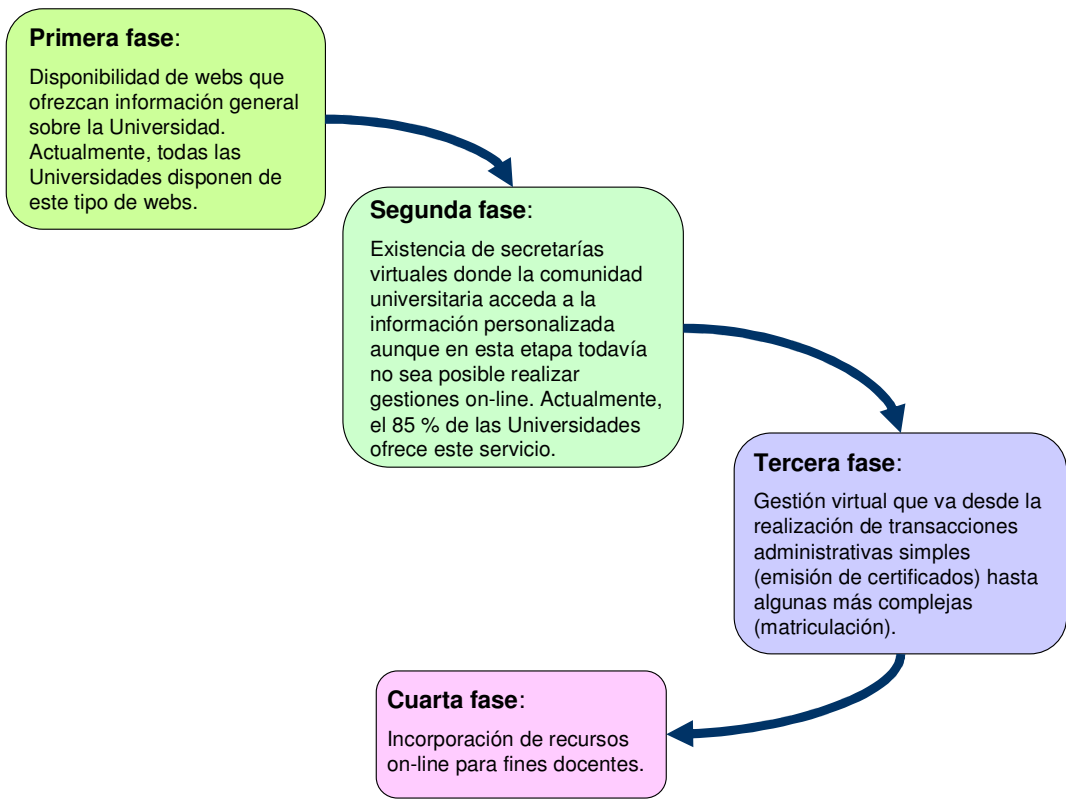

Fuente: adaptada de Fundación Auna (2004).

Figura 33. Etapas de desarrollo de las TIC en las Universidades españolas.

El primer paso consiste en que la institución se haga presente en Internet a través de un sitio web (el portal institucional) que ofrezca información general sobre la Universidad, los servicios que ofrece, etc. Según datos de Fundación Auna (2004), todas las Universidades españolas han superado ya esta etapa.

Una vez que la Universidad tiene presencia en Internet, debe abordar la incorporación paulatina de sus procesos al canal on-line, comenzando desde los más sencillos hasta llegar a los más complejos. Entre los primeros se encuentra el proporcionar al usuario, previa identificación, información personalizada en su relación con la institución. Por ejemplo, en el caso de la Universidad Politécnica de Valencia, todos los miembros de la comunidad universitaria disponen de una intranet a través de la cuál pueden acceder a información de las asignaturas en que están matriculados, al directorio interno de la Universidad, a la realización de diversas consultas, etc.

En un tercer estadio del desarrollo TIC de la Universidad, se comienzan a incorporar servicios de tramitación electrónica como la matriculación on-line.

Llegados a este punto, la Universidad ya habrá integrado en el canal on-line gran parte de las actividades de gestión, por lo que el último paso consistirá en extender la tecnologización a los ámbitos de la docencia y la investigación a través de la incorporación de recursos de estos ámbitos al portal institucional de la institución, ya sea ofreciendo cursos on-line, utilizando las TIC como soporte a la enseñanza presencial, etc.

\subsection{E-LEARNING Y FORMACIÓN EN RED}

El empleo de las TIC en la actividad docente de las Universidades se ha intensificado muy significativamente a lo largo de la segunda mitad de la década de los 1990. Este uso de las infraestructuras y los recursos tecnológicos, desde la utilización de los sistemas de aprendizaje y de autoaprendizaje basados en programas informáticos (CBT, Computer Based Training) hasta el empleo de Internet como soporte para el desarrollo de la actividad docente, son la base material de la transformación que está experimentando tanto la definición como la realización de la actividad docente universitaria (Vilaseca, 2003). 


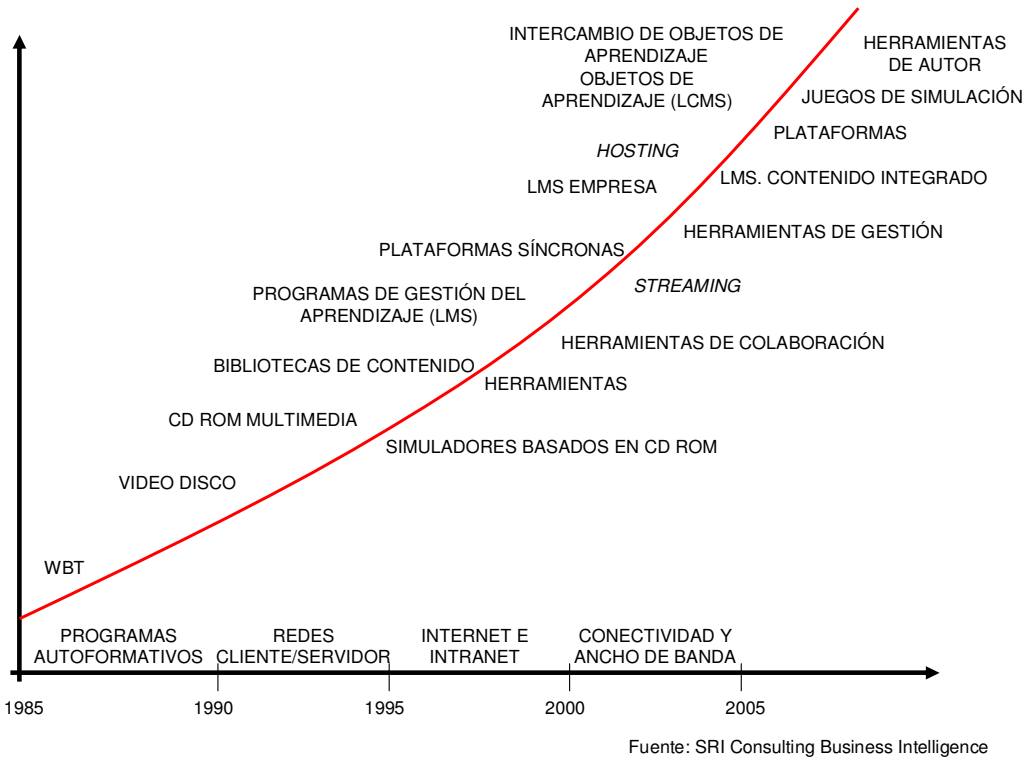

Fuente: reproducido de Roldán (2005).

Figura 34. Evolución de las plataformas de e-learning.

Esta transformación ha estado potenciada por la convergencia de los patrones de evolución del entorno universitario, del cambio organizativo y de la integración de las tecnologías digitales en la actividad de las Universidades, y ha incidido en la forma de concebir la actividad docente, dibujando una transición hacia lo que algunos autores llaman formación en red ${ }^{15}$ (Duart, 2002).

En efecto, la implantación de las TIC en la realización de la actividad docente de las Universidades ha introducido nuevas posibilidades de integración de recursos tecnológicos, de introducción de elementos de flexibilidad, de conectividad y de interacción y comunicación entre las personas que participan en el proceso formativo y con los diferentes recursos docentes disponibles para hacerlo efectivo. Es decir, el empleo de las TIC con finalidades formativas está generando importantes transformaciones tanto de los métodos que enmarcan el desarrollo de la actividad como de los mecanismos y prácticas aplicables a su organización (Marcelo et al., 2002).

Este hecho ha comportado la aparición de una nueva forma de docencia basada en el empleo intensivo de las TIC y que ha recibido la denominación, comúnmente aceptada, de elearning ${ }^{16}$.

Por e-learning entendemos el empleo de las TIC para proporcionar una serie de servicios formativos que permiten la adquisición de habilidades y de capacidades. Se trata, por tanto, de la actividad docente que lleva a cabo los procesos de enseñanza y aprendizaje por medio del uso de

${ }^{15}$ El término "formación en red" fue acuñado por Duart en ROI y e-learning: más allá de beneficios y costes. FUOC, 2002. Disponible en http://www.uoc.edu/duart0902/esp/duart0902/duart0902.html

${ }^{16}$ Cabe matizar, sin embargo, que a pesar de que el término anglosajón e-learning es más habitual para denominar esta actividad docente y de aprendizaje, existen autores que emplean expresiones alternativas para designa la misma realidad. Así, por ejemplo, el profesor Anthony W. Bates, director de la división de educación a distancia y tecnologia de la Universidad de la British Columbia (Canadá), o la profesora Betti Collis, de la Universidad de Twente (Holanda) utilizan el término telelearning, y el profesor Greville Rumble, de la Open University del Reino Unido habla de e-education. En el ámbito español, un informe sobre el estado de esta actividad elaborado por la Universidad Politécnica de Madrid en 1998 utiliza el término teleeducación y en un estudio financiado por las UNESCO en 1998 se emplea teleformación. 
redes informáticas y de telecomunicaciones. Integra y supera las definiciones más restrictivas de formación basada en ordenador (CBT, Computer Based Training), de formación basada en web (WBT, Web Based Training) o de la formación basada en Internet (IBT, Internet Based Training). La disposición en red de los diferentes recursos empleados en el desarrollo de la actividad docente delimita sus características fundamentales (Rosenberg, 2001):

- que se realice en red, lo que permite una actualización inmediata, almacenaje y recuperación, distribución y poder compartir los contenidos y la información;

- que se haga llegar al usuario final a través de un ordenador utilizando estándares tecnológicos de Internet; y

- que esté centrado en la más amplia visión de soluciones al aprendizaje que vayan más allá de los paradigmas tradicionales de la formación.

La definición de Rosenberg, sin embargo, resulta un poco anticuada, en tanto y en cuanto limita el dispositivo del usuario final a un ordenador. Esta limitación es comprensible si tenemos en cuenta la escasa penetración de los servicios móviles de datos hace cinco años debido fundamentalmente, a la escasa velocidad de transmisión soportada por las redes existentes (GPRS no se pondría en marcha en España hasta medidados de 2000 y UMTS entraría en juego en 2005) y por el precio de los terminales como PDA o smart-phones. Sin embargo, hoy en día, la disponibilidad de la banda ancha móvil y el abaratamiento de los terminales ha tenido como consecuencia la oferta de gran cantidad de servicios móviles de datos, como la transmisión de vídeo en tiempo real e incluso de televisión.

Una generalización del concepto de e-learning, desde el punto de vista meramente tecnológico es la propuesta por Brown (2004). Este autor distingue entre on-line learning y el m-learning (ver Figura 35). El on-line learning se corresponde con lo que Rosenberg denominaba $e$-learning, es decir, el acceso a los contenidos formativos a través de un ordenador de sobremesa (fijo o portátil) y, generalmente, una conexión a Internet. Sin embargo, la gran aceptación de las tecnologías móviles en la Sociedad, sobre todo en los sectores más jóvenes, ha planteado la necesidad de incorporar esta nueva modalidad de acceso a la formación a las soluciones de e-learning. El m-learning puede definirse como el conjunto de procesos de aprendizaje y docencia que tienen como contexto un entorno móvil y ubicuo.

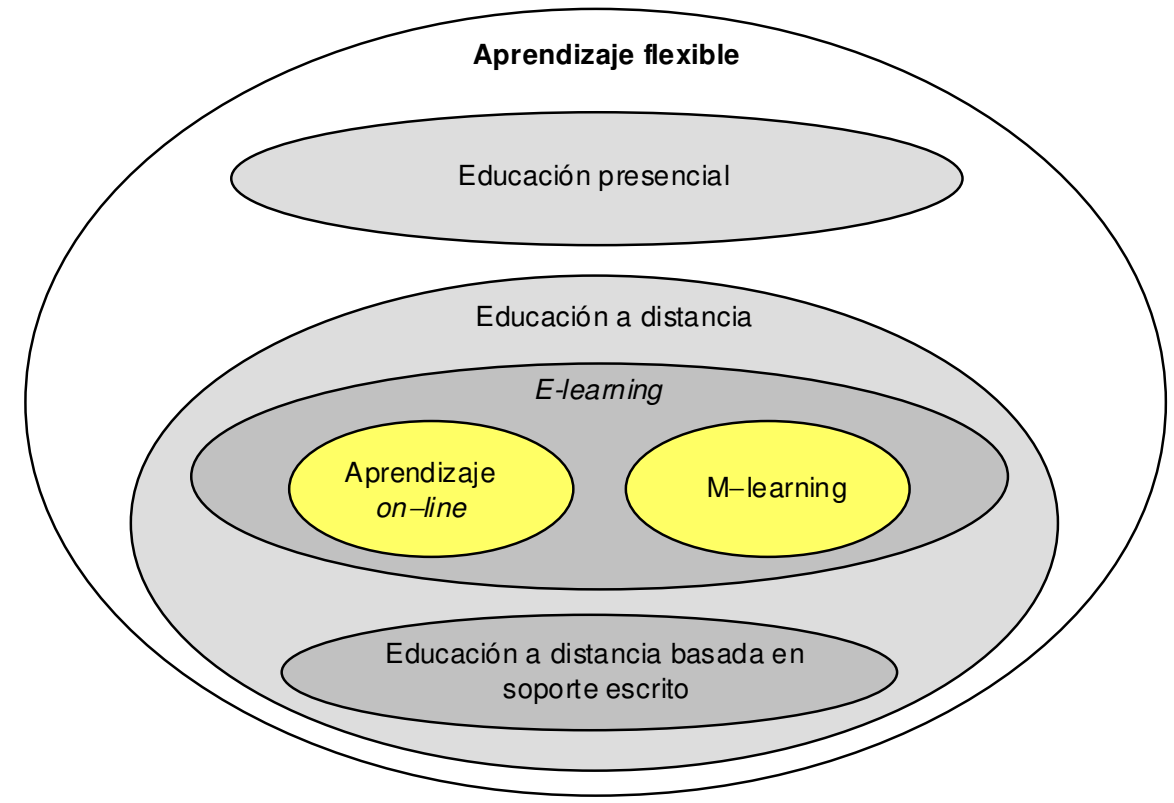

Fuente: adaptada de Brown (2004).

Figura 35. M-learning como componente del E-learning. 
Una vez contextualizado el concepto de $e$-learning, conviene establecer una frontera entre lo que se considera $e$-learning y lo que es, simplemente, la utilización de las nuevas tecnologías como herramienta auxiliar. Sangrá (2001) sugiere una distinción entre modelos dependiendo del peso relativo de sincronía y asincronía (ver tabla de la Figura 36):

\section{Modelos principalmente síncronos}

La virtualidad se encuentra en el hecho de poder superar la barrera de la distancia. Metodológicamente, estos modelos no difieren en exceso de los modelos presenciales, aún cuando tengan diferencias, obvias en algunos casos y notables en otros.

A menudo hacen uso de los sistemas de videoconferencia y chat, así como de sesiones presenciales en las cuales plantean conferencias, tutorías, etc. El correo electrónico suele ser la herramienta más asíncrona que utilizan. En los casos más extremos y, por tanto, más alejados de la virtualidad propiamente dicha (según Rosenberg esto no sería e-learning), se basan en clases presenciales periódicas con el uso complementario de TIC.

Modelos parcialmente asíncronos

Acostumbran a ser modelos de transición en instituciones que aún tienen importantes reservas sobre la eficiencia de modelos completamente síncronos.
Suelen basarse en el uso de un entorno virtual de aprendizaje que a menudo no llega a ser una verdadera comunidad educativa virtual, sino más bien un espacio virtual repositorio de materiales y que también se utiliza como tablón de anuncios.

Este espacio se complementa con alguna sesión presencial y el uso de sistemas de videoconferencia y chat, determinando por tanto, un modelo híbrido, con un uso restringido de las posibilidades sincrónicas.

Modelos esencialmente asíncronos
Se basan en el aprovechamiento máximo de las potencialidades de los entornos virtuales de aprendizaje (EVA), que aportan, fundamentalmente, flexibilidad e interactividad; permiten acceder a las fuentes de información y recursos ubicadas en Internet, así como a los materiales didácticos integrados en el entorno virtual y proporcionados por la propia institución; y permiten la vinculación a una verdadera comunidad virtual de personas que aprenden (Duart y Sangrà, 2000).

Fuente: adaptado de Sagrá (2001).

Figura 36. Clasificación de modelos de aprendizaje con Nuevas Tecnologías.

Las TIC se constituyen, pues, como el principal instrumento materializador de la disponibilidad en red de recursos de aprendizaje y de las nuevas formas de comunicación y de acceso a los procesos y recursos institucionales. En otras palabras, el e-learning se configura como un elemento instrumental de primera magnitud de la formación en red. Por formación en red entenderemos la descentralización en red de los diferentes procesos que intervienen en la realización de la actividad formativa (docencia, dotación de materiales didácticos, disponibilidad de servicios de soporte como el acceso a la biblioteca, etc.) de los diferentes cursos y programas. Así, en el concepto de formación en red convergen los desarrollos de las TIC, de los modelos pedagógicos y de los modelos organizativos de la Universidad alrededor de dos elementos 
principales: la realización en red de la docencia, que integra los distintos recursos educativos que se emplean de una manera flexible y variable, y la gestión en red de los recursos requeridos para el desarrollo de dicha actividad (Castillo, 2004). Se trata, entonces, de una formación concebida para la red y realizada en red e impulsada por el uso intensivo de las TIC (Kahn, 1997; Ferraté, 2002), y que, en tanto que nuevo escenario relacional, transforma las tareas docentes habituales.

A modo de recapitulación, las características principales de la formación en red son:

- Interacción: la morfología de red posibilita que la comunicación sea directa y que abarque el conjunto de sus distintos puntos, de manera que todos los agentes que participan en el proceso formativo pueden comunicarse multilateralmente a través de los entornos definidos.

- Flexibilidad: los distintos recursos educativos se pueden combinar de manera variable en el proceso formativo, posibilitando la generación de múltiples objetivos de aprendizaje. Además, el contenido de la formación puede ser objeto de una continua definición a partir de la convergencia de los criterios de los académicos de las necesidades de los estudiantes, y pueden convivir diferentes ritmos de desarrollo del proceso de aprendizaje.

- Sistema abierto: los estudiantes pueden acceder a la red desde cualquiera de sus puntos de acceso y moverse libremente dentro de su perímetro, escogiendo entre las distintas opciones formativas e incidiendo así en la evolución de la oferta de formación.

- Globalidad: los recursos educativos disponibles en la red se pueden distribuir en todos sus nodos sin ningún tipo de restricción geográfica. Este hecho determina la potenciación del carácter global tanto de la demanda como de la oferta de formación, es decir, tanto estudiantes como profesores convergen en la red desde distintos orígenes geográficos.

- Complementariedad: los productos formativos (materiales didácticos, acción docente, etc.) se pueden adaptar a finalidades de aprendizaje distintas, ofreciendo múltiples combinaciones de sus componentes en función de las características individuales y de las necesidades formativas de cada estudiante.

- No discriminación: la disponibilidad en red de los elementos necesarios para la realización de la actividad docente, y su carácter flexible, abierto y global permiten superar las limitaciones tradicionales de carácter espacial, temporal, demográfico, lingüístico, cultural e incluso asociado a disparidades individuales del acceso a la enseñaza.

- Integración y autonomía: la integración de los diferentes recursos de información y de comunicación multilateral determina la autonomía del proceso, de manera que la actividad formativa puede desarrollarse íntegramente en un entorno de red.

- Escalabilidad: la aplicación de recursos a la actividad docente es flexible, de manera que se posibilita su adaptación al volumen de demanda de cada curso o programa.

Si las TIC son el elemento impulsor y la base instrumental que permite la materialización de la formación en red, las causas de su origen se encuentran en el particular comportamiento de la demanda de enseñanza universitaria. Así, el concepto de formación en red se configura como una respuesta a dos líneas principales de la evolución de la demanda universitaria (Castillo, 2004): por un lado, la ampliación del ámbito de penetración de la enseñanza universitaria en la Sociedad, es decir, la mejora del acceso al conocimiento gracias a la eliminación de las barreras tradicionales de acceso a los contenidos formativos proporcionando al estudiante un contenido disponible de manera global, flexible y adaptable a sus necesidades individuales; y, por otro lado, la adaptación de la demanda de formación continua a lo largo de la vida (lifelong learning) que ha permitido a los trabajadores adquirir las habilidades requeridas y las competencias propias de su puesto de trabajo, así como adaptarse de manera constante a las necesidades formativas cambiantes derivadas de las constantes alteraciones del contenido y de la forma de organizar su trabajo; una necesidad formativa constante que se basa en procesos de aprendizaje y desaprendizaje de acuerdo con las competencias definidas en dicho puesto de trabajo.

Finalmente, resaltar que el empleo del e-learning presenta una serie de implicaciones significativas en la configuración de la actividad docente universitaria que han impulsado la 
transformación de dicha actividad en los ámbitos tecnológicos, metodológicos y logísticos (Collis y Moonen, 2006).

\subsection{ESTRATEGIAS DE UTILIZACIÓN DEL E-LEARNING}

La penetración de las TIC en las Universidades de los países desarrollados se constituye en el principal instrumento impulsor de la transformación de la actividad de formación universitaria. La diferente concreción que adopta el uso de estas tecnologías en cada Universidad está comportando una diversificación de los modelos de enseñanza, que incorporan diferentes grados de integración tecnológica.

Esta digitalización del proceso formativo no se encuentra recogida entre los criterios oficiales de clasificación y caracterización de los sistemas universitarios (Castillo, 2004). A pesar de su elevada divergencia entre países, los principales criterios categorizadores de las instituciones universitarias se centran en la forma de organizar la oferta de los distintos niveles formativos. Así, a escala internacional, la distinción fundamental se establece entre sistemas de enseñanza superior unitarios o binarios (Kirstein, 1999):

- Los sistemas de enseñanza superior unitarios son aquellos en los que un tipo de principal de instituciones de enseñanza superior integran todos los diferentes tipos de programas de estudio de los niveles de formación universitaria (estudios de grado y postgrado, que incluye el tercer ciclo). Algunas de estas instituciones presentan una oferta formativa más orientada a la investigación mientras que otra se centran en la formación orientada a la profesional.

- Los sistemas de enseñanza superior binarios o duales consisten en la convivencia de dos tipos de principales de instituciones de enseñanza superior: un tipo A formado por las Universidades tradicionales que combinan la enseñanza universitaria y la investigación; y un tipo B que ofrece una enseñanza más orientada a la formación profesional, sin presentar un perfil destinado a la investigación.

A partir de los trabajos de Vincent-Lancrin, (2004), Larsen y Vincent-Lancrin (2005), Miller (2003) y Ritzen (2006), Brunnel y Uribe (2007), distinguen seis escenarios futuros en los que se desarrollará la Educación Superior y los representan gráficamente según dos dimensiones:

1. Rango de la oferta institucional

Hace referencia a la amplitud de la oferta universitaria, siendo un extremo la oferta restringida y el otro una oferta amplia. Es posible emplear las fórmulas propuestas en el apartado 5.3.2.1.2 sobre la especialización de la oferta formativa, si bien, la propuesta de Brunnel y Uribe (2007) también se refiere a la variedad de titulaciones ofrecida por la Universidad, no sólo en cuanto a áreas de conocimiento sino también en cuando a tipo de titulación.

2. Composición de la demanda

En este eje se representan las características de la demanda y pretende dar una idea de los aspectos recogidos en el apartado anterior, siendo los extremos la educación superior de grado y la formación continua y de postgrado.

Un punto importante en este eje, es la distribución relativa de estos tipos de formación. La Figura 37 muestra el porcentaje de usuarios de formación reglada, postgrado y ocupacional como porcentaje del número de usuarios de Internet en los últimos tres meses. En la gráfica puede verse como, actualmente, la formación reglada on-line predomina sobre las otras dos. 


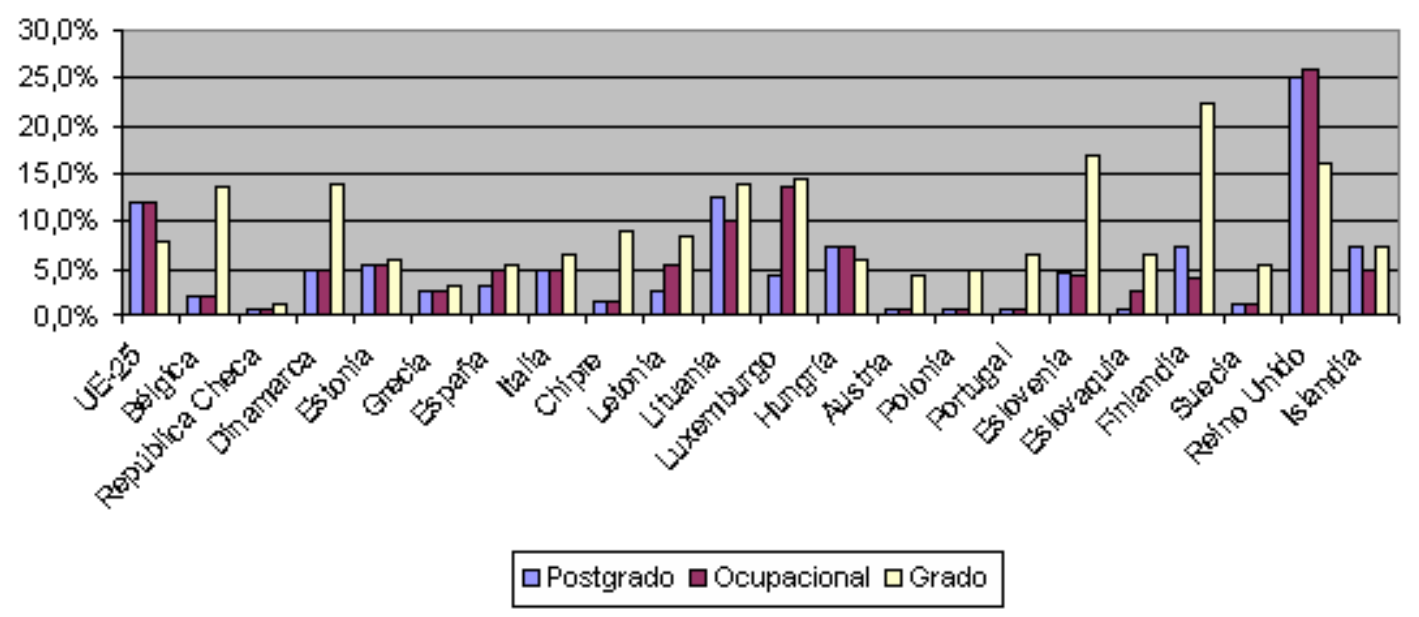

Fuente: elaboración propia a partir de Fundación Auna ${ }^{17}$ (2006).

Figura 37. Usuarios de formación de grado, ocupacional y de postgrado en los últimos tres meses como porcentaje del número de usuarios de Internet. UE-25 y EEA. 2005.

La Figura 38 muestra los escenarios identificados a que se hacía referencia anteriormente:

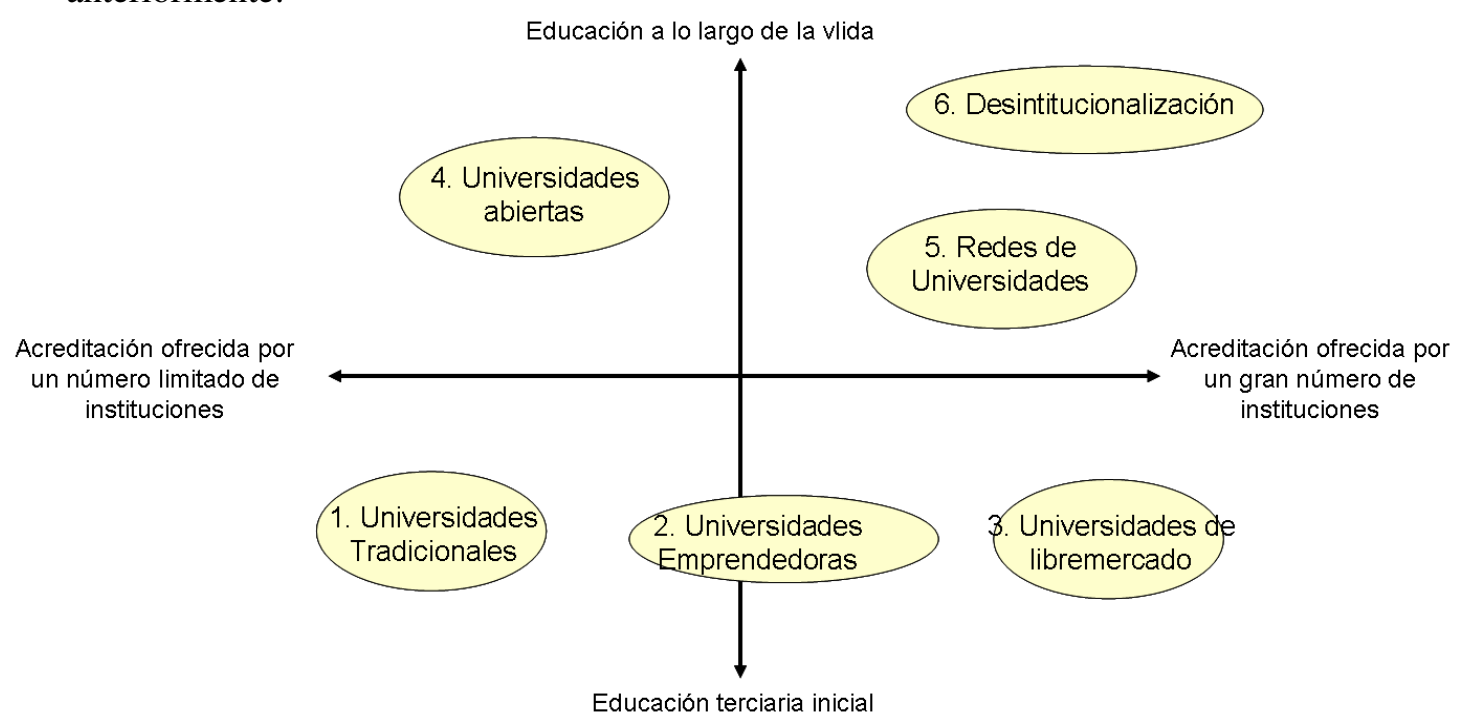

Fuente: modificado de Vincent-Lancrin (2004).

Figura 38. Escenarios para los sistemas universitarios.

Algunos estudios de la OECD (Vincent-Lancrin, 2004; Larsen y Vincent-Lancrin, 2005; Millar, 2003; Ritzen, 2006), caracterizan estos escenarios a partir de una serie de variables adicionales: financiación, carácter de la actividad universitaria, nivel de globalización de la institución y papel que desempeñan el e-learning y las TIC (ver tabla de la Figura 39):

${ }^{17}$ Los valores del gráfico han sido estimados por el investigador a partir de los gráficos originales, por lo que es posible que exista cierta inexactitud. Sin embargo, la tendencia general es la misma. 


\begin{tabular}{l|l|l|l|l|l|l}
\hline & 1 & 2 & 3 & 4 & 5 & 6 \\
\hline Formación reglada & & & & & & \\
\hline Formación de postgrado y continua & & & & & & \\
\hline Financiación pública predominante & & & & & & - \\
\hline Financiación mitxa & & & & & & - \\
\hline Financiación privada predominante & & & & & & - \\
\hline Docencia e investigación & & & & & & \\
\hline Docencia predominante & & & & & & \\
\hline Especialización según misiones & & & & & & \\
\hline Mercado predominantemente local & & & & & & \\
\hline Mercado internacional predominante o importante & & & & & & \\
\hline Importancia de las TIC y el e-learning & & & & & \\
\hline Utilización residual de las TIC y el e-learning & & & & & & \\
\hline
\end{tabular}

Fuente: adaptado de Vincent-Lancrin (2004).

Figura 39. Características de los escenarios futuros para la Educación Superior.

Teniendo en cuenta lo anterior, las características de los seis tipos de universidades serían las siguientes (Vincent-Lancrin, 2004; Brunner y Uribe, 2007):

1. Universidades tradicionales

Las Univesidades tradicionales se caracterizan por un empleo residual de las TIC y el elearning y un mercado predominantemente local (lo cual explica, en parte, el primer hecho), presentando una orientación investigadora y docente dirigida a un mercado eminentemente de formación reglada y financiada con fondos públicos. El importante papel del Gobierno en su gestión deja poco margen para iniciativas orientadas al mercado.

2. Universidades emprendedoras

La principal diferencia con el caso anterior es que estas universidades (públicas o privadas) disponen de mayor autonomía debido a la diversidad de fuentes de financiación.

En este tipo de universidades la investigación suele considerar como una importante fuente de ingresos, por lo que el prestigio es uno de los aspectos más valorados. Sin embargo, esta orientación al mercado se lleva a cabo sin perder los valores académicos básicos. Es precisamente, esta orientación comercial, la que confiere importancia a los mercados internacionales y al e-learning.

3. Universidades de libremercado

Las fuerzas del mercado son los principales motores de este tipo de Universidades. Estas fuerzas determinan la orientación de la Universidad (docencia o investigación), el área de conocimiento (Negocios, Humanidades, etc.) y el público objetivo (estudiantes jóvenes, estudiantes a tiempo parcial, formación a distancia, educación de adultos, formación continua, etc.).

La dimensión internacional del mercado tiene una importancia considerable y las TIC son muy empleadas en la metodología docente. En principio, las actividades de investigación se limitan a proyectos concretos bajo demanda. 
4. Universidades abiertas

Se trata de Universidades mucho más preocupadas por un mercado global y que invierten relativamente pocos recursos en investigación.

Estas Universidades están más orientadas a las demandas por parte de los estudiantes potenciales y su oferta formativa suele estar conformada por cursos cortos con una amplia penetración del e-learning, que se enfoca desde una perspectiva empresarial y al que se dedican gran cantidad de recursos.

5. Redes de Universidades

Los estudiantes definen sus propios cursos a partir de todas las asignaturas ofertadas por las Universidades participantes. Este modelo de Universidad se caracteriza por un empleo intensivo del e-learning. Resulta bastante común que la oferta educativa se centre en la formación continua, con gran influencia de empresas o Universidades Corporativas.

Los recursos dedicados a la investigación suelen ser escasos.

6. Desinstitucionalización

Se trata de un escenario extremo en el que la educación superior formal desaparece, dejando esta responsabilidad a los propios estudiantes, que se deberán "autoformar", y a las empresas.

La vertiente práctica de la formación se efectúa mediante la experiencia de profesionales que transmitien sus conocimientos a través de un acuerdo de aprendizaje o gracias al uso de las TIC.

En este escenario, la investigación está poco especializada en los campos que exigen una inversión reducida (como es el caso de las Humanidades), sin embargo, en casos en los que es necesario un desembolso imporante, se suele agrupar en centros públicos y privados de $\mathrm{I}+\mathrm{D}$.

También puede observarse una correspondencia entre la importancia del mercado internacional y la utilización de las TIC y el e-learning para desempeñar la actividad universitaria.

Dentro de estas clasificaciones, conviven universidades de enseñanza presencial y a distancia, de titularidad pública y privada, con una oferta formativa amplia y generalizada o especializada. En este sentido, en un gran número de países se establece la distinción entre las instituciones universitarias centradas en estudios politécnicos y el resto de centros dedicados a las Ciencias, las Humanidades y las Artes. Éste es el caso de las Escuelas Tècnicas Superiores de España, los Instituts Universitaires de Technologie de Francia, los Ammattikorkeakoulu de Finlandia, los Institutes of Technology de Irlanda, los Institutos Politéchnicos de Portugal, los Technical and Further Education Colleges de Australia, las Universidades Tecnológicas, los Institutos Tecnológicos i els Institutos Politécnicos de Mèxico, o las Politechniki de Polònia. Adicionalmente, algunos países separan los centros universitarios dedicados a la enseñanza del arte, con es el caso de los Estados Unidos, como los Baccalaureate (Liberal Arts) Colleges y los Associate of Arts Colleges, Canadá, con los College of Applied Arts and Technology/Collège d'Arts appliqués et de Technologie, o Polònia, con los Sztuk Pieknych.

El hecho de que las funcionalidades de información y de comunicación inherentes a las TIC hayan tenido una aplicación natural en la actividad de formación de las Universidades a distancia, ha motivado que las organizaciones supranacionales que nacen de la asociación de este tipo de Universidades hayan considerado el criterio del uso de las TIC en las propuestas de ordenación de los diferentes modelos de enseñanza superior a distancia que coexisten en la actualidad. Así, el International Council for Distance Education (ICDE) ha establecido una clasificación cronológica de los distintos modelos tomando como variables de referencia no únicamente el tipo de tecnología empleada sino también algunos de los aspectos más significativos que definen la naturaleza de la enseñanza a distancia (Taylor, 2001): su capacidad de introducir flexibilidad en términos de espacio, tiempo y ritmo de aprendizaje, la consecución de un cierto estándar de calidad en los materiales producidos, el potencial de interacción que permiten y su incidencia en los costes de la organización. 


\begin{tabular}{l|l|l|l|l|l}
\hline & \multicolumn{2}{|l|}{ Flexibilidad } & $\begin{array}{l}\text { Materiales } \\
\text { de alta } \\
\text { calidad }\end{array}$ & Interacción & $\begin{array}{l}\text { Costes varibles } \\
\text { tendentes a } \\
\text { cero }\end{array}$ \\
\hline & Tiempo & Espacio & $\begin{array}{l}\text { Ritmo } \\
\text { de } \\
\text { estudio }\end{array}$ & & \\
\hline
\end{tabular}

Primera generación

Modelo de correspondencia

\begin{tabular}{l|l|l|l|l|l|l}
\hline $\begin{array}{l}\text { Tecnología de } \\
\text { impresión }\end{array}$ & Sí & Sí & Sí & Sí & No & No \\
\hline
\end{tabular}

Segunda generación

\begin{tabular}{|c|c|c|c|c|c|c|}
\hline $\begin{array}{l}\text { Modelo } \\
\text { multimedia }\end{array}$ & & & & & & \\
\hline Impresión & Sí & Sí & Sí & Sí & No & No \\
\hline Audiocasette & Sí & Sí & Sí & Sí & No & No \\
\hline Videocasete & Sí & Sí & Sí & Sí & No & No \\
\hline CBT & Sí & Sí & Sí & Sí & No & No \\
\hline Vídeo interactivo & Sí & Sí & Sí & Sí & Sí & No \\
\hline
\end{tabular}

Tercera generación

Modelo de teleaprendizaje

\begin{tabular}{|c|c|c|c|c|c|c|}
\hline Audioconferencia & No & No & No & No & Sí & No \\
\hline Videoconferencia & No & No & No & No & Sí & No \\
\hline $\begin{array}{l}\text { Comunicación } \\
\text { audiográfica }\end{array}$ & No & No & No & Sí & Sí & No \\
\hline $\begin{array}{l}\text { Difusión } \\
\text { TV/Radio }\end{array}$ & No & No & No & Sí & Sí & No \\
\hline
\end{tabular}

Cuarta generación

\begin{tabular}{|c|c|c|c|c|c|c|}
\hline $\begin{array}{l}\text { Multimedia } \\
\text { interativa }\end{array}$ & Sí & Sí & Sí & Sí & Sí & Sí \\
\hline Recursos Web & Sí & Sí & Sí & Sí & Sí & Sí \\
\hline $\begin{array}{l}\text { Comunicación a } \\
\text { través del } \\
\text { ordenador }\end{array}$ & Sí & Sí & Sí & Sí & Sí & No \\
\hline
\end{tabular}

Quinta generación

Modelo de aprendizaje flexible inteligente

\begin{tabular}{l|l|l|l|l|l|l}
\hline $\begin{array}{l}\text { Multimedia } \\
\text { internactivo on- } \\
\text { line }\end{array}$ & Sí & Sí & Sí & Sí & Sí & Sí \\
\hline Recursos Web & Sí & Sí & Sí & Sí & Sí & Sí \\
\hline
\end{tabular}

Fuente: reproducido de Taylor (2001).

Figura 40. Modelos de eduación a distancia en función de las tecnologías aplicadas. 
En este contexto, el uso del e-learning por parte de las Universidades puede convertirse en un criterio homogéneo y general aplicable en la clasificación de las Universidades en función del grado de integración de las TIC en su actividad docente. Como se ha podido constatar en capítulos y apartados anteriores, el e-learning es común a las Universidades presenciales y a distancia, de modo que conviven modelos de formación basados en metodologías tradicionales con modelos duales y modelos centrados en el uso intensivo de las TIC en los distintos tipos de instituciones universitarias. Además, e-learning considera la implantación de tecnologías de distinto tipo con una finalidad común, ya que se caracterizan por la integración en el proceso formativo de todo un conjunto de aplicaciones basadas en las redes informáticas y en la medida del grado de evolución del proceso de transformación de los modelos de enseñanza universitaria derivada de la integración de las TIC en la realización la actividad formativa.

Así, a partir de la graduación de la intensidad de uso del e-learning en la actividad de enseñanza universitaria, es posible establecer una clasificación de las Universidades en cuatro grupos diferenciados (ver Figura 41):

- Universidades de e-learning

El primer grupo de universidades recibe el nombre de Universidades de e-learning y está formado por Universidades caracterizadas por el uso principal de e-learning para la realización de su actividad docente y que en la actualidad se concretan en Universidades abiertas y a distancia de nueva creación y en Universidades a distancia tradicionales que han adaptado su modelo educativo para el desarrollo de esta actividad. Como ejemplos podemos citar Universitat Oberta de Catalunya (UOC) o la Universidad Nacional de Educación a Distancia (UNED) en España. A nivel internacional, citaremos la Athabasca University de Canadá o la Open University del Reino Unido.

- Universidades duales

Integran las universidades de enseñanza dual, es decir, las Universidades en las que la actividad formativa presencial y virtual conviven de manera integrada. Este el caso, por ejemplo, la Penn State University, la University of Illinois, o del University of Maryland University College (UMUC) de los Estados Unidos.

- Universidades con uso complementario del e-learning

Es el caso de las universidades presenciales con un modelo educativo tradicional pero que han adoptado el uso de sistemas de e-learning como una vía de soporte su metodología presencial o para canalizar una parte de su oferta formativa. En este nivel se integran la mayoría de Universidades presenciales europeas, como ejemplo de nuestro entorno más inmediato destacaremos, entre otras, la Universidad Politécnica de Valencia (UPV), la Universitat Pompeu Fabra (UPF), la Universitat Politècnica de Catalunya (UPC), la Universitat Autònoma de Barcelona (UAB) o la Universitat de Barcelona (UB).

- Universidades tradicionales

Un cuarto grupo, que integra las universidades a distancia y las universidades presenciales con modelos de enseñanza y aprendizaje tradicionales $\mathrm{y}$, por tanto, con un empleo residual de las TIC en la formación. 


\begin{tabular}{l|l}
\hline Tipo de Universidad & Descripción \\
\hline $\begin{array}{l}\text { Universidades de e- } \\
\text { learning }\end{array}$ & $\begin{array}{l}\text { Empleo de los sistemas de e-learning como elemento principal de la } \\
\text { docencia. }\end{array}$ \\
\hline Universidades duales & $\begin{array}{l}\text { Modelo de formación a distancia flexible y basado en TIC y } \\
\text { modelos presenciales con integración de sistemas de e-learning. }\end{array}$ \\
\hline $\begin{array}{l}\text { Universidades con un uso } \\
\text { complementario del e- } \\
\text { learning }\end{array}$ & $\begin{array}{l}\text { Modelos a distancia tradicionales pero flexibles y modelos } \\
\text { presenciales con un uso del e-learning como soporte a la } \\
\text { metodología tradicional. }\end{array}$ \\
\hline $\begin{array}{l}\text { Universidades } \\
\text { tradicionales }\end{array}$ & $\begin{array}{l}\text { Modelos a distancia y presenciales que presentan un uso residual de } \\
\text { las TIC. }\end{array}$ \\
\hline
\end{tabular}

Fuente: elaboración propia.

Figura 41. Clasificación de las Universidades en función de su empleo del e-learning.

\subsection{MODELOS ORGANIZATIVOS EN UNIVERSIDADES VIRTUALES}

En la actualidad, son numerosos los autores que coinciden en afirmar que las TIC están produciendo unas transformaciones de gran magnitud sobre la actividad docente universitaria y sobre la organización de la actividad académica. Una de las principales manifestaciones de estos cambios, generalizados en los países desarrollados a partir de mediados de la década de los 1990, en el sector de la Universidad ha sido la aparición de una institución universitaria de nuevo tipo que basa su modelo académico y organizativo en el uso intensivo de las TIC. Este conjunto de universidades se han designado en la literatura internacional habitualmente con el término universidad virtual ${ }^{18}$ (también e-university).

Por universidad virtual entenderemos aquellas universidades que llevan a término su actividad de formación fundamentalmente a través de sistemas e-learning. El empleo principal del e-learning como una variable definidora de este tipo de universidades determina que se trate de instituciones basadas en una metodología de enseñanza y aprendizaje a distancia. Bajo este concepto se integran diferentes tipos de universidades, atendiendo a otros criterios: titularidad pública o privada, enseñanza generalista o especializado, entre otros.

Así, lo que caracteriza a las universidades virtuales es la dependencia de las TIC para el desarrollo de su actividad docente. Es decir, a diferencia de las Universidades presenciales y de las Universidades a distancia tradicionales, las universidades virtuales no pueden llevar a la práctica la formación sin la integración y empleo de las TIC.

A pesar de tratarse de un tipo de institución muy reciente, existen ya algunos trabajos que tratan de catalogar los diferentes modelos organizativos que se derivan de la praxis de estas Universidades. Así, a partir de las aportaciones de Farrell (1999) y de Sangrà (2001) se pueden establecer cuatro modelos diferenciados de universidades virtuales:

1. Universidades virtuales como organizaciones virtuales

Son universidades creadas específicamente para realizar una actividad de e-learning, algunas de las cuales parten de modelos de universidades abiertas y a distancia. Se

${ }^{18}$ El término universidad virtual ("virtual university") fue empleado por primera vez en el año 1996 en área de California para definir la utilización de las autopistas de información ("super-highways") por parte de las Universidades con propósitos educativos (Boshier, Brand, Dabiri, Fujitsuka y Tsai, 2001). 
caracterizan por disponer de un modelo organizativo y pedagógico particular y diferenciado del resto de universidades presenciales y a distancia. Dentro de esta categoría se incluyen, entre otras, la Universitat Oberta de Catalunya, Jones Internacional University, la Athabasca University, la Capella University (EEUU), la Irish Internacional University (Irlanda), la Open University (Reino Unido) o el instituto de Tecnología de Buenos Aires (ITBA).

2. Universidad presencial con extensión universitaria virtual

Se trata de un modelo muy extendido en las Universidades y que consiste en incorporar formación virtual en cursos de postgrado y extensión universitaria en instituciones educativas cuya oferta de formación reglada es eminentemente presencial. Este es el caos del CEPADE, de la Universidad Politécnica Madrid.

El caso de La Salle es también aquí significativo, con sus master exclusivamente online. Lo mismo están haciendo las universidades de Stanford y Harvard con sus MBA. La Stanford Graduate School of Business y la Harvard Business School han unido esfuerzos para poder ofrecer virtualmente sus master a los alumnos.

3. Universidad virtual adosada a la universidad tradicional

Se trata de universidades virtuales creadas por universidades tradicionales en su mismo entorno a través de espacios virtuales gestionados de forma independiente pero compartiendo los elementos básicos de la universidad tradicional (oferta formativa, normativa académica, servicios de biblioteca, etc.). Se desarrollan y proporcionan materiales impresos y electrónicos, tanto para estudiantes virtuales como para los presenciales. El modo dual es muy popular en varias universidades, en especial en Australia, Reino Unido, Canadá y Estados Unidos, donde un alto número de universidades dicta al menos un programa de estudios a distancia.

En este grupo se integran, por ejemplo, la Universidad Virtual del TEC de Monterrey, la Universidad Virtual de Quilmes o Phoenix Online University.

4. Universidades virtuales como espacios virtuales interuniversitarios.

Se trata una universidad virtual creada a través de un consorcio de diversas universidades tradicionales y se materializa en la disponibilidad de un espacio virtual común en el que converge la oferta de los diferentes planes de estudio. Este espacio se gestiona de forma compartida pero autónoma en la Universidades participantes en el consorcio.

En algunos otros casos, existe una entidad central, como la Université Virtuelle en Pays de Loire, Francia (UVPL), en el que el portal y las plataformas están mantenidos por el equipo técnico de la UVPL.

La Figura 42 muestra algunos ejemplos en el ámbito español. El Grupo9 Universidades realiza una oferta conjunta de asignaturas impartidas a través de medios telemáticos. Este Grupo lo conforman las universidades de Islas Baleares, Zaragoza, La Rioja, Navarra, País Vasco, Cantabria, Oviedo, Extremadura y Castilla La Mancha. Otros ejemplos son el proyecto ADA-Madrid o Intercampus de las universidades públicas catalanas.

\begin{tabular}{l|l}
\hline Grupo G9 & $\begin{array}{l}\text { Cantabria, Castilla-La Mancha, Illes Balears, La Rioja, Oviedo, País Vasco, } \\
\text { Pública de Navarra y Zaragoza }\end{array}$ \\
\hline ADA Madrid & $\begin{array}{l}\text { Alcalá, Autónoma de Madrid, Carlos III, Complutense, Politécnica de } \\
\text { Madrid, Rey Juan Carlos }\end{array}$ \\
\hline Intercampus & $\begin{array}{l}\text { Autónoma de Barcelona, Barcelona, Girona, Lleida, Oberta de Cataluña, } \\
\text { Politénica de Cataluña, Pompeu Fabra y Rovira i Virigili }\end{array}$ \\
\hline IUP & $\begin{array}{l}\text { Carlos III, Autónoma de Barcelona y Alicante en colaboración con } \\
\text { Santillana Formación }\end{array}$ \\
\hline Universia & 745 Universidades en colaboración con el BSCH. \\
\hline
\end{tabular}

Figura 42. Campus virtuales compartidos en España. 
Tschang y Della Senta (2001) identifican un modelo de asociación basado en acuerdos y articulaciones entre universidades existentes, que pueden estar en el mismo país o en diversos países. Es el caso de la UK Open University, que ofrece en franquicia sus cursos a instituciones "asociadas", localizadas en su mayor parte en países en desarrollo, o en Singapur y Hong Kong. Otro ejemplo es la Virtual University for Europe o EuroPACE, en la que participan 45 universidades, junto con empresas, gobiernos y redes internacionales. Se trata de una asociación internacional sin fines de lucro, con un objetivo académico específico: es una red de universidades europeas y de sus socios en educación y formación.

Otros autores (Dean, 2004; Standing Stones, 2000, Tschang y Della Senta, 2001; Finquelievich y Prince, 2006) incluyen también el modelo de intermediación (Brokerage) en el que la o las Universidades se asocian con una empresa que proporciona cursos utilizando los recursos de enseñanza de instituciones existentes. Como ejemplo, la Open Learning Australia (OLA), actualmente llamada Open Universities Australia. Esta organización pertenece a una asociación de siete universidades australianas; sus cursos son desarrollados por 18 "proveedores académicos". Las unidades que un alumno estudia, y las calificaciones que recibe son emitidas por estas universidades y otras organizaciones, y son idénticas a las que reciben los estudiantes que asisten a los campus presenciales.

Tampoco hay que despreciar la competencia, cada vez mayor, de las Universidades Corporativas. Fueron empresas como IBM, McDonald y Motorola las que introdujeron este tipo de docencia. En Estados Unidos está previsto que se incrementen gradualmente desde aproximadamente 2000, a principios del siglo XXI, hasta 3700 a finales de la primera década del siglo. Aunque su número es menor en Europa (100), también presentan una clara tendencia de crecimiento (Serrano, 2002). Un ejemplo en España, es la Universidad Corporativa de Unión Fenosa.

\subsection{INCIDENCIA DEL E-LEARNING EN LA ESTRUCTURA ORGANIZATIVA DE LA UNIVERSIDAD}

La integración del e-learning en la actividad universitaria potencia la aparición de un modelo de formación en red que incide en la determinación de la metodología académica y en la forma de organizar la actividad formativa. En este sentido, la incorporación de las TIC en las universidades, y en concreto el empleo de sistemas e-learning, se convierten en uno de los motores fundamentales del proceso de integración tecnológica, de la transformación de la metodología educativa y del cambio organizativo en el sector universitario.

De este modo, se puede afirmar que el desarrollo de la actividad de formación en red, caracterizada fundamentalmente por los elementos de flexibilidad, interacción e integración de los recursos formativos, se estructura a partir de tres ejes vertebradores, que enmarcan y gradúan la transformación de la Universidad en los tres ámbitos apuntados (Castillo, 2004):

1. La organización de los recursos formativos, orientada a la gestión en red del proceso de formación, y a la flexibilidad del proceso y de los productos formativos, adaptando su definición a las especificidades y necesidades de los estudiantes.

2. El modelo metodológico, orientado a la centralidad del estudiante en el proceso de formación a través de la disponibilidad en red de los recursos educativos, de la interacción entre profesores y estudiantes en el desarrollo del proceso de formación y de la interactividad asociada a las soluciones educativas (Bates, 2003).

3. La integración de las TIC, orientada al uso de las mismas en la realización de la actividad de formación y a la innovación tecnológica, es decir, a la generación de aplicaciones tecnológicas que permitan la mejora continua del proceso en términos tanto de eficacia como de eficiencia en la formación de los estudiantes.

Estos ejes permiten definir el concepto de universidad en red como la universidad que se sitúa en el sector en que convergen los puntos máximos de organización, metodología y 
tecnología, que determinan el punto de llegada de la tendencia a la transformación del sector universitario. Así, la universidad en red presenta las siguientes características (Castillo, 2004):

- Un proceso de formación flexible y adaptable a las características y oscilaciones de la demanda, que se realiza y gestiona en red.

- Una metodología centrada en el estudiante, con componentes de flexibilidad temporal, espacial y de dispositivo, interacción, interactividad y acceso global y abierto a los recursos de información.

- Un uso intensivo de las TIC con un fomento de la internalización de procesos de innovación tecnológica.

Estos tres ámbitos de transformación, la organización, la metodología y las TIC, permiten establecer una nueva clasificación de las Universidades y que atiende al criterio del nivel de uso de los sistemas e-learning para la realización de la actividad de formación, permitiendo determinar el estado de cada universidad en el proceso de transformación de sus dimensiones organizativa, metodológica y tecnológica.

Así, a partir del cruzamiento de las variables que definen la universidad en red y la variable de medida del nivel de integración y uso de sistemas de e-learning, podemos establecer un estado de la universidad en el proceso de cambio, basado en la matriz de doble entrada que se recoge en la Figura 43:

\begin{tabular}{l|l|l|l|l|l|l|l}
\hline & \multicolumn{3}{l|}{ Organización } & \multicolumn{3}{l}{ Metodología } & TIC \\
\hline & Gestión & Flexibilidad & Flexibilidad & Interacción & Interactividad & Aceso & Innovación \\
\hline $\begin{array}{l}\text { Universidades } \\
\text { de e-learning }\end{array}$ & Alta & Alta & Alta & Alta & Alta & Alta & Alta \\
\hline $\begin{array}{l}\text { Universidades } \\
\text { duales }\end{array}$ & Media/Alta & Media/Alta & Media/Alta & Media/Alta & Media/Alta & Media/Alta & Media/Alta \\
$\begin{array}{l}\text { Universidades } \\
\text { con un uso } \\
\text { complementario } \\
\text { del e-learning }\end{array}$ & Media & Media & Media & Media & Media & Media & Media \\
\hline $\begin{array}{l}\text { Universidades } \\
\text { tradicionales }\end{array}$ & Media/Baja & Media/Baja & Media/Baja & Media/Baja & Media/Baja & Media/Baja & Media/Baja \\
\hline
\end{tabular}

Fuente: modificada de Castillo (2004).

Figura 43. Matriz de transformación de la Universidad.

De la figura anterior se deducen dos implicaciones interesantes: por un lado, el hecho de que los parámetros que definen el concepto de universidad en red permiten graduar el ámbito de la transformación de la universidad derivada de la integración de las TIC en la actividad de formación; y, por otro, la constatación de que la intensidad de uso de las TIC, medido en este caso a través del nivel de adopción de sistemas e-learning, es una variable explicativa del grado de transformación organizativa, metodológica y tecnológica de la Universidad (Bates, 2001). 


\section{CAPÍTULO 5 ANÁLISIS DEL SECTOR}

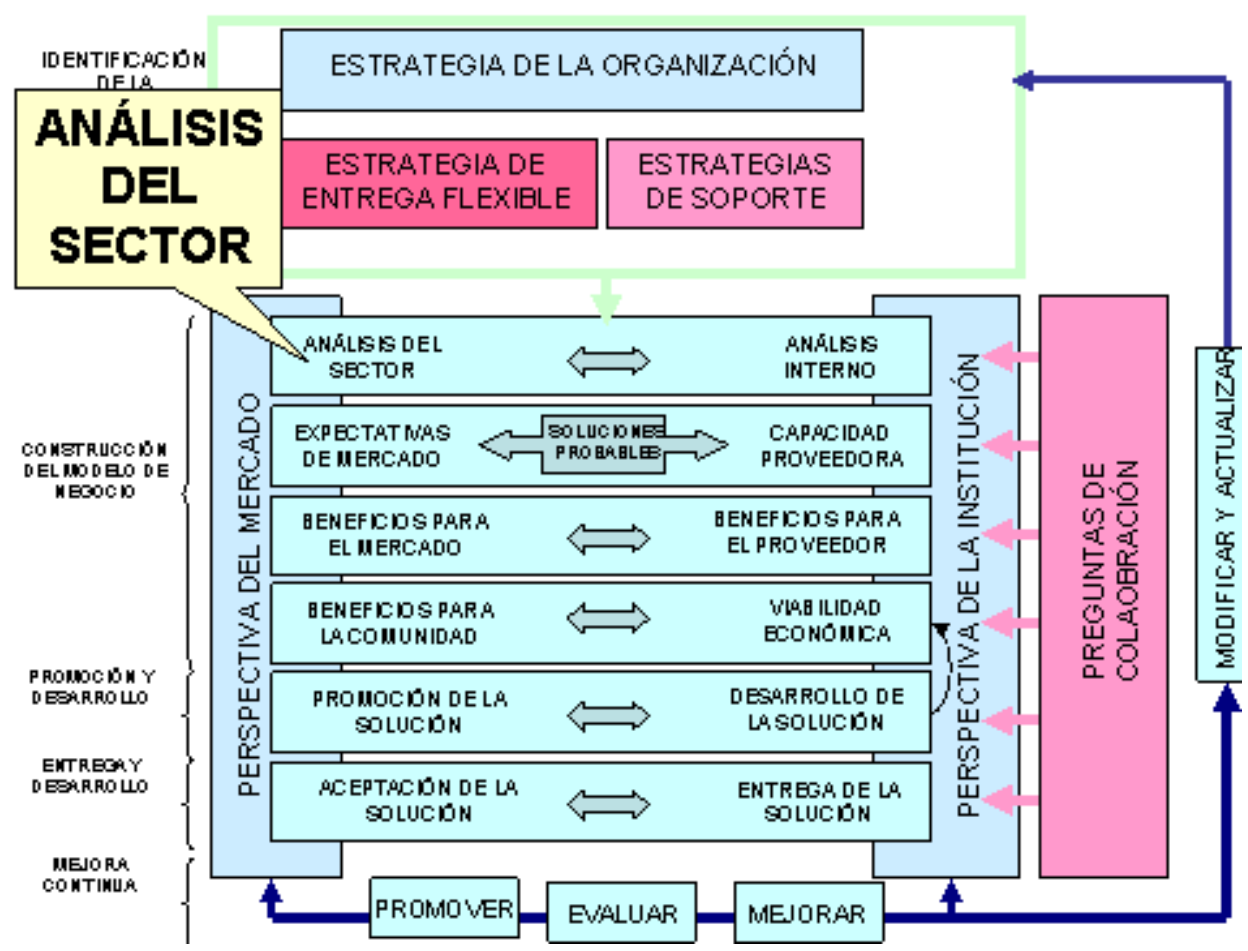

Hax y Maluf (1984) señalan que el análisis de la industria y de la competencia es un proceso para definir lo más relevante del entorno específico de una empresa, así como para identificar y caracterizar el comportamiento de los competidores más significativos en un determinado mercado. De hecho, Dalmau y Oltra (1997) llaman la atención sobre la identificación de las causas que hacen que existan sectores de actividad en los que la rentabilidad esperada de sus empresas es mayor que en otros e identifican a las imperfecciones del mercado como las responsables de que se produzca esta situación. Según estos autores, las imperfecciones del mercado dependen de la estructura del mismo y, por tanto, no son el resultado de una decisión o acción de la empresa u organización. Por tanto, independientemente cuál sea el sector, si se quiere desarrollar una actividad en él resultará imprescindible conocer cuál es su estructura, tanto estática como dinámica, ya que ello proporcionará las bases para el éxito empresarial. 


\subsection{CONCEPTO DE SECTOR INDUSTRIAL}

Las primeras aproximaciones al concepto de sector industrial toman como base de definición las empresas que operan en el mismo y la actividad principal que realizan. Como razona Bueno (1996), si consideramos que efectivamente es relevante en la definición de un sector el tipo de actividad básica o primordial que llevan a cabo las empresas que en él operan, en su aplicación práctica podemos encontrarnos con el problema de que en un sector dado pueden coexistir empresas especializadas y empresas diversificadas, por lo que estas últimas "inflan" artificialmente el sector en que se clasifican, o con el problema de que las empresas diversificadas no aparecen clasificadas en los sectores en que desarrollan actividades secundarias.

Por ello, los grandes sectores se suelen dividir en subsectores, ramas de actividad o segmentos sectoriales. Una definición cerca de lo que puede ser un segmento sectorial es la propuesta por Hax y Majluf (1984) al entender que una industria puede ser definida como un grupo de empresas que ofrecen el mismo producto o servicio, o productos o servicios que son sustitutivos cercanos unos de otros. Según esta visión, lo relevante en la definición de un sector o segmento sectorial es que los productos o servicios que ofrecen las empresas sean capaces de desempeñar idéntica función y, por tanto, ser sustitutivos unos de otros. Sin embargo, en el caso de una empresa diversificada sería necesario saber la parte de su tamaño imputable a cada producto.

En la misma línea, Dalmau y Oltra (1997) defienden que la definición de sector industrial debe ser completa pero a la vez flexible, de manera que admita modificaciones conforme se vaya profundizando en el conocimiento del sector, y proponen entender un sector como un grupo de empresas cuyos productos tienen tantos atributos en común que compiten por los mismos compradores.

Michael Porter (1990) propone como definición operante de un sector (fabril o de servicios) un grupo de competidores que fabrican productos o prestan servicios y compiten directamente unos con otros. Un sector estratégicamente diferenciado comprende productos o servicios en los que las fuentes de ventaja competitiva son similares.

Para Carús (2000), la delimitación de fronteras sectoriales, en cualquier caso, es una cuestión de grado, aunque advierte que definiciones excesivamente generalistas (como Banca, Automóvil o Turismo) no son estratégicamente significativas porque tanto la naturaleza de la competencia como las fuentes de ventaja competitiva varían mucho dentro de ellos.

Teniendo en cuenta todas las consideraciones anteriores, a la hora de delimitar lo más exactamente posible las fronteras del sector objeto de nuestro estudio, encontramos operativo definir las organizaciones que ofrecen productos o servicios que son sustitutivos cercanos unos de otros, compiten directamente unas con otras y cuyas fuentes de ventaja competitiva son similares, en función de la definición de negocio propuesta por Abell (1980) según la cual por negocio se entiende los productos y mercado de una empresa.

El sector o segmento sectorial de actividad en particular es el escenario donde las empresas ganan o pierden la ventaja competitiva. Además, su estructura y la cadena de valor de las empresas que lo constituyen están en fuerte interacción. La estructura de un sector industrial, por un lado, condiciona la composición de la cadena de valor de una empresa que opera en él y, por otro, es un reflejo de las cadenas de valor de los competidores.

Así, la estructura del sector determina las relaciones con proveedores y clientes que se reflejan tanto en la configuración de la cadena de valor de una empresa como en la manera en que se dividen los márgenes con clientes y proveedores, en lo que constituye el sistema de valor (Carús, 2000).

Por otra parte, el conjunto de las cadenas de valor de todos los competidores es la base para muchos elementos en la estructura del sector industrial. Las economías de escala y aprendizaje que ofrece un sector, por ejemplo, surgen de la tecnología empleada por los competidores en sus 
respectivas cadenas de valor. Los requisitos de capital para competir en un sector industrial son el resultado del capital requerido en las cadenas. Igualmente, la diferenciación en los productos del sector resulta de las formas en que los productos o servicios de las empresas competidoras son usadas en las cadenas de valor de los compradores.

Así, muchos elementos de la estructura de un sector industrial pueden ser diagnosticados analizando las cadenas de valor de competidores en dicho sector.

El sector de la educación virtual abarca servicios que van desde la capacitación estructurada en cursos pequeños e independientes hasta la formación en postgrados. Este amplio espectro tiene como efecto que los competidores existentes varíen desde microempresas que imparten un cursillo repetidas veces hasta grandes instituciones de educación como son las universidades nacionales y extranjeras; de forma tal que en este mercado coexisten grandes grupos competitivos cuyos integrantes son similares entre sí, pero que tienen diferencias notorias con otros competidores pertenecientes a otros grupos competitivos. El método de identificación del competidor basado en la propuesta de Chen (1996) que se estudiará en un epígrafe posterior servirá para descubrir cuáles son los competidores más directos y que más pueden erosionar la ventaja competitiva de la institución. En cualquier caso, nuestro análisis se centrará en las instituciones de formación superior.

En este aspecto, las Instituciones de formación superior, imparten cursos de formación superior, sin perjuicio de que aprovechar la tecnología y/o infraestructura instalada para impartir cursos de capacitación de menor envergadura, pero que no constituyen su razón de ser principal, sino sólo ingresos marginales (y además, se enmarcan dentro de la educación continua que les corresponde apoyar).

Acotado entonces el campo, este análisis está enfocado a considerar y tener en cuenta al momento de implementar un programa de educación virtual, todas las fuerzas que pueden afectar al organismo que trabajará con este modelo de educación a distancia.

\subsection{SELECCIÓN DE UN MODELO DE ANÁLISIS SECTORIAL}

La literatura sobre estrategia proporciona un amplio abanico de herramientas para el análisis de la dinámica competitiva. Sin ánimo de ser exhaustivos, citaremos las siguientes (Furrer y Thomas, 2000):

- Teoría de juegos (Camerer, 1991; Dixit y Nalebuff, 1991)

La teoría de juegos consiste en el análisis del comportamiento racional en situaciones que implican la interdependencia de objetivos y resultados (Camerer, 1991) y es especialmente útil para predecir las reacciones de una organización a los movimientos competitivos de otras organizaciones (Oster, 1999). Von Neuman y Morgenstern (1944) distinguieron dos tipos de juegos: por un lado, los basados en reglas, en los que los actores se comportan según un conjunto de principios establecidos como contratos o acuerdos comerciales (Brandenburger y Nalebuff, 1995); y los juegos libres, en los que los actores interaccionan sin ningún tipo de restricción. En general, los negocios son una compleja mezcla de ambos tipos.

Cuando el entorno es predecible y el número de variables implicadas no es muy grande, los juegos basados en reglas constituyen la mejor herramienta de análisis de la dinámica competitiva (Furrer y Thomas, 2000).

En este contexto, la teoría de juegos ha sido empleada por numerosas empresas para tomar decisiones acerca de aspectos de marketing, capacidad de expansión, adquisiciones, etc. (Oster, 1999). Sin embargo, su utilidad está limitada por restricciones como la racionalidad de los actores o la posibilidad de identificar todos los movimientos competitivos de cada uno de ellos. Si se violan estos supuestos, particularmente si el número de actores es demasiado grande, las variables implicadas tienen un ámbito demasiado amplio o el entorno no es predecible, es aconsejable emplear otras herramientas. 
- Análisis de escenarios (Wack, 1985a, b; Schoemaker, 1991, 1993, 1995), modelos de simulación y modelos de sistemas dinámicos (Morecroft, 1984; Warren, 1995, 1999)

Cuando el entorno es impredecible y únicamente hay implicadas pocas variables de decisión, los escenarios, las simulaciones y el modelado dinámico del sistema ayudan a identificar posibles estrategias y predecir sus resultados. Dadas la incertidumbre y la complejidad del entorno, estos modelos se centran más en la probabilidad de la evolución a largo de plazo de las variables que caracterizan dicho entorno que en los movimientos competitivos a corto plazo de los actores del mercado.

Los sistemas complejos, por naturaleza, son impredecibles y, por tanto, los modelos deben poner de manifiesto la existencia de relaciones no lineales y fuerzas ocultas que rijan el mercado en que se apliquen (Lengnick-Hall y Wolff, 1999). En general, todas estas técnicas se basan en el estudio de la interacción entre un número limitado de variables conocidas en situaciones de incertidumbre, interdependencia y complejidad. Por su parte, los escenarios se centran en la descripción alternativas futuras presentadas a modo de esquema o narración (Schoemaker, 1993), mientras que las simulaciones hace hincapié en las consecuencias de las distintas estrategias y, finalmente, el modelado de sistemas (Warren, 1995) emplea las realimentaciones y las redes que surgen entre las relaciones causa-efecto para analizar la interacción entre las variables bajo estudio.

A la hora de analizar la dinámica competitiva, estos tres tipos de herramientas evalúan la influencia de las variables de entorno en los movimientos de los competidores así como las repercusiones de los movimientos de los competidores en la estrategia de la organización.

- Modelos militares (von Clausewitz, 1911; Sun-Tzu, 1963, 1993)

Si el número de variables de decisión estratégicas es elevado pero el entorno es predecible, los modelos militares son los más adecuados para describir la dinámica competitiva del mercado.

Los modelos militares o estrategias de guerrilla (Kotler y Achrol, 1984; Lengnick-Hall y Wolff, 1999; Ries y Trout, 1986) están construidos sobre la analogía entre las estrategias militares y las estrategias de negocios y han utilizado como base el trabajo de estrategas militares como Sun-Tzu $(1963,1993)$ o von Clausewitz (1911). La lógica que se esconde tras estos modelos es que una organización puede llegar a ser mejor que sus competidoras si es capaz de desestabilizar la situación actual con rapidez y repetidamente con el fin de crear las condiciones que le sean más idóneas para competir (Lengnick-Hall y Wolff, 1999).

- Modelos de competencia multipunto (Karnani y Wernerfelt, 1985; D’Aveni, 1994; Chen, 1996)

Otro tipo de modelos de estrategia competitiva son aquellos que asignan probabilidades a los posibles movimientos de los competidores. Pertenecen a este tipo las aproximaciones de Karnani y Wernerfelt (1985), Chen y sus colaboradores (Chen, 1996; Chen y MacMillan, 1992; Smith et al., 1991), o D’Aveni (1994). Al considerarse el entorno estable, estos modelos se centran en los movimientos de los actores.

El modelo de Karnani y Wernerfelt (1985) sobre la competencia multipunto describe una situación en la que las organizaciones compiten entre sí simultáneamente en varios mercados y establece las condiciones que motivan a las empresas a entrar o atacar el mercado de otra empresa, a responder de una determinada manera a los ataques de otra organización y cómo se produce un nuevo equilibrio en el mercado como consecuencia de dichas interacciones.

Una de las principales aportaciones de este modelo fue que puso de manifiesto el hecho de que competir en varios mercados a la vez ofrece a las organizaciones mayor número de alternativas competitivas (Smith y Wilson, 1995), y en esas circunstancias, la gestión de los recursos puede reconfigurar el contexto competitivo (McGrath et al., 1998) y modificar la estructura competitiva que influye en los movimientos de las mismas (Baum y Korn, 1996).

Todos estos aspectos fueron recogidos por Chen y sus colaboradores (Chen, 1996; Chen y MacMillan, 1992; Smith et al., 1991) que asignaron una probabilidad a la respuesta de un competidor a un determinado movimiento competitivo. Esta probabilidad se basa en el 
supuesto de que el competidor es dependiente del mercado particular en que tiene lugar el movimiento competitivo en cuestión, del tipo de movimiento, de la reputación de la organización que lo lleva a cabo y de los recursos del competidor al que va dirigida.

El modelo de D’Aveni (1994), por otra parte, plasma la evolución de las industrias a través de una serie de ataques y contraataques que dan lugar a lo que define como interacciones estratégicas dinámicas. Puesto que las organizaciones atacan y contraatacan deben intentar conseguir destruir, neutralizar o inutilizar las ventajas competitivas de sus rivales. Este movimiento puede emplearse, por tanto, para aclarar el siguiente movimiento de una organización o para anticipar las próximas acciones de los competidores (D’Aveni, 1994).

- Utilización de marcos de trabajo (Porter, 1980; Hertz y Thomas, 1982; Thomas, 1984)

Los modelos vistos hasta ahora abstraen la complejidad de la competencia para aislar un conjunto reducido de variables cuyas interacciones se examinan en detalle, por lo que la validez de los resultados que proporcionan depende del grado de correspondencia entre las suposiciones que llevan a cabo y la realidad (Furrer y Thomas, 2000). Ningún modelo es capaz de abarcar absolutamente todas las variables de un entorno dado, por lo que, en última instancia, únicamente son aplicables a conjunto limitado de organizaciones o mercados que sí se ajustan a los supuestos de que dicho modelo parte (Porter, 1991).

En los entornos impredecibles, en los que existen múltiples variables de decisión, la complejidad asociada es demasiado grande como para establecer un modelo de competencia. En estos casos, es mejor centrarse en las variables y utilizar un marco de trabajo para identificar las más importantes y las relaciones entre ellas (Porter, 1980; Thomas, 1984).

Un marco de trabajo engloba gran cantidad de variables y busca capturar la complejidad de la competencia actual. La lógica subyacente a un marco de trabajo está contenida en la elección de las variables que incluye, el modo en que éstas se organizan, las interacciones entre ellas y la manera en que los distintos patrones de variables y las elecciones de las organizaciones afectan a los resultados (Porter, 1991). Uno de los marcos de trabajo más famosos es el modelo de fuerzas competitivas de Porter (1980) que, con alguna modificación, será tratado en detalle en apartados posteriores.

El principal problema que se plantea con estas herramientas es que, en general, han sido planteadas para analizar escenarios muy concretos, por lo que su utilidad suele estar limitada a situaciones similares a aquellas para las que fueron diseñadas (Porter, 1991). En Furrer y Thomas (2000) se clasifican todas estas herramientas en cuatro grandes grupos en función de dos variables que dan lugar a la matriz de rivalidad (ver Figura 44). Estas dos variables son:

- El número de variables de decisión: esta dimensión hace referencia al ámbito de la estrategia de manera que éste es tanto menor cuanto menor es el número de variables implicadas. A medida que la complejidad de la situación y el número de variables aumentan, resulta más difícil modelar los movimientos competitivos de los actores.

- El grado de incertidumbre del entorno: un entorno predecible se caracteriza porque las variables que lo describen o bien permanecen constantes o bien varían muy lentamente, sugiriendo que los cambios competitivos desembocan en situaciones evolutivas y no revolucionarias. Por otra parte, en un entorno impredecible se producen cambios drásticos que son imposibles o muy difíciles de prever, haciendo imposible la identificación del rango de alternativas estratégicas de todos los actores y el predecir el resultado de cada una de ellas.

Combinando estas dos dimensiones Furrer y Thomas (2000) definen la matriz de rivalidad cuyo objetivo es proporcionar el tipo de herramienta más adecuada a las características del entorno competitivo, dados el número de variables de decisión y el grado de incertidumbre de dicho entorno. 
VARIABLES DE DECISIÓN

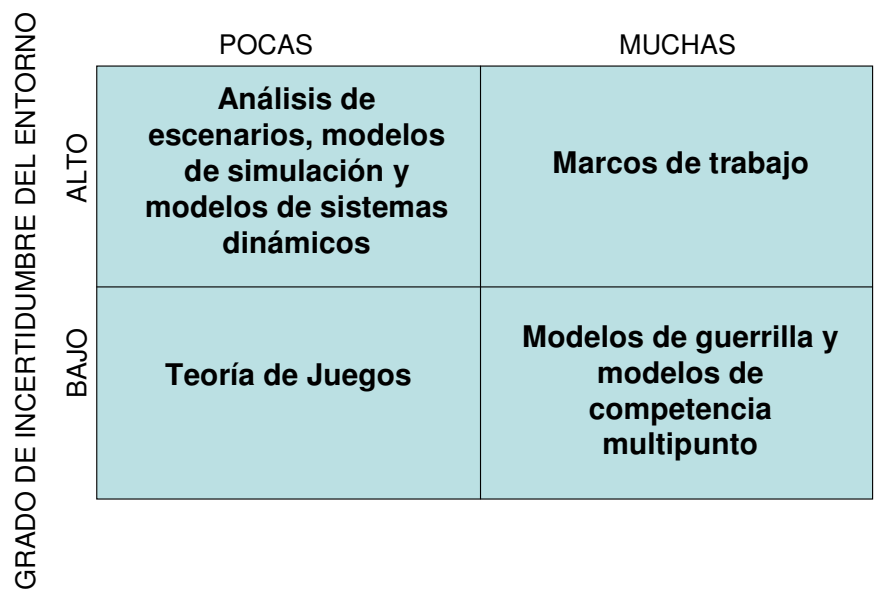

Fuente: modificado de Furrer y Thomas (2000).

Figura 44. Matriz de rivalidad.

El problema ahora es, pues, seleccionar un marco de análisis para el sector de la Educación Superior válido para un entorno virtual, por lo que habrá que determinar cuáles son las características del mercado de la Educación Superior como tal.

Desde el punto de vista económico, el mercado de la Educación Superior es un mercado fuertemente jerárquico compuesto por organizaciones con unas características muy concretas (Hansmann, 1980, 1990):

- Poseen recursos procedentes de fuentes no convencionales que alteran el rol de los ingresos por venta y las estrategias de fijación de precios (Winston, 2000).

- Su proceso de producción se caracteriza porque la calidad principal del insumo (los estudiantes egresados) son a la vez parte del producto o servicio que vende la Universidad (Rothschild y White, 2003).

- Su misión, visión y valores están orientadas a maximizar el prestigio por encima de la ganancia (Winston, 2003).

Por otra parte, y desde el punto de vista sociológico, la competencia en la Educación Superior presenta un marcado carácter posicional (Brunner y Uribe, 2007), en el que los consumidores escogen una universidad en función de las ventajas o beneficios sociales asociados al prestigio de las titulaciones emitidas por dicha Universidad.

Teniendo en cuenta esta caracterización de la Educación Superior, es posible afirmar que se encuentra en la frontera entre las aproximaciones de competición multipunto (la oferta formativa de las Universidades suele abarcar varias áreas de conocimiento) y los marcos de trabajo puesto que existen múltiples variables de decisión y, por otra parte, el entorno es moderadamente impredecible. Por todos estos motivos, en esta tesis se propone emplear un marco de trabajo que permita conocer la estructura del sector y que, complementado con un modelo de competencia multipunto, permita identificar a los competidores directos a partir del estudio de la dinámica del sector. 


\subsection{ANÁLISIS ESTRUCTURAL}

Como señala Porter (1980), el análisis estructural del sector es un soporte fundamental para formular la estrategia competitiva. Este análisis competitivo de la institución consiste en relacionarla con su entorno competitivo. La aplicación del modelo de fuerzas competitivas consigue una valoración de las fuerzas relativas entre los diversos agentes que participan en el mercado dentro del que se desarrollará el negocio y trata de comprender la estructura del mercado en que se está compitiendo y las razones que determinan dicha estructura. Para el autor, dicho análisis tiene como base el estudio de las conocidas cinco fuerzas competitivas (clientes actuales, clientes potenciales, presión de productos o servicios sustitutivos, poder negociador de los clientes y poder negociador de los proveedores) que configuran la estructura básica de un sector industrial y que determinan su rentabilidad a largo plazo. La competencia en un sector depende de la posición relativa de estas fuerzas y de su interacción y resulta evidente que supera a la simple competencia entre los competidores existentes (Carús, 2000).

Por otra parte, es necesario tener presente que el signo de las fuerzas competitivas enumeradas, que como veremos a continuación, depende de un amplio número de factores estructurales ya que, como advierte Porter (1980), no todas ellas son relevantes en todos los sectores. Por tanto, el marco teórico propuesto debe ser utilizado para identificar rápidamente sólo aquellas características estructurales clave que determinan la naturaleza de la competencia en un sector o segmento sectorial particular.

El diagnóstico del atractivo del sector, mediante el estudio de sus elementos estructurales, sólo es el punto de partida para la organización que trata de conseguir alguna ventaja competitiva con carácter de perdurabilidad. Como señala Ballarin (1985), el análisis singuralizado del propio caso particular es una tarea ineludible para ello. Cada organización debe plantearse alcanzar unos costes suficientemente bajos o si, por el contrario, va a tratar de competir a través de una estrategia de diferenciación.

Para Dalmau y Oltra (1997), el primer paso en el análisis sectorial consiste en decidir qué aspectos serán objeto de la investigación y para qué. En general, el objetivo del análisis sectorial es tener un conocimiento profundo y de conjunto de los datos económicos del sector, entre los que cabe destacar (Dalmau y Oltra, 1997):

- Tamaño del mercado.

- Ámbito de rivalidad.

- Tasa de crecimiento del mercado y posición del sector en su ciclo de vida.

- Número de competidores y sus tamaños relativos.

- Número de compradores y sus tamaños relativos.

- La prevalencia de la interacción hacia atrás o hacia delante.

- Facilidad de entrada y salida.

- Ritmo de cambio tecnológico, tanto de innovación en procesos productivos como en la introducción de nuevos productos.

- Si los productos de las firmas rivales son muy diferenciados o esencialmente idénticos.

- Nivel de presencia de las economías de escala en fabricación, transporte o ventas.

- Si son necesarios unos niveles altos de utilización de la capacidad para conseguir una producción eficiente a bajo coste.

- Si la industria tiene una fuerte curva de experiencia o no.

- Requerimientos de capital. 
- Si la rentabilidad del sector está por encima o por debajo de lo normal.

- El ciclo de vida del sector también debe ser tenido en cuenta.

Porter (1980) establece los siguientes elementos estructurales a la hora de abordar el análisis estratégico de cualquier sector industrial:

- Competencia actual

- Competencia potencial

- Poder negociador de los proveedores

- Poder negociador de los clientes

- Amenaza de productos o servicios sustitutivos

Dadas las características especiales del sector de la Educación Superior, y de la Educación en general, completaremos este marco con la inclusión de poder negociador del Estado, como manifestación del grado de influencia que las actuaciones gubernamentales pueden tener sobre el sector de la Educación.

Por otra parte, para caracterizar la competencia emplearemos el modelo de rivalidad propuesto por Chen (1996) y que, a partir del cálculo de dos parámetros (contacto multimercado y similitud en recursos), permite clasificar a los competidores en actuales y potenciales, así como subrayar su carácter más o menos peligroso.

\subsubsection{Rivalidad e identificación del competidor}

La esencia de la dinámica competitiva es que los competidores responden a movimientos competitivos (estímulos) solamente si tienen conciencia de dichos movimientos, si están motivados para responder al o los movimientos en cuestión y si son capaces de llevar a cabo una respuesta (Chen et al., 1992). De acuerdo con esta definición, son tres los motores del comportamiento competitivo: conciencia, motivación y capacidad. La carencia de alguno de estos tres elementos casi con toda probabilidad resultará en una falta de respuesta o en una respuesta ineficiente al movimiento competitivo.

Los investigadores de la dinámica competitiva suelen considerar motivación y capacidad como dos factores casi sinónimos puesto que están estrechamente ligados (Gimeno, 1999). De hecho, la puesta en marcha de cualquier movimiento competitivo exige la presencia de ambas. Igualmente, Nelson y Winter (1982) también emplean explícitamente estos dos factores en su teoría sobre el cambio económico.

La motivación hace referencia a los incentivos que dirigen a una organización a tomar un determinado movimiento o acción competitiva (Smith et al., 2001). Las investigaciones sobre dinámica competitiva asumen que las acciones competitivas óptimas están motivadas por los beneficios para la organización a nivel global. Como Smith et al. (2001) resumen, la motivación está relacionada con las ganancias y las pérdidas percibidas, las cuales se derivan de la creencia de si se generarán ventajas de las acciones o si el no tomar ninguna acción conllevará una pérdida.

Por otra parte, la capacidad se interpreta como la centralización de una percepción de la estrategia y la implementación, en línea con la definición tradicional de gestión estratégica (Barney, 1986; Barney y Arikan, 2001). Si los recursos o capacidades exigidos para percibir e implantar una acción estratégica no están al alcance de la organización, ésta debe retrasar e incluso abandonar su puesta en marcha, tal y como aconsejan la teoría de recursos (Barney, 1991; Peteraf, 1993) y la teoría de la capacidad competitiva (Makadok, 2001; Teece, Pisano, y Shuen, 1997).

La dinámica competitiva es, por tanto, el resultado de una serie de acciones competitivas y respuestas competitivas entre las organizaciones de una industria en particular (Hitt, 2003). La importancia de conocer la dinámica competitiva de un sector industrial (en nuestro caso, el elearning en la formación universitaria) es relevante para una organización que se encuentra en éste 
porque le permite predecir posibles respuestas de la competencia y, por tanto, prevenir los efectos de sus acciones.

Con el fin de explicar la dinámica competitiva, Chen (1996) propuso el modelo de la Figura 45. En este modelo se explica cómo se llega a la dinámica competitiva de una industria pasando de las competidoras, los motivos para competir, cómo compiten y exponiendo el posible resultado.

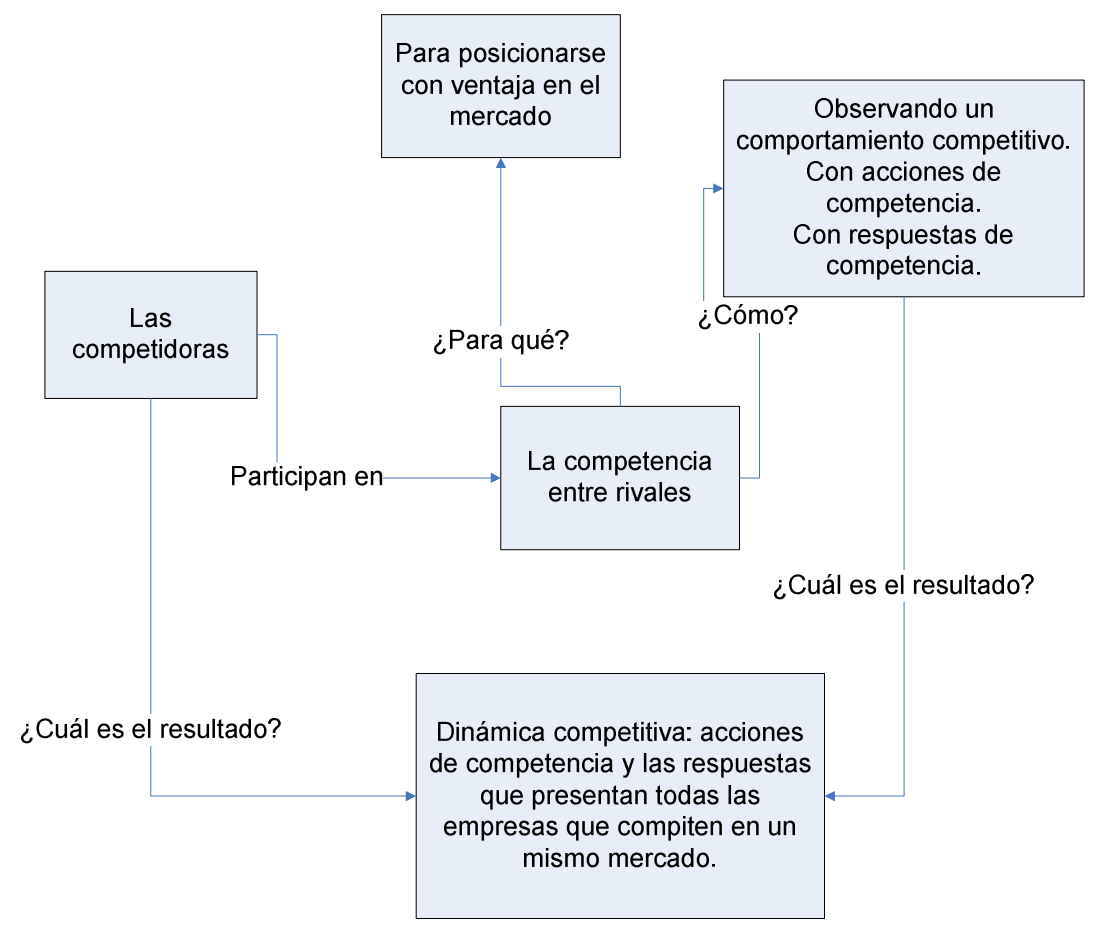

Fuente: adaptado de Chen (1996).

\section{Figura 45. Dinámica competitiva.}

A partir de este modelo de rivalidad, en este trabajo el principal propósito es ofrecer una descripción de la situación competitiva ante la que se encuentran las instituciones del mercado del e-learning que permita identificar a los principales competidores de cada una de ellas y realizar inferencias sobre la tensión competitiva que perciben. Para ello, se partirá de la línea propuesta por Chen (1996) y que se basa en la utilización del contacto multimercado (Edwards, 1955; Bernheim y Whinston, 1990) y de la similitud en recursos (Caves y Porter, 1977). Otra de las aportaciones de Chen (1996), además de la posibilidad de identificar al competidor, es que permite realizar una medición de la tensión competitiva entre cada par de organizaciones. Como se verá en un epígrafe posterior, la aplicación del método de análisis propuesto por Chen (1996) ofrece una visión clara de las relaciones entre los participantes en un sector industrial y ayuda a dibujar el mapa competitivo de cada entidad.

La rivalidad entre organizaciones puede definirse como el conjunto de acciones de competencia y las respuestas que presentan dichas organizaciones cuando compiten entre sí para posicionarse con ventaja en el mercado (Hitt, 2003). Chen (1996) propone un modelo de rivalidad basado en la identificación del competidor, cuya incorporación a los modelos de análisis estratégico de sectores industriales relacionados con el e-learning constituye una de las aportaciones de esta tesis. 


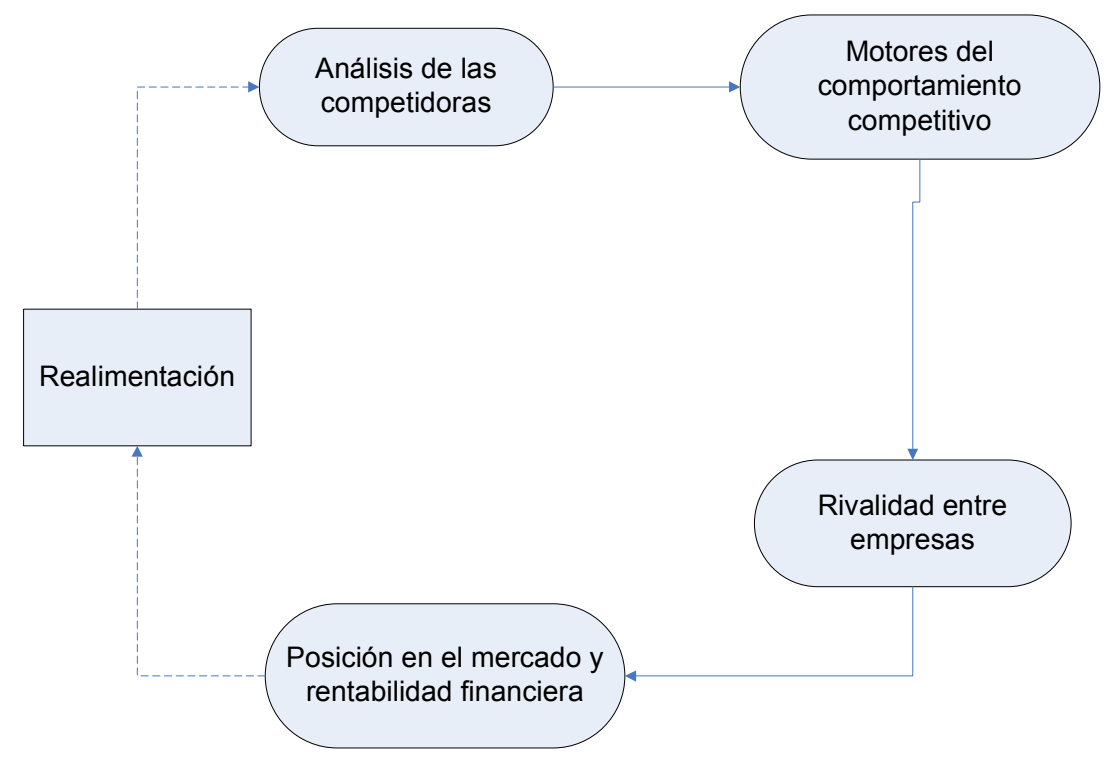

Fuente: adaptado de Chen (1996).

Figura 46. Modelo de rivalidad.

La identificación de los rivales con los que compite una determinada organización ha sido objeto de estudio recurrente, tanto desde el punto de vista académico como empresarial. La práctica más frecuente desde la economía ha consistido en calificar como competidores a todas las organizaciones participantes en una industria, definida a partir de aspectos como el grado de sustituibilidad de los productos o servicios, la tecnología utilizada en su producción o sus características. La gestión de organizaciones ha optado por aproximaciones basadas en los productos y mercados en los que opera la organización (Ansoff, 1965) o criterios similares, como el propuesto por Abell (1980) y que define un negocio según tres dimensiones: la necesidad del consumidor que se satisface, los mercados atendidos y la tecnología empleada para ello.

La identificación del grado de rivalidad en un sector industrial ha partido, en muchas ocasiones, del análisis del competidor. No obstante, la mayor parte de los estudios se basan en índices agregados (Herfindahl, cuota de mercado de las n mayores organizaciones, etc.) que no tienen en cuenta ninguna medida de rivalidad y que consideran que ésta es idéntica para toda las organizaciones que compiten en el sector en cuestión.

Por otra parte, las aproximaciones realizadas hasta el momento acerca de la identificación del competidor y del análisis de la rivalidad han hecho especial énfasis en la identificación de características estructurales del sector, dejando escaso margen de intervención sobre el comportamiento del mismo a las organizaciones que participan en él y para la consecución de una ventaja competitiva (Fuentelsaz et al., 2002). Tampoco se han encontrado en la literatura sobre dirección estratégica, estudios acerca de la rivalidad entre organizaciones en sectores industriales y, mucho menos, en el sector del e-learning por ser éste uno de relativa juventud. No obstante, existen trabajos realizados desde la perspectiva de la Teoría de Recursos que, tomando como unidad de análisis a la organización, concluyen que la obtención de una ventaja competitiva sostenible puede basarse en la capacidad de la organización para desarrollar recursos valiosos y difíciles de imitar o reemplazar por parte de sus competidores (Barney, 1991). Sin embargo, estos análisis suelen omitir la importancia que el ambiente externo a la organización tiene en el comportamiento competitivo de la organizaciones (Fuentelsaz et al., 2002) y que, según Priem y Butler (2001), es el mercado en donde indirectamente se genera el valor de los recursos.

En los últimos años, no obstante, se ha producido un notable progreso en el estudio de la identificación del competidor y de la rivalidad competitiva. En el primer caso, estudios comos los de Chen (1996) o Bergen y Peteraf (2002) reconocen la importancia de la realización de análisis detallados de la situación competitiva de cada organización, mientras que en el segundo caso, los 
trabajos existentes sugieren centrar el estudio de la rivalidad en la observación de los movimientos competitivos ofensivos y defensivos desarrollados por las organizaciones (Smith et al., 1992; Porter, 1980). Es, precisamente, este segundo aspecto (la identificación del competidor) el que atrae nuestra atención en este trabajo.

La originalidad del trabajo de Chen (1996), y que justifica su utilización en esta tesis, radica en que aborda el estudio de la rivalidad a partir de la consideración de dos parámetros: el contacto multimercado y la similitud en recursos. Sin embargo, este enfoque ya fue puesto de manifiesto en otros trabajos (Porter, 1979; Gimeno y Woo ,1996; Young et al., 2000; Caves y Porter, 1977; Bergen y Peteraf, 2002 y Chen, 1996).

La relación entre el contacto multimercado y la similitud de recursos puede representarse de manera gráfica (ver Figura 47). Cuanto mayor sea el área sombreada, tanto mayor será la rivalidad entre empresas. Empresas con recursos similares y/o un grado de contacto multimercado alto tomarán conciencia de las interdependencias existentes entre ellas y se reconocerán como competidores próximos. Nótese que la mayor tensión competitiva se produce cuando el contacto multimercado y la similitud en recursos son elevados.

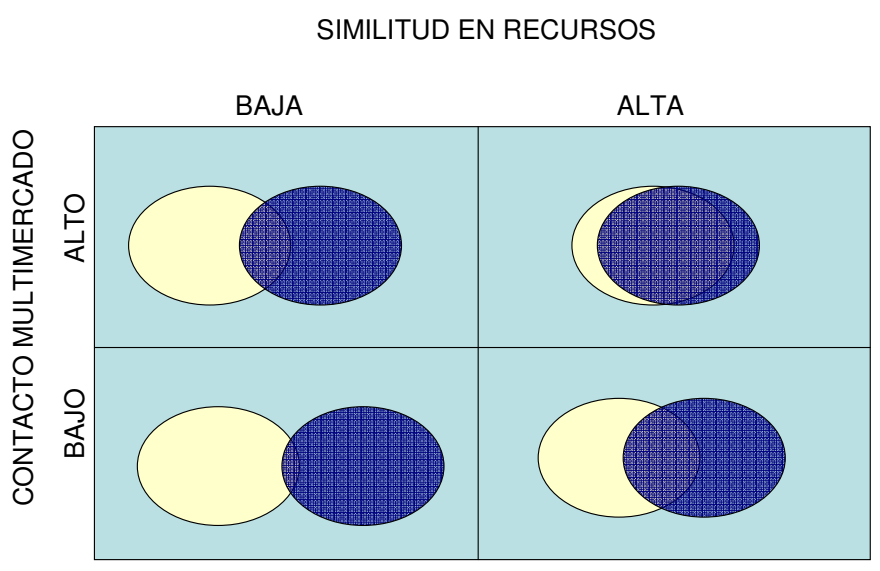

Fuente: elaboración propia.

Figura 47. Relación entre el contacto multimercado y la similitud en recursos.

Una de las originalidades del trabajo de Chen (1996) es que el autor subraya que la rivalidad debe concebirse como una propiedad característica de cada par de empresas, definiendo el concepto de asimetría competitiva, es decir, que la posición relativa entre dos competidores no tiene por qué ser la misma en ambos sentidos de la relación.

La medición de ambos conceptos para las organizaciones de un sector concreto permite identificar, para cada competidor, aquellos rivales con los que existe una mayor dependencia mutua y, por tanto, una tensión competitiva mayor.

En los epígrafes siguientes se estudian con más detalle el cálculo del contacto multimercado y la similitud en recursos y cómo interpretar los resultados del análisis.

\subsubsection{CONTACTO MULTIMERCADO}

En los últimos años han proliferado trabajos que emplean el contacto multimercado para explicar la competencia entre organizaciones, tanto teóricamente (Bernheim y Whinston, 1990; 
Spagnolo, 1999; Matsushima, 2001) como empíricamente (Baum y Korn, 1996, Haveman y Nonnemaker, 2000; Gimeno, 2002).

La revisión de la literatura sobre contacto multimercado indica que la compentencia mutua entre organizaciones en distintos mercados puede reducir la intensidad de la rivalidad entre ellas (Edwards, 1955). Para explicar este fenómeno se suelen señalar dos causas (Fuentelsaz et al., 2002):

1. El comportamiento competitivo agresivo puede acarrear pérdidas

En esta línea argumental, se suele subrayar el efecto de las represalias de las organizaciones atacadas en alguno de los mercados en que compiten. Es decir, si una organización se ve amenazada en un mercado por alguna competidora que compite también entre otros mercados, la primera puede que trate de defender su posición simultáneamente en todos los mercados en que compiten o en algún mercado distinto a aquel en el que se recibió el ataque. De este modo, las posibles ganancias de un ataque en un determinado mercado podrían verse compensadas por las pérdidas derivadas de las represalias del competidor en otros mercados comunes entre ambas organizaciones (Porter, 1980). Este último efecto puede acentuarse cuando las posiciones competitivas de las organizaciones son asimétricas y la represalia tiene lugar en mercados en los que el atacante tiene una posición valiosa (Karnani y Wernerfelt, 1985).

2. Tolerancia competitiva por el aumento del conocimiento mutuo

El hecho de que varias organizaciones coincidan simultáneamente en más de un mercado puede tener como consecuencia un aumento de la tolerancia competitiva como consecuencia del mayor grado de conocimiento mutuo (Scott, 1982), tanto es así que pueden establecerse mecanismos de comunicación entre ellas que desemboquen en algún tipo de cooperación (Scott, 2001). Boeker et al. (1997), en misma línea que Scott (1982, 2001), indican que esta transmisión de información estratégica sobre los competidores permite una mejor comprensión de las relaciones entre ellos y de las reacciones a ataques competitivos mutos.

Los resultados empíricos obtenidos confirman la existencia de este efecto negativo del contacto multimercado sobre la rivalidad entre organizaciones en aspectos como la entrada en nuevos mercados (Baum y Korn, 1996), el crecimiento de la empresa (Haveman y Nonnemaker, 2000), la influencia en los precios (Parker y Roller, 1997, Evans y Kessides 1994) o los resultados (Scott 1982, Gimeno y Woo, 1996), incluso en aquellos casos en los que la coincidencia en los dominios de mercado de las organizaciones se produce de forma aleatoria (Gimeno, 2002).

Sin embargo, la literatura de ecología de las poblaciones (Hannan y Freeman, 1977) señala que la coincidencia de varias organizaciones en distintos mercados intensifica la rivalidad entre dichas organizaciones. Algo que parece lógico, si se tiene en cuenta que la competencia es la lucha de las organizaciones por ocupar una posición en el mercado (Scherer, 1980; Hitt, 2003). Por otra parte, la idea que subyace a estos modelos es que, al ser los recursos del entorno limitados, la coincidencia de varias organizaciones en su consumo debe llevar, al menos potencialmente, a un incremento de la rivalidad.

Por tanto, si se consideran conjuntamente estas dos visiones, se concluye que los efectos del contacto multimercado sobre la rivalidad son indeterminados (Fuentelsaz et al., 2002). Pese a esta imposibilidad de extracción de conclusiones tajantes acerca de la repercusión del contacto multimercado sobre la rivalidad, sí que se pone de manifiesto su importancia en la identificación del competidor: por un lado, el contacto multimercado determina con qué organizaciones existirá una mayor interrelación en el mercado (Porter, 1979); y, por otro, dichas interrelaciones aumentan la identificación como tales de los rivales de una organización. Por tanto, el empleo del contacto multimercado en la identificación del competidor queda justificado. 
Ahora el problema se traslada a cómo medir el contacto multimercado. Chen (1996) en su propuesta, señala la importancia de contemplar dos aspectos en el cálculo de este índice:

- La importancia del mercado para la organización, puesto que no a todos mercados se les otorga la misma relevancia por parte de la misma.

- La magnitud relativa de la presencia de la organización en el mercado en el que existe la coindencia.

Teniendo en cuenta estas dos consideraciones, el contacto multimercado de la organización $b$ respecto a la organización $a, M_{a b}$, a través de la siguiente expresión:

$$
M_{a b}=\sum_{i=1}^{n} \frac{P_{a i}}{P_{a}} \cdot \frac{P_{b i}}{P_{b}}
$$

donde $M_{a b}$ es la importancia del contacto multimercado de la empresa $b$ con la entidad $a$ (o presión competitiva ejercida por $b$ sobre $a$ ), $P_{a i}$ la presencia de $a$ en el mercado $i, P_{a}$ es la actividad de la empresa $a$ en todos los mercados en los que participa, $P_{b i}$ recoge la presencia de $b$ en el mercado $i$ y $P_{b}$ es su volumen total de actividad en ese mercado. De este modo, $P_{a} / P_{a}$ indica la importancia del mercado $i$ para la entidad $a$, mientras que $P_{b i} / P_{b}$ sugiere la participación de la empresa $b$ en el mercado $i$.

De la expresión anterior se deduce la posibilidad de que exista asimetría en la relación entre el contacto multimercado entre dos organizaciones debido a que la presión competitiva ejercida por $b$ hacia la organización $a$, en principio, no tiene por qué coincidir con la ejercida por $a$ sobre $b$.

\subsubsection{SIMILITUD EN RECURSOS}

La similitud en recursos se refiere al grado de parecido en los competidores que poseen recursos del mismo tipo y en la misma cantidad (Chen, 1996). Aunque son varios los trabajos existentes en la literatura tradicional acerca de la importancia de los recursos en el estudio de la rivalidad entre organizaciones (Caves y Porter, 1977; Porter, 1979; Peteraf, 1993a), algunos estudios más recientes coinciden en señalar la importancia de los recursos a la hora de imitar el comportamiento competitivo de los rivales y responder más rápidamente a los ataques recibidos por su parte (Bergen y Peteraf, 2002; Young et al., 2000).

En cuanto a las condiciones que deben cumplirse en el cálculo del índice de similitud en recursos, son análogas a las comentadas para el contacto multimercado. De hecho, la expresión empleada para la obtención de la similitud en recursos de la organización $b, R_{a b}$, con la $a$ es muy similar:

$$
R_{a b}=\sum_{i=1}^{n} \frac{R_{a i}}{R_{a}} \cdot \frac{R_{b i}}{R_{b}}
$$

donde $R_{a i}$ es la cantidad total del recurso $i$ que posee la organización $a, R_{a}$ la cantidad total de recursos que posee, $R_{b i}$ es la cantidad total del recurso $i$ que posee $b$. Por tanto, $R_{a i} / R_{a}$ representa la importancia del recurso $i$ para la entidad $a$ y $R_{b i} / R_{b}$ la proporción del recurso $i$ que posee la empresa $b$ en relación a la cantidad total de dicho recurso utilizada en el sector.

El problema en el caso de la similitud en recursos radica en la identificación y medición de los recursos empleados por cada organización, a diferencia de lo que ocurre con el contacto multimercado en donde resulta relativamente sencillo determinar la presencia de una organización en un mercado dado (por ejemplo, empleando como indicador de la misma su cuota de mercado). En efecto, la identificación de los recursos capaces de generar ventajas competitivas no es una tarea sencilla, hasta tal punto que algunas organizaciones son incapaces de hacerlo. Esta situación suele dar cuando la ventaja competitiva sustenta sobre tareas y procedimientos rutinarios (Lipman y Rumelt, 1982, Henderson y Cockburn, 1994). 
Una aproximación para superar siquiera parcialmente estos problemas consiste en utilizar los recursos productivos empleados en la generación de los programas formativos, los destinados a la acción docente on-line y aquellos utilizados para el soporte a los estudiantes.

\subsubsection{INTERPRETACIÓN DE LOS RESULTADOS}

Una vez que ya se dispone de la información necesaria para calcular el contacto multimercado y la similitud en recursos para los competidores de una determinada organización, el paso siguiente es construir un gráfico como el de la Figura 48 para cada entidad.

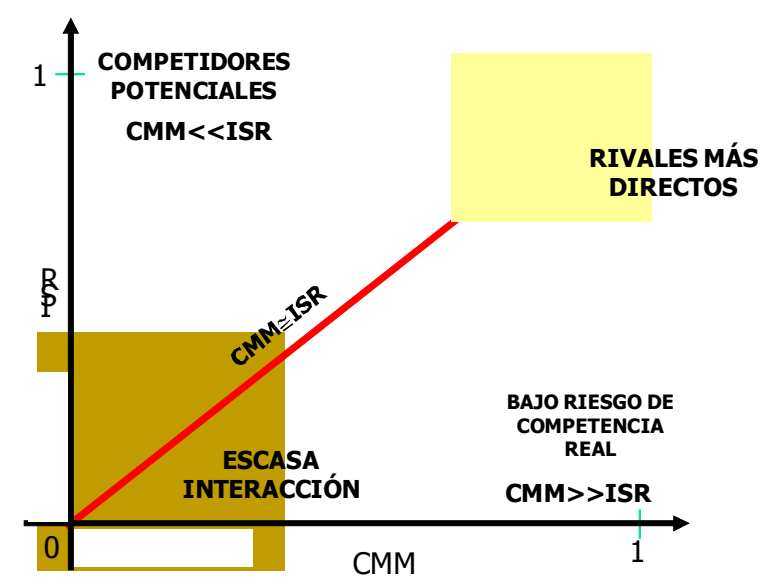

Fuente: elaboración propia.

Figura 48. Interpretación de los resultados.

A partir de esta representación gráfica resulta relativamente sencillo distinguir entre tres zonas:

\section{1. $\mathrm{CMM \cong ISR}$}

En la diagonal de la gráfica se encuentran todas las organizaciones que presentan igual contacto multimercado (CMM) e igual índice de similitud en recursos (ISR), tanto en valores bajos como en valores elevados.

Los rivales más importantes serán aquellos que, estando en la diagonal, se situarán en la parte superior derecha, siendo las organizaciones con las que apenas existe relación las que se ubiquen en la parte inferior izquierda.

2. $\mathrm{CMM}>\mathrm{ISR}$

Una organización situada en esta zona presenta un alto contacto multimercado con la organización bajo estudio pero, simultáneamente, una baja similitud en recursos, lo que indica que, a pesar de coincidir en varios mercados sus estrategias deben ser diferentes, habida cuenta de las diferencias en las dotaciones de recursos.

3. $\mathrm{CMM}<\mathrm{ISR}$

Las organizaciones situadas en esta zona representan una amenaza potencial para la organización bajo estudio, ya que, a pesar de que no existe una coincidencia en los mercados en los que operan, se trata de organizaciones de características muy similares y en un futuro podrían convirtirse en competidores directos.

\subsubsection{CORRECCIONES NECESARIAS}

Sin embargo, el enfoque anterior adolece de una limitación y es que no considera las características particulares del sector de la Educación Superior ni las del e-learning. Por ello, se hace necesaria la introducción de parámetros correctores que le pongan remedio a esta situación.

El primero de los factores correctores, y que aplicará sobre el contacto multimercado como se verá más adelante, es la orientación disciplinar. Este parámetro se calcula con el objetivo de 
determinar el grado de especialización de cada universidad, se ha calculado un índice en base al número de titulaciones, modificando el planteamiento propuesto en Moreno (2005), según la expresión:

$$
C E_{j}=\frac{1}{2} \cdot \sum_{i=1}^{h}\left|\frac{x_{i j}}{x_{j}}-\frac{x_{i}}{x}\right|
$$

Donde $x_{i j}$ es el número de titulaciones ofrecidas por la Universidad $j$ en la rama $i$, en $x_{j}$ es el número de titulaciones ofrecidas por la Universidad $j, x_{i}$ es el número de titulaciones de la rama $i$ del conjunto de Universidades y $x$ es el total de titulaciones ofrecidas por las Universidades. Cuanto más próximo a la unidad esté el valor de este coeficiente, tanto mayor será el grado de especialización de la Universidad de que se trate.

A partir de esta expresión es posible obtener el coeficiente de especialización por ramas como la parte de la expresión anterior correspondiente al valor absoluto de cada uno de los términos del sumatorio:

$$
C E_{a i}=\left|\frac{x_{a i}}{x_{a}}-\frac{x_{i}}{x}\right|
$$

$\mathrm{Su}$ efecto es el de ponderar la importancia relativa de cada rama de conocimiento, del tal modo que el contacto multimercado pasa a calcularse a través de la fórmula:

$$
C M M_{a b}=\sum_{i=1}^{n}\left(C E_{a i} \cdot \frac{P_{a i}}{P_{a}}\right) \cdot\left(C E_{b i} \frac{P_{b i}}{P_{b}}\right)
$$

Por otra parte, la utilización intensiva de las TIC (Tecnologías de la Información y las Comunicaciones) aplicadas a la docencia que supone el e-learning, va a determinar la importancia de éstas y de la inversión en bienes tecnológicos, observándose un desplazamiento desde los bienes tradicionales (más basados en infraestructuras físicas) hacia los bienes tecnológicos. Además, a luz de lo que parecen estar haciendo las Universidades actuales respecto a la introducción de las TIC a nivel institucional, parece conveniente introducir un factor que exprese el compromiso de cada institución con la implantación de un campus virtual. Todo esto lo hemos conseguido mediante un coeficiente institucional que pondera la importancia de los recursos estratégicos en el cálculo del índice de similitud en recursos. De este modo, la expresión que proporciona el índice de similitud en recursos en dos organizaciones quedaría como:

$$
I S R_{a b}=\sum_{i=1}^{n}\left(c_{a} \cdot \frac{R_{a i}}{R_{a}}\right) \cdot\left(c_{b} \cdot \frac{R_{b i}}{R_{b}}\right)=c_{a} \cdot c_{b} \sum_{i=1}^{n}\left(\frac{R_{a i}}{R_{a}}\right) \cdot\left(\frac{R_{b i}}{R_{b}}\right)
$$

\subsubsection{Competencia actual}

El competidor inmediato de una universidad virtual son las universidades tradicionales. De hecho, algunas de ellas están incorporando elementos de virtualidad con el fin de atraer y retener estudiantes (Alexander, 2001; Ryan et al, 2000; Bates, 1997; Collis y Moonen, 2001). Estas entidades, dadas las características de la educación a distancia, pueden estar ubicadas en cualquier lugar del país o del mundo.

En general, la existencia de un cierto grado de rivalidad entre competidores del sector da origen a movimientos competitivos de carácter ofensivo y defensivo bajo un modelo o patrón de acción y reacción que puede acabar dejando a la empresa que tomó la iniciativa, y al propio sector en general, en una situación más o menos favorable que aquella de la que se partía. La intensidad de la competencia entre las empresas que componen el sector depende del tipo de competencia, 
los elementos susceptibles de generar una ventaja competitiva (que se estudiarán en el capítulo 7) y las barreras a la movilidad y de salida (Carús, 2000).

\subsubsection{TIPO DE COMPETENCIA}

El tipo de competencia en un sector industrial está configurada por factores estructurales de dicho sector (Carús, 2000). En este trabajo se propone utilizar el número y el tipo de instituciones, la caracterización de la oferta formativa, la relación entre la oferta y la demanda y la relación entre la oferta y la matrícula.

\subsection{Número y tipo de instituciones}

En general, cuando las organizaciones integrantes de un sector son de distinta naturaleza, tienen objetivos diferentes o no siguen estrategias similares para alcanzarlos, la rivalidad competitiva se ve incrementada gracias la dificultad de identificar una pauta que explique el comportamiento competitivo de las mismas.

El número y el tipo de organizaciones que forman parte del sector del e-learning resulta harto difícil de establecer debido a la diversificación de actividades característica del sector (AEFOL, 2003). En efecto, el sistema de valor del e-learning ${ }^{19}$ es suficientemente flexible como para dar cabida a las más variadas combinaciones de actividades y ello hace imposible obtener una cifra exacta de empresas dedicadas a este sector industrial.

Una posibilidad es emplear la clasificación propuesta por Azcorra et al. (2001) y que distingue los siguientes tipos de entidades:

- Universidades públicas y universidades privadas.

- Escuelas de negocios.

- Entidades con experiencia anterior en otras metodologías educativas (presenciales, a distancia, etc.).

- Entidades de nueva creación que han surgido para impartir formación on-line, no ofreciendo formación en ningún otro formato que no sea el virtual.

- Otras, bajo cuya denominación se incluyen las entidades no recogidas en las categorías anteriores.

Otro enfoque es el indicado en el capítulo 4 y que clasifica a las instituciones de educación en función según un doble criterio: la intensidad de utilización del e-learning en la metodología docente (ver Figura 49) y el modelo organizativo (ver Figura 50).

${ }^{19}$ Este concepto será tratado con el máximo detalle en el epígrafe 7.3. Aquí puede entenderse el sistema de valor con una representación de las interdependencias entre las organizaciones que participan en el sector en base a las actividades de la cadena de valor que aglutinan. 


\begin{tabular}{l|l}
\hline Tipo de Universidad & Descripción \\
\hline $\begin{array}{l}\text { Universidades de e- } \\
\text { learning }\end{array}$ & $\begin{array}{l}\text { Empleo de los sistemas de e-learning como elemento principal de la } \\
\text { docencia. }\end{array}$ \\
\hline Universidades duales & $\begin{array}{l}\text { Modelo de formación a distancia flexible y basado en TIC y } \\
\text { modelos presenciales con integración de sistemas de e-learning. }\end{array}$ \\
\hline $\begin{array}{l}\text { Universidades con un uso } \\
\text { complementario del e- } \\
\text { learning }\end{array}$ & $\begin{array}{l}\text { Modelos a distancia tradicionales pero flexibles y modelos } \\
\text { presenciales con un uso del e-learning como soporte a la } \\
\text { metodología tradicional. }\end{array}$ \\
\hline $\begin{array}{l}\text { Universidades } \\
\text { tradicionales }\end{array}$ & $\begin{array}{l}\text { Modelos a distancia y presenciales que presentan un uso residual de } \\
\text { las TIC. }\end{array}$ \\
\hline
\end{tabular}

Fuente: elaboración propia.

Figura 49. Clasificación de las Universidades en función de su empleo del e-learning.

\begin{tabular}{l|l}
\hline \multicolumn{1}{c|}{ Modelo organizativo } & \multicolumn{1}{c}{ Descripción } \\
\hline $\begin{array}{l}\text { Universidades virtuales como organizaciones } \\
\text { virtuales }\end{array}$ & $\begin{array}{l}\text { Son universidades creadas específicamente para } \\
\text { realizar una actividad de e-learning, algunas de las } \\
\text { cuales parten de modelos de universidades abiertas y } \\
\text { a distancia. Se caracterizan por disponer de un } \\
\text { modelo organizativo y pedagógico particular y } \\
\text { diferenciado del resto de universidades presenciales } \\
\text { y a distancia. }\end{array}$ \\
\hline
\end{tabular}

Universidad presencial con extensión universitaria virtual

Universidad virtual adosada a la universidad tradicional
Se trata de un modelo muy extendido en las Universidades y que consiste en incorporar formación virtual en cursos de postgrado y extensión universitaria en instituciones educativas cuya oferta de formación reglada es eminentemente presencial.

Se trata de universidades virtuales creadas por universidades tradicionales en su mismo entorno a través de espacios virtuales gestionados de forma independiente pero compartiendo los elementos básicos de la universidad tradicional (oferta formativa, normativa académica, servicios de biblioteca, etc.).

Universidades virtuales como espacios virtuales interuniversitarios

Se trata una universidad virtual creada a través de un consorcio de diversas universidades tradicionales y se materializa en la disponibilidad de un espacio virtual común en el que converge la oferta de los diferentes planes de estudio. Este espacio se gestiona de forma compartida pero autónoma en la Universidades participantes en el consorcio.

Modelo de intermediación

La o las Universidades se asocian con una empresa que proporciona cursos utilizando los recursos de enseñanza de instituciones existentes.

Universidad Corporativa

Unidad de negocios de una empresa que se encarga de gestionar los planes de formación de los empleados de la misma. 


\subsection{Caracterización de la oferta formativa}

La oferta formativa de un determinado conjunto de Universidades puede caracterizarse a partir de los siguientes aspectos (CRUE, 2006):

1. Especialización de la oferta

Este parámetro ya ha sido estudiado en el apartado 5.3.1.4 y hace referencia a la estructura de titulaciones de la institución. Se emplea, además, como parámetro corrector del contacto multimercado.

2. Diversificación de la oferta

El tipo de enseñanzas que ofrecen las universidades de una región a medida que se expanden afecta al grado de concentración de las ramas de enseñanza y a la diversificación de la oferta en la dicha región, es decir, contribuyen a que determinadas enseñanzas aumenten o reduzcan su presencia en la región.

Con objeto de identificar estos efectos, en CRUE (2006) se proponen dos indicadores: la concentración de ramas de enseñanza y la diversificación de la oferta en dicha región.

Para evaluar la mayor o menor concentración de las ramas de enseñanza se ha utilizado el índice de Theil a partir de los alumnos matriculados en cada rama a través de la expresión:

$$
I_{\text {THEIL }}=\frac{\ln N+\sum_{j=1}^{N} x_{j} \ln x_{j}}{\ln N}
$$

Donde $x_{j}$ es el porcentaje de alumnos matriculados en la rama $i$, respecto del total de alumnos en la región $j$ y $N$ el número de regiones. La concentración máxima se obtiene cuando el valor de este índice está próximo a la unidad.

Generalmente, lo relevante no es tanto el valor del índice, que lógicamente es suele ser reducido ya que la oferta es relativamente amplia, sino los cambios que se producen tras incluir algún nuevo competidor o los acontencidos tras un periodo de tiempo determinado.

Otro parámetro importante es el coeficiente de diversificación de la oferta. En general, los estudios de cualquier rama se pueden cursar en cualquier región del país, si bien no en todas ellas se ofrecen los mismos estudios, ni el peso específico de cada tipo de enseñanza es el mismo variando, por tanto, el grado diversificación entre regiones. Este coeficiente de diversificación de de una región se obtiene a través de la siguiente expresión (Moreno, 2005; Martín-Guzmán y Martín Pliego, 1993):

$$
C D_{j}=1-\frac{\left(\sum_{i=1}^{h} x_{i j}\right)^{2}}{h \cdot \sum_{i=1}^{h} x_{i j}^{2}}
$$

Donde $x_{i j}$ es el número de titulaciones de la rama $i$ impartidas en la provincia $j$ y $h$ es el número total de ramas de estudio.

3. Relación entre la oferta y la demanda

La relación oferta a demanda $\left(R O D_{i j}\right)$ que se evalúa para una titulación $i$ en una Universidad $j$, se define como:

$$
R O D_{i j}=\frac{O_{i j}}{D_{i j}}
$$


Donde $O_{i j}$ es la oferta de plazas de la titulación $i$ en la Universidad $j$ y $D_{i j}$ es el número de alumnos que solicitan una plaza en la misma titulación de dicha Universidad.

Según los valores de $R O D_{i j}$, es distinguir cinco situaciones posibles (ver Figura 51), que varían desde el equilibrio a la sobreoferta y a la sobredemanda, con situaciones intermedias y variadas con un componente diferenciado entre universidades.

\begin{tabular}{l|l}
\hline Situación & Valores de $\boldsymbol{R O D}_{i j}$ que la caracterizan \\
\hline Muy elevada sobreoferta & $R O D_{i j}>250 \%$ \\
\hline Elevada sobre oferta & $125 \%<R O D_{i j}<250 \%$ \\
\hline Equilibrio entre oferta y demanda & $75 \%<R O D_{i j}<125 \%$ \\
\hline Sobredemanda & $50 \%<R O D_{i j}<75 \%$ \\
\hline My elevada sobredemanda & $0 \%<R O D_{i j}<50 \%$ \\
\hline
\end{tabular}

Fuente: Reques (2004).

Figura 51. Relación entre la oferta y la demanda.

Este parámetro también puede evaluarse para un conjunto de universidades.

4. Relación entre la oferta y la matrícula

La relación oferta a matrícula $\left(R O M_{i j}\right)$ que se evalúa para una titulación $i$ en una Universidad $j$, se define como:

$$
R O M_{i j}=\frac{O_{i j}}{M_{i j}}
$$

Donde $O_{i j}$ es la oferta de plazas de la titulación $i$ en la Universidad $j$ y $M_{i j}$ es el número de alumnos que se matriculan en la misma titulación de dicha Universidad.

Según los valores de $R O M_{i j}$, es distinguir seis situaciones posibles (ver Figura 52), que varían desde el equilibrio a la sobreoferta y a la sobredemanda, con situaciones intermedias y variadas con un componente diferenciado entre universidades.

\begin{tabular}{l|l}
\hline Situación & $\begin{array}{l}\text { Valores de } \boldsymbol{R O M}_{i j} \text { que la } \\
\text { caracterizan }\end{array}$ \\
\hline Muy bajo nivel de matrícula & $0 \%<R O M_{i j}<25 \%$ \\
\hline Bajo nivel de matrícula & $25 \%<R O M_{i j}<50 \%$ \\
\hline Nivel de matrícula medio & $50 \%<R O M_{i j}<75 \%$ \\
\hline Alto nivel de matrícula & $75 \%<R O M_{i j}<90 \%$ \\
\hline Muy alto nivel de matrícula & $90 \%<R O M_{i j}<100 \%$ \\
\hline Ampliación de matrícula & $R O M_{i j}>100 \%$ \\
\hline
\end{tabular}

Fuente: Reques (2004).

Figura 52. Relación entre la oferta y la demanda.

Al igual que en el caso anterior, este parámetro también puede evaluarse para un conjunto de universidades. 


\subsubsection{BARRERAS A LA MOVILIDAD Y DE SALIDA}

Las barreras a la movilidad sirven de protección a las organizaciones que forman parte de un grupo estratégico ${ }^{20}$ frente a la entrada otras. Su principal efecto es la dificultad que suponen a la hora de modificar la posición competitiva de la organización en el sector.

Por otra parte, las barreras de salida son los factores que obligan a una organización a continuar compitiendo en el sector incluso en situaciones de rentabilidad baja o negativa, lo que puede disminuir el valor del sector. Las principales fuentes de barreras de salida son (Carús, 2000):

- Activos altamente especializados para el negocio en particular y que tienen poco valor liquidativo y/o altos costes de conversión o transferencia.

- Costes fijos de salida, como fuertes pasivos laborales por tipos y cuantía de contratos laborales o altos costes de reinstalación.

- Interrelaciones estratégicas con otras unidades de negocio de la empresa matriz en términos de imagen, habilidad comercial, acceso a los mercados financieros, instalaciones compartidas, etc.

- Barreras emocionales: apego de propiedad al negocio, lealtad hacia los empleados, etc.

- Restricciones sociales y legales: la negociación o falta de apoyo institucional o social para el abandono derivadas de una preocupación por la pérdida de empleo, de imagen o por los efectos económicos negativos para la región.

Teniendo esto en cuenta, podemos afirmar que en el e-learning, las barreras de salida son altas, pues la tecnología que se utiliza está especialmente diseñada para ser usada en el sector educacional y el costo de usarla para otros fines es muy elevado y no tendría sentido.

\subsubsection{Competencia potencial}

La competencia potencial de un sector industrial se nutre de la amenaza de entrada de nuevos competidores y de la aparición de nuevos productos que puedan sustituir a los actuales en el sector (Porter, 1980).

\subsubsection{BARRERAS DE ENTRADA}

Bajo el concepto de barreras de entrada se agrupa un conjunto de factores de tipo económico, social e institucional que constituyen un freno o impedimento para el ingreso de nuevas empresas en el sector.

Aunque las barreras de salida y las barreras de entrada son conceptualmente diferentes, Porter (1980) estima que la consideración de ambas es un aspecto importante del análisis sectorial porque a menudo están relacionadas. Así, considerando conjuntamente las barreras de ingreso y las barreras de salida y que ambas, en el caso más simplificado, pueden ser altas o bajas, se pueden formalizar cuatro tipos de rentabilidad del sector:

- Barreras de salida bajas (abandonan los fracasados) y barreras de entrada altas (los intentos de entrar serán desanimados). En este caso, el rendimiento se configura como elevado y estable.

- Barreras bajas tanto de entrada como de salida facilitan los ingresos y los abandonos. Los resultados se configuran como bajos.

- Barreras altas, tanto de entrada como de salida, se crea un situación de alto potencial de utilidades, pero permanece el riesgo de que los fracasados permanezcan luchando en el sector. Los rendimientos serán altos pero inestables.

- Barreras de salida altas y barreras de entrada bajas, los rendimientos además de bajos por la facilidad de ingreso son arriesgados por las dificultades para abandonar que encuentran las

\footnotetext{
${ }^{20}$ Un grupo estratégico es el conjunto de empresas en un sector industrial que siguen una misma o similar estrategia a lo largo de las dimensiones estratégicas.
} 
empresas de pobres resultados. Estas lucharán antes del abandono y, por tanto, existe el riesgo de que los rendimientos bajen. Es la combinación más desfavorable de un sector.

Porter (1980) sostiene que la amenaza de ingreso en un sector industrial depende, además del grado de reacción por parte de las empresas presentes en el mismo, de las barreas de ingreso, en el sentido de que si son altas la amenaza de entrada será escasa. Bueno Campos (1996) identifica tres causas de amenaza de entrada de nuevos competidores:

- Creación de empresas o nuevos competidores coincidiendo con circunstancias de sectores en crecimiento, caracterizados por una alta rentabilidad junto a pocas y de escasa importancia barreras de salida.

- Liberación económica o liberalización de los mercados, que facilitan un aumento de la competencia internacional.

- Aparición de nueva competencia por procesos de diversificación y por la combinación del fenómeno de desregulación y la innovación tecnológica.

Tales factores se agrupan en las siguientes categorías (Carús, 2000):

1. Economías de escala

Las economías de escala reflejan las reducciones en el coste unitario del producto, servicio o procesos de todo tipo que se producen como consecuencia de mayores volúmenes de actividad por periodo. Presentan impedimentos porque fuerzan al pretendiente a operar a gran escala, con el riesgo de una inmediata reacción por parte de los competidores existentes, o a ingresar a pequeña escala aceptando una desventaja inicial en coste.

Las características del e-learning como producto (contenido digital) hacen el coste de producción sea prácticamente independiente del número de unidades producidas y que el coste de reproducción sea prácticamente nulo, por lo que no existen economías de escala. Sin embargo, debe tenerse en cuenta que los contenidos habrá que actualizarlos entre distintas ediciones del curso o programa y que ello lleva asociado ciertos costes.

2. Diferenciación del producto

La diferenciación del producto o servicio supone para las empresas establecidas gozar de un cierto grado de identificación de la marca y lealtad por parte de los clientes. Así, los impedimentos de entrada residen en las grandes (en recursos y en tiempo) y arriesgadas inversiones que tiene que realizar un nuevo competidor para dar prestigio a su marca y superar la lealtad de los clientes de los competidores existentes.

La baja transparencia del mercado y el conocimiento limitado de los productos de elearning probablemente representarán serios retos para los clientes, sobre todo corporativos, en los próximos años. Por tanto, la marca será la mejor seña de identidad de un producto de calidad para evitar errores más costosos. Los proveedores de e-learning están actualmente reconduciendo los principales factores que constituyen una marca, tales como la calidad, la consistencia, la competencia, la reputación y una base leal y reconocida de clientes.

También existe el factor experiencia, lo que hace muy difícil que una entidad cualquiera pueda participar en este sector. A no ser que sean entidades con un fuerte potencial en educación y con respaldo de un prestigio ya ganado en materia de educación.

Con el fin de proyectar una imagen de marca integral, sólida y consistente que permita a las instituciones tener un respaldo estratégico, las Universidades deben adoptar, entre otras, las siguientes medidas (Fuentes, 2005):

- Concretar su identidad corporativa, a partir de la formulación de un mensaje institucional unificado, claro, concreto y conciso que impacte en cualquier público del mundo.

- Fomentar redes académicas que potencialicen la divulgación de los resultados de trabajos académicos y de investigación.

- Fortalecer las acciones de relaciones públicas en tiempo real, para contribuir a la proyección de la imagen institucional.

- Construir vínculos estables para generar confianza con los diferentes públicos. 
3. Inversión en TIC elevada y altos costes fijos iniciales

En general, la necesidad de fuertes volúmenes de capital constituye una barrera de entrada, lo cual supone una ventaja para los competidores existentes.

El hecho de que el e-learning se caracterice por la realización de la formación a través de las TIC determina la importancia relativa de la inversión tecnológica y del uso de las mismas. Esta dotación de infraestructuras y aplicaciones tecnológicas provoca que la inversión TIC en el marco de la actividad docente sea de una cuantía relativamente elevada sobre el total de inversiones realizadas, de manera que se produce un desplazamiento de recursos, desde los elementos tradicionales basados en la infraestructura física hacia los bienes tecnológicos. Es decir, en la formación tradicional, una parte importante de los costes proceden de las aulas, el material que se entrega a los alumnos, etc. La virtualidad que caracteriza al e-learning elimina, o al menos reduce al mínimo, el impacto económico de este tipo de conceptos, aunque a costa de incrementar enormemente la importancia de las TIC, imprescindibles en un entorno virtual. Además, este gasto inicial está sometido a una obsolescencia muy rápida, lo cual genera un elevado nivel de riesgo para este tipo de inversiones.

Estos elevados costes iniciales en teoría se compensan por unos menores costes de personal y porque el alto gasto de desarrollo de curso se amortiza en las sucesivas repeticiones del mismo. No obstante, este modelo impide la entrada de empresas que no dispongan de importantes presupuestos en generación de contenidos y de una cuota de mercado (número de matrículas) suficientemente grande para poder amortizar la inversión inicial.

En relación a lo anterior, cabe hacer las siguientes reflexiones:

- Para amortizar el gasto inicial son necesarios un número de alumnos mayor de lo que quizá sea aconsejable desde el punto de vista metodológico.

- La repetición sin cambio alguno en los materiales aumenta el riesgo de que estos queden obsoletos y desactualizados.

- En ocasiones, una elevada calidad en los materiales (y, por tanto, un incremento en el coste de generación de los mismos) no es percibida como tal por el alumno. Por tanto, habrá que determinar la sensibilidad de los alumnos que forman parte del mercado potencial a las variaciones de calidad de los materiales formativos con el fin de aumentar la eficiencia y el rendimiento económico de dichos materiales.

Una manera de reducir los costes asociados a las TIC es el fomento de los procesos de innovación tecnológica, por la necesidad de adaptar los estándares tecnológicos a las particularidades de los procesos formativos y de actualizar y mejorar continuamente la funcionalidad de los diferentes componentes del sistema.

\subsubsection{PRODUCTOS O SERVICIOS SUSTITUTIVOS}

El análisis de las condiciones en las que pueden aparecer productos sustitutivos es un cometido fundamental para la determinación de una posición competitiva sólida y duradera. Detectar posibles sustitutos de un producto o servicios es una tarea sutil, que implica la búsqueda minuciosa de otros productos o servicios que pueden desempeñar la misma función que el producto del sector en cuestión.

En general, cada empresa en un sector o segmento sectorial está compitiendo con empresas de otro u otros segmentos sectoriales que producen bienes o servicios sustitutivos. Estos, al igual que los nuevos ingresos, limitan el rendimiento potencial de un sector a través de establecer un límite sobre los precios que sus empresas pueden cargar, es decir, el impacto de los productos sustitutivos puede ser entendido, sintéticamente, como la elasticidad general de la demanda del sector. Cuanto más atractiva sea la relación precio/desempeño (en términos de satisfacción del consumidor) ofrecida por los productos sustitutivos, más sólido será el límite a los beneficios del sector. Además, los productos sustitutivos no solo limitan los beneficios en tiempos normales, sino que también pueden reducir la rentabilidad de un sector en tiempos de bonanza. 
Los productos sustitutivos que merecen atención prioritaria son aquellos que:

- Siguen una tendencia alcista en su relación precio/desempeño, respecto al producto del sector en cuestión; o,

- Son producidos en sectores con altas tasas de rentabilidad. En este caso, los sustitutos pueden entrar rápidamente a escena si algún desarrollo aumenta la competencia en sus propios sectores y causa una reducción de precios o mejora de su desempeño. El análisis de tales tendencias puede tener importancia al decidir si se trata de atacar estratégicamente o planear con él una estrategia como fuerza clave inevitable (Porter, 1980).

El pronóstico de riesgo de sustitución, de acuerdo con lo anterior, debe basarse en la determinación de la relación precio/desempeño que caracteriza al producto que potencialmente puede sustituir al actual y en los costes de cambio que pueden afectar al comprador.

Además, deben evaluarse los retos e impactos que representan para la organización los efectos de las nuevas tecnologías, concretadas en productos nuevos, sustitutivos o de los que constituyen el campo de actividad de la empresa (Bueno Campos, 1996).

Por otra parte, también posibilitan la modificación o ampliación de los ciclos de vida de productos y sectores. En ocasiones pueden hacer que se pase del crecimiento al declive, omitiéndose la madurez, o una innovación tecnológica puede hacer que el crecimiento de un sector se revitalice después de un periodo de declive.

En general, un mercado no resulta atractivo si existen este tipo de productos, sobre todo, cuando están más avanzados tecnológicamente o pueden entrar a competir a precios más bajos.

En la actualidad, el mayor competidor de las Universidades en cuanto a formación continua se refiere son las Universidades Corporativas ya que éstas satisfacen las demandas de formación de los empleados de la empresa a la que pertenecen y estos, por tanto, no se matricularán en ninguno de los cursos que conforman la oferta de las Universidades (Clarke y Hermens 2001; Rosenberg 2001). Por lo que respecta a las enseñanzas de grado, las amenazas de productos o servicios sustitutivos son las mismas que para la formación presencial tradicional.

Cabe hacer notar que la educación virtual puede también ser observada como un complemento de la educación presencial ya adquirida por un estudiante que desea complementar sus estudios o perfeccionarse.

En comparación con la educación presencial, la actitud del cliente hacia la educación virtual es menos favorable, debido a un problema de cultura (a veces, subestimada) y disciplina que ha significado que exista una mayor lealtad hacia los servicios tradicionales de las Universidades e Institutos, pero sólo en la medida en que éstos tengan un respaldo en cuanto a experiencia y a logros concretos en materia de educación.

Desde una perspectiva de sustitutos, la realidad es que no es la educación presencial el sustituto de la virtual, sino por el contrario, es la educación virtual la que se ha requerido como un muy buen sustituto de la educación presencial y lo será cada vez más en la medida que mejore la tecnología que soporta al e-learning.

\subsubsection{Negociación con los proveedores}

Cualquiera que sea el sector, una empresa que desarrolle su actividad en él se ve obligada a hacer compras de materiales y mano de obra a proveedores. Estos pueden reducir la rentabilidad del negocio al ejercer presión sobre los precios y reducir así el margen propio. Una situación de alto poder por parte de los proveedores merma rentabilidad a las empresas del sector que les compra, ya que éstas son incapaces de recuperar los aumentos de coste mediante sus propios precios y los proveedores se apropian así de la mayor parte del valor añadido total a distribuir. Por ello, un mercado no será atractivo cuando los proveedores estén organizados en gremios, puedan imponer sus condiciones y/o cuando los insumos sean realmente críticos para la actividad propia. 
El poder negociador de los proveedores se concreta en la medida en que por la escasez o especificidad de su oferta, en que por la posición de monopolio o por su integración vertical, puedan ejercer presión en los precios, cantidades y calidades de los productos ofertados, por lo que pueden alterar la posición competitiva de la empresa cliente.

Al igual que en el caso de los clientes, las condiciones que determinan el poder de los proveedores pueden variar con el tiempo o como resultado de decisiones estratégicas que tome la empresa.

En general, las Universidades invierten en e-learning con las esperanza de obtener, a largo plazo, menores gastos de infraestructuras y de personal (Weigel, 2000) a la vez de una mayor cuota de mercado. De hecho, ésta es también una de las razones que empuja a las Universidades a formar consorcios o redes de universidades. Otra opción es establecer algún tipo de alianza con algún proveedor que asuma algunas de las actividades del sistema de valor. En este sentido, el poder negociador de las empresas que suministran componentes tecnológicos y plataformas computacionales es relativamente bajo. La oferta de insumos en estos momentos es fuerte y los precios pueden ser manejados con facilidad. No ocurre lo mismo con la prestación de servicios de marketing educativo, ya que este tipo de actividades no suele estar muy extendida en las Universidades y el número de proveedores de estos servicios no es elevado.

\subsubsection{Negociación con los clientes}

Una base importante de las tasas de rentabilidad que puedan alcanzarse en cualquier sector económico es el valor que tal sector genera. Que el sector pueda apropiarse de ese valor en parte depende del poder de negociación con sus clientes y proveedores. Igualmente, clientes y proveedores intentarán aumentar sus participaciones a costa del sector. El vehículo fundamental en esta distribución son los precios de compra y de venta a los clientes, y la cuantía de participación de unos y otros depende del poder de negociación de los mismos.

Los clientes o compradores intentarán forzar la bajada de precios, negociar por una calidad superior o más servicios y enfrentar a los competidores. Sin embargo, debe entenderse que el poder negociador será ejercido por determinados clientes que se demuestran como importantes grupos de compradores dentro del sector.

Se entenderá por cliente a todo potencial demandante de educación que, por razones de tiempo o impedimentos de distancia, deseen estudiar, capacitarse o perfeccionarse a través de un programa on-line y que cuentan con medios tecnológicos para acceder a la educación virtual.

En la enseñanza reglada, el poder negociador de los estudiantes (clientes) es reducido puesto que los precios de la formación están regulados por ley. Sin embargo, en la formación no reglada, sobre todo si es on-line, los estudiantes tienen mayor libertad para escoger puesto que permite a los estudiantes matricularse en cualquier universidad el mundo.

Los demandantes de educación tratan de acceder a una calidad lo más alta posible, forzando de esta manera a un manejo de las variables precio-calidad de los servicios, entre los organismos que utilizan los modelos presenciales versus los que podrían utilizar un modelo virtual. Aunque son dos servicios distintos, apuntan a satisfacer la misma necesidad con el mismo resultado: un diploma; por lo tanto, es de esperar que exista una fuerte competencia entre ellos, por lo cual el cliente, aún sin tener un alto poder negociador, se ve favorecido por esta competencia.

Sin embargo, es necesario resaltar que el mercado de la educación superior no es muy sensible al precio, por lo que basar la estrategia competitiva en una competencia en precios puede ser arriesgado (Temperini, 2004). Por el contrario, si una organización desea establecer una posición competitiva estable a largo plazo debe construir relaciones con los clientes (alumnos) duraderas. La satisfacción de los clientes no se logra únicamente con la calidad de los cursos o programas formativos, sino que también influye la oferta de servicios, la calidad de la atención y 
soporte al cliente, las tutorías, etc. Todos estos aspectos resultan de vital importancia, habida cuenta del carácter crítico de la imagen de marca.

\subsubsection{Negociación con el gobierno}

Un aspecto de enorme importancia en la actualidad y aún por concretar satisfactoriamente es la definición del papel de los Gobiernos en la determinación del modo en que evolucionará la Educación Superior internacional en Internet.

Brunner y Uribe (2007) identifican dos tareas fundamentales que deben llevar a cabo los Gobiernos cuyo objetivo sea impulsar un modelo de Educación Superior orientado a mercado, y que son:

1. Velar por el libre acceso al mercado

En primer lugar, se debe favorecer la entrada en el mercado de nuevos competidores, garantizándoles libertad para diseñar su oferta de productos y servicios y el libre acceso a los recursos.

Por otra parte, también debe velarse porque los consumidores puedan elegir libremente la institución que más se adecúe a sus preferencias y necesidades.

2. Contrarestar los efectos indeseados de la libre compentecia

Uno de los aspectos más importantes derivados de la misión social de Educación Superior, es la articulación de las medidas necesarias para garantizar el acceso a la Educación por parte de cualquier ciudadano, proveyendo financiación (becas) a aquellas personas que no puedan asumir los costes de los programas formativos ofrecidos por las Universidades.

Además, el Gobierno deberá procurar que exista información suficiente sobre la calidad y el precio de la oferta formativa, establecer mecanismos de garanticen dicha calidad, etc.

Con el fin de introducir estos cambios se plantean tres tipos de políticas diferentes:

1. Desregulación

Se corresponde con el objetivo de creación de un mercado universtario a través de la apertura del sistema tratando de fomentar la competencia entre las instituciones del sector (Levy, 2006; Weiler, 1999).

2. Privatización

Consiste en la generación de un mercado administrado con el que se intenta alterar el comportamiento tradicional de las Universidades (sobre todo, de las públicas) a través de programas de incentivos.

La privatización puede manifestarse bien en la propiedad y gestión de la institución (Brunner y Tillett, 2007), o bien forzando a la institución a orientarse competitivamente adoptando comportamientos estratégicos (Gornitzka y Maassen, 2000).

3. Regulación de la competencia

Jongbloed (2004) postula que las actuaciones regulatorias de los Gobiernos en un modelo de Educación Superior orientado al mercado pueden dirigirse en varias direcciones. En primer lugar, a la forma de estructurarlos estableciendo las barreras de entrada al sector (servicios ofrecidos y en qué condiciones, grados de integración vertical, etc.). También pueden actuar sobre la conducta competitiva de las orgranizaciones influyendo o estableciendo condiciones en las estrategias de precios o en la conformación de la oferta, por ejemplo. Finalmente, los Gobiernos pueden obligar a las Universidades a aceptar una serie de "reglas de juego".

Por otra parte, en muchos sectores, el Gobierno puede ser un comprador o un proveedor con influencia en la competencia sectorial por las políticas que adopte. Desde el punto de vista institucional, el apoyo al e-learning se materializa en dos tipos de iniciativas (AEFOL, 2003): 
1. Subvenciones directas, tanto para la construcción de campus virtuales, como realización de cursos online. Con este tipo de medidas se corre el riesgo de fomentar un cierto oportunismo de empresas que solicitan ayudas, y que una vez obtenido y finalizado el proyecto no continúan invirtiendo en e-learning.

2. Realización de proyectos educativos liderados por las Administraciones Públicas, subcontratando empresas del sector del e-learning. Este tipo de iniciativas han sido generalmente exitosas, ya que dan a conocer el e-learning bien hecho, y los proveedores de servicios han debido competir por un contrato que se deberá de renovar. Esta medida resulta particularmente útil puesto incitan a competir por unos servicios especiales, no por un proyecto global, que en función de la calidad del servicio prestado a un proyecto concreto se pueden renovar contratos. 


\section{CAPÍTULO 6 EXPECTATIVAS DEL MERCADO}

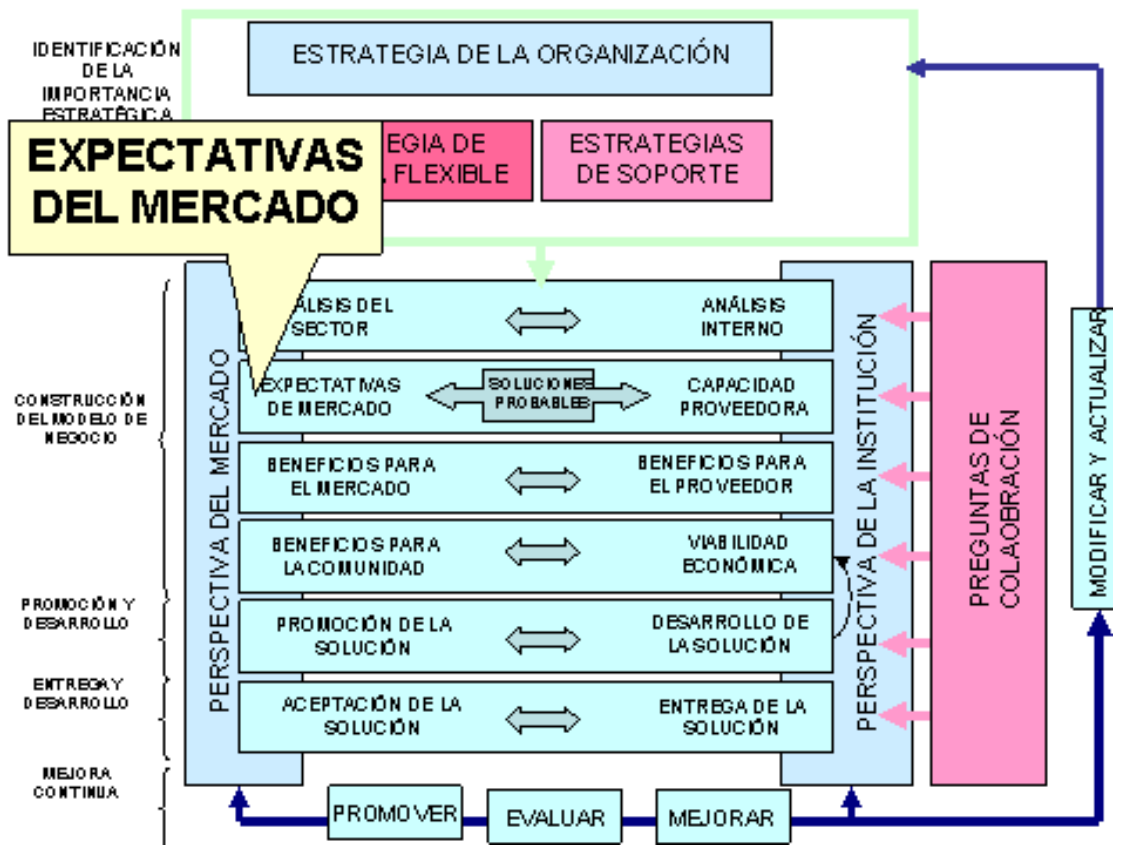

Dentro este de grupo de actividades se incluyen todas aquellas cuyo objetivo es identificar qué variables influyen en el comportamiento de los consumidores potenciales (en este caso, estudiantes potenciales) y realizar un estudio de la demanda que permita conocer la evolución del mercado objetivo a lo largo del tiempo.

Hay que hacer notar aquí que en la sección de definición de alcance estratégico ya se ha debido realizar una segmentación del mercado previa, aunque es en la sección que nos ocupa en donde se lleva a cabo una investigación más profunda.

\subsection{ANÁLISIS DE LA DEMANDA}

La evolución del e-learning en la Formación Superior tiene su explicación en la difusión de las TIC durante segunda mitad de la década de los 1990 y en las iniciativas, por parte de las instituciones educativas, de cubrir las necesidades de formación de segmentos que tradicionalmente se encontraban nada o poco incluidos en su oferta educativa: la formación continua y la formación de los trabajadores. Sin embargo, a pesar de esta expansión, su uso no presenta una intensidad elevada ni está todavía generalizado, como también ponen de manifiesto 
los datos disponibles acerca de las Universidades europeas (PLS RAMBOLL Management, 2004). No obstante, la intensidad de la utilización tecnológica depende del tipo de formación de que se trate.

En el caso de la educación de grado, la mayoría de las instituciones educativas apenas ofertan cursos que utilicen exclusivamente las nuevas tecnologías como medio de transmisión, sino que éstas suelen funcionar como mecanismo complementario de la docencia presencial que permite prestar un servicio personalizado al estudiante a la vez que favorece la distinción a la hora de posicionarse para la captación de nuevos estudiantes (Area et al., 2002; CRUE, 2004, Duart y Lupiáñez, 2005). De hecho, en España, exceptuando la UOC y la UNED, son pocas las universidades donde se pueden conseguir títulos de licenciaturas o diplomaturas oficiales a través de formación on-line.

Sin embargo, en la formación de postgrado (mayoritariamente relacionada con estudios de doctorado que tienen un componente de elección individual más acusado, y en general relacionada con la adquisición de nuevos conocimientos reglados no vinculados necesariamente a un fin laboral) y en la formación continua (generalmente, relacionada con las necesidades de formación requeridas para el desarrollo de un determinado puesto de trabajo), el panorama es bien distinto, hasta tal punto que son estos dos segmentos del mercado los que están impulsando el e-learning a nivel de educación superior. Un aspecto importante es el hecho de que la pérdida de exclusividad por parte de las Universidades en este tipo de formación y, además de entre ellas, deben competir con nuevos agentes formativos como son las universidades corporativas u organismos dedicados en exclusiva a este sector como el Instituto Universitario de Postgrado (asociación empresauniversidad) o las Universidades Corporativas como la de Unión Fenosa (http://www.unionfenosa.es).

Centrando el interés en la demanda, se observa que España es uno de los países de la Unión Europea con menor tasa de penetración de la formación on-line. En un estudio publicado por la Fundación Auna (2004:2006) sobre el estado de la Sociedad de la Información en nuestro país, se observa cómo tan sólo Portugal muestra un tasa menor (ver Figuras 53a y 53b).

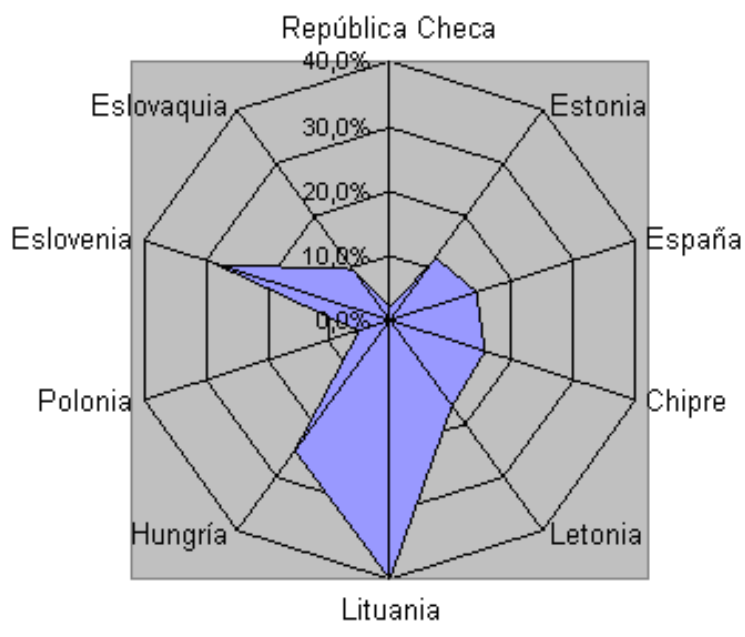

Fuente: adaptado ${ }^{21}$ de Fundación Auna (2006).

Figura 53a. Posición relativa de España respecto de los países de la UE de reciente incorporación. Número de usuarios de Internet por motivos formativos en los últimos tres meses como porcentaje del número de usuarios de Internet en 2005.

${ }^{21}$ Los valores del gráfico han sido estimados por el investigador a partir de los gráficos originales, por lo que es posible que exista cierta inexactitud. Sin embargo, la tendencia general es la misma. 


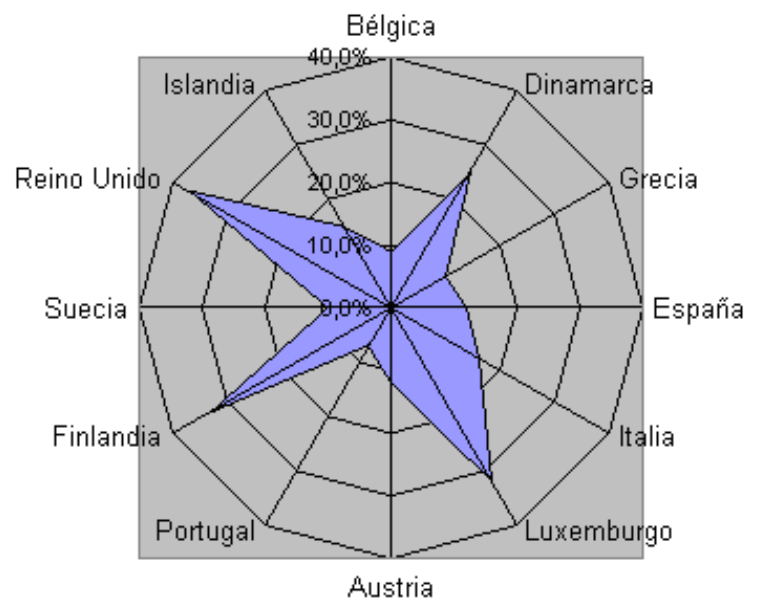

Fuente: adaptado ${ }^{22}$ de Fundación Auna (2006).

Figura 53b. Posición relativa de España respecto de los países de la UE-15 y EEA. Número de usuarios de Internet por motivos formativo en los últimos tres meses como porcentaje del número de usuarios de Internet en 2005.

Entre las causas de esta baja tasa de penetración no se encuentra, como podría pensarse en un principio, una tasa igualmente reducida de la penetración de Internet. En efecto, el mismo informe de la Fundación Auna (2006) señala que no es posible inferir una correlación directa entre la tasa de acceso a Internet y la tasa de penetración de la formación on-line, tal y como muestra la Figura 54.

口Usuarios de Internet en los tres últimos meses u Usuarios de formación on-line en los tres últimos meses

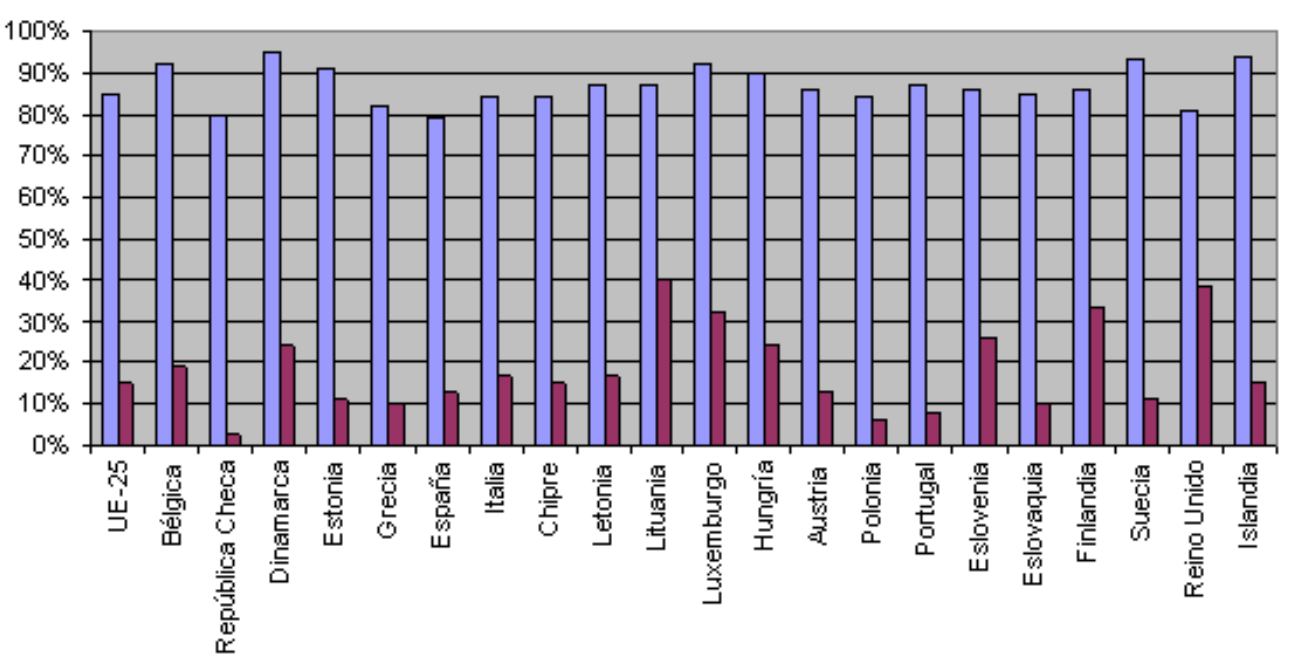

Fuente: Fundación Auna (2006)

Figura 54. Usuarios de formación on-line en los últimos 3 meses respecto del total de internautas y de población total. UE-25 y EEA, 2005 en \%.

En cuanto a las modalidades de formación señaladas anteriormente, en formación de reglada de nuevo encontramos a España en los últimos puestos a nivel europea (ver Figura 55).

${ }^{22}$ Los valores del gráfico han sido estimados por el investigador a partir de los gráficos originales, por lo que es posible que exista cierta inexactitud. Sin embargo, la tendencia general es la misma. 


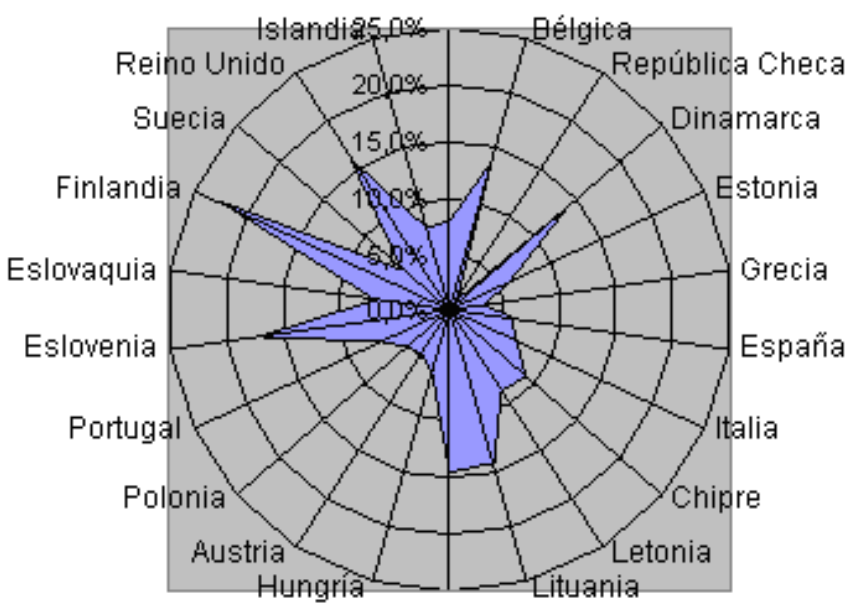

Fuente: $\operatorname{adaptado}^{23}$ de Fundación Auna (2006).

Figura 55. Usuarios de Internet para formación on-line reglada en los últimos tres meses como porcentaje del número de usuarios de Internet. UE-25 y EEA, 2005.

En la formación ocupacional y de postgrado, la situación no es tampoco halagüeña (ver Figura 56). A pesar de que en formación ocupacional se encuentra relativamente cerca de la media europea (4,5\% en España frente a 6,9\% en la UE-25), los índices todavía están alejados de los países como el Reino Unido $(21,3 \%)$. En cuanto a la formación de postgrado, de nuevo nos encontramos entre los países con menor tasa de penetración $(3,1 \%)$.

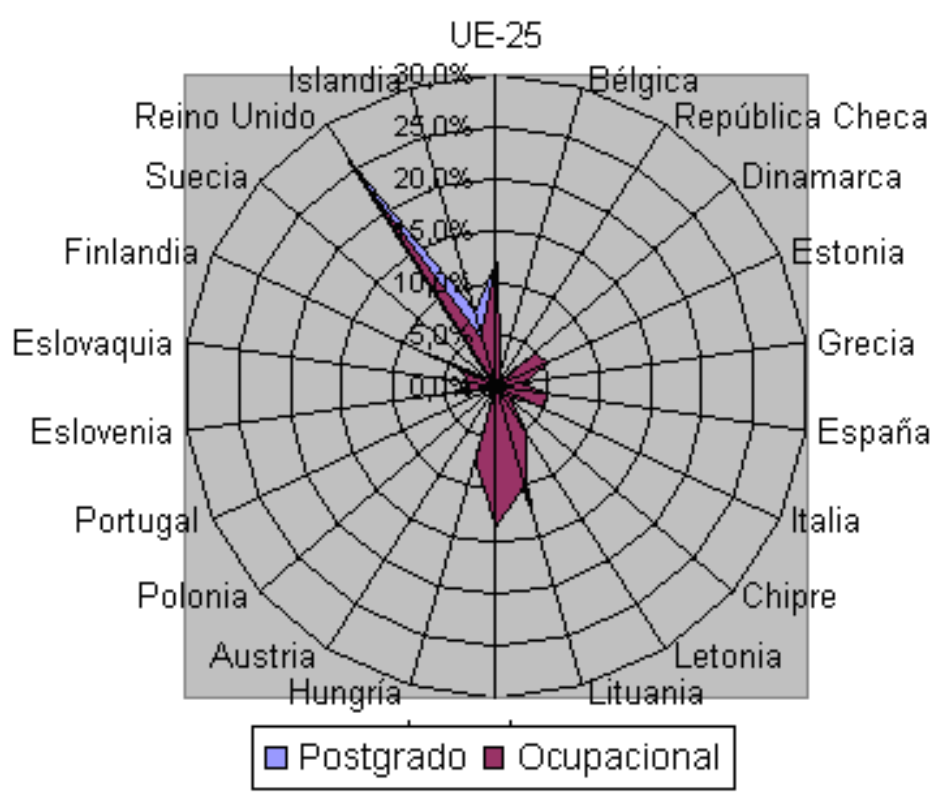

Fuente: adaptado ${ }^{24}$ de Fundación Auna (2006).

Figura 56. Usuarios de Internet para formación ocupacional y cursos de postgrado en los últimos tres meses como porcentaje del número de usuarios de Internet. UE-25 y EEA. 2005.

${ }^{23}$ Los valores del gráfico han sido estimados por el investigador a partir de los gráficos originales, por lo que es posible que exista cierta inexactitud. Sin embargo, la tendencia general es la misma.

${ }^{24}$ Los valores del gráfico han sido estimados por el investigador a partir de los gráficos originales, por lo que es posible que exista cierta inexactitud. Sin embargo, la tendencia general es la misma. 
Un indicador interesante en es la relación entre el porcentaje de usuarios de formación ocupacional sobre los usuarios de formación de postgrado, ya que indica qué modalidad formativa es mayoritaria en cada país. Un valor de este indicador mayor superior a la unidad, indica que la formación ocupacional es mayoritaria. En general, puede apreciarse que la utilización del e-learning para formación ocupacional es mayor que para formación de postgrado, si bien entre 2004 y 2005 las diferencias se han reducido (ver Figura 57). Esta reducción ha sido considerable en algunos países que ha pasado de 10 usuarios de formación ocupacional por cada usuario de formación de postgrado a una relación de 0,96. En nuestro país se ha producido un efecto curioso y es que la relación se ha invertido, es decir, se ha pasado de una mayor proporción de usuarios de formación on-line ocupacional en 2004 a una proporción inversa (mayor importancia de la formación on-line de postgrado) en 2005, según los datos de la Fundación Auna $(2004,2005)$.

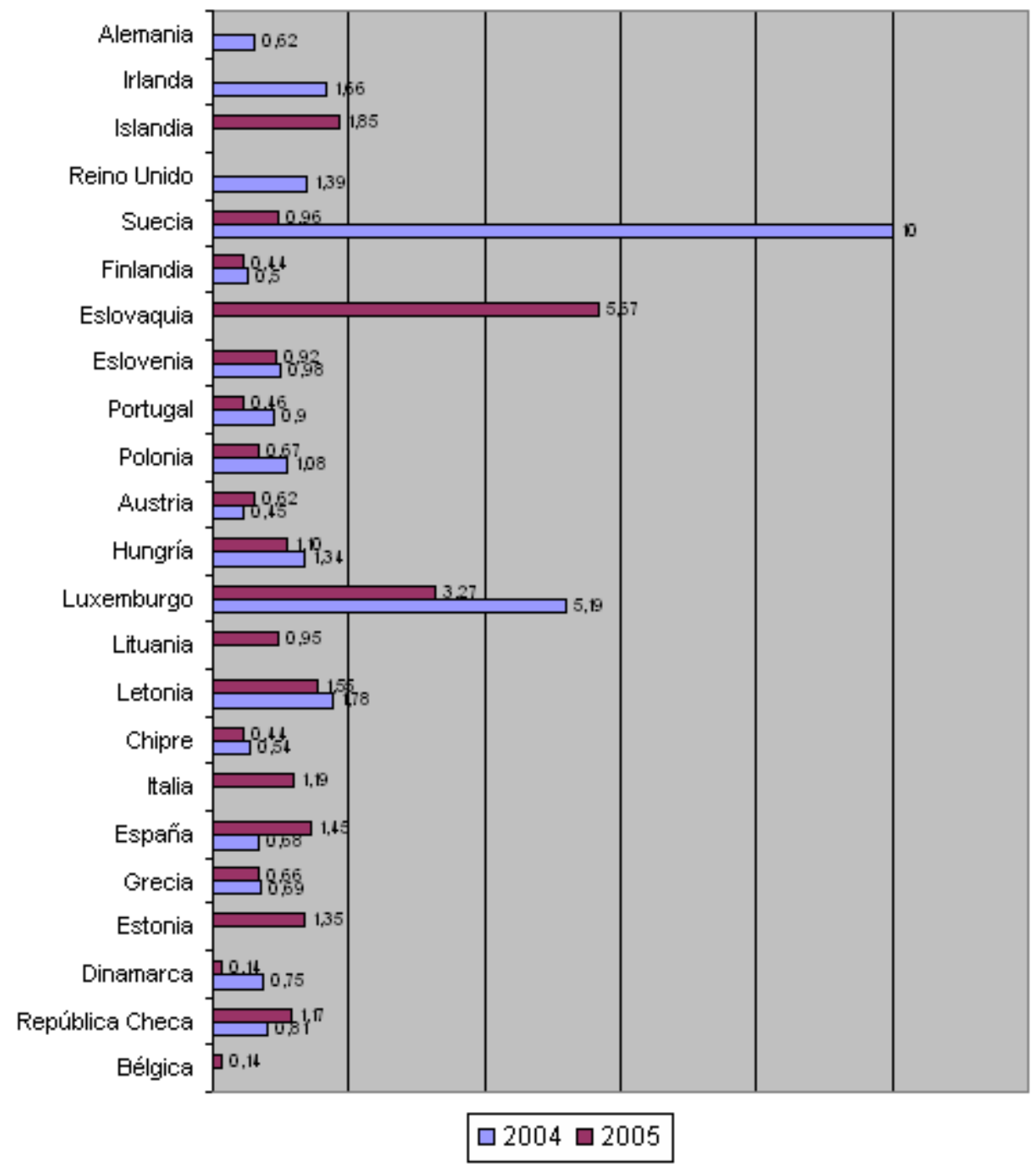

Fuente: adaptado de Fundación Auna (2005:2006).

Figura 57. Ratio entre el número de usuarios en los últimos 3 meses de formación on-line ocupacional y de postgrado. UE-25 y EEA. 2004:2005.

La situación general es que la importancia de la formación ocupacional es mayor que la de la formación de postgrado. Esto podría indicar que el principal propósito de la formación on-line es el laboral, por lo que conviene contrastarlo con el grado de penetración de esta modalidad formativa en las empresas. La Figura 58 recoge el porcentaje de empresas de más de 10 empleados que opta por programas de formación on-line para sus empleados. Como puede verse, 
España se encuentra por encima de la media, aunque sus parámetros están muy alejados de los valores alcanzados en los países de reciente incorporación.

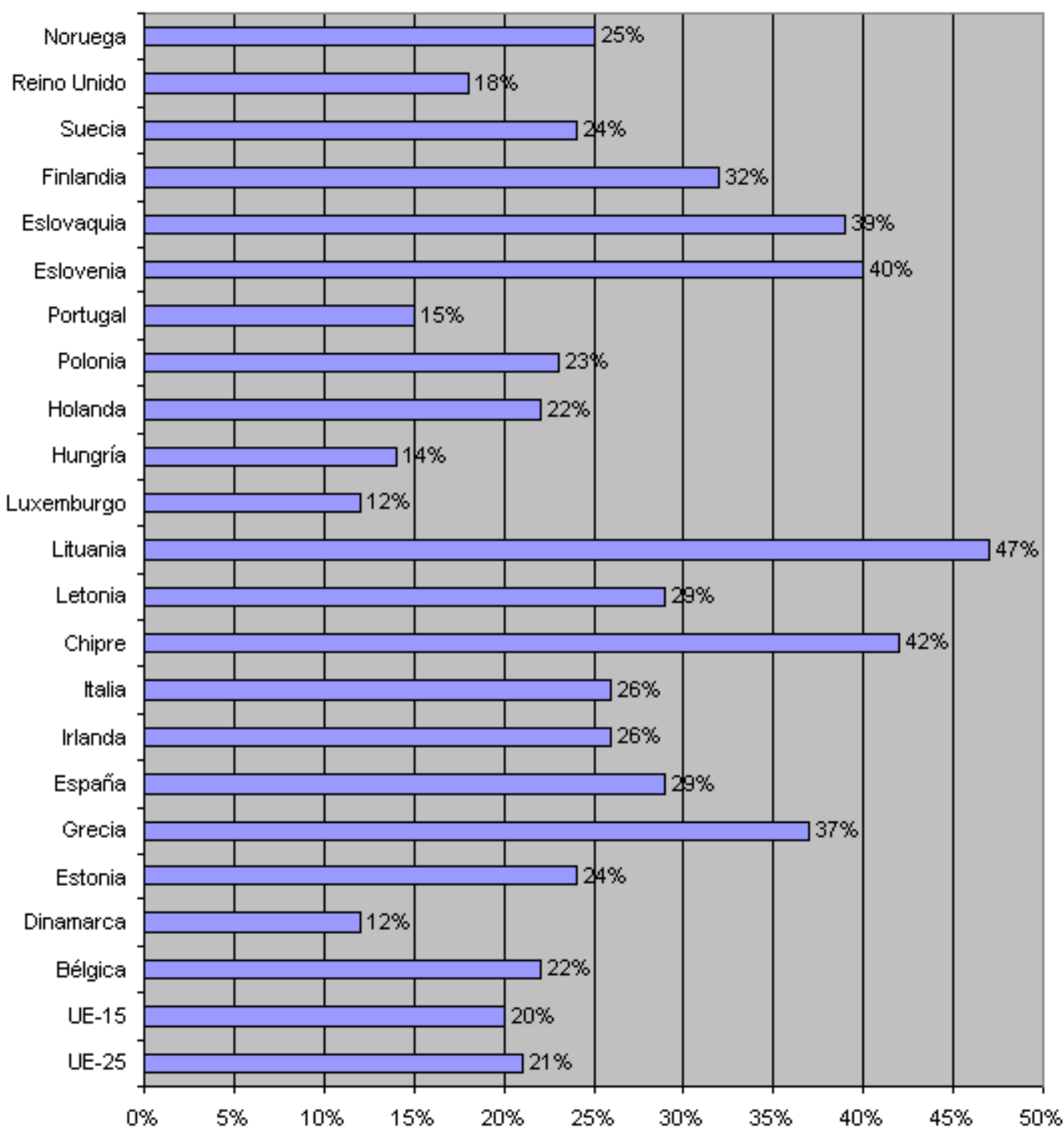

Fuente: adaptado de Fundación Auna (2006).

Figura 58.Empresas de más de 10 trajadores que utilizan aplicaciones de formación on-line para sus empleados. UE-25 y EEA, 2005, en porcentaje sobre el total de empresas.

Otro aspecto a destacar es el aumento en el número de campus virtuales (propios y compartidos) en el entorno universitario español. Según Area et al. (2002) y la Fundación Auna (2004), el número de campus virtuales totales pasó de 36 a 49 entre el 2002 y el 2003, gracias a un aumento notable del número de universidades con campus propio (ver Figura 59). 


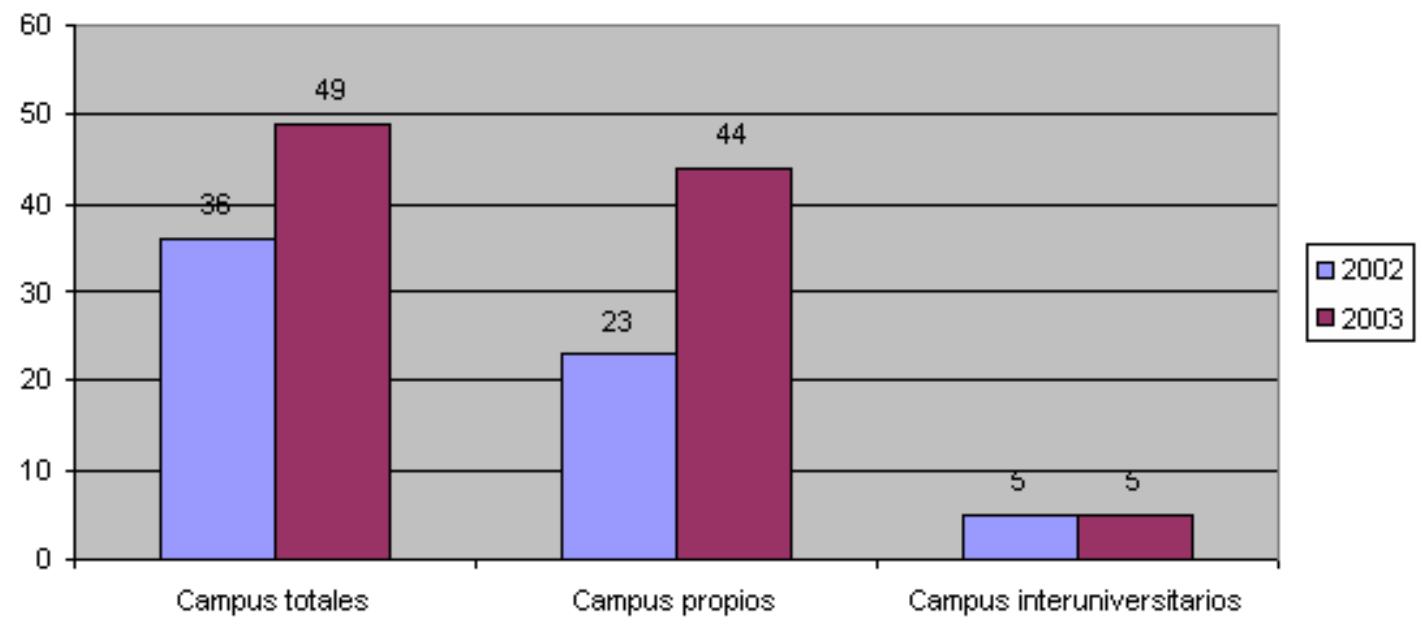

Fuente: elaboración propia a partir de Area et al. (2002) y Fundación Auna (2003).

Figura 59. Evolución de los campus virtuales en España.

Sin embargo, el grado de implantación real en las Universidades españolas es muy diferente en cada una de ellas debidas, en parte, a que la inversión y el esfuerzo que supone la virtualización de la docencia no siempre se ven recompensadas con un aumento en el número de matrículas (Duart y Lupiáñez, 2005). Un impulsor en este sentido puede ser el Espacio Europeo de Educación Superior que incluye en la valoración del trabajo las tareas on-line. Ello puede hacer un aumento de la oferta de cursos a corto y medio plazo, probablemente en forma de campus interuniversitarios a nivel internacional.

\subsection{PERFIL SOCIODEMOGRÁFICO DEL CONSUMIDOR DE FORMACIÓN ON-LINE}

Puesto que la solidez de una ventaja competitiva, en última instancia, está determinada por el éxito de la organización en el mercado y, por tanto, por la capacidad de dicha organización para satisfacer las necesidades de los consumidores que forman parte de dicho mercado, resulta de gran utilidad conocer el perfil del consumidor tipo.

Por tanto, resulta imprescindible disponer de un amplio conocimiento de los segmentos del mercado hacia los que se orienta la oferta educativa de la institución, siendo incluso capaz de personalizarla en función de los intereses de cada cliente y cubrir así sus expectativas de una forma óptima. Richard Honack (citado en Fuentes, 2005) califica a los consumidores actuales como "nanoconsumidores" pretendiendo indicar con ello la velocidad a la que suceden los cambios (nanosegundos) y que dichos consumidores exigen recibir un servicio inmediato y satisfactorio. Es decir, que las organizaciones deben contar con un sistema de información fiable y de fácil acceso, capaz de responder en tiempo real a las necesidades de sus usuarios (estudiantes, profesores, etc.).

Es posible obtener este perfil sociodemográfico a partir de un análisis detallado de los siguientes aspectos:

1. Nivel de estudios

Este indicador muestra cómo cuanto menor es el nivel de estudios de los españoles, tanto menor es su grado de utilización de la formación on-line como alternativa para su educación. Una de las posibles causas puede ser la distribución de los usuarios de Internet en 
función de su nivel de estudios, que viene a respaldar la afirmación anterior, tal y como muestra la Figura 60.

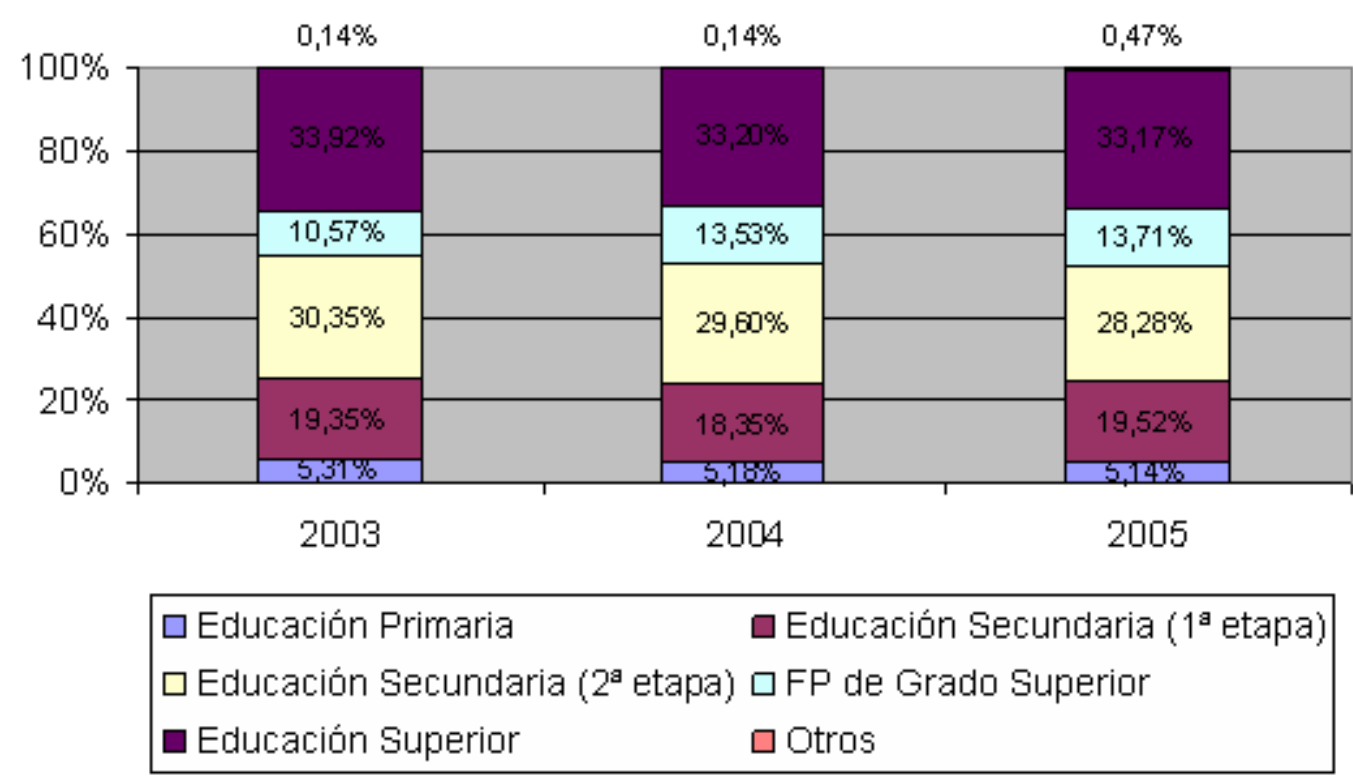

Fuente: elaboración propia a partir de datos del INE (2003:2006).

Figura 60. Distribución de usuarios de Internet por nivel de estudios en España.

Efectivamente, la proporción de individuos que hacen uso de la formación vía Internet es notablemente mayor entre el estrato de usuarios con niveles formativos medio y alto.

Con respecto a los primeros, la Figura 61 muestra cómo en la UE los valores en este perfil de usuarios duplican a los correspondientes al estrato de educación básica. La formación de grado es la elegida mayoritariamente, seguida de la formación ocupacional. Se mantiene la pauta de elevada dispersión, con países destacados como Finlandia y Reino Unido, y en este estrato los niveles para España se sitúan cercanos a la media europea.

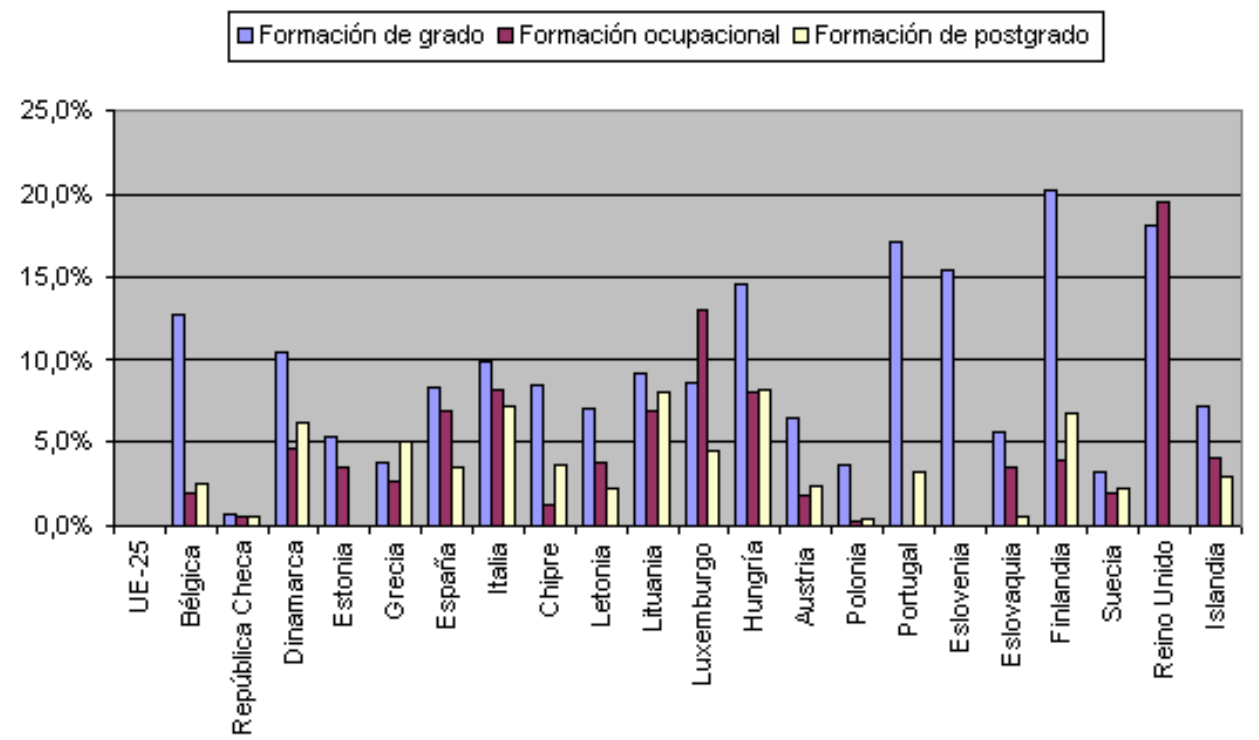

Fuente: Fundación Auna (2006).

Figura 61. Usuarios de formación on-line en los últimos 3 meses respecto del total de la población con nivel de educación medio. U-25 y EEA (2005). 
En cuanto a los usuarios pertenecientes a un nivel educativo alto, en la Figura 62 se observa que entre este tipo de usuarios en la UE los niveles de uso de la formación on-line son claramente superiores a los de estratos con niveles educativos más bajos y que predomina la formación de tipo ocupacional, aunque seguida muy de cerca por la formación de grado.

口Formación de grado $\square$ Formación ocupacional $\square$ Formación de postgrado

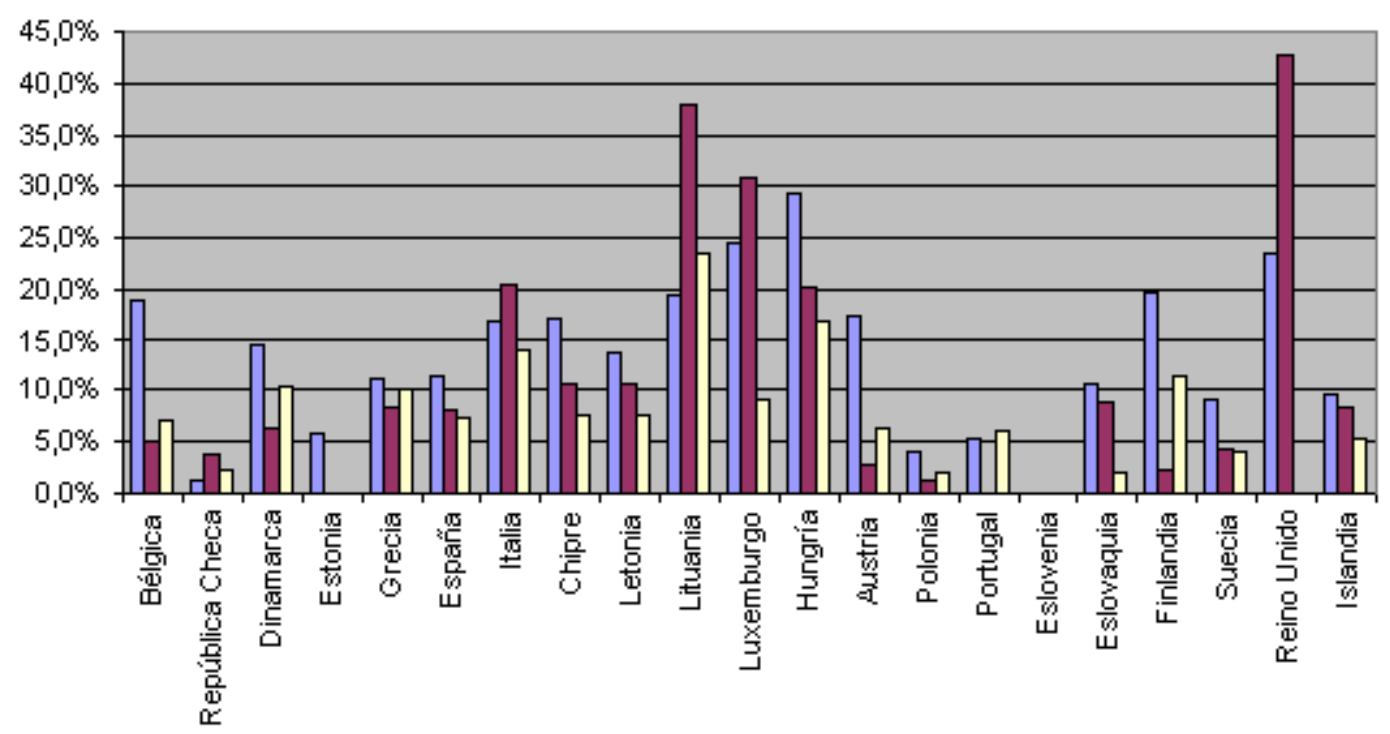

Fuente: Fundación Auna (2006).

Figura 62. Usuarios de formación on-line en los últimos 3 meses respecto del total de la población con nivel de educación alto. U-25 y EEA (2005).

Rasgos comunes a los estratos de formación media y baja son la elevada dispersión y el liderazgo de países como Reino Unido o Lituania. En el caso de España, los niveles de uso se encuentran por debajo de la media europea y el perfil de usuario también es distinto, predominando los que han elegido formación de grado.

A pesar de las notables diferencias entre países, lo que probablemente se deba a las divergencias en los planes de política educativa, de los datos analizados parece desprenderse que el tipo de formación on-line predominante es, en general, la formación de grado, lo que denota que la formación on-line es una herramienta altamente valorada por las personas que quieren mejorar su nivel de formación, consecuencia probablemente de la mayor flexibilidad ofrecida por este tipo de cursos frente a la formación presencial. Con respecto al perfil de usuario, los de niveles de educación media y alta presentan mayores porcentajes de usuarios de formación on-line que los niveles de educación baja.

2. Por ocupación

Una forma alternativa de analizar la orientación de la formación on-line predominante en cada país es centrar el enfoque en la distribución de los distintos tipos de formación según la situación de actividad profesional del usuario: trabajador por cuenta propia, por cuenta ajena o estudiante. En la Figura 63 se recogen los datos de la formación on-line realizada por los trabajadores por cuenta propia. En general, la opción de formación mayoritaria entre los trabajadores autónomos es la de postgrado, con excepción de Italia y Luxemburgo. En el caso de España, el porcentaje de trabajadores por cuenta propia que realizan formación de postgrado a través de Internet es similar a la media europea, si bien el perfil de formación es ligeramente distinto al ser inferior el porcentaje de usuarios en este estrato de la formación ocupacional. Con respecto a la UE-25, de nuevo se observa una elevada dispersión en la distribución por países, destacando especialmente Chipre, Hungría y Lituania. 


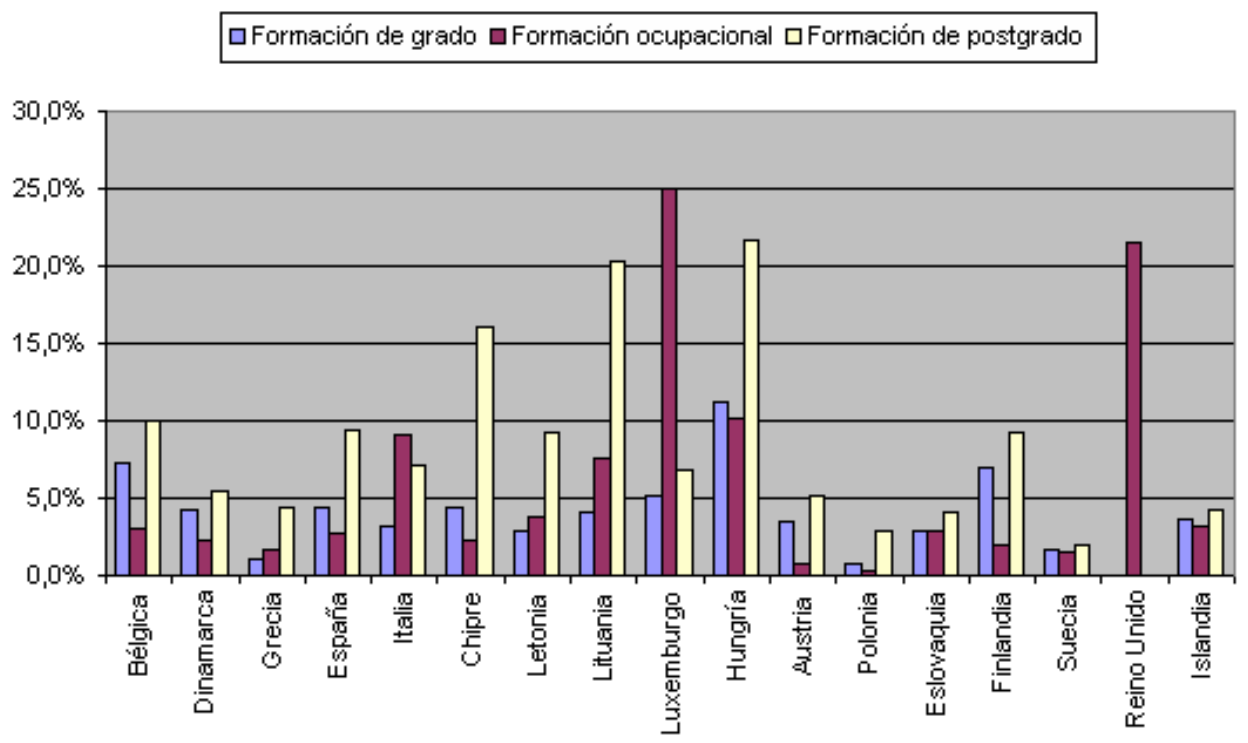

Fuente: Fundación Auna (2006).

Figura 63. Usuarios de formación on-line en los últimos 3 meses respecto del total de la población.Trabajadores por cuenta propia. U-25 y EEA (2005).

Con respecto a los trabajadores por cuenta ajena (ver Figura 64), a nivel europeo la formación mayoritaria para este tipo de trabajadores es la ocupacional, pero este resultado no es la pauta común a todos los países, lo que puede ser consecuencia probablemente de los distintos niveles de implantación de las herramientas de formación on-line en las empresas. Como en casos anteriores, destacan el Reino Unido, Lituania y Luxemburgo con los mayores niveles de trabajadores por cuenta ajena usuarios de formación on-line, en este caso ocupacional. En España, los datos muestran que los niveles de usuarios de formación on-line se sitúan por debajo de la media europea y, el número de usuarios de la formación ocupacional es ligeramente inferior al de usuarios de formación de grado.

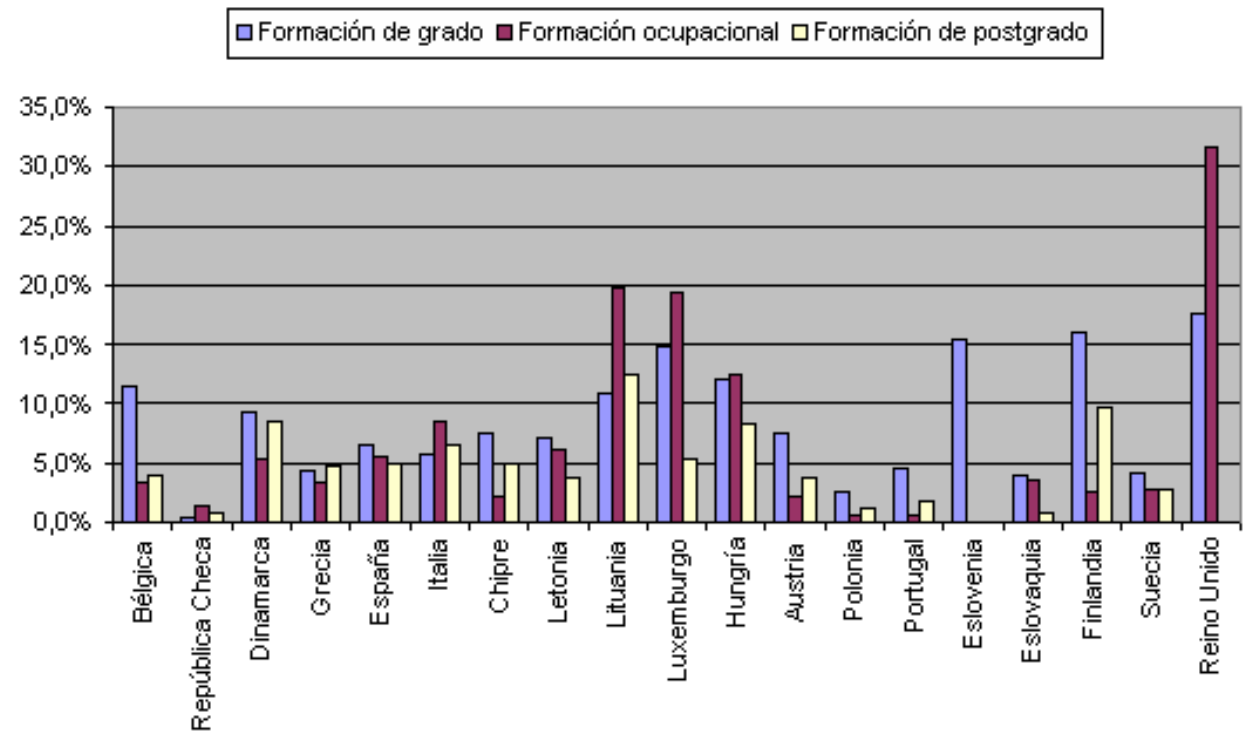

Fuente: Fundación Auna (2006).

Figura 64. Usuarios de formación on-line en los últimos 3 meses respecto del total de la población.Trabajadores por cuenta ajena. U-25 y EEA (2005). 
Por último, en la Figura 65 se analizan las opciones de formación on-line elegidas por los estudiantes. Entre este sector de la población, a pesar de las ya recurrentes diferencias entre países, se produce una pauta común: el predominio de los usuarios que optan por la formación de grado o de postgrado.

口Formación de grado aFormación ocupacional aFormación de postgrado

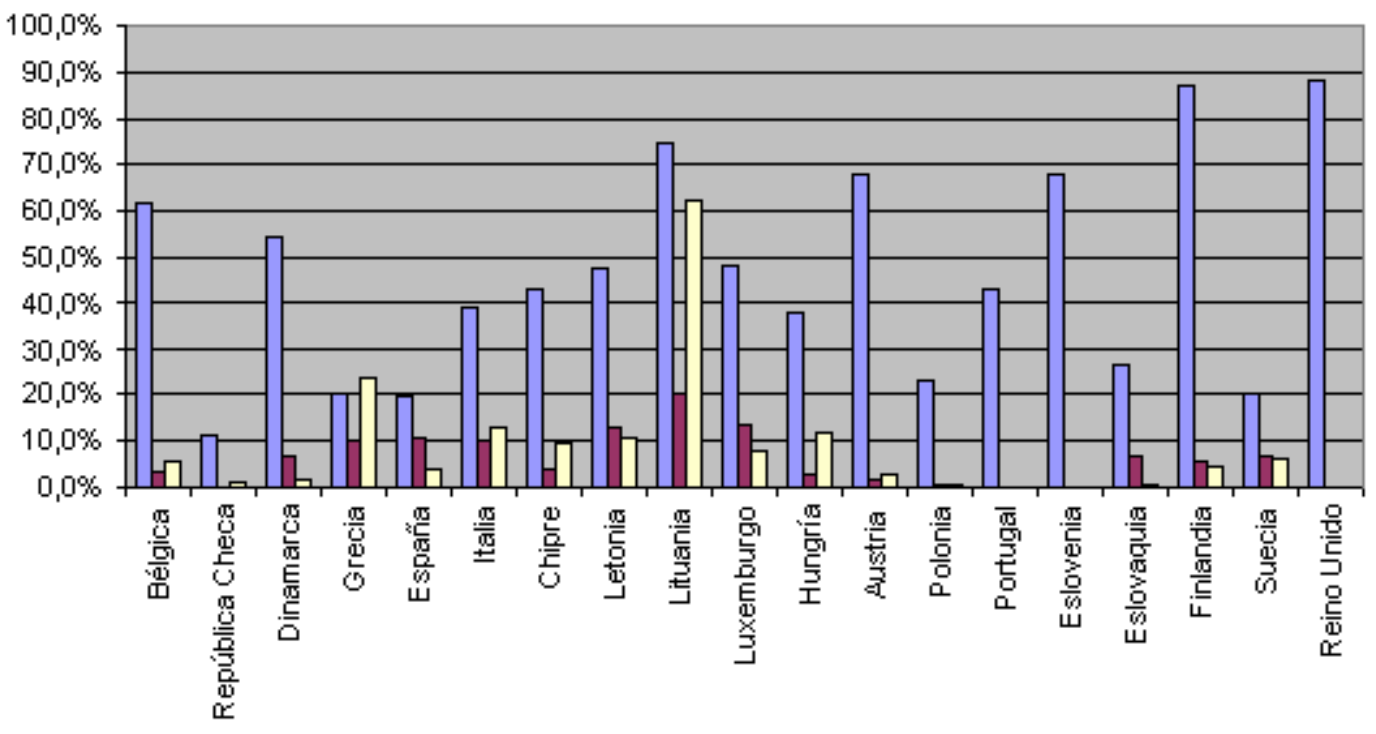

Fuente: Fundación Auna (2006).

Figura 65. Usuarios de formación on-line en los últimos 3 meses respecto del total de la población. Estudiantes. U-25 y EEA (2005).

Asimismo, los niveles de uso de las herramientas de formación on-line entre este estrato poblacional son notablemente mayores que en otros sectores analizados. La dispersión entre países es menos acusada, si bien se detectan ciertas diferencias entre los países punteros (Finlandia, Lituania y Reino Unido) y los que registran menores niveles (Grecia, España, República Checa y Suecia). Con respecto a nuestro país, las cifras sitúan a España por debajo de la media europea, aunque con una distribución de los tres tipos de formación similar a la de mayoría de los países de la UE, al predominar los usuarios de formación reglada.

3. Edad

Aunque no se dispone de datos acerca de la distribución por edades de los usuarios de la formación on-line, es posible obtener una aproximación a partir del análisis por edades de los usuarios de Internet (ver Figura 66), puesto que los usuarios de e-learning son un subconjunto de estos últimos. 


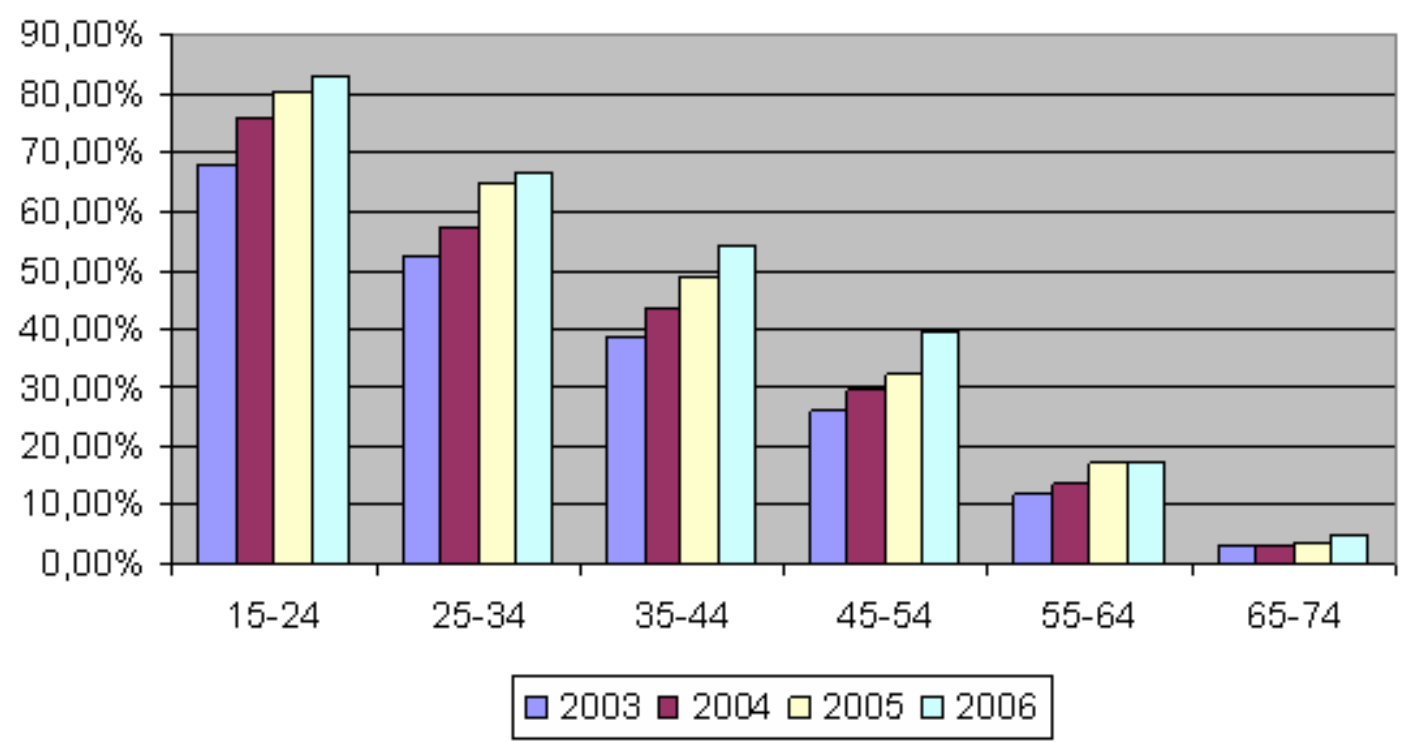

Fuente: elaboración propia a partir de datos del INE (2003:2006).

Figura 66. Distribución por edades del número de usuarios de Internet en España como porcentae de la población total.

4. Clase social

Igualmente, es posible obtener una aproximación al valor de este parámetro para los usuarios de formación on-line, empleando la distribución por clase social de los usuarios de Internet. En este caso, existe una gran diferencia entre las clases altas y las más bajas y, además, su evolución no varía sustancialmente a lo largo del tiempo, observándose mayores incrementos relativos en las clases sociales con mayor poder adquisitivo, si bien los incrementos se producen en todos los estratos de la Sociedad (Telefónica, 2006). Esta tendencia indica el peligro de que la llamada brecha digital aumente.

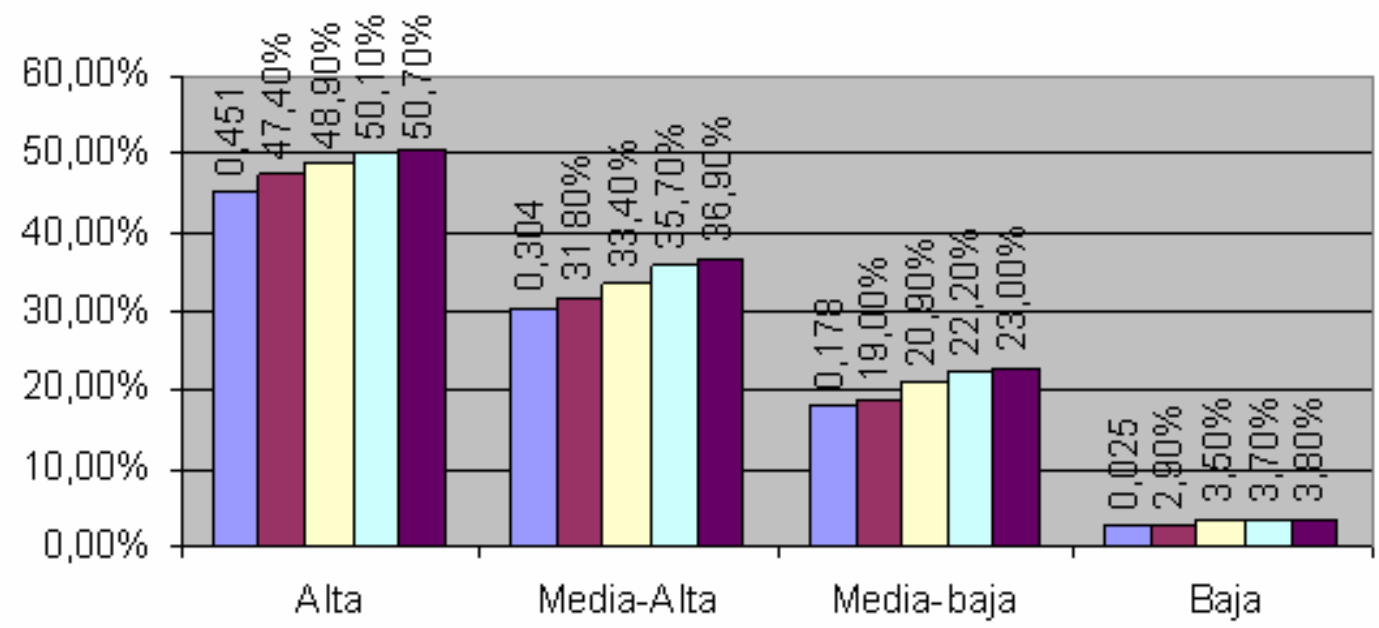

mar-05 a may-05 $\square$ nov-05 a mar-06 a may-06

Fuente: Informe Sociedad de la Información en España (Telefónica, 2006).

Figura 67. Internautas por clase social en España. 


\section{Género}

Aunque los datos que se presentan en este epígrafe son los relativos a la distribución por géneros de los internautas españoles (ver Figura 68), a la hora de extrapolar los datos a la formación on-line, es necesario tener en cuenta las desigualdades en la incorporación de la mujer al mundo laboral.

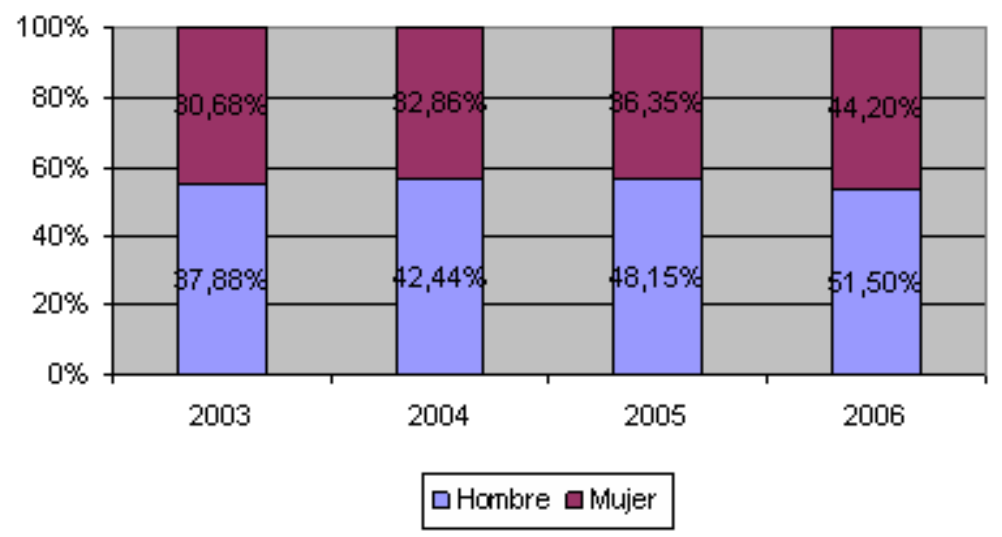

Fuente: elaboración propia a partir del datos del INE (2002:2006).

Figura 68. Género de los usuarios de Internet en España.

A partir de esta información es posible concluir que el perfil del estudiante que opta por el e-learning está muy definido. Se trata de un usuario de las nuevas tecnologías, familiarizado con el ordenador e Internet, que compatibiliza sus estudios con la actividad laboral, perteneciente a clases sociales medias o altas y entre 24 y 35 años. Estas conclusiones son respaldadas por el informe Formación a Distancia 2005 del Centro de Estudios Financieros que, además, añade que a proporción entre hombres y mujeres está muy igualada, tienen entre 28 y 31 años, la mayor parte de ellos trabaja de día y aprovecha la noche para estudiar, sobre todo entre las 20 y las 23 horas, franja horaria en que lo hace el $46 \%$. Además, la mayoría (62\%) se informó sobre el programa on-line a través de Internet.

\subsection{PROCESO DE DECISIÓN DEL CONSUMIDOR}

A partir del trabajo de Stanton (1997) y Foskett (2001), es posible identificar en el proceso de decisión del estudiante potencial las siguientes etapas:

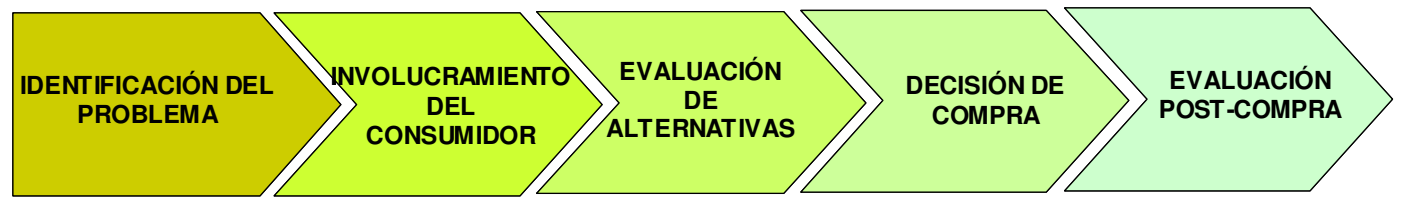

Figura 69. Etapas del proceso de compra.

1. Identificación del problema

En primer lugar, el consumidor detecta una necesidad que desea tener satisfecha, ya sea ésta un problema o una oportunidad. Esta necesidad puede provenir de factores internos al consumidor (por ejemplo, considerar que le falta formación en tal o cual área de conocimiento) o de factores externos a él (la exigencia por parte de la dirección de la empresa en que trabaja de que se forme en cierta materia).

Un factor importante es el grado es la importancia del problema y el grado de involucramiento del consumidor en su resolución. No es lo mismo que la matriculación en un curso on-line sea voluntaria para el consumidor que el que haya venido impuesta por algún factor externo. Si la exigencia de ver resuelto el problema es muy apremiante, el consumidor 
llevará a cabo una búsqueda activa de información que le asista en la resolución del problema. Las fuentes de información empleadas por el consumidor pueden ser muy diversas: desde conocidos o colegas hasta vendedores, pasando por fuentes públicas como Internet o revistas especializadas, por lo que las necesidades en esta etapa varían de acuerdo con las circunstancias particulares de cada individuo (Woodrow, 1998), aunque tienden a centrarse en los beneficios personales, sociales y económicos que les reportará el participar o no en el programa formativo de que se trate (Foskett, 2001).

2. Evaluación de alternativas

Tras recopilar toda esta información, el paso siguiente es la evaluación de las alternativas encontradas. Este punto es particularmente importante en el planteamiento de una estrategia de marketing, ya que conocer los factores que impulsan al consumidor a decidirse por una opción y no por otra resulta vital para la puesta en marcha de un marketing efectivo por parte de la institución educativa.

Los parámetros que influyen en los alumnos potenciales a la hora de decidirse por una institución de formación superior u otra han sido estudiados por un número considerable de autores. Watts (1972) desarrolló un modelo teórico del proceso de decisión de una institución de educación superior en un entorno caracterizado por una baja tasa de participación en la educación superior. Connor et al. (1999) sugieren que la elección es el resultado de la interacción de los estudiantes y el propio sistema educativo, en la medida en que ambos representan la demanda y la oferta del mercado. En esta misma línea se sitúa el modelo desarrollado por Bredo et al. (1993), que incluye, además de los anteriores, factores sociales, económicos y políticos. Con un enfoque integrador Foskett (2001) considera que la decisión final es la combinación de tres elementos interrelacionados entre sí: los estudiantes, la institución y el entorno externo.

El primero de los factores es la materia en que el alumno potencial desea formarse y ampliar sus conocimientos y habilidades. Si las materias o áreas de conocimiento que interesan al alumno potencial no se encuentran incluidas en la oferta de la institución, ésta quedará automáticamente descartada. Otro de los factores que señalan los estudios son de carácter geográfico, sin embargo, en el caso de la formación on-line, éstos presentan una menor importancia habida cuenta de que el carácter virtual de la relación entre el estudiante y la institución elimina las barreras espaciales. No obstante, es importante señalar que elementos de carácter regional o cultural como el idioma sí que determinan, en cierto modo, la decisión final.

Foskett (2001) agrupa los factores de influencia en varios grupos. Sin embargo, el trabajo de Foskett está orientado hacia un sistema de formación presencial y no resulta directamente aplicable a las universidades virtuales. En estos casos, conviene modificar la propuesta de este autor señalando los siguientes grupos de factores de decisión:

- Factores relacionados con las experiencias de aprendizaje en la institución.

- Factores relacionados con la institución, como la reputación de sus docentes o los servicios de asistencia a los estudiantes o los requisitos de admisión.

- Factores relacionados con el entorno externo, como las expectativas de conseguir un mejor empleo o una mejora en el nivel de vida.

En un estudio realizado por el Instituto Universitario de Postgrado sobre la demanda internacional de master y formación de postgrado on-line en lengua española (2006), se concluyó que la variedad de motivos que influyen en la decisión de los estudiantes, entre los que destacan los beneficios personales, la ampliación de conocimientos y la esperanza de conseguir una mejora laboral. 


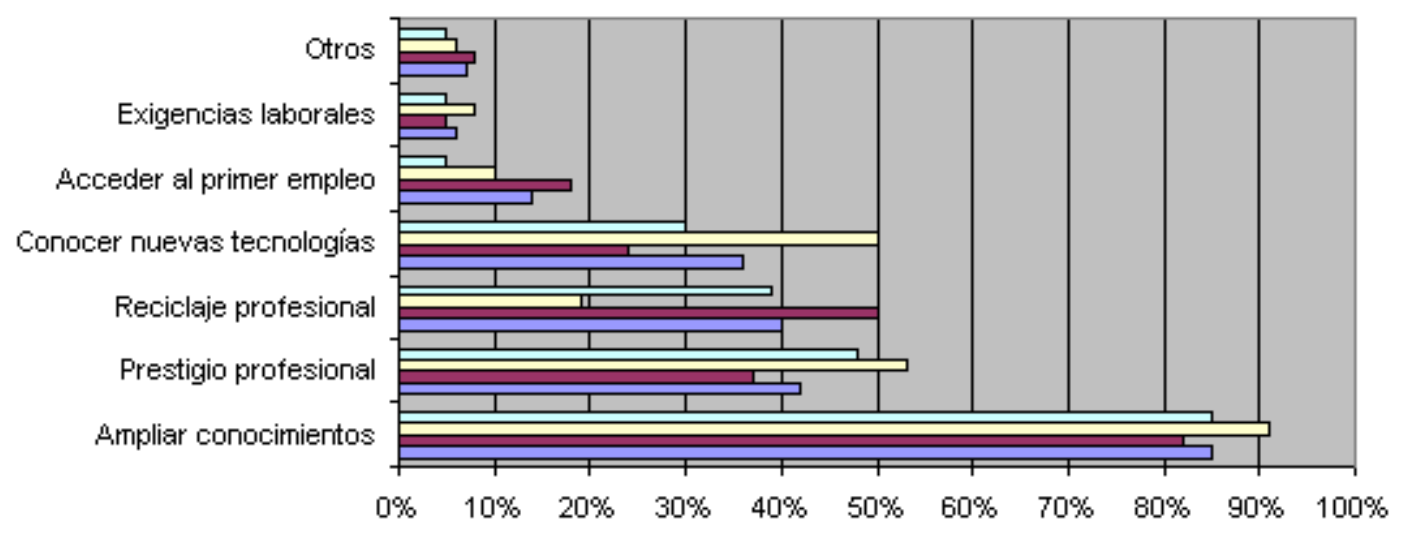

$\square$ Total $\square$ España $\square$ Países lationamericanos de habla hispana $\square$ Países de habla no hispana

Fuente: adaptado $^{25}$ a partir de UIP (2006).

Figura 70. Motivaciones señaladas por los candidatos para realizar un máster on-line.

Por supuesto, estos factores interactúan entre sí aunque lo realmente crítico es la visión particular e individual de cada estudiante y la importancia relativa que éste confiera a los factores de influencia. En Connor et al. (1999) es posible encontrar una relación de los factores de decisión más influyentes en distintos grupos sociales, descripción que resulta particularmente útil a la hora de identificar el mercado objetivo de la institución y desarrollar las acciones de marketing más adecuadas a dicho mercado objetivo (ver Figura 71).

Otro estudio en la misma línea es el informe Formación a Distancia 2005 del Centro de Estudios Financieros, según el cual el $63 \%$ de los estudiantes de formación on-line de postgrado señala los intereses personales como principal motivo a la hora de decidir realizar un curso a distancia, seguido de las necesidades en el desempeño del puesto de trabajo (45\%) y del reciclaje profesional (42\%). Sobre qué razones se tienen en cuenta a la hora de elegir un centro u otro para seguir este tipo de estudios, las más importantes son el prestigio del centro y el contenido del curso, según un 52\%, mientras que el precio es un factor menos determinante (27\%). Estos datos confirman las hipótesis de los modelos de Watts (1972), Bredo et al. (1993), Connor et al. (1999) y Foskett (2001) y el hecho de que el mercado de la Educación Superior se rige por el principio de la competencia por prestigio.

Por último, señalar que en este punto no es necesario un conocimiento detallado de la institución puesto que la evaluación suele hacerse a nivel general en términos de los factores indicados.

3. Refinado y toma de la decisión

Una vez pasado el primer filtro que supone la etapa anterior, tiene un lugar una selección más fina en la que se revisan los factores de decisión con un mayor nivel de detalle y se busca información adicional como la relación calidad/precio o la duración del programa. Al final de esta etapa, el consumidor ya ha elegido la institución en cuyo programa formativo se inscribirá.

4. Decisión de compra

Cuando el consumidor ya ha seleccionado la alternativa que finalmente escogerá, el siguiente paso es la decisión de compra propiamente dicha. Entre los factores que influyen en esta etapa están la cercanía, la velocidad en el servicio, el precio, la garantía y el valor añadido de la oferta.

${ }^{25}$ Los valores del gráfico han sido estimados por el investigador a partir de los gráficos originales, por lo que es posible que exista cierta inexactitud. Sin embargo, la tendencia general es la misma. 
5. Evaluación post-compra

Finalmente, tiene lugar un proceso de evaluación post-compra en el cual el consumidor experimenta algún tipo de reacción tras haber adquirido el producto o servicio. Si la reacción es positiva, con probabilidad muy alta el consumidor recomendará el producto o servicio a otros consumidores.

\begin{tabular}{|c|c|}
\hline & Factores de decisión más importantes \\
\hline \multicolumn{2}{|l|}{ Por sexo } \\
\hline Hombres & $\begin{array}{l}\text { Prestigio, vida social, calidad docente, } \\
\text { perspectivas de empleo, requisitos de admisión }\end{array}$ \\
\hline Mujeres & $\begin{array}{l}\text { Prestigio, calidad docente, perspectivas de } \\
\text { empleo, requisitos de admisión, ubicación, } \\
\text { soporte académico }\end{array}$ \\
\hline \multicolumn{2}{|l|}{ Por edad } \\
\hline Jóvenes (<21 años) & $\begin{array}{l}\text { Prestigio, vida social, calidad docente, } \\
\text { perspectivas de empleo, requisitos de admisión }\end{array}$ \\
\hline Jóvenes maduros (21-24 años) & $\begin{array}{l}\text { Calidad docente, soporte académico, } \\
\text { perspectivas de empleo }\end{array}$ \\
\hline Maduros (más de 25 años) & $\begin{array}{l}\text { Actitud hacia los estudiantes maduros, calidad } \\
\text { docente, soporte académico, posibilidad de } \\
\text { estudiar a distancia }\end{array}$ \\
\hline \multicolumn{2}{|l|}{ Por clase social } \\
\hline Clase media-alta & $\begin{array}{l}\text { Prestigio, calidad docente, perspectivas de } \\
\text { empleo, vida social, ubicación }\end{array}$ \\
\hline Clase trabajadora & $\begin{array}{l}\text { Perspectivas de empleo, calidad docente, } \\
\text { prestigio, soporte académico }\end{array}$ \\
\hline
\end{tabular}

Fuente: adaptado de Connor et al. (1999).

Figura 71. Factores de decisión en distintos grupos sociales. 


\section{CAPÍTULO 7 ANÁLISIS INTERNO Y CAPACIDAD PROVEEDORA}

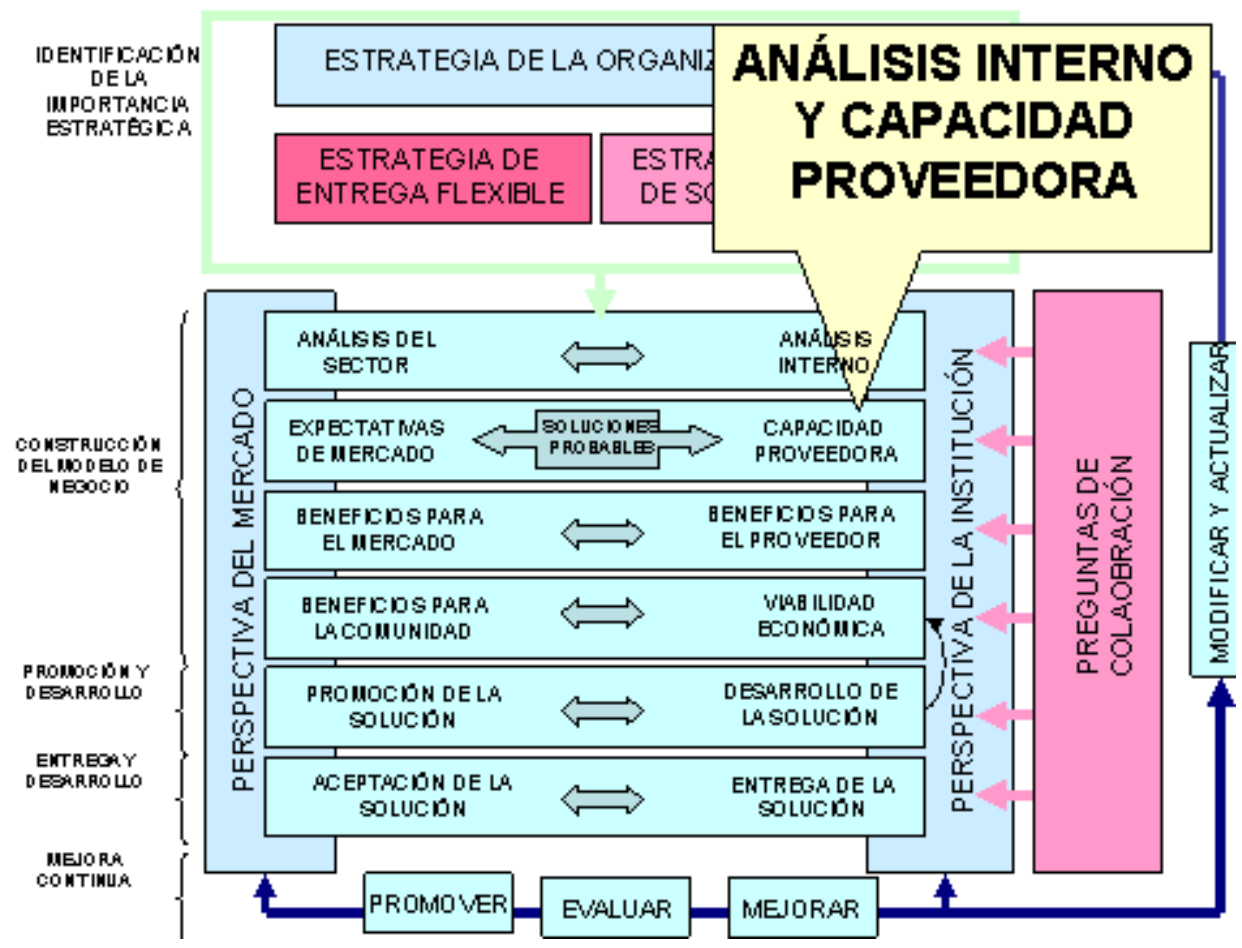

Las fuentes de ventaja competitiva residen en la reunión de factores internos y externos, mezclados por la organización de tal suerte que dicha mezcla resulte inimitable por otros competidores, sea duradera y sea valiosa para cliente (Duarte, 2004). Por tanto, sostener ese valor superior para el cliente supondrá que la organización debe ser capaz de construir barreras muy elevadas a la imitación y anticiparse a los posibles movimientos de los competidores.

Las ventajas competitivas posicionan de manera distinta a los competidores existentes, dependiendo del ámbito competitivo de sus respectivas cadenas de valor y de las estrategias genéricas a partir de las que aquellas se cristalizan. Todos estos aspectos se estudiarán en este capítulo. 


\subsection{ESTRATEGIAS COMPETITIVAS}

Las estrategias genéricas de Porter y Millar (1986), combinadas con el ámbito competitivo, dan como resultado cuatro fuentes de ventaja competitiva, tal y como se comentaba en el epígrafe 7.2.1.

VENTAJA COMPETITIVA

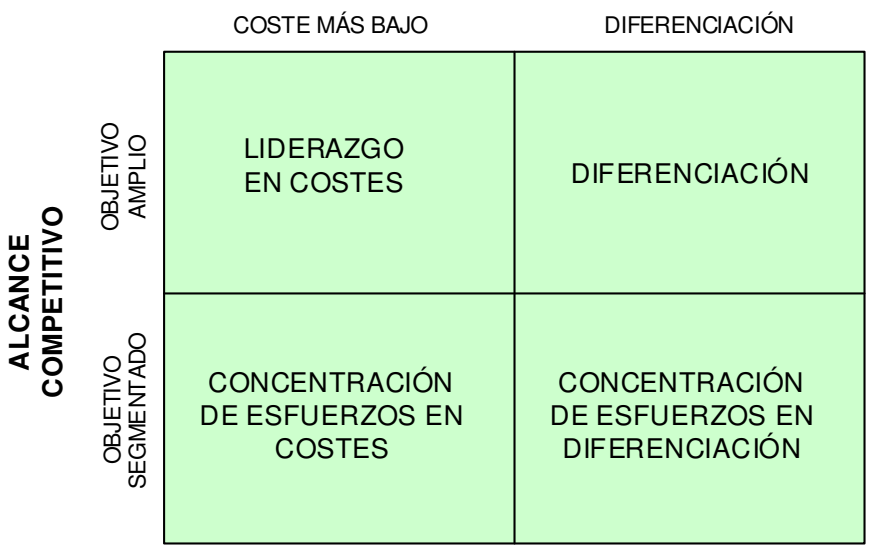

Figura 72. Estrategias genéricas según ventaja y alcance competitivos.

El escoger una alternativa exige el estudio de la cadena de valor y del sistema de valor del e-learning con el fin de identificar las actividades susceptibles de convertirse en fuente de ventaja competitiva, ya sea por diferenciación o por liderazgo en costes, en cuyo caso también deben tenerse en cuenta las consideraciones sobre las estructura de costes del e-learning que indican en el capítulo siguiente.

\subsection{CADENA DE VALOR DEL E-LEARNING}

Para analizar el impacto de Internet desde una perspectiva organizativa y de negocio se ha utilizado el marco teórico de la cadena de valor (Porter, 1980). Porter consideraba que una organización está formada por una secuencia de actividades que es necesario realizar para diseñar, producir, vender, entregar y dar soporte a sus productos o servicios y denominó a esa secuencia de actividades cadena de valor.

La cadena de valor caracteriza la actividad de negocio en términos de procesos, que Porter dividió en primarios y secundarios:

- Las actividades primarias son aquellas implicadas en la producción del producto y su venta o entrega al comprador y la asistencia posterior a la venta. Son:

- Logística de entrada: actividades relacionadas con la recepción, almacenamiento y distribución de insumos del producto (manejo de materiales, control de inventarios, devolución a los proveedores, etc.).

- Operaciones: actividades relacionadas con la transformación de insumos en la forma final del producto (maquinado, empaquetamiento, ensamblaje, mantenimiento de equipo, etc.).

- Logística de salida: actividades asociadas con la recopilación, almacenamiento y distribución física del producto a los compradores, como almacén de materias terminadas, manejo de materiales, operación de vehículos de entrega, etc.

- Marketing y ventas: actividades relacionadas con proporcionar un medio por el cual los compradores puedan comprar el producto e inducirlos a hacerlo (publicidad, fuerza de ventas, selección del canal, etc.). 
- Servicio: actividades relacionadas con la prestación de servicios para realizar o mantener el valor del producto, como instalación, reparación, mantenimiento, etc.).

- Las actividades primarias están ayudadas por las actividades secundarias: que dan soporte a las actividades primarias y se apoyan entre sí, proporcionando insumos, tecnología, recursos humanos y varias funciones de la empresa. Son las siguientes:

- Abastecimiento: se refiere a la función de comprar insumos utilizados en la cadena de valor, no a insumos comprados en sí.

- Desarrollo de Tecnología: cada actividad de valor representa tecnología, sea conocimientos (know-how), procedimientos, o la tecnología dentro del proceso.

- Administración de recursos humanos: actividades implicadas en la búsqueda, contratación, entrenamiento, desarrollo, etc. de todos los tipos de personal.

- Infraestructura de la empresa: consiste en varias actividades, incluyendo la administración general, planificación, finanzas, contabilidad, asuntos legales, etc. Apoya normalmente a toda la cadena de valor y no a actividades individuales.

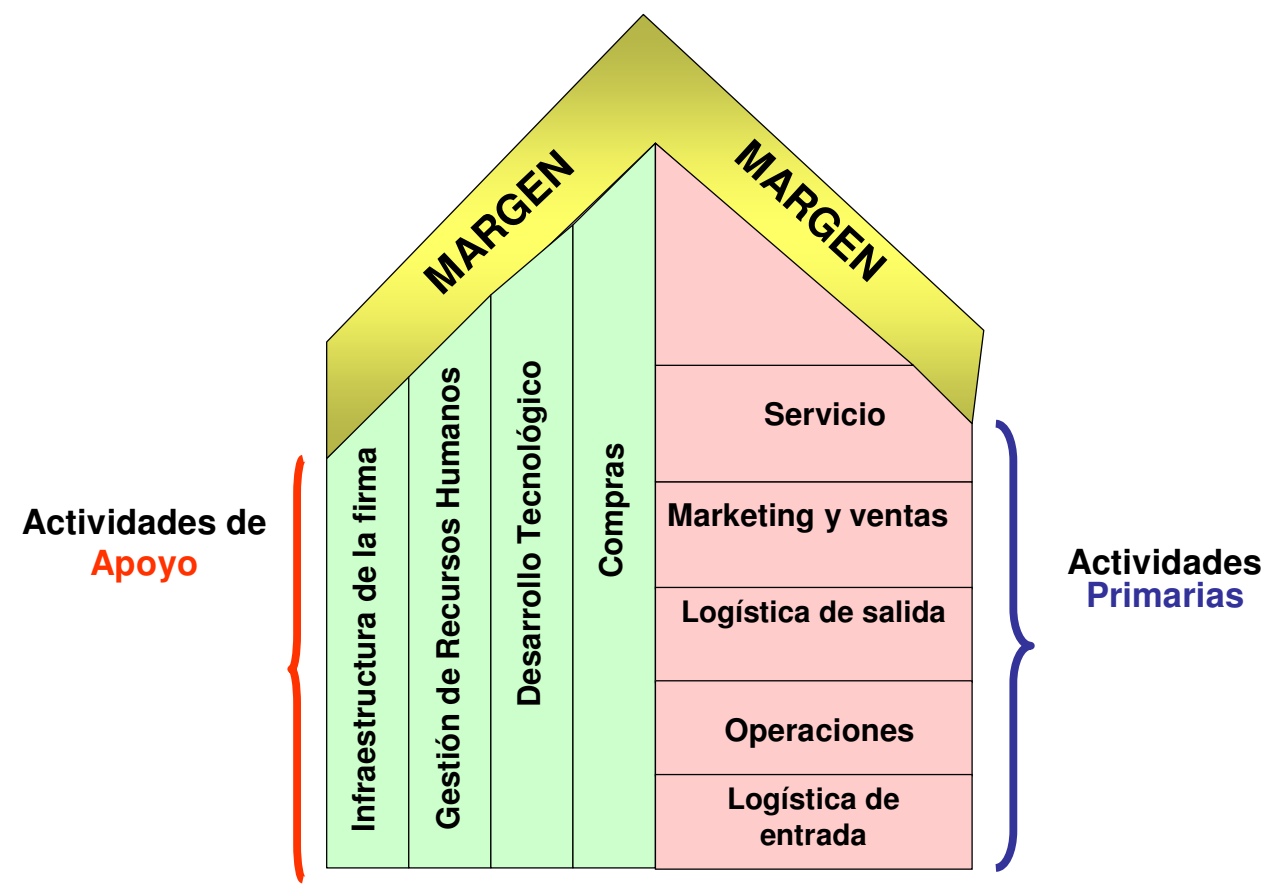

Fuente: adaptador de Porter (1985)

Figura 73. Cadena de valor.

La cadena de valor de Porter (1980) está muy orientada a sectores productivos en los que la información, más que una fuente de valor en sí misma, es un elemento de apoyo a los procesos o actividades que forman parte de dicha cadena. Sin embargo, autores como Andreu et al. (1996), sugieren que los vínculos entre procesos de la cadena, y que son soportados por el sistema de información de la entidad, pueden explotarse hasta tal punto que es posible reconfigurar la propia cadena de valor, si bien, tal y como señala Porter (2001), no en todas las actividades es posible crear valor únicamente con la información.

López y Sandulli (2007) observan que para crear valor con la información ésta debe convertirse en productos y servicios del mercado electrónico que sean exclusivos de la información, es decir, que se realicen a través de y con información (Rayport y Sviokla, 1996).

Amit y Zott (2001) identifican cuatro aspectos principales y catalizadores para la creación de valor en Internet: 


\section{Eficiencia}

La eficiencia de una transacción aumenta cuando los costes por transacción decrecen. Cuanto mayor sea la eficiencia de la transacción en un determinado negocio electrónico, menores son los costes y por consiguiente mayor es el valor creado. Esta eficiencia se puede obtener de varias formas, por ejemplo, reduciendo las asimetrías informativas que se producen entre vendedores y compradores proporcionando información actualizada.

2. Complementariedades

Surgen cuando un conjunto de productos proporciona mayor valor que el valor total que representan estos productos consumidos por separado. El análisis de Amit y Zott destaca que los negocios en Internet proporcionan un mayor potencial de creación de valor ofreciendo paquetes de productos/servicios complementarios a sus clientes. Estas complementariedades pueden ser verticales (por ejemplo, un servicio de orientación laboral y profesional o una agencia de colocación de estudiantes) u horizontales (por ejemplo, compra on-line en una librería que disponga en su catálogo de las obras de la bibliografía recomendada en un programa formativo) que son proporcionadas por empresas colaboradoras.

3. Retención

El potencial de creación de valor en e-business puede depender en gran medida de la capacidad de motivar a los compradores a realizar repetidas compras y a la capacidad de crear incentivos lo suficientemente atractivos para mantener vivas las relaciones con socios estratégicos. La retención impide la migración de clientes y socios estratégicos y tiene como base los costes de cambio (Teoría de Costes de Transacción), también la teoría de los Recursos de la Empresa que sugiere que la marca, la confianza entre comprador-vendedor contribuyen a retener.

4. Innovación

La creación de valor a través de la innovación ha sido ampliamente estudiada en la literatura y especialmente por Schumpeter (1934). Adicionalmente a las tradicionales fuentes de creación de valor a través de la innovación (introducción de nuevos productos y servicios; nuevos métodos de producción, distribución o marketing; o apertura de nuevos mercados), la evidencia demuestra que los e-business también pueden innovar en la forma de estructurar sus transacciones. Las características diferenciales de los mercados electrónicos (eliminación de las restricciones geográficas y físicas, posibilidad de intercambio de información del cliente al vendedor, y otras técnicas de optimización de los flujos informativos) hacen que las posibilidades para la innovación sean infinitas.

Teniendo en cuenta el impacto general de Internet en la cadena de valor, en las actividades relacionadas con la infraestructura, Internet potencia el uso de información en tiempo real para la toma de decisiones (Del Águila, Padilla y Serarols, 2006). En este sentido, Malhotra (1993) considera que Internet permite la fragmentación de procesos de negocio favoreciendo que las empresas ofrezcan una cartera reducida de productos y/o servicios y se concentren en sus competencias esenciales. Mediante la especialización éstas pueden implementar estrategias de colaboración con terceras para desarrollar aquellas actividades secundarias para su negocio. Además, Internet permite el desarrollo de nuevos y/o complementarios modelos de negocio (Rappa, 2005) basados en la creación de valor mediante el uso intensivo de la información (Rayport et al., 1995). Las organizaciones pueden crear valor sustituyendo actividades de la cadena de valor tradicional por actividades de la cadena de valor virtual; siendo éstas últimas más eficientes y flexibles.

Considerando lo anterior, Rayport y Sviokla (1995) definen lo que llaman de la cadena de valor virtual, basada en la obtención, organización, personalización, síntesis y distribución de la información. Por consiguiente, el primer paso que debe seguir toda organización para identificar las oportunidades y amenazas y los flujos de información en un mercado en el que desea competir, es el análisis de la cadena de valor y del sistema de valor (Ward y Peppard, 2002). 
Recogiendo las consideraciones anteriores, Daniel (1996), en un informe sobre la Open University del Reino Unido, divide las operaciones de una universidad virtual en actividades discretas agrupadas en cuatro categorías: docencia, investigación, gestión y soporte al estudiante:

\begin{tabular}{l|l}
\hline \multicolumn{1}{c|}{ Actividad } & \multicolumn{1}{c}{ Actividad } \\
\hline Docencia & Gestión institucional \\
\hline Planificación curricular & Preparar desarrollo institucional \\
\hline $\begin{array}{c}\text { Planificación de nuevos sistemas de } \\
\text { docencia }\end{array}$ & Relaciones públicas \\
\hline Control de calidad & Planificación de marketing \\
\hline Producción de cursos & Financiación \\
\hline Sistemas de estudiantes de nuevo ingreso & Recursos humanos y política universitaria \\
\hline Distribución de materiales didácticos & Soporte a los órganos de gobierno \\
\hline Tutorías y orientación & Infraestructura física \\
\hline Gestión de tutores y orientadores & Gestión económica \\
\hline Residencias & Compras \\
\hline Evaluación continua & Publicidad y promoción \\
\hline Investigación & Ventas \\
\hline Planificación de la investigación & Soporte a estudiantes \\
\hline Evaluación de oportunidades & Política y sistemas de admisión \\
\hline Desarrollo de planes & Registro de alumnos \\
\hline Soporte a la investigación & Recogida de fondos \\
\hline & Asistencia financiera \\
\hline & Acreditación económica \\
\hline & Impuestos externos \\
\hline
\end{tabular}

Fuente: adaptado de Daniel (1996)

Figura 74. Actividades de formación a distancia de la Open University.

Este autor plantea que el empleo de las actividades genéricas de Porter no resulta particularmente útil puesto que aproximadamente la mitad de las actividades se incluirían dentro de las actividades primarias. En su lugar, Daniel (1996) desarrolla su propia aproximación basada en las funciones internas de la universidad y clasifica las actividades primarias y secundarias de la siguiente manera:

- Actividades primarias:

- Investigación

- Desarrollo de materiales educativos, cursos y programas.

- Marketing y ventas.

- Servicios educativos.

- Actividades secundarias:

- Gestión de la institución

- Servicios de infraestructura 


\section{- Gestión de recursos humanos}

Sin embargo, hay autores que critican a Daniel (1996) el hecho de que su aproximación esté demasiado orientada al caso de la Open University y a las instituciones completamente virtuales. Por ejemplo, Panda (2003), postula que deben tenerse en cuenta también la evaluación de los programas educativos, el establecimiento de indicadores de calidad, la auditoria de calidad y la certificación.

Anderson y Elloumi (2004) postulan que el análisis de la cadena de valor es un medio de conseguir una posición competitiva estable y sólida, estableciendo una relación entre la ventaja competitiva y la cadena de valor y definiendo ésta de una manera más genérica y adecuada al caso del e-learning en las Universidades modernas. Conseguir una ventaja competitiva únicamente es posible a través del entendimiento profundo de las actividades de la cadena de valor de la institución y de su refinado con el fin de que proporcionen mayor valor para el cliente final que las de la competencia. Con estas consideraciones, Anderson y Elloumi (2004) adaptaron el trabajo de Porter resultando la cadena de valor representada en la Figura 75. Los elementos marcados en negrita coinciden con la definición original de Porter, los que aparecen en itálica deben ser revisados para incorporar las particularidades del e-learning $\mathrm{y}$, finalmente, los elementos en texto plano constituyen la entrada a la cadena de valor de la universidad.

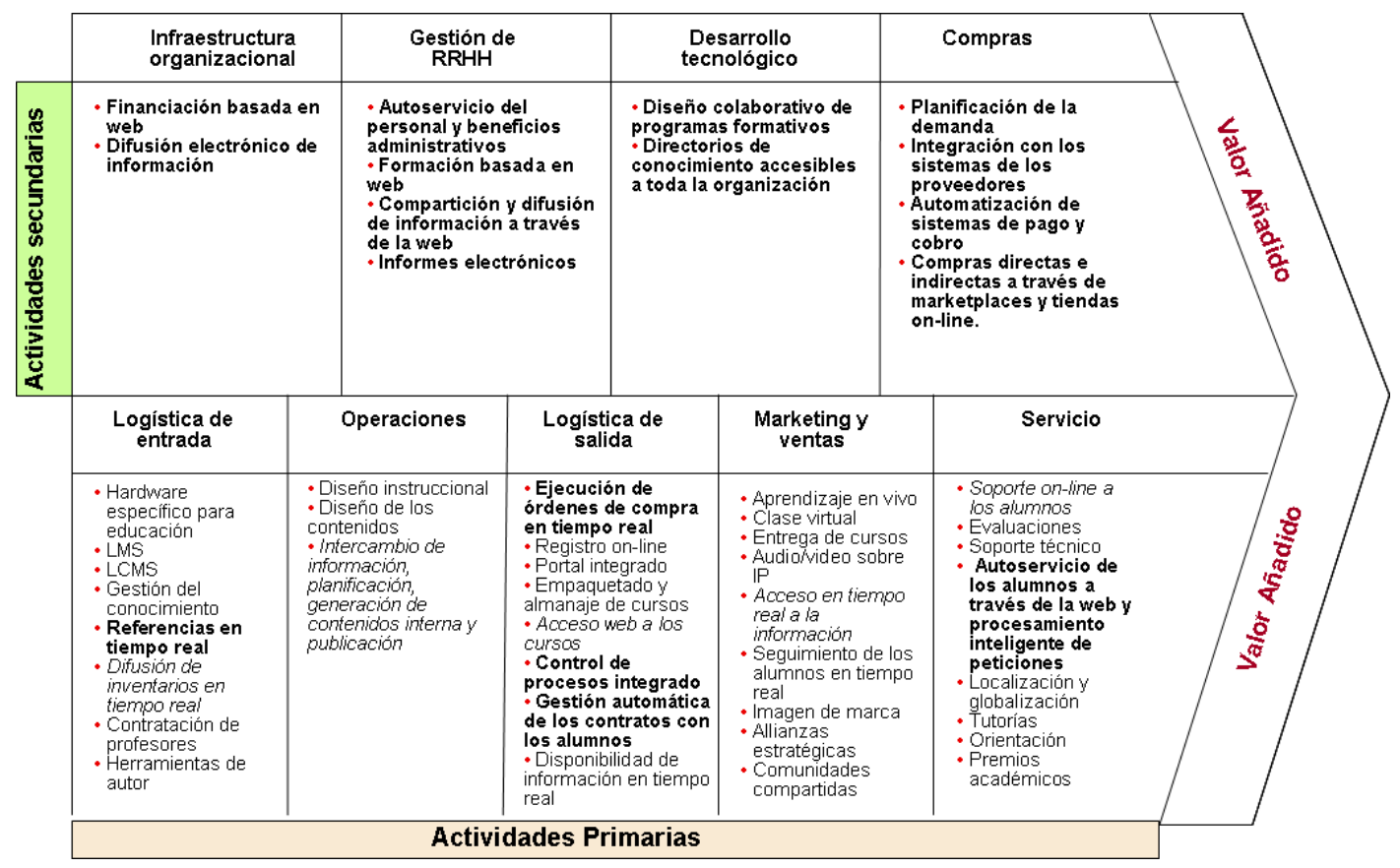

Fuente: Elloumi (2004), adaptado de Porter (2001).

Figura 75. Cadena de valor del e-learning

Centrándonos en la formación permanente, conviene observar la cadena de valor propuesta por Montesinos (2004) y que distingue las siguientes actividades (ver Figura 76):

- Análisis de la demanda: determina qué productos son los que se ajustan a las necesidades del mercado. Por esta razón, se debe identificar a los clientes potenciales y confeccionar una oferta que responda a dichas necesidades.

- Diseño del programa: consiste, por un lado, en el diseño académico del curso o programa formativo (definición de contenidos, metodología, temario, etc.) y, por otro lado, en el diseño organizativo (planificación operativa, propuesta de precios, previsión de gastos, logística del curso, etc.). Una vez diseñado el curso, deberán completarse los trámites necesarios según la normativa de cada universidad o institución educativa.

- Información y publicidad: engloba los procesos de promoción y distribución del programa formativo en cuestión. 
- Matrícula y gestión del ingreso: en aquellos cursos en los que existen requisitos previos al ingreso en el curso, debe haber una etapa de selección y admisión del alumnado en la que se recogen los documentos acreditativos necesarios, se realiza la selección y se comunica el resultado a los solicitantes.

En algunos casos, existe una oferta de becas que se han de gestionar entre los alumnos admitidos en el paso anterior. Una vez admitidos, se realiza la matrícula y la posterior gestión del cobro identificando los ingresos recibidos y haciendo un control de impagados.

- Docencia y soporte a la docencia: es el punto de interacción entre el profesor y el alumno y de la calidad de estos procesos dependerá, en gran medida, la percepción que tendrá el cliente (alumno) sobre la calidad de la formación que ofrece la institución.

- Finalización y control de calidad: la evaluación de la calidad se realiza a la finalización del curso, generalmente a través de encuestas. El resultado de la evaluación debe permitir, por un lado, confirmar un diseño determinado u otro y, por otro, indicar la calidad individual de cada uno de los profesores que han participado en el desarrollo del curso.

- Postventa: recoge los servicios ofertados a los alumnos una vez han finalizado el curso. El objetivo es fidelizarlos y fomentar su repetición en otros cursos, su promoción ante compañeros, etc.

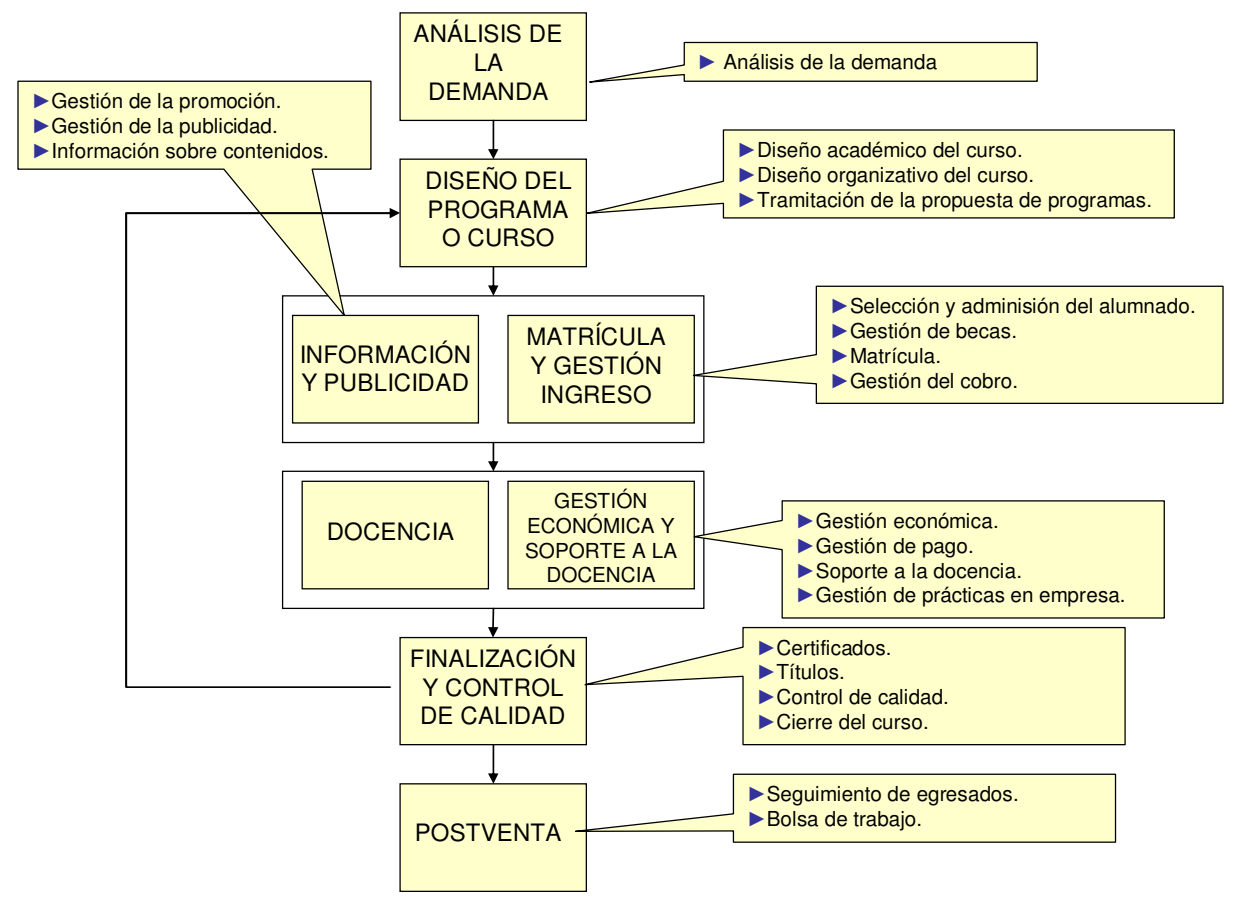

Fuente: adaptada de Montesinos et al. (2004)

Figura 76. Cadena de valor de la formación permanente universitaria.

A partir de los trabajos de Daniel (1996), Anderson y Elloumi (2004) y Montesinos (2004), se propone la siguiente cadena de valor para la formación on-line en Educación Superior de la Figura 77. La cadena de valor para una universidad virtual se encuentra integrada por actividades y procesos específicos de este tipo de instituciones (Castillo, 2004), en donde las actividades primarias soportan el conjunto de procesos conducente a la generación de producto de la actividad principal de la formación; y las actividades secundarias se asocian a las actuaciones de coordinación de los recursos inherentes a la acción docente y de soporte metodológicos y operativo de la misma, de información y atención al estudiante en la gestión de la producción y distribución de los bienes y servicios que la Universidad pone a disposición del estudiante, de 
gestión de la información para la mejora de la eficiencia del sistema y de dotación infraestructural y gestión administrativa de la actividad organizativa.

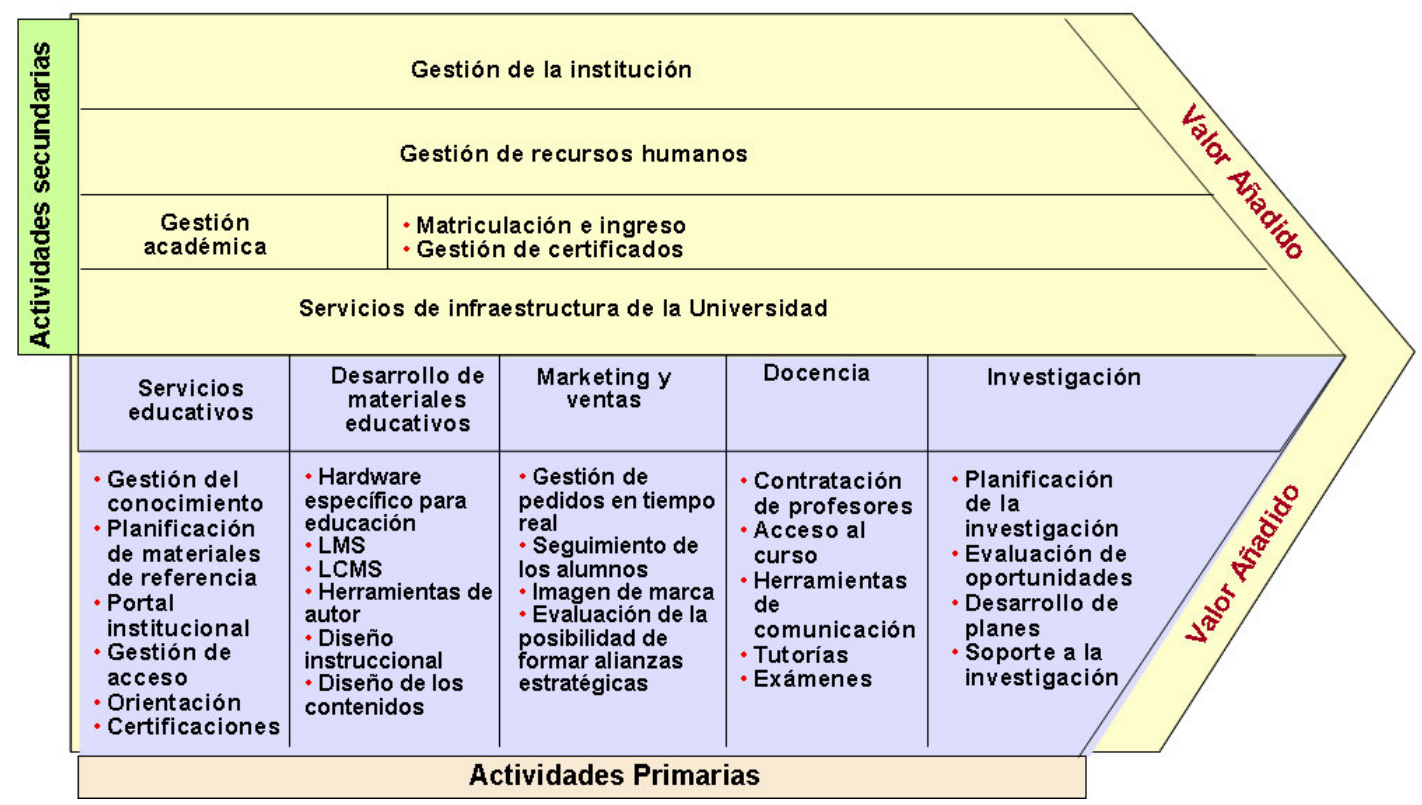

Figura 77. Cadena de valor para la formación permanente on-line.

\subsection{SISTEMA DE VALOR}

La cadena de valor también puede aplicarse para realzar las relaciones entre la organización y sus proveedores y entonces recibe el nombre de sistema de valor (Ward y Peppard, 2002; Dean, 2004). De este modo, un sistema de valor incluye a proveedores que ponen a disposición las entradas necesarias para la compañía y su cadena de valor. Una vez que la empresa crea los productos ellos pasan a través de la cadena de valor a los distribuidores, y así todo el camino hasta los clientes finales (los estudiantes, en este caso). Tanto la cadena de valor (a nivel interno) como el sistema de valor (a nivel externo), tienen como propósito inicial analizar las operaciones de la corporación para poder incrementar la eficiencia, efectividad y competitividad.

Elloumi (2004) extiende la cadena de valor al ámbito externo de la Universidad en función del conjunto de actividades de dicha cadena una organización concreta desarrolla y denomina sistema de valor a esta generalización del concepto de cadena de valor.

Así, es posible distinguir entre los siguientes tipos de proveedores:

- Proveedores de contenidos

- Proveedores de aplicaciones: el software específico para e-learning está compuesto por:

- Herramientas de autor

- Plataforma específica: LMS, LCMS, etc.

- Herramientas de comunicación

- Proveedores de hardware

- Proveedores de servicios 


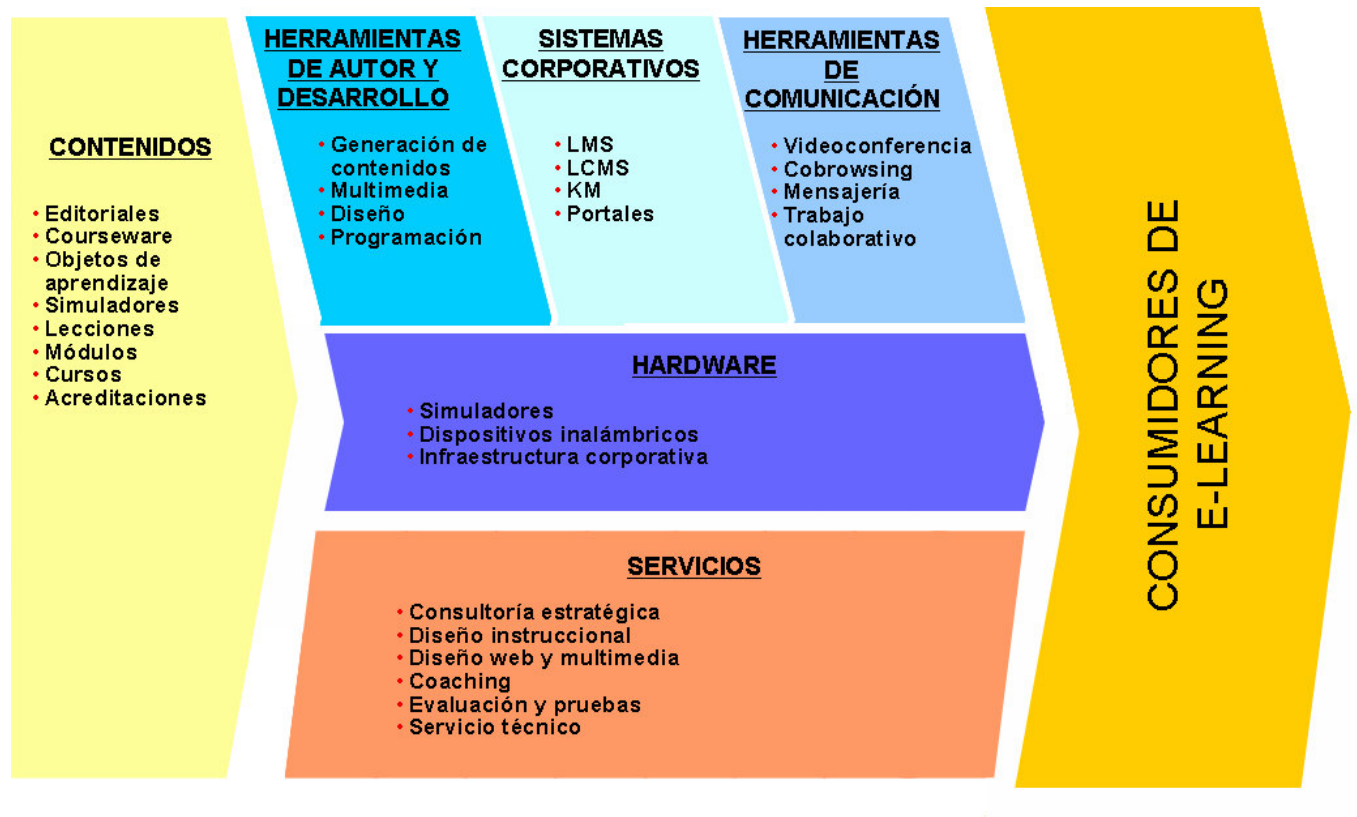

Fuente: adaptado de Elloumi (2004).

Figura 78. Sistema de valor del e-learning.

Por supuesto, existe la posibilidad de concentrar toda esta provisión en una única entidad que denominaremos proveedor integral. Este tipo de compañías pueden ayudar a los consumidores de e-learning a realizar todo el proceso de implementación y seguimiento de una forma sencilla, y ofreciendo los servicios de múltiples proveedores. Los primeros en moverse que consigan establecer una marca rápidamente probablemente estarán entre los líderes del mercado.

Generalmente, las Universidades tienen capacidad para abarcar todas las actividades de la cadena de valor y del sistema de valor. Sin embargo, en algunos casos se establecen alianzas estratégicas con otras universidades o con empresas privadas con el fin de compartir costes o de posicionarse en algún segmento concreto.

\subsection{VENTAJA COMPETITIVA}

De acuerdo con Su Hu (1995), una ventaja es una fortaleza que ha creado o desarrollado una organización referente a la competición, dentro de un terreno competitivo o relativo a una alternativa de la organización en un contexto particular. Por otra parte, Ma (1999a) establece que una ventaja competitiva es el diferencial en los atributos o factores de una organización que le permiten servir mejor a los clientes que otras organizaciones, creando así un mayor valor para el cliente y pudiendo alcanzar, de ese modo, un desempeño superior.

De estas dos definiciones se desprende el carácter relativo de la ventaja competitiva. En efecto, una ventaja es siempre relativa, no solamente concierne a las fortalezas que posee la organización, sino que a las que posean los competidores, ya que se basa en que las fortalezas de la organización que posee la ventaja sean únicas, difíciles de imitar y superiores a las de los competidores (Barney, 1991). Por otra parte, la consecución de la ventaja está condicionada al entorno en que se desenvuelve la organización, en donde juegan un papel importante la estructura del sector, la posición del mercado y el papel de los competidores (Porter, 1980; Scherer y Ross, 1990). De ahí la importancia de disponer de herramientas de análisis de sectores industriales que permitan identificar las posibles fuentes de ventaja competitiva, dadas las características de un sector industrial concreto.

Existen muchos tipos de ventajas derivadas los criterios en función de los cuáles ésta puede variar: actividades de la cadena de valor, fuentes externas, recursos y capacidades de la 
organización, beneficios obtenidos, estrategias genéricas, etc. Sin embargo, cualquier tipo de ventaja persigue el mismo objetivo: lograr resultados positivos para la organización en términos de rentabilidad, posicionamiento y cuota de mercado (Duarte, 2004). Estos factores se ven condicionados por dos factores comunes a cualquier tipo de ventaja: por un lado, la creación de un valor superior para el cliente por medio de productos y servicios diferenciados; y, por otro, el liderazgo en costes.

\subsubsection{Creación de ventajas competitivas}

La creación de ventajas competitivas, sobre todo desde la perspectiva de la gestión empresarial, es un tema que ha sido abordado por una gran cantidad de autores (Barney, 1991; Collis, 1991; Day y Wensley, 1988a; Hamel y Prahalad, 1990 y 1991; Hunt y Morgan, 1995; Ma, 1999a, 1999b, 1999c; Mintzberg, 1990; Porter, 1985, 1990, 1991, 1996). El marco general adoptado por la mayoría sugiere que las organizaciones obtienen ventajas competitivas mediante la implementación de estrategias que exploten sus fuerzas internas, respondondiendo a las oportunidades del medio ambiente, mientras neutralizan las amenazas externas y refuerzan sus debilidades internas (Barney, 1991). Las ventajas competitivas invariablemente deben conducir a posiciones de desempeño superior, caracterizadas por posicionamiento y rentabilidad (Kay, 1993; Ma, 1999a).

En una idea básica, los elementos de una ventaja competitiva se pueden agregar en tres dimensiones (Day y Wensley, 1988a): fuentes de ventaja competitiva, posiciones de ventaja y resultados. Aunque en la Figura 79 estas dimensiones estén expuestas secuencialmente y tengan como fundamento habilidades y recursos superiores para la creación de ventajas que permitan a la empresa reducciones de costes significativas en la oferta al cliente de un valor superior, los resultados como rentabilidad y cuota de mercado no depende única y excluvisamente de ellas.

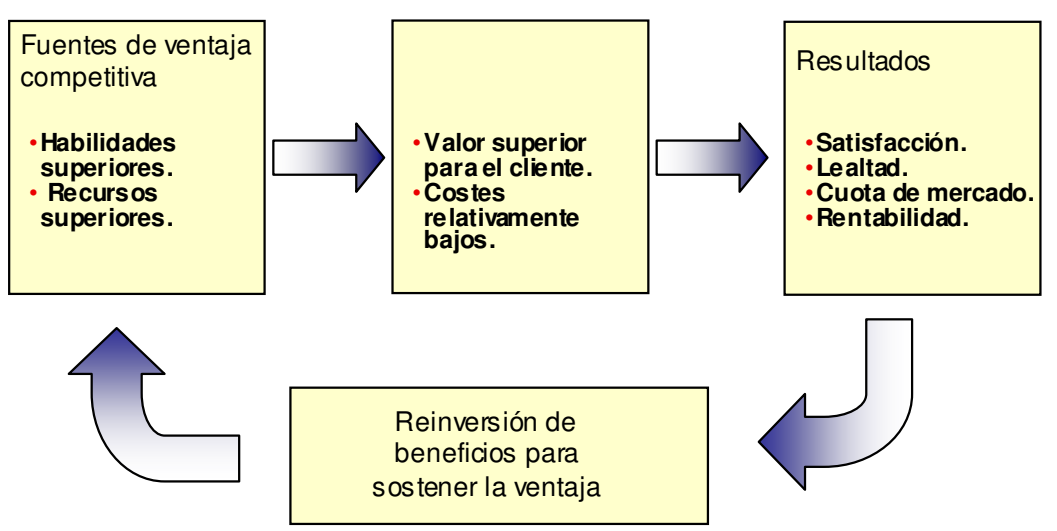

Fuente: adaptación de Duarte (2004).

Figura 79. Elementos de la ventaja competitiva.

Para alcanzar un desempeño superior, y en particular un desempeño superior persistente, una organización suele requerir de múltiples ventajas competitivas (Ma, 1999a). Por otra parte, sostener dicha ventaja competitiva va más a allá de la reinversión en dichos recursos (Day y Wensley, 1988a; Funk, 2003), aun cuando esta actividad sea medular para tal fin. A tal efecto, Slater (1996) afirma que una ventaja competitiva es sostenible cuando crea un valor que no puede 
ser erosionado fácilmente en el tiempo por medio de factores como calidad, servicio, bajos costes, velocidad, innovación o aprendizaje.

\subsubsection{VENTAJAS COMPETITIVAS DERIVADAS DE FACTORES INTERNOS}

Una parte importante de la literatura defiende que la fuente de la ventaja competitiva sostenible se encuentra en la visión basada en recursos (Barney, 1986a, 1991, 2001; Collis, 1991, 1994; Moingeon, et al., 1998; Rumelt, 1984; Wernerfelt, 1984). Estos autores consideran que las organizaciones poseen recursos o competencias valiosos, que incluyen también activos intangibles como las destrezas, la reputación y las relaciones. Sin embargo, estas corrientes de pensamiento no consideran que el valor competitivo de los recursos pueda ser fácilmente aumentado o eliminado por cambios en la tecnología, en el comportamiento competitivo e incluso por los cambios en las preferencias de los consumidores (Doyle y Wong, 1998; Porter, 1991).

Desde esta visión, Barney $(1991,2001)$ establece que los recursos que pueden dar origen a ventajas competitivas se agrupan en tres categorías:

- Recursos físicos: incluyen aspectos como la tecnología empleada, instalaciones, equipos y mobiliario, localización geográfica o la facilidad de acceso a materias primas.

- Recursos humanos: el entrenamiento, la experiencia, la inteligencia, las relaciones o las capacidades directivas son algunos ejemplos de recursos pertenecientes a este grupo.

- Recursos organizativos: como la estructura de la organización, su planificación formal e informal, los sistemas de control y coordinación o las relaciones informales entre los grupos de la organización.

Sin embargo, Barney $(1991,2001)$ no considera otros tipos de recursos como la información o el capital que, según Porter (1991), también pueden significar una fuente de ventaja competitiva. Otros autores consideran que los recursos y habilidades de las organizaciones son valiosos si apoyan a dichas organizaciones en la formulación e implementación de estrategias que mejoren su eficiencia $\mathrm{y}$, por tanto, las conduzcan a mejores lugares de rentabilidad y posicionamiento. Entre estos recursos y habilidades (llamados a veces competencias empresariales), Gilmore y Carson (1996) destacan la motivación, la creatividad y la comunicación, mientras que Bartlett y Goshal (2002), mencionan a las personas como importantes fuentes de ventaja.

Continuando con la visión basada en los recursos, Barney $(1991,2001)$ establece que una organización posee una ventaja competitiva cuando implementa una estrategia de crear valor que simultáneamente no esté siendo empleada por cualquier competidor actual o potencial y cuando dichos competidores son incapaces de duplicar los beneficios de dicha estrategia. El hecho de que una ventaja competitiva sea sostenible, no quiere decir que sea duradera, de hecho, pocas lo son y acaban desapareciendo porque sus características singulares declinan por sí mismas o porque disminuyen su valor en los mercados en los que aplican (Kay, 1994).

Mantener la puntuación generada por las ventajas existentes no quiere decir crear ventajas nuevas. La esencia radica en crear ventajas competitivas para el futuro con mayor rapidez a la que los competidores imitan las que una organización posee actualmente (Hamel y Prahalad, 1990). Los cambios que a menudo suceden en la estructura de la industria o en la competencia pueden provocar que los recursos que actualmente sean la fuente de una ventaja competitiva sostenible, se conviertan en poco útiles en un futuro. Aaker (1989) arguye que las condiciones para que una ventaja competitiva sea duradera se logran por medio de la forma de competir, el lugar donde se compite y las bases para la competición.

Porter (1996) ofrece una visión más centrada en funciones operativas de las organizaciones y menciona que las actividades son la unidad básica de la ventaja competitiva, pero que por sí solas no constituyen una fuente de ventaja competitiva, sino que más bien el origen de las ventajas competitivas se centra en la forma en que una organización configure y relacione sus actividades, 
a la vez que reconoce que la ventaja competitiva sostenible sólo es posible a través de compensaciones o intercambio con otras posiciones.

Para Quinn et al. (1996), el verdadero enfoque estratégico significa la capacidad de conseguir más poder para sostenerse en el sector seleccionado que ninguna otra organizción. Una verdadera ventaja sostenible se deriva generalmente de desarrollar aspectos que otros competidores no puedan reproducir o imitar fácilmente y que permiten crear valor para el cliente (Llonch, 1993).

En esta misma línea, una gran parte de la literatura, sobre todo en las dos últimas décadas, se ha centrado en investigar el papel del conocimiento como fuente de ventaja competitiva. Bernroider (2002) establece que las organizaciones dedicadas a las tecnologías pertenecen a la industria del conocimiento, ya que su principal producto es, precisamente, el conocimiento por sí mismo y su principal resultado es el conocimiento trasladado a productos y servicios.

\subsubsection{VENTAJAS COMPETITIVAS DERIVADAS DE FACTORES EXTERNOS}

El enfoque de la ventaja competitiva basada en factores externos está dominado por la teoría de la Economía Industrial, cuyo origen se centra en el paradigma Estructura-ConductaResultados (Bain, 1956). De acuerdo con este paradigma, la estructura de una industria determina su conducta o estrategia empresarial que, a su vez, decide sus resultados (Scherer y Ross, 1990).

Bajo este enfoque, se observa la ventaja competitiva como la posición superior de desempeño que una organización alcanza por medio de las estrategias genéricas de Porter (1980, 1985): la difenciación en productos o servicios por los que los clientes estén dispuestos a pagar un precio extra y el liderazgo en costes que permite a la organización ofrecer productos o servicios no diferenciados a un menor coste que los competidores. Por tanto, la estrategia empresarial no es sino una respuesta de las empresas a las presiones de la industria para sobrevivir y prosperar (Collis, 1991). En este contexto, una ventaja competitiva se hace sostenible en función del comportamiento de factores como las barreras de entrada, las economías de escala, los efectos de la curva de aprendizaje o el papel de los competidores, por lo que es posible su análisis a partir de la estructura del sector.

En los ambientes de negocios, una ventaja competitiva debe ser rara entre las organizaciones actuales. Muchas empresas poseen recursos y habilidades similares, por lo que, en estos casos, no constituyen una fuente de ventaja competitiva sino que la verdadera fuente es aquélla que se produzca de mezclar estos recursos y habilidades de tal modo que sean inimitables e insustituibles (Duarte, 2004). Porter (1991) denomina a esta mezcla elecciones directivas y afirma que para explicar el éxito empresarial se requiere de una teoría de la estrategia que enlace las circunstancias medioambientales con el comportamiento de la organización para lo que propone la cadena de causalidad representada en la Figura 80: 


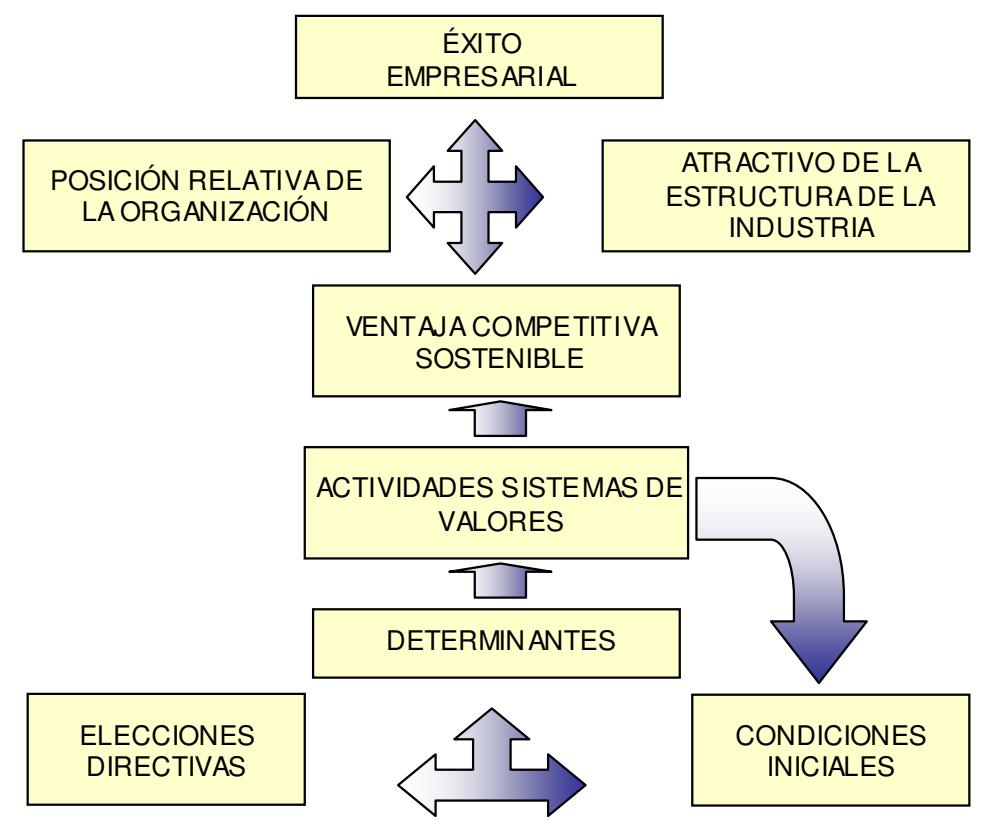

Fuente: adaptada de Porter (1991).

Figura 80. Cadena de causalidad del éxito en diversas industrias.

Bajo este enfoque, inicialmente el éxito empresarial podría estar en función de dos aspectos específicos:

- El atractivo del sector en el que la organización compite, dado por las cinco dimensiones competitivas de Porter (1985).

- La posición relativa de la organización en el sector.

Esta visión de Porter considera que la estructura de la industria es una función de factores endógenos, aunque también está parcialmente influida por las propias organizaciones que forman parte de ella. Es decir, la posición relativa de la organización en el sector no es una causa sino un resultado de dicha estructura y de la consecución de una ventaja competitiva sostenible (Duarte, 2004).

Sin embargo, desde la perspectiva de la Economía Industrial, una ventaja competitiva no puede examinarse independientemente del entorno competitivo de la organización, dentro del que se incluyen la línea de productos y servicios, los segmentos del mercado objetivo, el grado de integración vertical y el grado de relación con otras organizaciones con las que se haya coordinado la estrategia.

Porter (1991) reconoce también que la sostenibilidad de una ventaja competitiva vista de la perspectiva del rival depende del número de ventajas competitivas inmersas en la cadena de valor y, en particular, de los determinantes específicos que subyacen a cada una. Por lo tanto, la razón por la que algunas organizaciones consigan ventajas competitivas dentro de la cadena de valor responde a dos aspectos sustanciales (Duarte, 2004): las condiciones iniciales por las que a lo largo de su historia la organización ha obtenido una cierta reputación; y las elecciones directivas que ha realizado dicha organización independientemente de sus condiciones iniciales. 


\section{CAPÍTULO 8 VIABILIDAD ECONÓMICA}

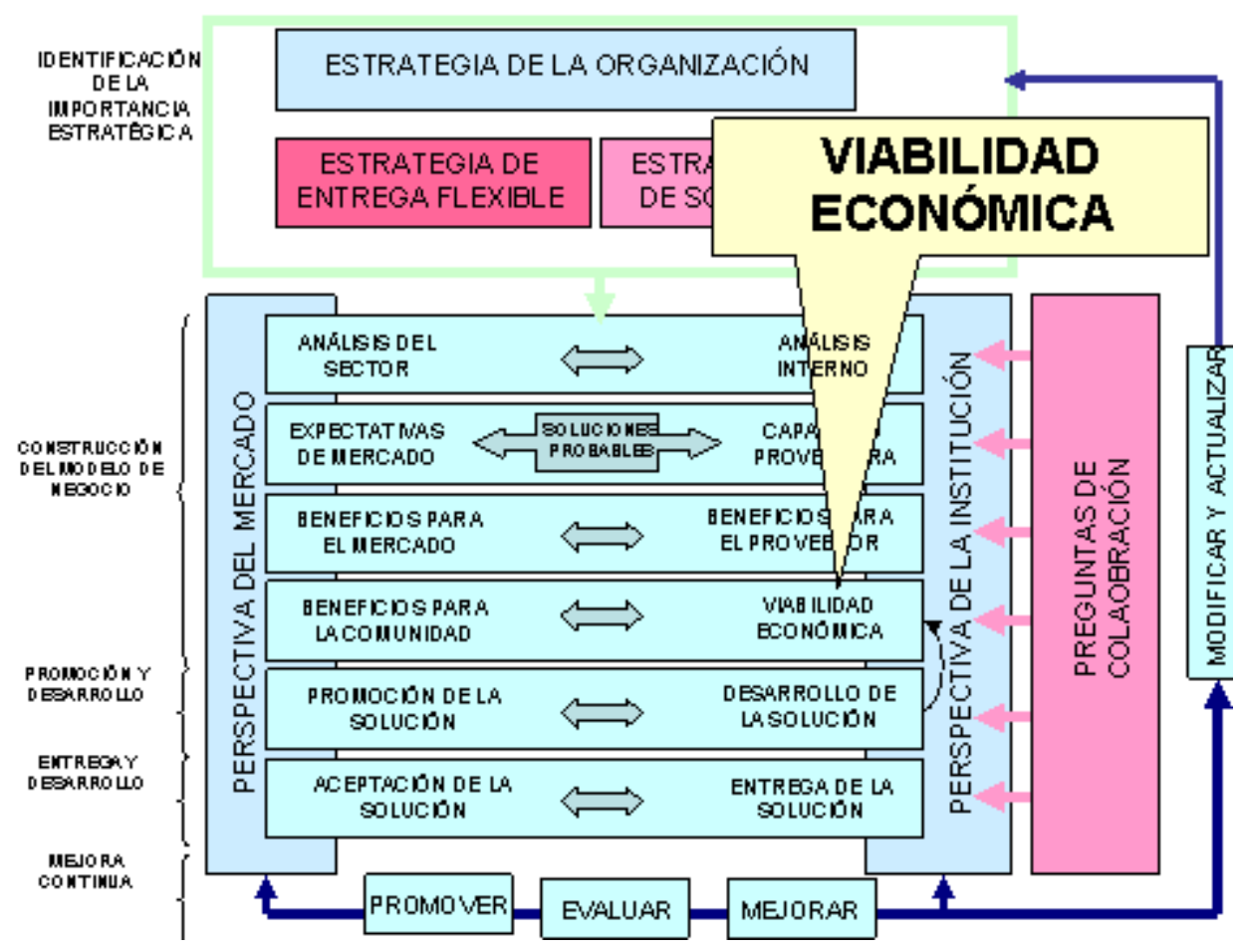

\subsection{ESTRUCTURA DE COSTES}

Las características productivas particulares del e-learning inciden sobre la dotación de recursos productivos y, por tanto, sobre la estructura de costes de la actividad.

El coste de un elemento puede definirse como el valor de los recursos que ha sido necesario emplear en su obtención, realización o puesta en marcha (Sánchez, Aragonés y Gómez-Senent, 1999). Sin embargo, a pesar de esta claridad en la definición, su aplicación práctica suele ser compleja, ya que es bastante común la existencia de recursos de utilización compartida en la elaboración de varios elementos, siendo la imputación de cada parte difícil. En el caso del elearning, la integración de las TIC en la actividad docente tiene una clara incidencia en recursos productivos (por ejemplo, infraestructura, equipamiento y trabajo) también empleados por las actividades de gestión y de investigación. Esto supondrá una limitación en el establecimiento de la estructura de costes del e-learning en instituciones educativas. 
La compartición de costes (y recursos) entre elementos distintos lleva a una primera clasificación de los costes:

- Costes directos: son aquéllos en los que se incurre directa y específicamente a causa de un determinado elemento. Perranton y Hülsmann (2000a) identifican cuatro partidas de costes directos en la obtención de los recursos tecnológicos y su aplicación a la actividad docente: costes de desarrollo (planificación y producción), costes de reproducción, costes de distribución y costes de soporte por la realización de la actividad. Rumble (2001) coincide con estos autores al indicar, principalmente, las siguientes partidas: desarrollo de materiales, seguimiento y soporte docente on-line de los estudiantes, provisión on-line de los servicios administrativos, la provisión de infraestructura y soporte necesarios para que el sistema de elearning pueda funcionar y la planificación y la gestión del sistema.

- Costes indirectos: son los que corresponden a recursos compartidos. En esta categoría se incluyen los gastos relacionados con el mantenimiento, la infraestructura TIC y los servicios generales, entre otros.

Sin embargo, la dificultad de imputación directa de costes en situaciones como ésta, en que el volumen de recursos compartidos es elevado, hace que resulte más práctico distinguir entre costes fijos y costes variables. Los primeros hacen referencia a los que no dependen del número de elementos producidos, mientras que los segundos son los que sí lo hacen. El trabajo de Hülsmann (2000) se basa en el estudio de once titulaciones de universidades e institutos politécnicos europeos y con un empleo muy variado de las TIC para el desarrollo de los mismos. En él establece que el coste total del programa o titulación, $T C$, depende de los costes fijos totales, $F$, y de coste variable unitario, $V$, según una función lineal del número de estudiantes matriculados, $s$ :

$$
T C(s)=F+V \cdot s
$$

En general, convendrá que la mayor parte de los costes sean variables y que los costes fijos sean mínimos.

Osiakwan y Wright (2001) hacen un análisis comparativo entre cursos de distinto tipo, en este caso entre cursos presenciales y cursos desarrollados a través de sistemas de aprendizaje a distancia basados en el acceso remoto y bajo un punto de vista de coste-beneficio. Dos son las conclusiones fundamentales que se extraen de sus resultados:

- El análisis descriptivo de las partidas de coste asociadas a cada una de las dos tipologías de cursos llega al detalle descripción que se recoge en la Figura 81, concluyendo que tanto los costes fijos como los costes variables de los cursos de e-learning analizados son superiores a los derivados de cursos presenciales, siendo también los ingresos más elevados.

- La mejora de la eficiencia de una institución a través del desarrollo de cursos de e-learning se consigue, fundamentalmente, a través de la escala: la posibilidad que ofrecen las TIC de disminuir los costes fijos asociados a la mano de obra (mediante la tecnificación del parte del trabajo docente) y de reducir los costes variables gracias al peso poco significativo de los costes de reproducción y liberación de los materiales didácticos.

Adicionalmente, cabe destacar también la evidencia empírica del elevado volumen de costes fijos generados por la importante inversión inicial requerida para el desarrollo de cursos basados en sistemas telemáticos, y que se explica por la integración de factores productivos de infraestructuras tecnológicas y recursos de naturaleza intangible (trabajo especializado y aplicaciones tecnológicas educativas y de gestión). En este sentido, hay que destacar que en todos los casos, los costes fijos mayores no se deben principalmente a la infraestructura tecnológica sino al trabajo, al requerirse tiempos más largos y, sobre todo, equipos humanos mayores (Kaplún, 2005).

Hülsmann (2000) comparó el comportamiento de costes de los programas educativos en distintos formatos, tratando de identificar un modelo de costes para el formato tradicional 
presencial, el formato a distancia y el e-learning. Su estudio concluye que los programas on-line tienen una estructura de costes inversa al los programas presenciales caracterizada por un peso superior de los costes de producción (los costes fijos de planificación y generación del curso son del $55 \%$, aproximadamente) sobre el total de los costes respecto de la importancia de los costes derivados de desarrollo docente (costes variables de reproducción, distribución y soporte). Esta importancia relativa de los costes de producción en el formato on-line tampoco coincide con la de los cursos a distancia tradicionales, en donde es de alrededor del $80 \%$ de los costes totales (Bates, 1995; Rumble, 1997). Por otra parte, también se observa que el volumen de los costes directos es distinto para los tres formatos, de manera que la eficiencia del curso depende del número de estudiantes que participan en él (y que han pagado por ello). Así, para cursos con gran número de matrículas (más de 100 estudiantes por grupo) el coste unitario mínimo se obtiene en los sistemas tradicionales de educación a distancia; si la dimensión es media (entre 15 y 1000 estudiantes), el mínimo se encuentra en los sistemas de e-learning; y, finalmente, si la dimensión es reducida (menos de 15 estudiantes), los sistemas de enseñanza presencial se manifiestan más eficientes en coste.

\begin{tabular}{|c|c|}
\hline & Peso sobre los costes totales \\
\hline \multicolumn{2}{|l|}{ Cursos presenciales } \\
\hline \multicolumn{2}{|l|}{ Costes fijos } \\
\hline $\begin{array}{l}\text { Preparación del curso (programa, } \\
\text { documentación, etc.) }\end{array}$ & 100 \\
\hline \multicolumn{2}{|l|}{ Costes variables } \\
\hline Gestión de estudiantes & 4 \\
\hline Gestión material del curso & 20 \\
\hline Desplazamientos & 43 \\
\hline Profesores & 19 \\
\hline Otros & 14 \\
\hline \multicolumn{2}{|l|}{ Cursos de e-learning } \\
\hline \multicolumn{2}{|l|}{ Costes fijos } \\
\hline Preparación del material didáctico & 27 \\
\hline Diseño instruccional y tecnológico & 26 \\
\hline Tecnologías de red & 20 \\
\hline Telecomunicaciones & 27 \\
\hline \multicolumn{2}{|l|}{ Costes variables } \\
\hline Evaluación & 6 \\
\hline Edición y distribución de material & 29 \\
\hline Gestión de estudiantes & 3 \\
\hline Consultoría & 24 \\
\hline Tutoría & 35 \\
\hline Soporte & 3 \\
\hline
\end{tabular}

Fuente: adaptado de Osiakwan y Wright (2001)

Figura 81. Partidas de costes fijos y variables en la realización de cursos presenciales y de elearning. 
A partir de la identificación de categorías de costes fijos y variables, han aparecido propuestas de definición de la naturaleza de las partidas de coste más o menos importantes (Morgan, 2002; Bates, 1999), tal y como ilustra la Figura 82. Esta definición y catalogación de elementos permite aislar la evolución de los efectos de cada partida sobre la estructura de costes.

\begin{tabular}{l|c|c}
\hline \multicolumn{1}{c|}{ Partidas } & Coste fijo & Coste variable \\
\hline Expertos en la materia & $\mathrm{X}$ & \\
\hline Diseño instruccional & $\mathrm{X}$ & \\
\hline Especialista en Internet & $\mathrm{X}$ & \\
\hline Diseño de interfaces & $\mathrm{X}$ & \\
\hline Marketing & $\mathrm{X}$ & \\
\hline Servidor & $\mathrm{X}$ & \\
\hline Biblioteca & $\mathrm{X}$ & \\
\hline Derechos de propiedad de materiales y programas & $\mathrm{X}$ & \\
\hline Profesores internacionales & $\mathrm{X}$ & \\
\hline Tutores docentes & & $\mathrm{X}$ \\
\hline Servicios de administración & & $\mathrm{X}$ \\
\hline Canon de la Universidad & & $\mathrm{X}$ \\
\hline
\end{tabular}

Fuente: adaptado de Castillo (2004).

Figura 82. Partidas de costes asociadas al e-learning en función de su categoría.

Las categorías de costes fijos más importantes en términos de peso relativo son el factor trabajo especializado y las diferentes aplicaciones de las TIC. Y entre los correspondientes a la tipología de costes variables, cabe destacar la presencia también del factor trabajo especializado (fundamentalmente soporte docente on-line), y del mantenimiento de las TIC y su aplicación a los servicios administrativos de matrícula y gestión de los materiales (Bates, 1999; Rumble, 2001).

Adicionalmente a la definición de categorías de costes, se identifican una serie de clases de costes inherentes a la realización de la actividad de e-learning, las cuales son igualmente una adaptación de las clases generalmente aceptadas en la gestión de los costes organizativos de las instituciones de educación a distancia (Rumble, 1986):

- Recursos humanos.

- Bienes de infraestructura no tecnológica, que incluye los servicios asociados a la reparación y mantenimiento.

- Plataforma tecnológica, hardware y software específico.

- Costes operativos.

- Recursos centrales, que comprende los servicios transversales de carácter institucional, como biblioteca o sistemas de información.

- Costes de estructura, que integra los costes fijos de administración, tanto los que presentan una relación directa con la gestión administrativa de los estudiantes como las matrículas o la gestión de los materiales, como los más vinculados indirectamente. 
En aras a facilitar su análisis, un modo de ordenarlos es el propuesto por Kaplún (2005) que los agrupa en tres grandes áreas: producción de materiales, realización de cursos y costes de gestión e infraestructura. Por otra parte, además de los costes propiamente dichos, es necesario incluir en el estudio una serie de factores que influyen en el comportamiento de los costes a lo largo del tiempo, entre los que destacan los siguientes (Telelearn $\left.{ }^{26}, 1999\right)$ :

- Duración del programa: un curso más largo permite una mejor distribución de los costes fijos $y$, por tanto, implica un menor coste fijo unitario por estudiante.

- Repetición: los programas o los componentes individuales de cada curso pueden ser fácilmente reproducidos sin incurrir en costes adicionales.

- Duplicación: sin añadir costes de producción, los cursos y programas puede ser duplicados. Este elemento presenta esencialmente el mismo efecto que el manifestado en la duración del curso (mejor base de reparto de los costes fijos y menores costes unitarios por estudiante).

- Número de estudiantes: el aumento en el número de estudiantes permite asumir un claro efecto de escala $y$, consecuentemente, reducir el coste unitario por estudiante. Adicionalmente, y dado el valor relativamente reducido de los costes variables, un número de estudiantes adicional provocará un incremento muy reducido de los costes totales, potenciando la reducción de los costes totales medios.

- Punto de equilibrio: de los puntos anteriores se deduce que el número de estudiantes a partir del cual los sistemas telemáticos presentan retornos positivos es superior, en términos generales, al asociado a sistemas de formación tradicionales. Es también importante destacar que la posición del punto de equilibrio es directamente proporcional a la dotación del contenido y recursos multimedia.

\subsubsection{Planificación y producción de materiales}

Aglutinan las diferentes partidas consideradas como costes fijos asociados a la etapa inicial de búsqueda y planificación, incluyendo el factor humano, el desarrollo de materiales didácticos, los costes iniciales de las licencias de software y la dotación de hardware y los costes asociados a la ubicación del personal y el equipamiento.

La producción de materiales en formato electrónico implica la participación de un importante del factor humano, concretado en las principales partidas de trabajo académico y trabajo técnico (Arizona Learning Systems, 1998). Además, el tipo de tecnología educativa aplicada en el material determina la dotación de recursos humanos y tecnológicos desatinados a su generación, incidiendo así en el volumen de la estructura de costes. En efecto, un hecho de particular importancia en la estructura de costes del e-learning es que las diferentes tipologías de tecnologías de producto. Estas tecnologías pueden agruparse en dos grandes categorías:

- Tecnologías síncronas: integran elementos multimedia y recursos de aprendizaje basados en Internet.

El profesor y el alumno se escuchan, se leen y/o se ven en el mismo momento, independiente de que se encuentren en espacios físicos diferentes. Esto permite que la interacción se realice en tiempo real, como en una clase presencial.

- Tecnologías asíncronas, que integran elementos tecnológicos como la conferencia a través de un ordenador, la televisión digital, etc.

El profesor y el alumno interactúan en lugares diferentes y en tiempos distintos. Esto permite al alumno, a través de documentación, material y actividades en línea, entregados por el profesor, realizar su propio proceso de aprendizaje, planificando su ritmo y su tiempo de

${ }^{26}$ Telelearn es un proyecto del programa Leonardo (en el marco de acciones para la cooperación europea en materia de educación) de la Comisión Europea que desarrolló durante 1998 y 1999. 
dedicación al estudio y de participación en tareas o actividades individuales o en grupo, sin necesidad de estar en conexión directa con los profesores y los otros alumnos.

Estas tecnologías presentan una estructura de costes muy similar (Bates, 1994; Bartolic y Bates, 1999; Hülsmann, 2000), con la excepción de las partidas integradas en el grupo de desarrollo (costes fijos), y ofrecen un comportamiento dependiente del número de estudiantes (costes variables). A pesar de este comportamiento homogéneo de los factores en conformación de las estructuras de costes, los datos disponibles revelan que las funciones de costes totales y de costes unitarios asociados a cada tecnología manifiestan un comportamiento diferenciado (pendiente de la curva o la $V$ en la ecuación de Hülsmann).

Si se analizan de forma separada las dos tecnologías, considerándolas como generadores de un producto formativo independiente y autónomo con una metodología de aprendizaje particular asociada, se puede constatar que la estructura de costes fijos y variables es diferente en cada tecnología.

La utilización de las tecnologías síncronas como tecnología de producto, comporta la generación de costes fijos de desarrollo relativamente reducidos derivados, principalmente, de la infraestructura técnica necesaria (Rumble, 1989). Los costes de reproducción y distribución del curso son también muy reducidos. Sin embargo, no ocurre lo mismo con los costes de soporte que pueden ser significativos y que integran tanto los costes laborales de la acción docente como los de soporte técnico (formación y asistencia) a los diferentes usuarios (profesores, tutores y estudiantes) y los costes de vinculación de esta tecnología con otros recursos. Bates (1994) considera estas tres últimas partidas como variables. De esta manera, la función de costes totales a medio plazo sitúa su inicio cerca al origen de ordenadas con una pendiente significativa.

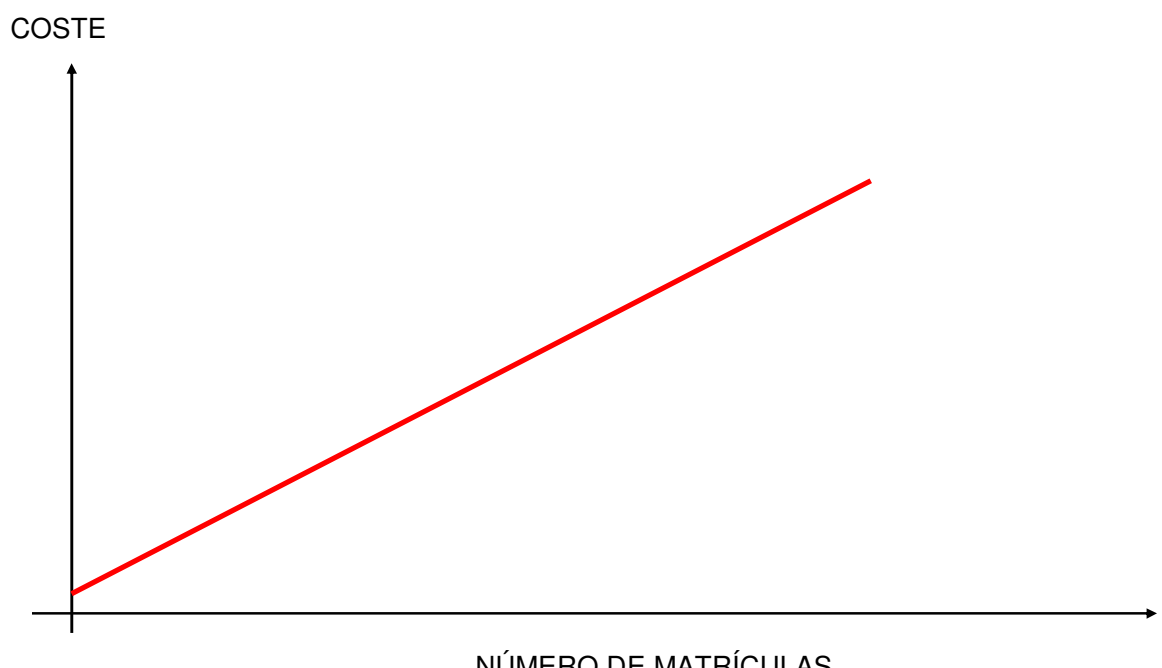

Fuente: adaptado de Bates (1994).

Figura 83. Costes directos totales asociados a las tecnologías síncronas.

Por otra parte, en las tecnologías asíncronas los costes de desarrollo se incorporan los costes fijos asociados a la distribución de los programas formativos. Así, este grupo de costes integra tanto los costes del factor trabajo asociados a la tarea de los equipos interdisciplinares destinada a la planificación y producción (académicos, expertos en contenidos, tecnólogos, metodólogos, diseñadores), como los costes de capital relativos a la infraestructura tecnológica 
requerida tanto para la producción del producto formativo como para el funcionamiento del entorno de aprendizaje (equipos, servidores, aplicaciones informáticas, etc.). Este hecho implica que su cuantía sea muy significativa. Por otra parte, los costes de reproducción tienden a cero y los costes de distribución serán reducidos (Castillo, 2004). Por último, los costes de soporte directamente asociados a la utilización de las TIC presentan una cuantía considerable derivada de las necesidades de formación y asistencia tecnológica y de los costes laborales asociados a la realización de la acción docente. En este caso, la función de costes presenta un origen en ordenadas superior al de las tecnologías síncronas (debido a los mayores costes fijos), tal y como recoge la Figura 84.

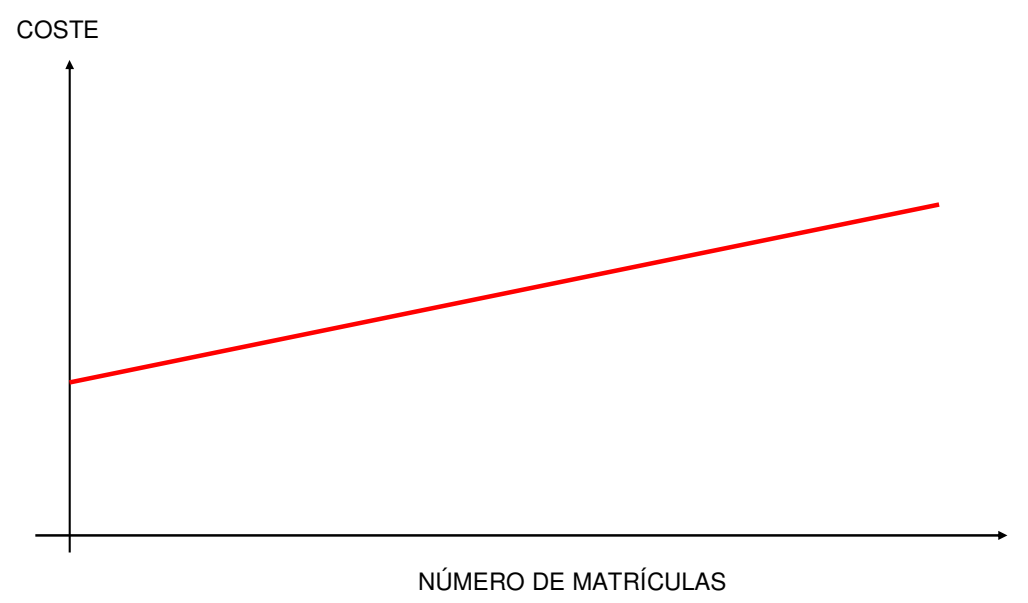

Fuente: reproducido de Castillo (2004).

Figura 84. Costes directos totales asociados a las tecnologías asíncronas.

Finalmente, en la Figura 85 se recoge el resumen de las principales conclusiones del análisis de la estructura de costes de las dos tecnologías consideradas.

\begin{tabular}{c|l}
\hline Tipo de tecnología & \multicolumn{1}{c}{ Descripción } \\
\hline Tecnologías síncronas & $\begin{array}{l}\text { Ausencia de costes fijos si existe la dotación tecnológica adecuada. } \\
\text { Costes variables significativos por las necesidades tecnológicas de } \\
\text { comunicación que aumentan con el volumen de estudiantes. }\end{array}$ \\
\hline Tecnologías asíncronas & $\begin{array}{l}\text { Costes iniciales importantes atribuibles a la inversión tecnológica y } \\
\text { la intervención de personal especializado, junto con costes variables } \\
\text { de reproducción y distribución muy reducidos. }\end{array}$ \\
\hline
\end{tabular}

Fuente: elaboración propia a partir de Bates, 1994; Perranton y Hülsmann, 2000; Castillo, 2004.

Figura 85. Estructura de costes de las TIC.

\subsubsection{Realización del curso}

Integra una parte de las partidas de coste correspondientes a la distribución de materiales y la acción docente on-line (Kaplún, 2005; Telelearn, 1999). Además, es una práctica extendida (Perranton, 2004; Kaplún, 2005) considerar dentro de este apartado el coste de oportunidad para 
los estudiantes, si bien, éste no tiene una repercusión directa sobre la estructura de costes de la institución educativa.

En cuanto a los costes de distribución, de nuevo dependen del tipo de tecnología empleada (Kaplún, 2005). Fernández (2001) compara los costes asociados a diferentes tecnologías de distribución, algunas de ellas aplicables a modelos formativos presenciales. Los resultados de esta comparación se resumen en la Figura 86. Para el caso virtual, queda corroborada la dependencia del tipo tecnología síncrona o asíncrona en la determinación de los costes fijos y variables asociados a la distribución de los materiales didácticos que forman parte del programa formativo.

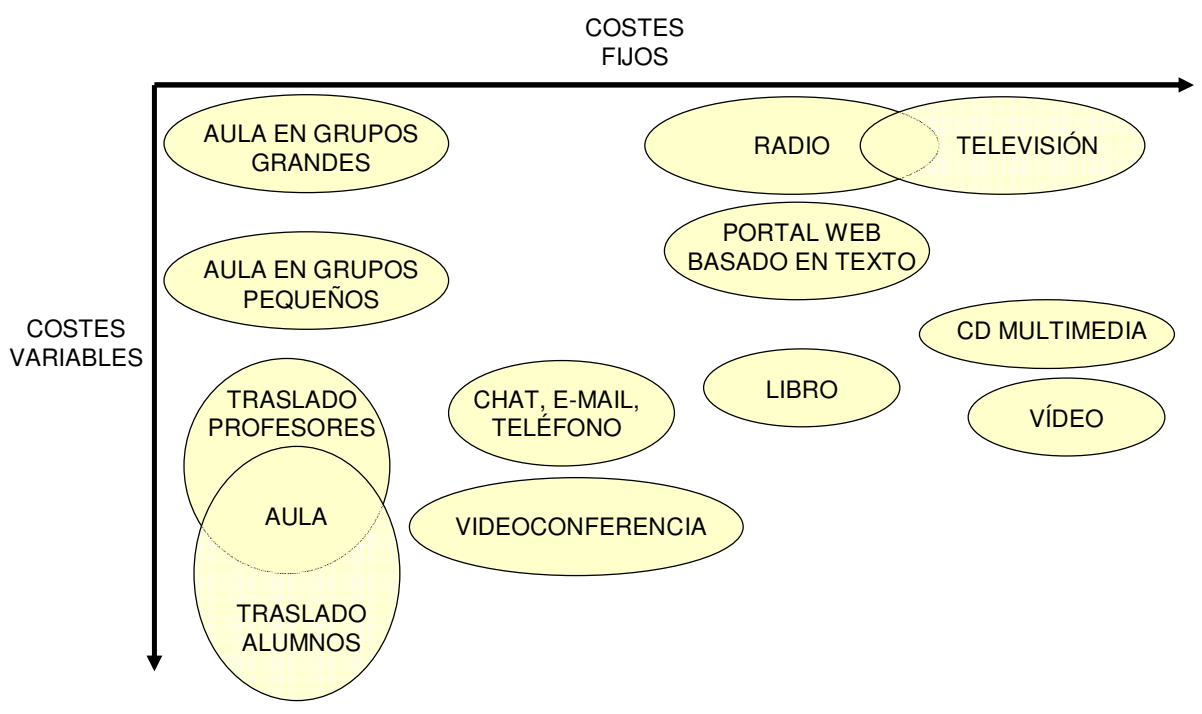

Fuente: modificado de Kaplún (2005).

Figura 86. Costes fijos y variables asociados a distintas tecnologías de distribución.

En cuanto a la docencia on-line, el carácter virtual de la formación supone la reducción de gastos de desplazamiento, de costes de oportunidad en términos de tiempo, tanto de profesores como de estudiantes, y de la exigencia de infraestructuras físicas. Sin embargo, el soporte docente on-line a los estudiantes está comportando, a la inversa de lo supuesto a priori, la generación de un importante coste atribuible al factor trabajo por el hecho de tratarse en la práctica de tarea muy intensiva en mano de obra, con un grado incluso superior a la docencia presencial (Boettcher, 1999). La introducción de las TIC en la docencia está produciendo la sustitución del trabajo por trabajo con nuevas capacitaciones y habilidades tecnológicas, más que sustitución del trabajo por tecnología (Castillo, 2004).

Aunque no se suela incurrir en costes adicionales por ello, conviene tener en cuenta la actividad de seguimiento académico, ya que el progreso del estudiante puede ser monitorizado y controlado de una manera continua.

\subsubsection{Gestión e infraestructura}

Dentro de este apartado se incluyen los costes de administración de los estudiantes, como los relacionados con la gestión administrativa de la matrícula de los estudiantes, los trámites administrativos o el proceso de evaluación. Por otra parte, la tecnología que permite la realización on-line del curso o programa (el soporte docente y administrativo on-line), determina la aparición 
de costes fijos de carácter recurrente derivados de las acciones de mantenimiento y de reposición de la infraestructura tangible (la plataforma tecnológica) e intangible (aplicaciones tecnológicas educativas y de gestión).

\subsubsection{Número de matrículas}

El hecho de que los costes totales sean función del número de matrículas hace que éste adquiera una especial importancia cuando se trata de analizar a partir de qué cantidad de estudiantes matriculados el curso resulta rentable. El análisis de la rentabilidad de un proyecto de e-learning o de un programa formativo on-line resulta complejo, habida cuenta de la variedad de factores de carácter intangible que, por tanto, son muy difíciles de cuantificar (Duart, 2002). No obstante, Taylor y Osorio (2005) proponen utilizar para este análisis el estudio del punto equilibrio a partir del modelado de los ingresos como una función lineal del número de matrículas. El punto de equilibrio es una herramienta financiera que permite determinar el momento en el cual las ventas cubrirán exactamente los costes, de tal manera que cuando las ventas exceden ese valor habrá beneficios y cuando están por debajo, se producirán pérdidas.

Taylor y Osorio (2005) discuten en su trabajo las distintas estrategias existentes para el aumento de la rentabilidad de un programa formativo on-line y, para facilitar la compresión de su exposición agrupan los costes en las siguientes categorías:

- Costes fijos $(C F)$ : son los mismos independientemente del nivel de ventas (matrículas). Un ejemplo de coste fijo es la amortización de los equipos que adquiere la institución para soportar el programa de formación.

- Costes de desarrollo $(C D)$ : son derivados de la generación de contenidos y de la entrega de los mismos a los estudiantes. Por ejemplo, los costes de desarrollo son mayores cuando el mismo fichero PDF se entrega al estudiante a través de una plataforma de $e$-learning que cuando se le hace llegar anexado a un correo electrónico. No se incluyen en los costes fijos porque dependen del formato del curso on-line y, en general, un mayor coste de desarrollo implica una mayor calidad de la formación virtual.

- Costes variables $(C V)$ : dependen del número de estudiantes matriculados, como por ejemplo, los costes derivados de las tutorías.

Además, para el análisis del punto de equilibrio es necesario conocer el precio de la matrícula $(P M)$, entendido como es el ingreso por matrícula que recibirá la institución del estudiante. Con esta información, el punto de equilibrio, $P E$, se calcula a través de la expresión:

$$
P E=\frac{C F+C D}{P M-C V}
$$

Gráficamente, el punto de equilibrio es la intersección entre la recta que representa los ingresos derivados de las ventas $(P M \cdot P E)$ y la que representa los costes $(C F+C D+C V \cdot P E$,$) , tal y$ como se muestra en la Figura 87: 


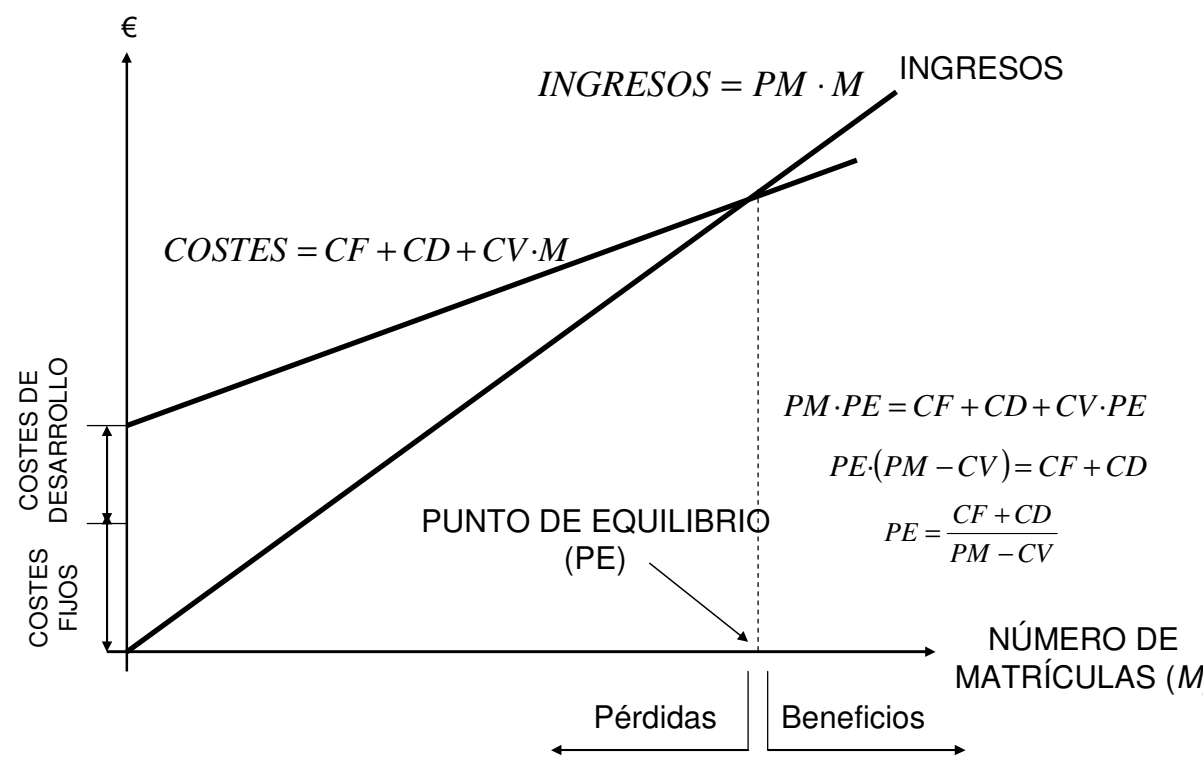

Fuente: elaboración propia.

Figura 87. Análisis gráfico del punto de equilibrio.

Antes de proseguir, conviene aclarar las limitaciones de esta técnica (Taylor y Osorio, 2005): los costes fijos no suelen ser constantes, los costes variables suelen presentar una distribución en escalones y los ingresos no acostumbran a ser lineales.

Llegados a este punto cabe plantearse qué ocurre cuando las rectas de ingresos y costes no se cruzan. El único motivo posible de que esto suceda es que los costes fijos y/o los de desarrollo sean tan elevados que la intersección que da lugar al punto de equilibrio nunca se produzca. La conclusión es que es necesario controlar los costes de desarrollo, es decir, que la riqueza del formato del curso debe adaptarse a las características del mercado objetivo.

Otro aspecto a tener el cuenta es la influencia de la cuota de mercado de la institución (Karelis, 1999). El cruce que constituye el punto de equilibrio debe darse, forzosamente, antes de que el número de matrículas alcance la cuota de mercado ya, en caso contrario, la intersección se daría para un número de matrículas que estaría fuera del rango correspondiente al de la institución, esto es, que el número de estudiantes necesario para que el programa formativa sea rentable sería mayor que el número de matrículas que la institución espera obtener.

\subsubsection{Número de ediciones del curso}

En general, los programas formativos de e-learning están caracterizados por unos elevados costes fijos que la institución espera amortizar a través del lanzamiento del curso en varias ediciones (Bates, 1994; Kaplún, 2005).

A la hora de estudiar la estructura de costes desde este punto de vista, conviene distinguir entre costes de capital y costes recurrentes. Según Jamison (1982) un coste de capital es aquel en el que se incurre para adquirir bienes o servicios que tendrán un tiempo de vida útil superior al de la propia compra, mientras que los costes recurrentes son aquellos cuya duración se restringe al instante de compra. En el ámbito de la formación on-line un ejemplo de coste capital sería el importe de la plataforma tecnológica de soporte, puesto que ésta sigue siendo válida para 
próximas ediciones de un curso; y, como ejemplo de coste recurrente, encontramos el salario de los profesores y los tutores, ya que debe pagárseles por cada curso impartido.

Por tanto, para comparar los costes de capital y los costes recurrentes es necesario algún método que permita convertir los costes de capital en costes referidos a cada edición del programa formativo (Perranton, 2004). Los métodos contables tradicionales resuelven este problema a través del concepto de amortización.

\subsection{ACTIVOS INTANGIBLES ASOCIADOS AL E-LEARNING}

El e-learning y la formación en red están potenciando la aparición en la actividad universitaria de una serie de nuevas capacidades productivas asociadas a la integración tecnológica, a la adaptación de los modelos pedagógicos y al cambio de elementos organizativos que influyen, no únicamente en la mayor dotación relativa de recursos tecnológicos sino también en la forma de llevar a la práctica la actividad docente y en la organización de la misma.

Por tanto, la inversión en TIC para el desarrollo del e-learning implica la inversión en bienes intangibles y la generación de una serie de competencias intangibles asociadas al capital tecnológico, estructural, relacional y humano de las Universidades. Las principales líneas en que se materializa esta relación son las siguientes (Castillo, 2004):

1. Extensión del impacto de las TIC a todos los ámbitos de la actividad universitaria

La introducción de aplicaciones tecnológicas no se circunscribe exclusivamente al ámbito del proceso formativo sino que se extiende por el resto de actividades asociadas a su desarrollo, la gestión académica y la administración. Las TIC inciden en la definición del diseño organizativo y de gestión de la actividad universitaria, introduciendo nuevas posibilidades de concreción basadas en la digitalización de la información (tanto su generación, como la gestión de su transmisión) y en la dotación de canales de comunicación, Así, la cultura informacional y la conectividad de los diferentes elementos organizativos permiten introducir novedades en las formas tradicionales de gestión de las Universidades.

Profundizando en este último punto, cabe destacar que la introducción de sistemas de elearning en la actividad de formación universitaria fomenta la aparición de nuevas formas de actuar en los ámbitos de la organización y la gestión universitarias (Uys, 2002). Esta serie de elementos intangibles asociados a la innovación organizativa se concretan en tres elementos principales:

- Intangibles vinculados a la gestión en red de la actividad formativa (Tapscott, 1996). La disponibilidad en red y la gestión compartida de los diferentes recursos productivos implica la existencia de procesos de control orgánicos y descentralizados basados en el conocimiento disponible en cada parte del proceso.

En este sentido, la adaptación de una estructura descentralizada comporta el establecimiento de una política de coordinación de unidades organizativas que potencie sinergias y evite posibles ineficiencias asociadas a las divergencias de objetivos y a la duplicidad de tareas. Así, la gestión de la formación en red potencia la identificación de los objetivos del proceso con una serie de principios centrales y fundamentales, a la vez que fomenta la diversidad de métodos y procedimientos entre las diferentes partes que componen la organización y la conectividad radial con otros componentes externos de la organización a través de una arquitectura abierta del proceso formativo. Este hecho determina la virtualización del proceso de producción a través de la composición de estructuras productivas basadas en la acción conjunta e interconectada de componentes o unidades internas y externas.

Por ejemplo, considérese que en la elaboración de los contenidos de un cierto programa formativo colaboran las siguientes unidades: 
- Expertos en la materia: habitualmente profesores que desean virtualizar la carga docente de imparten. Su misión es asegurar que los contenidos son técnica y académicamente correctos.

- Pedagogos on-line: encargados de garantizar que se cumplan los estándares de calidad pedagógica y del diseño instruccional.

- Producción: su misión es la generación física del contenido de los programas formativos a partir del material proporcionado por el experto en la materia y de las recomendaciones y guías de los pedagogos.

La Figura 88 muestra las necesidades de comunicación e interacción entre los distintos grupos implicados en el proceso productivo.

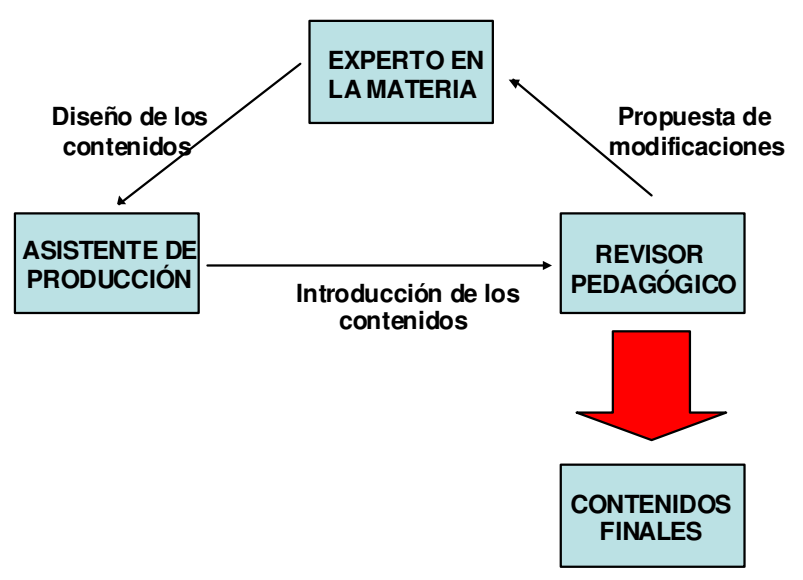

Fuente: elaboración propia.

Figura 88. Proceso de generación de contenidos.

Las posibilidades de comunicación e interacción entre los miembros de los grupos anteriores que ofrecen las TIC se traducen en una mejora (intangible) de la calidad percibida por el alumno.

- Intangibles vinculados a la flexibilidad productiva. El e-learning está modificando las pautas convencionales de la producción de formación de las instituciones universitarias. El e-learning supone la evolución de un paradigma centrado en el profesor (típico de la enseñanza presencial tradicional) a un paradigma centrado en el estudiante, en donde este último dispone de cierta libertad en la autodeterminación del contenido (es más sencillo modularizar la ofera formativa de la institución) y en el establecimiento del ritmo de aprendizaje, a diferencia de lo que ocurre en la formación tradicional en donde es el docente el que administra el ritmo de sus explicaciones forzando a los alumnos a seguirlo. Esta relativa facilidad del e-learning para constituirse como formación a medida fomenta la demanda del incremento de la flexibilidad del sistema formativo para adaptarse de forma constante a los diferentes requerimientos de los estudiantes, flexibilidad asociada tanto al proceso de formación como a las características de los productos formativos.

- Intangibles vinculados a las relaciones institucionales. La propiedad de los sistemas de elearning de ofrecer un acceso global y abierto a los recursos formativos a través de la capacidad de conexión de las redes informáticas comporta la integración en red de proveedores y destinatarios del programa formativo. Así, la disponibilidad de los recursos educativos en red y la descentralización del proceso formativo ha potenciado las 
relaciones de colaboración y cooperación entre Universidades y con otras entidades y organizaciones (Saffu y Mamman, 1999), por un lado, de acceder al público objetivo con viabilidad en términos de coste/beneficio; y, por otro, de compartir las distintas tareas del proceso productivo a través de la especialización en determinadas actividades de la cadena de valor el e-learning.

2. Innovación en la metodología docente

El e-learning potencia la aparición de procesos específicos de innovación metodológica. Estos procesos se concretan alrededor de dos ejes principales (Castillo, 2004):

- La consolidación de un modelo centrado en el aprendizaje del estudiante. Es decir, la consolidación de una organización de la actividad docente que parte del perfil y los requerimientos de los estudiantes, los cuales se configuran como un elemento activo en la programación del aprendizaje y en la dotación de los recursos formativos.

- La consideración de los diferentes programas formativos como piezas en el proceso de aprendizaje continuo de los individuos a lo largo de su vida (lifelong learning), dentro de una Sociedad en la que el trío profesión-formación-aprendizaje se está convirtiendo en una realidad con límites difusos y de difícil disociación.

Los dos ejes anteriores marcan las innovaciones tecnológicas y metodológicas a seguir con el fin de responder a la demanda de un incremento de flexibilidad asociada a los distintos elementos implicados en la actividad docente.

Estos cambios metodológicos van a tener cierta incidencia en algunos aspectos del proceso de enseñanza-aprendizaje, entiendo éste en su sentido más amplio y abarcando toda la relación del alumno con la institución educativa. Teare, Davies y Sandelands (1998) señalan la influencia de la innovación, entre otros, en los siguientes aspectos:

- La política de acceso a la Universidad se enfoca ahora al reconocimiento individual a través de acreditación del aprendizaje conseguido por la experiencia personal y profesional con un grado elevado de modularidad, adaptabilidad y personalización.

- El contenido curricular establecido por los estudiantes en función de su jerarquía de preferencias, caracterizada por una importante modularidad e interdisciplinariedad.

- Los sistemas de evaluación, se centran en la evaluación continua, con un peso importante de los instrumentos de autoevaluación y evaluación en grupo, y tienden a la individualización de los contenidos y de la habilidad objeto de evaluación.

- Los métodos de aprendizaje, enfocados a obtener una elevado grado de eficacia en los resultados del proceso, vinculados a las demandas sociales de habilidades y caracterizados por un importante margen de autogestión por parte del estudiante.

- Los recursos didácticos, fundamentales en una disposición abierta y en red, con la dotación de recursos tecnológicos multimedia que permitan la interacción y la adaptación a los requerimientos individuales, y caracterizadas por estar orientadas a la consecución de un aprendizaje eficaz, por parte del estudiante.

- Los criterios de accesibilidad, que persiguen superar las barreras espaciales y temporales de acceso al aprendizaje por medio de la utilización de entornos virtuales y abiertos de aprendizaje.

Es decir, las innovaciones metodológicas se están cimentando sobre la base de un crecimiento de las oportunidades de aprendizaje flexible y de un movimiento hacia la consecución de un mayor acceso a la educación.

3. Exigencia de mayor grado de capacitación y nuevas destrezas al personal de la Universidad.

La integración del e-learning está introduciendo alteraciones en la demanda de la capacidad y habilidades de los individuos, profesores, metodólogos o gestores, que participan en diferentes momentos del proceso formativo y en la gestión del factor trabajo (Castillo, 2004).

Por una parte, la realización del e-learning incide sobre los requerimientos de capacidad y habilidades de los trabajadores en tres dimensiones principales:

- La demanda de habilidades asociadas a la utilización de las TIC. 
- La demanda de nuevas capacidades vinculadas a la aplicación de las funcionalidades de las TIC al contenido de su trabajo y a su adaptación a las características metodológicas propias de esta actividad formativa.

- La demanda de capacidades de trabajo flexible, en red y cooperativo, a través de la conformación de equipos multidisciplinares y adaptables a las necesidades específicas de cada programa formativo, conforme a criterios basados en el conocimiento y no tanto en las atribuciones de responsabilidad conferidas a las diferentes unidades o áreas funcionales de la Universidad.

Por otra parte, la construcción de un modelo de relación laboral flexible, caracterizada por tres aspectos principales:

- La posibilidad de materializar la realización de la tarea laboral en redes y de gestionarla en red (teletrabajo).

- La habilitación de procesos formales de aprendizaje a través de la dotación del contexto y de los medios necesarios para hacer efectivo el aprendizaje individual y de equipo (Teare y Dealtry, 1998).

- El fomento de la socialización del aprendizaje individual y de equipo a través de la diseminación en el conjunto de la Universidad de los nuevos conocimientos conseguidos (Buckler, 1996).

Todo ello supone la construcción de un modelo cimentado en el trabajo en red, en el aprendizaje continuo y en el conocimiento compartido.

En resumen, la incorporación del e-learning a la actividad universitaria introduce una serie de alteraciones en elementos tecnológicos, metodológicos y organizativos. Unas modificaciones que son un claro exponente de un cambio cultural en el sector que determina la transición hacia un nuevo modelo tecnológico, metodológico, organizativo y de definición de la actividad universitaria. 


\section{CONCLUSIONES}




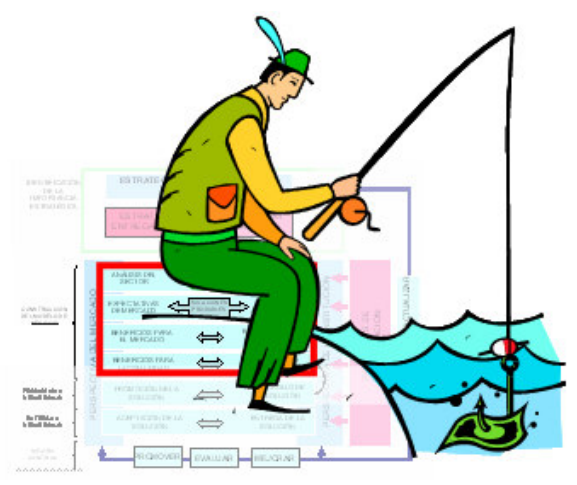

\section{CAPÍTULO 9 CONCLUSIONES}

\subsection{ANTECEDENTES}

Las tendencias contemporáneas de la globalización indican, al menos, tres características que es preciso tener en cuenta (Oyarzun, 2003):

- La Educación será la principal inversión tanto desde el punto de vista individual como social, extendiéndose en proceso continuo durante toda la vida útil de las personas.

- El sistema universitario tenderá a constituirse en grandes redes internacionales, acentuando la importancia de las TIC.

- El sistema social del trabajo exigirá condiciones de competencia y de empleabilidad que privilegien la innovación, el manejo de lenguajes y nociones diversas y la capacidad de adaptación a circunstancias cambiantes, e impondrá ritmos intensos de movilidad laboral.

Todo ello explica que gran cantidad de estudios y discusiones sobre la situación de la Educación Superior giren en torno a la internacionalización y que la destacan como principal agente de cambio.

La internacionalización de la Educación Superior responde a una necesidad, tanto de la Sociedad (demanda) como de la propia Universidad (oferta), por lo que las decisiones de gestión en las Universidades se encuentran condicionadas por una serie de variables exógenas derivadas de la evolución de este mercado. Existe un cierto consenso en la literatura internacional en el reconocimiento de que estas variables impulsoras del cambio en las Universidades, tanto en el ámbito organizativo como en las prácticas de gestión y docencia, de los países occidentales (Michael, 1997), que han estado encaminadas a la dotación de una mayor flexibilidad en la realización y gestión de su actividad. Estas variables impulsoras se integran en las siguientes categorías:

- La evolución de la demanda de enseñanza universitaria, que se concreta en la potenciación de la demanda social de ampliación del acceso a dicha formación, el incremento de la demanda de formación universitaria por parte de la población adulta.

- La adaptación de la oferta formativa a los nuevos requerimientos de capacidad y habilidades de los trabajadores para atender las exigencias de actualización y reciclaje permanente de las habilidades de los trabajadores, características estas de la economía del conocimiento (Moreno, 2004).

- La demanda social de una mayor transparencia informativa sobre los resultados de la gestión de la actividad Universitaria y de su efecto sobre el conjunto de la Sociedad. 
- La evolución de la financiación de las Universidades, caracterizada por una disminución de los recursos disponibles (Plain, 1995; Scannell, 1993; Pickens, 1993) y por una alteración de la composición de la estructura financiera con un incremento significativo de los recursos financieros privados y de la autofinanciación en detrimento de los fondos públicos.

- Promoción de la movilidad de los integrantes de la comunidad universitaria a través de la eliminación de los obstáculos a la libre circulación de estudiantes, profesores e investigadores (Fernández y Ruzo, 2004; Marginson y Van der Werde, 2006), favorecida por la utilización de las TIC, y que en Europa se ha materializado en el Espacio Europeo de Educación Superior.

- Establecimiento de un marco internacional para el comercio mundial de servicios educativos (GATS, 1995; Marginson y Van der Werde, 2006).

- La traslación de los modelos educativos estadounideneses, caracterizados por su orientación a mercado, a otros contextos (en nuestro caso el europeo) frente a los modelos educativos controlados por el Estado que han resultado en una menor competitividad a la hora de competir en el mercado internacional (Brunner y Uribe, 2007).

- La introducción de las TIC en las Universidades y sus repercusiones a todos los niveles de la actividad universitaria (Castillo, 2004).

Estos cambios se han manifestado principalmente en la adopción de parámetros de eficiencia (Lam, 1998; Messner y Ruhl, 1998; Michael, 1997; Odden y Clune, 1995), en la reducción de las estructuras organizativas (Appelbaum y Patton, 2002; Horn y Jerome, 1996; Dickman et al., 1996) y en fomento de procesos de descentralización en la ejecución de la actividad (Saffu y Mamman, 1999).

La principal implicación económica de todas estas transformaciones es la existencia de un mercado administrado (Shattock, 2003) o cuasi-mercado (Glennerster, 1991; Benczes, 1998; Dill, 1997), regido por el principio de competencia por prestigio y en el que el factor determinante no es el tamaño de las instituciones que participan en el sector, sino el volumen de las subvenciones que reciben (Hansmann, 1980, 1990).

Por todos estos motivos, las Universidades se enfrentan al reto de adaptarse a este nuevo paradigma socioeconómico. De este reto, y dado el papel que les toca desarrollar en nuestros tiempos, las instituciones de Educación Superior tendrán que salir especialmente airosas (Duart y Lupiáñez, 2005) a través del desarrollo de las estrategias y tácticas más adecuadas a cada caso. En este contexto, el empleo de las TIC en la actividad universitaria se está convirtiendo en un elemento instrumental importante para conseguir los objetivos marcados. En el ámbito del análisis de la formación universitaria, la integración de las TIC en la actividad docente ha comportado importantes transformaciones, tanto de los métodos que enmarcan el desarrollo de la actividad como de los mecanismos y prácticas aplicables a su organización (Marcelo, Puente, Ballesteros y Palazón, 2002), introduciendo nuevas posibilidades de integración de recursos tecnológicos, de incorporación de elementos de flexibilidad y conectividad y de aumento de la interacción y la comunicación entre profesores y estudiantes. Así, la convergencia de estos elementos de transformación, la incorporación de las tecnologías digitales en la actividad universitaria y el cambio organizativo de la Universidad que tendente a la dotación de una mayor flexibilidad en la realización y la gestión de las actividades de su cadena de valor, explica la aparición de una nueva forma de realizar la acción docente basada en el uso intensivo de las TIC: el e-learning.

Para facilitar dicho análisis, esta tesis pretende ofrecer una visión útil del comportamiento actual del mercado del e-learning y establecer un método de identificación de los elementos críticos en la construcción de modelos de negocio a partir del análisis estratégico de dicho sector. Asimismo se pretende formular una propuesta y aportar ideas que amplíen el conocimiento en dicho terreno y que, además, sirvan referencia para estudios futuros, tanto en el propio sector como en sectores afines. En cualquier caso, y dada la naturaleza dinámica y cambiante del entorno (Fuentes, 2005), las conclusiones que de este estudio se extraigan, deberán revisarse periódicamente (Rosenberg, 2001; Lerner, 1999). 


\subsection{PLANTEAMIENTO INICIAL}

Algunos autores (Horn y Jerome, 1996; Dickman et al., 1996) defienden que las Universidades deben reaccionar en este nuevo entorno a través de la asunción de prácticas empresariales. En efecto, tal y como Duart y Lupiáñez (2005) señalan, esta transferencia procedente del mundo empresarial será beneficiosa siempre y cuando se sepa trasladar adecuadamente y no se deje de lado la labor social de la Universidad. Un estudio de estas características obliga a manejar terminologías y conceptos más propios del mundo empresarial y de los negocios que del mundo académico, tal y como argumentábamos al comienzo de este trabajo.

Cuando cualquier organización se plantea competir en un determinado sector de actividad, independientemente de cuál sea ésta, el paso previo consiste en definir claramente el producto o servicio en términos de las necesidades de los consumidores (en este caso, estudiantes) que satisface y del valor que les aporta así como los medios a través de los cuáles dichas necesidades se satisfarán. El trabajo realizado en esta tesis, en términos de los parámetros propuestos por Abell (1980), trata sobre el negocio de la Educación Superior en formación reglada y no reglada (mercados) utilizando el e-learning como soporte de la formación en red (tecnologías) con el fin de que los estudiantes adquieran los conocimientos y habilidades necesarias para desempeñar una labor en la Sociedad (funciones), con el añadido de la flexibilidad y personalización del proceso de enseñanza-aprendizaje consecuencia del empleo del e-learning como opción tecnológica. Las conclusiones aquí extraídas bien pueden aplicarse a la internacionalización de los sistemas de Educación Superior, motivación principal de este estudio, y del que el Espacio Europeo de la Educación Superior es sólo un ejemplo particular.

Una vez definido el negocio, el paso siguiente será determinar cómo desarrollar una estrategia en el sector en el que se compite y en el que se luchará con otras organizaciones (casi todas instituciones de Educación Superior, aunque en algunos casos también empresas) cuya definición del negocio, según los parámetros de Abell (1980) es similar. La diferencia entre el éxito y el fracaso estará, pues, no la definición del negocio, sino en su implementación o modelo de negocio.

Como veremos, en el caso de la Educación Superior, las diferencias estriban en las alianzas estratégicas que puedan alcanzarse con proveedores educativos y, por tanto, en la posición que cada institución ocupe dentro del sistema de valor. Aclarados estos puntos, y teniendo en cuenta, la cadena de valor del e-learning y las características internas de cada institución, es posible construir el modelo de negocio a través del establecimiento de unas relaciones claras entre los tres planos que lo definen (Hoppe y Breitner, 2004): sistema de valor y cadena de valor de la institución y sistema de valor y modelo de ingresos. Sin embargo, no solo se trata de construir un modelo de negocio sostenible sino que, además, nos permita obtener ventajas competitivas sobre los modelos de negocio de las instituciones competidoras.

\subsection{CONSTRUCCIÓN DEL MODELO DE NEGOCIO}

Ante una tarea como la que se ha tratado en este tesis, Brunner y Uribe (2007) aconsejan abordarla a través de una estrategia de indicios empleando un diagrama base en el que se muestren las líneas de investigación que se vayan a seguir y permita al lector ubicarse independientemente del punto del diagrama en el que se encuentre. En nuestro caso, se ha empleado el marco de trabajo FLBPF (Flexible Learning Business Planning Framework) propuesto por ANTA, Australian National Training Autority, para la planificación estratégica de proyectos de aprendizaje flexible, independientemente de las tecnologías de soporte, y que presenta un enfoque orientado al mercado y a la organización y, que en esta tesis se ha aplicado a la dupla (Educación Superior, e-learning).

En el apartado 1.3.1 ya se describió con detalle este marco de trabajo, por lo que aquí nos limitaremos únicamente a recordar que, según los principios del modelo FLBPF, la planificación 
de una estrategia de e-learning en una institución de Educación Superior debe abordarse en un periodo divido en cuatro áreas o secciones, tal y como se muestra en la Figura 89:

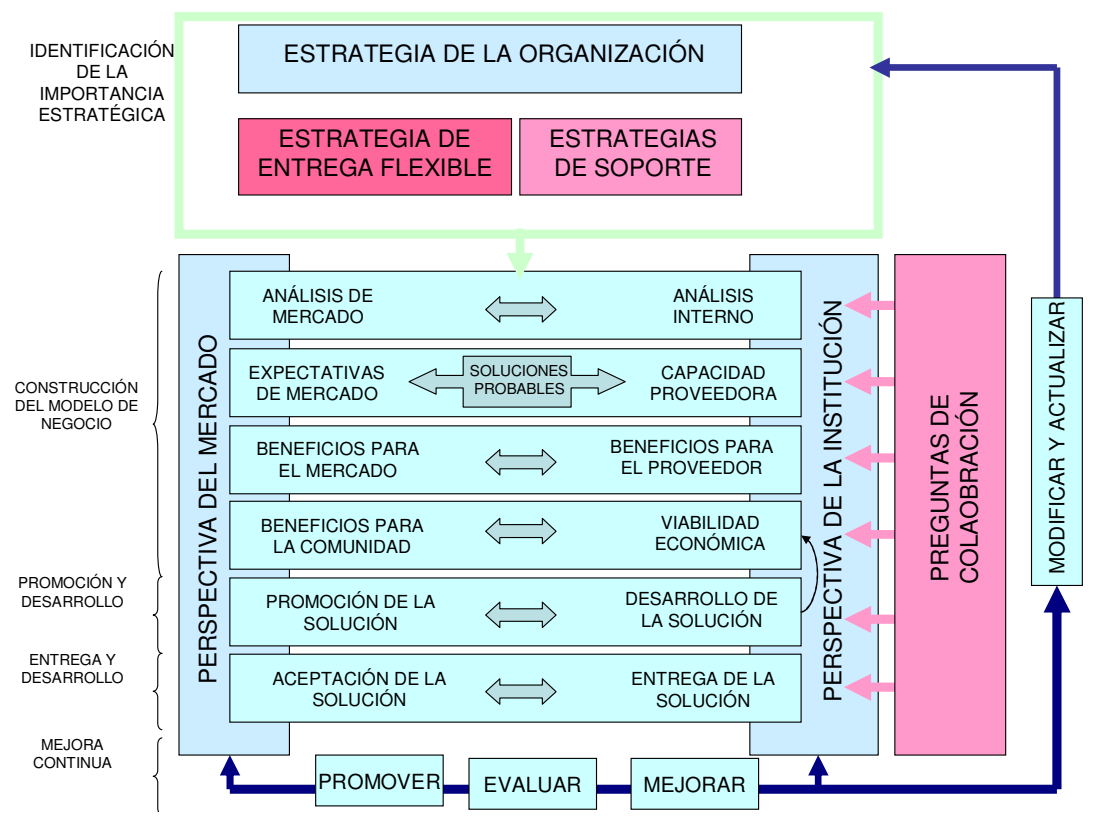

Fuente: adaptado de ANTA (2003).

Figura 89. Modelo FLBPF de ANTA.

En la fase de definición de la importancia estratégica deben establecerse claramente, al menos, dos aspectos. En primer lugar, debe determinarse el grado de intensidad que tendrá la utilización del e-learning en la institución, distinguiendo así entre universidades de e-learning, universidades duales, universidades tradicionales con el e-learning como herramienta de apoyo y universidades con un empleo residual del e-learning (ver apartado 4.3). El otro aspecto fundamental es el modelo organizativo de la universidad on-line (ver apartado 4.4), donde cabe distinguir entre universidades virtuales como organizaciones virtuales, universidades presenciales con extensión universitaria virtual, universidades presenciales adosadas a universidades tradicionales y espacios virtuales interuniversitarios. Obviamente, es necesario plantearse otros aspectos de índole estratégica (asignación de recursos, políticas internas y externas, etc.), que quedan fuera del ámbito de esta tesis por ser excesivamente particulares del contexto de cada Universidad.

Una vez dilucidados los aspectos anteriores, el siguiente paso es la construcción del modelo de negocio, cuyo objetivo último es evaluar la probabilidad de que una idea estratégicamente relevante para la institución sea, efectivamente viable antes de la asignación de recursos para la materialización de la misma. El epígrafe siguiente resume las conclusiones del análisis realizado en esta tesis.

El resto de fases del modelo FLBPF de ANTA (promoción y desarrollo, entrega y aceptación y mejora continua) quedan fuera del ámbito de esta tesis, que se ha centrado, sobre todo, en aspectos relacionados con la construcción del modelo de negocio.

Como ejemplo de aplicación los conceptos introducidos en los capítulos anteriores, estudiaremos el Sistema Universitario Valenciano, en el que se integran tanto universidades públicas como privadas, y contemplaremos los resultados desde el punto de vista de la Universidad Politécnica de Valencia.

\subsubsection{Análisis estratégico del sector}


El objetivo del análisis del sector es relacionar a la organización con su entorno competitivo, determinar la estructura del sector y las razones de que sea así (Porter, 1980). Para ello, deben identificarse las fuerzas o dimensiones competitivas y estudiar cómo interaccionan entre sí. En esta tesis se ha seguido el enfoque propuesto por Porter (1980) al que se añadido una fuerza competitiva más habida cuenta de que Europa en general y España en particular se rige por un modelo de sistema educativo regulado: el poder negociador del Gobierno. Por tanto, el diagrama de fuerzas competitivas será el que se muestra en la Figura 90, tras cuya aplicación se ha llegado a las conclusiones que se detallan en los epígrafes siguientes.

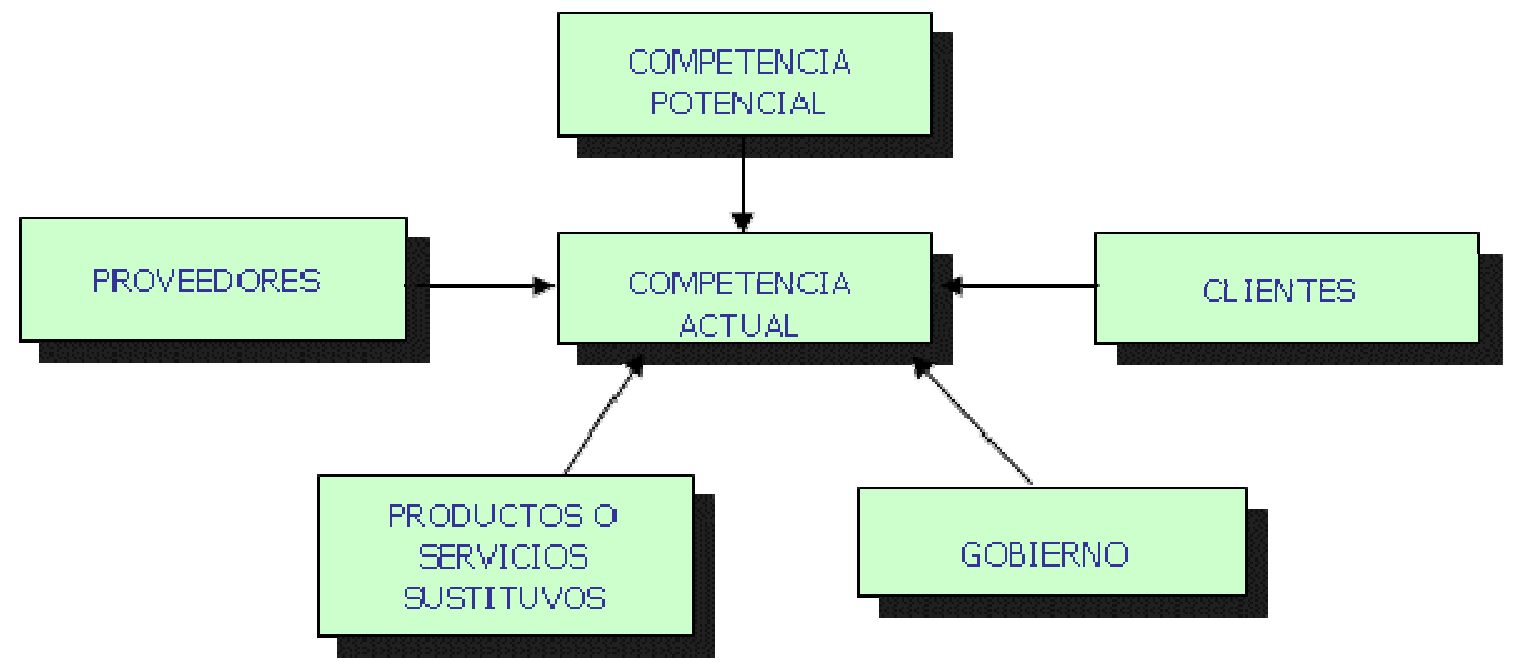

Figura 90. Modelo de fuerzas competitivas en el sector del e-learning y la Educación Superior.

\subsubsection{COMPTENCIA ACTUAL}

Los competidores actuales en el sector de la Educación Superior on-line son los mismos que en el caso del formato presencial tradicional. Con el fin de agruparlos de cara a investigaciones futuras, se propone seguir una clasificación basada en la intensidad de utilización del e-learning como metodología docente, por un lado, y en el modelo organizativo, por otro.

Otro enfoque es el indicado en el capítulo 4 y que clasifica a las instituciones de educación en función según un doble criterio: la intensidad de utilización del e-learning en la metodología docente (ver Figura 91) y el modelo organizativo (ver Figura 92).

\begin{tabular}{l|l}
\hline Tipo de Universidad & Descripción \\
\hline $\begin{array}{l}\text { Universidades de e- } \\
\text { learning }\end{array}$ & $\begin{array}{l}\text { Empleo de los sistemas de e-learning como elemento principal de la } \\
\text { docencia. }\end{array}$ \\
\hline Universidades duales & $\begin{array}{l}\text { Modelo de formación a distancia flexible y basado en TIC y } \\
\text { modelos presenciales con integración de sistemas de e-learning. }\end{array}$ \\
\hline $\begin{array}{l}\text { Universidades con un uso } \\
\text { complementario del e- } \\
\text { learning }\end{array}$ & $\begin{array}{l}\text { Modelos a distancia tradicionales pero flexibles y modelos } \\
\text { presenciales con un uso del e-learning como soporte a la } \\
\text { metodología tradicional. }\end{array}$ \\
\hline $\begin{array}{l}\text { Universidades } \\
\text { tradicionales }\end{array}$ & $\begin{array}{l}\text { Modelos a distancia y presenciales que presentan un uso residual de } \\
\text { las TIC. }\end{array}$ \\
\hline
\end{tabular}

Fuente: elaboración propia.

Figura 91. Clasificación de las Universidades en función de su empleo del e-learning. 


\begin{tabular}{|c|c|}
\hline Modelo organizativo & Descripción \\
\hline $\begin{array}{l}\text { Universidades } \\
\text { virtuales }\end{array}$ & $\begin{array}{l}\text { Son universidades creadas específicamente para } \\
\text { realizar una actividad de e-learning, algunas de las } \\
\text { cuales parten de modelos de universidades abiertas y } \\
\text { a distancia. Se caracterizan por disponer de un } \\
\text { modelo organizativo y pedagógico particular y } \\
\text { diferenciado del resto de universidades presenciales } \\
\text { y a distancia. }\end{array}$ \\
\hline $\begin{array}{l}\text { Universidad presencial con extensión universitaria } \\
\text { virtual }\end{array}$ & $\begin{array}{l}\text { Se trata de un modelo muy extendido en las } \\
\text { Universidades y que consiste en incorporar } \\
\text { formación virtual en cursos de postgrado y extensión } \\
\text { universitaria en instituciones educativas cuya oferta } \\
\text { de formación reglada es eminentemente presencial. }\end{array}$ \\
\hline $\begin{array}{l}\text { Universidad virtual adosada a la universidad } \\
\text { tradicional }\end{array}$ & $\begin{array}{l}\text { Se trata de universidades virtuales creadas por } \\
\text { universidades tradicionales en su mismo entorno a } \\
\text { través de espacios virtuales gestionados de forma } \\
\text { independiente pero compartiendo los elementos } \\
\text { básicos de la universidad tradicional (oferta } \\
\text { formativa, normativa académica, servicios de } \\
\text { biblioteca, etc.). }\end{array}$ \\
\hline $\begin{array}{l}\text { Universidades virtuales como espacios virtuales } \\
\text { interuniversitarios }\end{array}$ & $\begin{array}{l}\text { Se trata una universidad virtual creada a través de un } \\
\text { consorcio de diversas universidades tradicionales y } \\
\text { se materializa en la disponibilidad de un espacio } \\
\text { virtual común en el que converge la oferta de los } \\
\text { diferentes planes de estudio. Este espacio se gestiona } \\
\text { de forma compartida pero autónoma en la } \\
\text { Universidades participantes en el consorcio. }\end{array}$ \\
\hline Modelo de intermediación & $\begin{array}{l}\text { La o las Universidades se asocian con una empresa } \\
\text { que proporciona cursos utilizando los recursos de } \\
\text { enseñanza de instituciones existentes. }\end{array}$ \\
\hline Universidad Corporativa & $\begin{array}{l}\text { Unidad de negocios de una empresa que se encarga } \\
\text { de gestionar los planes de formación de los } \\
\text { empleados de la misma. }\end{array}$ \\
\hline
\end{tabular}

Fuente: elaboración propia.

Figura 92. Modelos organizativos de universidades virtuales.

Otro de los aspectos que influyen en la competencia actual son las barreras de salida, bajo cuya denominación se agrupan todos aquellos aspectos que obligan a seguir compitiendo en el sector.

En el caso del e-learning y la Educación Superior, se han identificado las siguientes barreras de salida:

- Dificultades de desinversión: activos altamente especializados y que tienen poco valor liquidativo, como es el caso de la plataforma de e-learning, sobre todo si se ha adquirido hardware/software especializado.

- Personal fijo: puede llegar a ser una barrera importante. Por esta razón, se aconseja contratar profesores a tiempo parcial y solamente tener fijos al personal administrativo.

- Cancelación de contratos con clientes: barrera importante se imparten cursos largos. Por otro lado, dado el papel social de la Universidad es posible que la institución se vea obligada a mantener titulaciones poco rentables.

\subsubsection{COMPETENCIA POTENCIAL}


La competencia potencial, entre otros aspectos, viene determinada por las barreras de entrada, que pueden definirse como el conjunto de factores de tipo económico, social e institucional que constituyen un freno o impedimento para el ingreso de nuevas empresas en el sector. Se han identificado las siguientes:

- Imagen de marca

El mercado de la Educación Superior es un mercado jerárquico (Hansmann, 1980, 1990) y en el que la imagen de marca y el prestigio adquieren una doble importancia. En primer lugar, supone una barrera de entrada muy alta que frena a nuevos competidores a entrar a competir en el mercado. Por otra parte, constituye uno de los factores determinantes tanto para la financiación pública, como para la financiación privada.

Con el fin de proyectar una imagen de marca integral, sólida y consistente que permita a las instituciones tener un respaldo estratégico, las Universidades deben adoptar, entre otras, las siguientes medidas (Fuentes, 2005):

- Concretar su identidad corporativa, a partir de la formulación de un mensaje institucional unificado, claro, concreto y conciso que impacte en cualquier público del mundo.

- Fomentar redes académicas que potencialicen la divulgación de los resultados de trabajos académicos y de investigación.

- Fortalecer las acciones de relaciones públicas en tiempo real, para contribuir a la proyección de la imagen institucional.

- Construir vínculos estables para generar confianza con los diferentes públicos.

- Acceso privilegiado a materias primas

Buenas materias primas. Los centros sin prestigio o no relacionados, tendrás dificultades para atraer buenos profesores. Si lo consiguen, será a alto coste. En caso de que el centro no disponga de formadores en plantilla que puedan acoplarse al curso que se quiere impartir, deberá saber qué busca cualquier formador a la hora de colaborar, especialmente en el caso de formación continua. Algunos aspectos importantes en este sentido son:

- Pagar bien la hora/crédito de clase.

- Posibilidad de promocionarse entre los alumnos.

- Ser un medio para facilitar al profesor la puesta al día en los temas de su especialidad o interés.

- Resultar atractivo para su curriculum.

- Economías de escala

Las economías de escala reflejan las reducciones en el coste unitario del producto, servicio o procesos de todo tipo que se producen como consecuencia de mayores volúmenes de actividad por periodo. Presentan impedimentos porque fuerzan al pretendiente a operar a gran escala, con el riesgo de una inmediata reacción por parte de los competidores existentes, o a ingresar a pequeña escala aceptando una desventaja inicial en coste.

En la contratación del profesorado, pueden tener lugar en grandes centros acreditados o universidades. También los procesos de generación de contenidos pueden beneficiarse de las economías de escala en la producción, sobre todo en el caso de grandes repositorios de objetos de aprendizaje, tal y como se tratará al estudiar la estrategia competitiva de liderazgo en costes.

- Necesidades de capital

La necesidad de fuertes volúmenes de capital constituye una barrera de entrada, lo cual supone una ventaja para los competidores existentes.

El hecho de que el e-learning se caracterice por la realización de la formación a través de las TIC determina la importancia relativa de la inversión tecnológica y del uso de las mismas, de manera que se produce un desplazamiento de recursos, desde los elementos tradicionales basados en la infraestructura física hacia los bienes tecnológicos. Además, este 
gasto inicial está sometido a una obsolescencia muy rápida, lo cual genera un elevado nivel de riesgo para este tipo de inversiones.

Estos elevados costes iniciales en teoría se compensan por unos menores costes de personal y porque el alto gasto de desarrollo de curso se amortiza en las sucesivas repeticiones del mismo.

Este modelo impide la entrada de empresas que no dispongan de importantes presupuestos en generación de contenidos y de una cuota de mercado (número de matrículas) suficientemente grande para poder amortizar la inversión inicial.

En relación a lo anterior, cabe hacer las siguientes reflexiones:

- Para amortizar el gasto inicial son necesarios un número de alumnos mayor de lo que quizá sea aconsejable desde el punto de vista metodológico.

- La repetición sin cambio alguno en los materiales aumenta el riesgo de que estos queden obsoletos y desactualizados.

- En ocasiones, una elevada calidad en los materiales (y, por tanto, un incremento en el coste de generación de los mismos) no es percibida como tal por el alumno. Por tanto, habrá que determinar la sensibilidad de los alumnos que forman parte del mercado potencial a las variaciones de calidad de los materiales formativos con el fin de aumentar la eficiencia y el rendimiento económico de dichos materiales.

Una manera de reducir los costes asociados a las TIC es el fomento de los procesos de innovación tecnológica, por la necesidad de adaptar los estándares tecnológicos a las particularidades de los procesos formativos y de actualizar y mejorar continuamente la funcionalidad de los diferentes componentes del sistema.

Teniendo en cuenta lo anterior, los competidores potenciales son, básicamente, los mismos que los actuales, a los que habría que añadir las Universidades Corporativas y los consorcios educativos.

Una Universidad Corporativa es una unidad, dentro de una empresa, encargada de la gestión de la formación de los empleados y suele ser una evolución del Departamento de Recursos Humanos y Formación. En este sentido, constituye un competidor en el área de formación continua y, en general, cualquier tipo de formación asociada al puesto de trabajo. Su principal ventaja es la cercanía al usuario final (empleado) y el hecho de que los contenidos pueden personalizarse a un nivel mucho mayor que el ofrecido por un curso impartido por una Universidad en el que, al estar destinado a un mercado más amplio (empleados de varias empresas), tiene un carácter más general. Además, este tipo de formación suele ser gratuita o contar con algún tipo de subvención para los empleados, compitiendo en precios con la equivalente impartida por una Universidad. A nivel internacional dos empresas pioneras fueron Motorola y McDonalds, y en España, encontramos la Universidad Corporativa de Unión Fenosa.

En cuanto a los consorcios educativos, en su sentido más amplio, son grupos de compañías o instituciones que aúnan esfuerzos para completar su oferta formativa, siendo los motivos de creación muy variados. Un ejemplo es el GWEC (Global Wireless Education Consortium) formado por Ericsson, A\&T Wireless Services, Lucent Technologies, Air Touch Communication y Motorola junto con la Mankato State University, el South Technical Collage y la University of Texas en Dallas. A mediados de los años 1990, todas las empresas dedicadas a las tecnológicas móviles, se enfrentaban al mismo problema: la dificultad para reclutar y retener profesionales cualificados, habida cuenta del crecimiento del sector. En 1996, se pensó en crear una solución educativa para toda la industria y, como consecuencia, se creó el GWEC. Con esta medida se logró, además, la reducción de los costes de la formación y la elevada calidad de los contenidos.

\subsubsection{PRODUCTOS O SERVICIOS SUSTITUTIVOS}

En la actualidad, el mayor competidor de las Universidades en cuanto a formación continua se refiere son las Universidades Corporativas ya que éstas satisfacen las demandas de formación 
de los empleados de la empresa a la que pertenecen y estos, por tanto, no se matricularán en ninguno de los cursos que conforman la oferta de las Universidades (Clarke y Hermens 2001; Rosenberg 2001). Por lo que respecta a las enseñanzas de grado, las amenazas de productos o servicios sustitutivos son las mismas que para la formación presencial tradicional.

Cabe hacer notar que la educación virtual puede también ser observada como un complemento de la educación presencial ya adquirida por un estudiante que desea complementar sus estudios o perfeccionarse.

En comparación con la educación presencial, la actitud del cliente hacia la educación virtual es menos favorable, debido a un problema de cultura (a veces, subestimada) y disciplina que ha significado que exista una mayor lealtad hacia los servicios tradicionales de las Universidades e Institutos, pero sólo en la medida en que éstos tengan un respaldo en cuanto a experiencia y a logros concretos en materia de educación.

Desde una perspectiva de sustitutos, la realidad es que no es la educación presencial el sustituto de la virtual, sino por el contrario, es la educación virtual la que se ha requerido como un muy buen sustituto de la educación presencial y lo será cada vez más en la medida que mejore la tecnología que soporta al e-learning así como el grado de alfabetización tecnológica de la población.

\subsubsection{NEGOCIACIÓN CON LOS AGENTES FRONTERA}

Llamaremos agente frontera a cualquier actor con cierta capacidad de influencia sobre el sector que se estudia (Bueno Campos, 1996), en este caso, el e-learning en la Educación Superior. El poder negociador de las Universidades con los distintos agentes frontera que participan en su entorno (proveedores, clientes y Gobierno) difiere en función del actor.

En primer lugar, el poder negociador de los proveedores educativos es reducido puesto que, como se ha visto en el epígrafe 5.3.3, las Universidades tienen capacidad para abarcar casi todo el sistema de valor completo. Sin embargo, también pueden ser considerados como proveedores los profesores, en relación a los cuales habría que subrayar que su poder negociador depende de los siguientes factores:

- Importancia estratégica del producto: adquiere importancia en cuanto el curso quiere tener cierto nivel o se pretende una diferenciación, ya que se precisa un material didáctico y profesorado cualificado en materias específicas difícilmente sustituibles.

- Concentración: suelen estar agrupados o relacionados con diversos tipos de asociaciones o entidades.

- Amenaza de integración hacia delante: existe la amenaza en el caso de que pertenezcan a asociaciones. Tienen como barrera la imagen de marca y la necesidad de capital.

- Peso de su coste en el producto: muy importante.

En lo que respecta a los clientes (ver epígrafe 5.3.4), su poder negociador en formación reglada es escaso, como también lo es el de la Universidad al estar aquella regulada por el Estado. Sin embargo, en la formación no reglada, los estudiantes pueden presionar para que la Universidad baje los precios, bajo la amenaza de irse a la competencia o adquirir un producto o servicio sustitutivo.

Finalmente, el papel del Gobierno es grande puesto que tiene capacidad de influir directamente en el comportamiento del sector, favoreciendo la competencia por la financiación pública y disciplinando el mercado a través de la regulación. Además, mediante el favorecimiento de subvenciones o proyectos de e-learning liderados por la Administración Pública pueden facilitar la entrada en el sector a empresas privadas.

\subsubsection{Segmentación}


La segmentación del mercado consiste en la definición de grupos de usuarios con necesidades razonablemente homogéneas, de tal forma que los clientes (estudiantes) de un mismo segmento del mercado en cuestión presentan necesidades que pueden ser satisfechas por el mismo producto o servicio.

En esta tesis se ha adoptado una segmentación multicriterio basada tanto en el tipo de formación como en los rangos de edad del mercado objetivo.

En cuanto al tipo de formación, con el fin de que la clasificación escogida resulta válida tanto para la situación actual como para la marcada por las directrices del Espacio Europeo de la Educación Superior, se han considerado tres grandes segmentos:

- Formación de grado: estudiantes cuyo objetivo es obtener una licenciatura o diplomatura universitarias.

- Formación de postgrado: estudiantes, con una titulación de grado, que desean alcanzar el máximo grado académico profundizando sus estudios en alguna disciplina concreta.

- Formación continua: orientada a la adquisición de conocimientos, habilidades y competencias con el fin de adaptarse y posicionarse en el mercado laboral.

En general, puede observarse un predominio de la formación de grado frente a las otras dos en la mayor parte de los países europeos. Esta hegemonía de la formación de grado también se mantiene al comparar la formación virtual y la formación presencial. Si examinamos, por ejemplo, el caso del Sistema Universitario Catalán (SUC), en el que conviven universidades tradicionales y una Universidad Virtual, la UOC, veremos que en todos los casos la mayoría de los estudiantes se pueden clasificar dentro del segmento de formación de grado, siendo el de formación de postgrado residual, tal y como muestra la Figura 93:

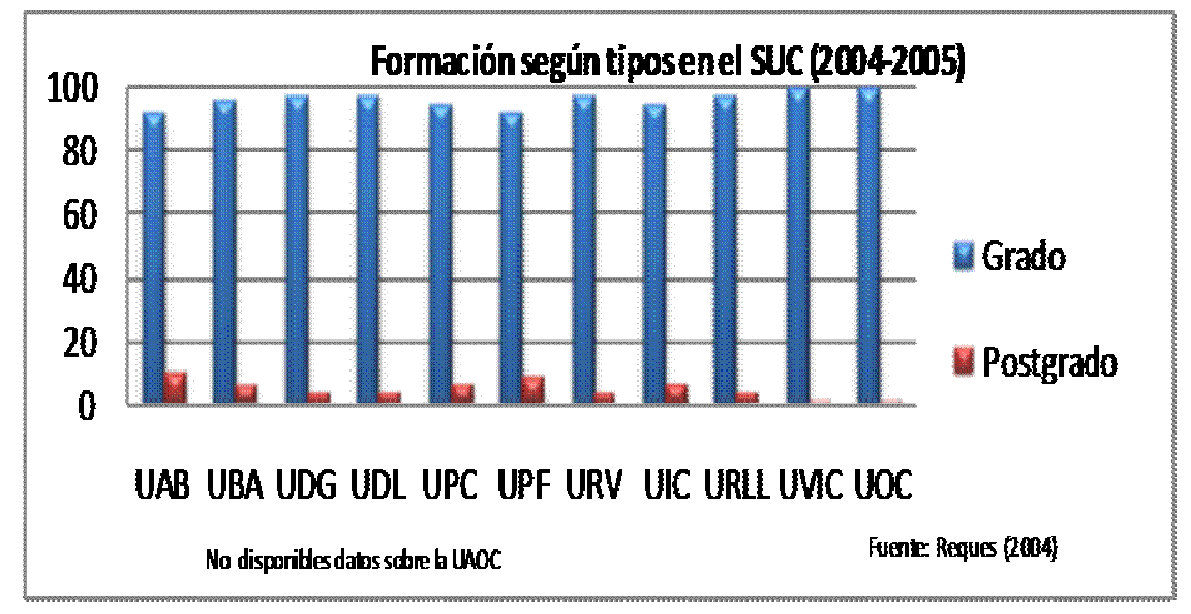

Fuente: Reques (2004).

Figura 93. Tipos de formación en el Sistema Universitario Catalán.

Teniendo en cuenta los datos anteriores, y en una primera aproximación, podría parecer que las universidades tradicionales y las universidades virtuales compiten por el mismo mercado: la formación de grado. Por ello, es necesario analizar la situación también desde otra perspectiva que pueda arrojar mayor información sobre los segmentos del mercado.

Estos sectores presentan características muy diferentes por lo que el primer paso en un análisis más profundo incluye determinar qué factores podrían aportar información adicional en cada sector. Si nos centramos en el caso de la formación de grado y estudiamos el segmento por tramos de edad, vemos que en el caso de las universidades tradicionales, la mayor parte de los estudiantes se encuentra comprendida entre los 18 y los 24 años de edad (ver Figura 94). Este hecho contrasta con el hecho de que las Universidades Virtuales se centran más en la población de 
entre 25 y 40 años para el mismo tipo de formación. Por ejemplo, en el caso de la UOC, este segmento representa más del $60 \%$ de su matrícula.

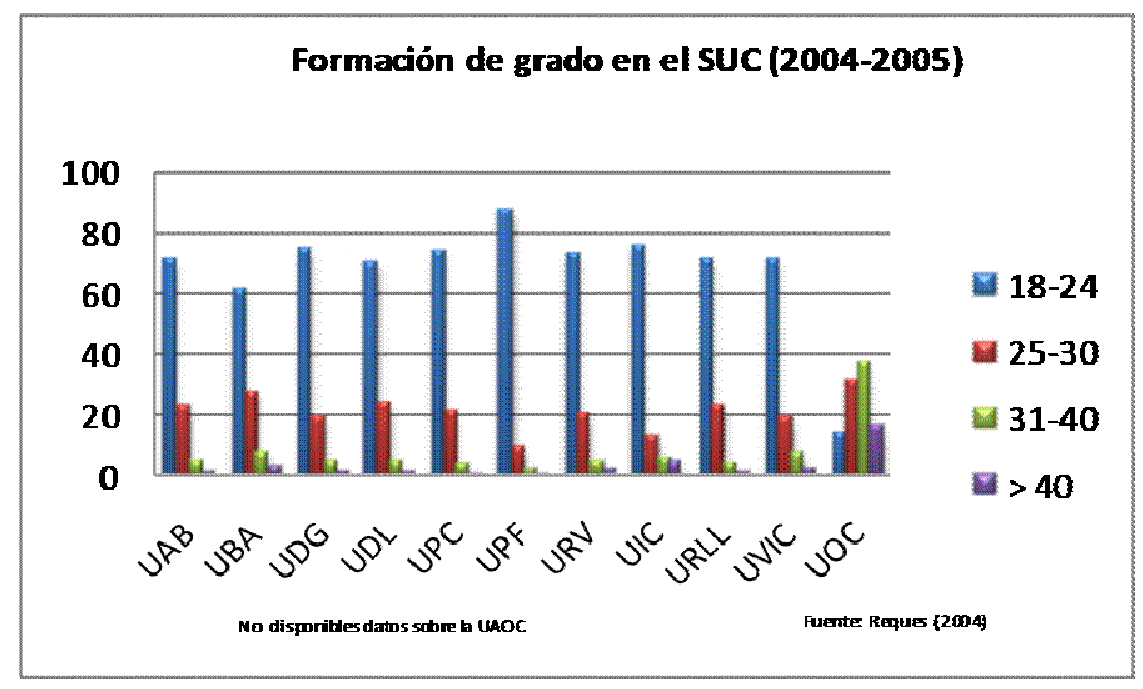

Fuente: Reques (2004).

Figura 94. Formación de grado por segmentos de edad en Sistema Universitario Catalán.

Por tanto, en la aplicación del proceso propuesto en esta tesis, escogeremos el sector de formación de grado y el rango de edad comprendido entre 18 y 24 años, por ser éste en el que parece existir, a primera vista, un mayor nivel de rivalidad.

Respecto al crecimiento del sector, aunque no han podido encontrarse datos que demuestren explícitamente, la evolución cuantitativa del e-learning en la Educación Superior, sí que se dispone de información suficiente para asegurar que se encuentra en la etapa de crecimiento de su ciclo de vida. Los indicios que justifican esta información son los siguientes:

- Aumento de la demanda universitaria debido, fundamentalmente, al incremento de la formación continua y la formación de personas adultas (OECD, 1998:2006).

Estos colectivos se caracterizan por ser estudiantes a tiempo parcial y estar limitados a unas restricciones de horarios que les impide acudir a clase con regularidad. En sentido, el elearning se posiciona como la opción ideal para que puedan acceder a formación.

- Aumento de la penetración del Internet en la Sociedad (Fundación Auna, 2004:2006, Telefónica, 2004:2006, INE 2001:2006)

- Aumento de las iniciativas de internacionalización y regionalización de la Educación Superior

De hecho, a lo largo del mundo están surgiendo numerosas iniciativas relacionadas con el desarrollo de espacios comunes de Educación Superior a través del desarrollo de programas de armonización de sistemas educativos. Dos ejemplos son los sistemas Europeos y el Latioamericano.

Un hecho notable en esta línea es que los espacios comunes son programas de unificación en los que el control del sistema educativo sigue estando bajo el Gobierno de cada país, a pesar de que se siga una política común de internacionalización a un nivel regional más o menos amplio.

- El número de Universidades que disponen de un campus virtual ha incrementando en los últimos años

En el caso concreto de España, este hecho ha quedado suficientemente probado en los estudios realizados por Area et al. (2002) y Fundación Auna (2003).

\subsubsection{Identificación del competidor}


A continuación se presentan los principales resultados referidos a las dos dimensiones que hemos destacado como relevantes: contacto multimercado (con el efecto de la orientación disciplinar) y similitud en recursos (considerando la actitud institucional).

\subsubsection{CONTACTO MULTIMERCADO}

El contacto multimercado es una medida del grado de coincidencia en varios mercados entre dos organizaciones y puede emplearse como medida de la presión competitiva que la una ejerce sobre la otra.

En este trabajo, se ha aplicado la expresión que se explicó en el apartado 5.3.1.4, utilizando como indicadores de la presencia de las universidades en el mercado los valores de matrícula y como mercado cada una de las áreas de conocimiento en que se divide la oferta formativa de las universidades. Los valores de matrícula se corresponden a formación presencial por un doble motivo: en primer lugar, no existen datos específicos de formación virtual; y, en segundo lugar, en el caso del SUV, salvo experiencias muy puntuales, el modelo de e-learning empleado es del tipo blended learning, es decir, de utilización del e-learning como apoyo a la docencia presencial.

Antes de proceder al cálculo del contacto multimercado, obtendremos los valores del orientación disciplinar de cada una de las instituciones que forman parte del sistema universitario bajo estudio.

Los resultados para el Sistema Universitario Valenciano se muestran en la Figura 95. La UPV es la Universidad más especializada, seguida de la UCV y del CEU. Llama la atención el hecho de que las Universidades Públicas (salvo la UPV), estén menos especializadas que las privadas.

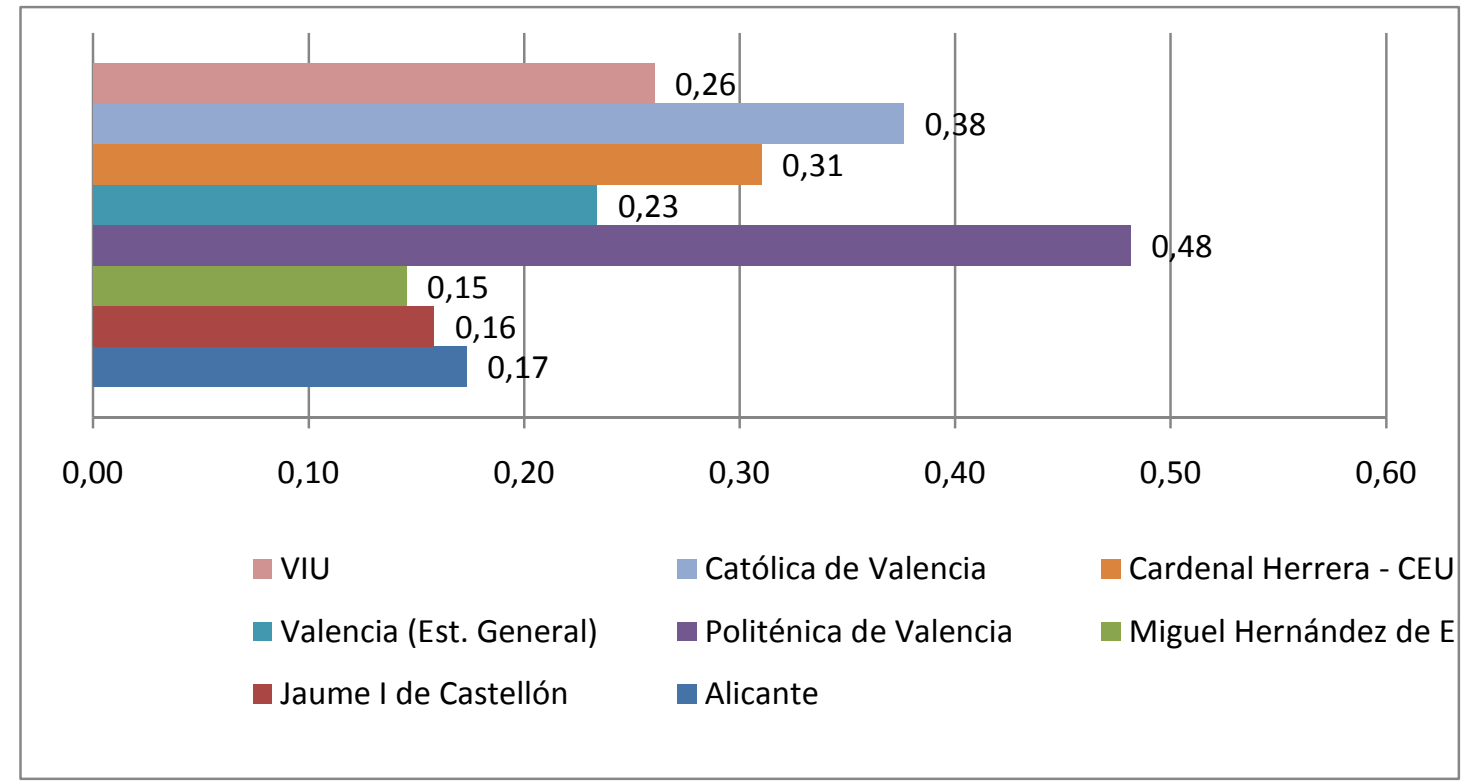

Fuente: elaboración propia a partir de CRUE (2006).

Figura 95. Especialización de las Universidades del SUV.

Debido a la falta de datos acerca de las universidades privadas, no ha sido posible incluirlas en análisis siguiente, por lo que, de ahora en adelante, quedan excluidas de cualquier conclusión que pueda extraerse. Teniendo esto en cuenta, los resultados para el caso del SUV se muestran en la Figura 96, donde los valores del contacto multimercado se han normalizado para que la suma de los valores de cada fila sea la unidad, es decir, que la presión competitiva percibida por cada una de las instituciones de las filas será igual a uno.

Centrémonos, por ejemplo, en la fila correspondiente a la UPV. 


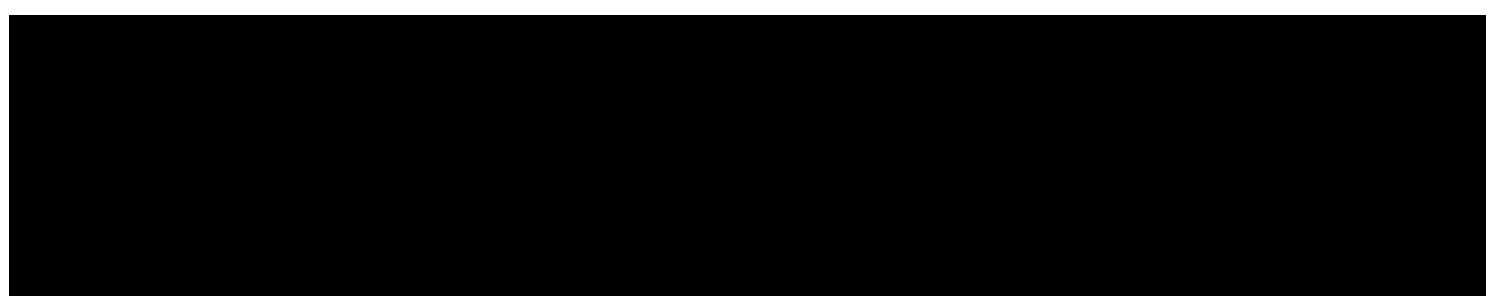

Fuente: elaboración propia.

Figura 96. Contactos multimercado para el caso del SUV.

El mayor valor corresponde a la Universidad de Alicante (UA), seguida de la Universidad de Valencia-Estudi General (UV). Además, el análisis de las filas también permite valorar la importancia relativa del contacto. Por ejemplo, la presión competitiva ejercida por la Universidad Jaime I de Castellón (UJI), es casi 4 veces menor que la ejercida por la UA. Toda esta información debe ser tenida en cuenta en la elaboración de la estrategia competitiva.

Por otra parte, los valores de las columnas contienen la presión competitiva ejercida por la Universidad de la columna sobre cada una de las universidades de las filas. En el caso de la UPV, el mayor valor se da para la Universidad de Alicante.

La tabla de la Figura 97 complementa la anterior, al mostrar el principal competidor multimercado de cada una de las universidades públicas del SUV atendiendo únicamente al valor de este parámetro.

\begin{tabular}{c|c|c}
\hline Universidad focal & $\begin{array}{c}\text { Universidad que ejerce mayor presión } \\
\text { competitiva }\end{array}$ & $\begin{array}{c}\text { Universidad sobre la que se ejerce mayor } \\
\text { presión competitiva }\end{array}$ \\
\hline UA & UPV & UPV \\
\hline UJI & UV & UV \\
\hline UMH & UPV & UJI \\
\hline UPV & UA & UA \\
\hline UV & UPV & UJI \\
\hline
\end{tabular}

Fuente: elaboración propia.

\section{Figura 97. Principales competidores de las Universidades Públicas del SUV.}

Como puede verse, el impacto competitivo de la VIU en este segmento del mercado, si tenemos en cuenta únicamente el contacto multimercado o presión competitiva, es mínimo. Algo que, por otra parte, resulta lógico si recordamos que no es tramo de edad no es uno de los objetivos de las universidades virtuales (ver Figura 94).

Sin embargo, tal y como se apuntó en el apartado 5.3.1.4, es necesaria la consideración del índice de similitud en recursos, fiel reflejo de la estrategia competitiva, para caracterizar adecuadamente la rivalidad entre instituciones.

\subsubsection{SIMILITUD EN RECURSOS}

La similitud en recursos es una medida del grado de parecido entre organizaciones que disponen de recursos del mismo tipo y constituye un reflejo de la estrategia competitiva de las organizaciones, de tal manera que dos universidades con dotaciones de recursos similares, tendrán estrategias parecidas y deberán ser consideradas como competidores.

En este trabajo, se ha aplicado el planteamiento propuesto en la Sección 1 considerando como recursos estratégicos el número de PDI (Personal Docente e Investigador) por rama de conocimiento, dada la disponibilidad de esta información. En cuanto a los coeficientes de actitud 
institucional se han empleado los de tabla de la Figura 98. Estos valores se han decidido subjetivamente en base a la revisión de la literatura especializada, por lo que sería conveniente establecer algún método objetivo para el cálculo de los mismos. No obstante, los expertos consultados han coincidido en afirmar que los valores considerados se ajustan a los valores que podrían proporcionar dichas expresiones objetivas.

\begin{tabular}{c|c}
\hline Universidad & Valor del coeficiente \\
\hline UA & 0,8 \\
\hline UJI & 1,1 \\
\hline UMH & 0,6 \\
\hline UPV & 1,3 \\
\hline UV & 1 \\
\hline
\end{tabular}

Fuente: elaboración propia.

Figura 98. Valores de los coeficientes de actitud institucional.

La tabla de la Figura 99 presenta los resultados para las universidades públicas del SUV. De nuevo, se han normalizado los valores de las celdas para que la suma de los elementos de cada fila sea la unidad.

$\begin{array}{lcrrrr} & \text { Alicante } & \begin{array}{c}\text { Jaume I de } \\ \text { Castellón }\end{array} & \begin{array}{c}\text { Miguel } \\ \text { Hernández de } \\ \text { Elche }\end{array} & \begin{array}{c}\text { Politécnica de } \\ \text { Valencia }\end{array} & \begin{array}{c}\text { Valencia } \\ \text { (Est. } \\ \text { General) }\end{array} \\ \text { Alicante } & 0,2278 & 0,3056 & 0,1304 & 0,3059 & 0,2581 \\ \text { Jaume I de Castellón } & 0,1797 & 0,2476 & 0,1339 & 0,3441 & 0,2941 \\ \text { Miguel Hernández de Elche } & 0,2435 & 0,3674 & 0,1910 & 0,3308 & 0,2419 \\ \text { Politénica de Valencia } & 0,2396 & 0,3662 & 0,1630 & 0,1982 \\ \text { Valencia (Est. General) } & & & & \text { Fuente: elaboración propia. }\end{array}$

Figura 99. Similitud en recursos para las Universidades del SUV.

\subsubsection{INTERPRETACIÓN CONJUNTA DE LOS RESULTADOS}

En este apartado se recogen los resultados de la interpretación conjunta de los valores obtenidos para el contacto multimercado y el índice de similitud en recursos en el segmento del mercado estudiado: formación de grado y rango de edad entre 18 y 24 años.

A partir del mapa competitivo de la UPV para este segmento (ver Figura 100), podría decirse que las universidades del SUV, respecto de la UPV, se encuentran en la zona de interacción competitiva baja, aunque la UA presenta un CMM elevado en este segmento. Por otro lado, la UJI se perfila como el competidor con estrategia competitiva más parecida que se explica por la elevada implicación de ambas instituciones en la implantación de un campus virtual. 


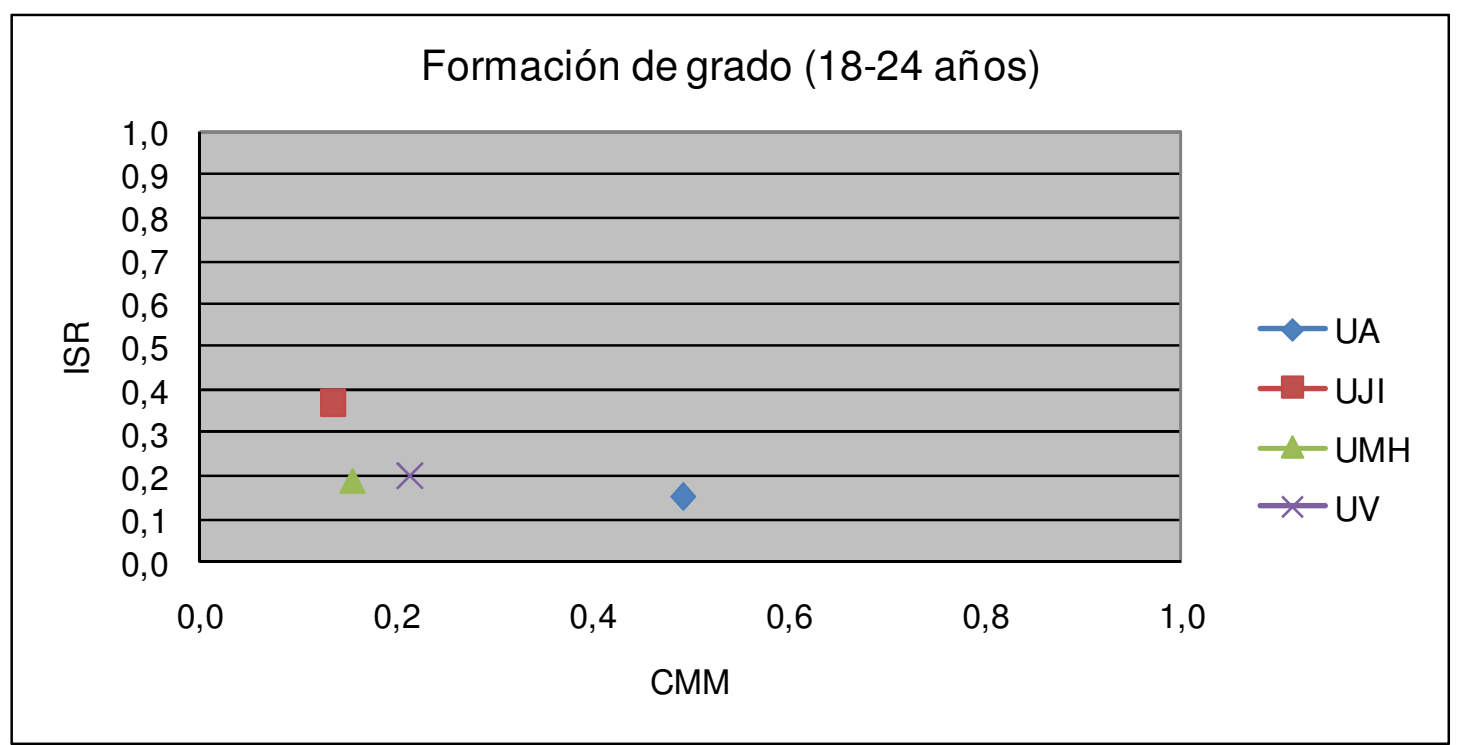

Fuente: elaboración propia.

Figura 100. Mapa competitivo de la UPV en el Segmento de formación de grado, rango de edad entre 18 y 24 años.

\subsubsection{Cadena de valor}

El estudio detallado de la cadena de valor para cada institución y la optimización de las actividades que la constituyen, permite a dicha institución identificar las potenciales fuentes de ventaja competitiva (Porter, 1980). En general, la ventaja competitiva resulta de la conjunción de factores endógenos y exógenos a la organización de tal suerte que la mezcla resultante sea inimitable y duradera y, además, aporte valor al cliente (Carús, 2002). Por otra parte, las estrategias genéricas propuestas por Porter (1980), liderazgo en costes y diferenciación, deben ser analizadas con cuidado a la hora de ser aplicadas al sector de Educación Superior on-line.

La cadena de valor de e-learning, a grandes rasgos, es la que se muestra en la Figura 101: 


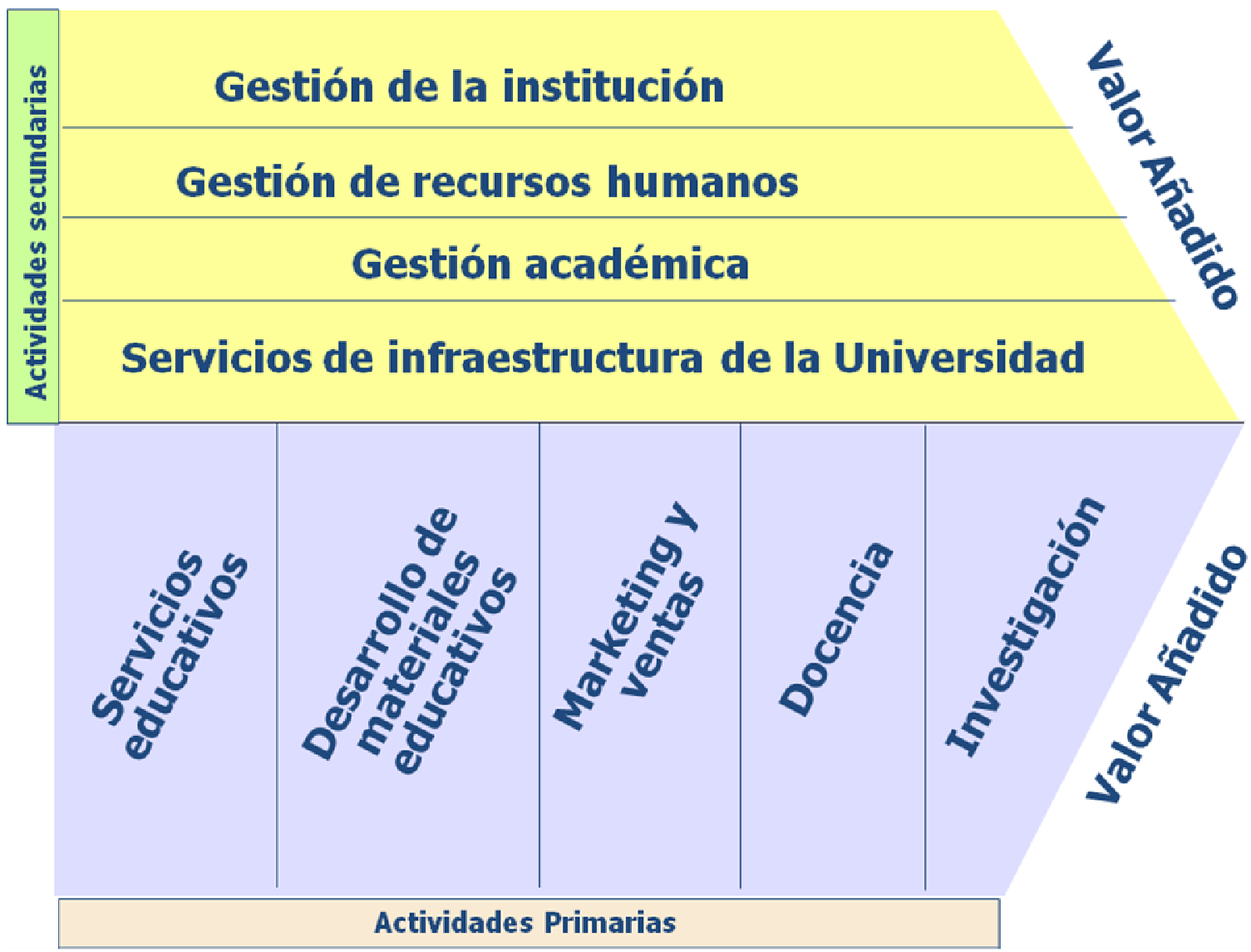

Fuente: elaboración propia

Figura 101. Cadena de valor del e-learning.

Teniendo esto e cuenta y a la hora de adaptar la cadena de valor de la UPV para incorporar, a nivel institucional, el e-learninig como herramienta competitiva, nos parece necesario formular las siguientes propuestas en cada una de las grandes áreas de la cadena de valor:

1) Investigación

Consideramos necesario potenciar las siguientes líneas de investigación:

a) Accesibilidad y usabilidad en plataformas de e-learning y su aplicación al campus virtual de la UPV.

b) Integración de nuevas tecnologías en plataformas de e-learning.

c) Evaluación de plataformas y contenidos.

d) Influencia del e-learning en la estrategia competitiva de las Universidades.

e) Aspectos legales de las TIC y del e-learning.

f) Desarrollo de estándares de calidad.

2) Docencia

a) Considerar las competencias TIC en el desarrollo profesional del PAS y del PDI.

b) Desarrollar de sistemas de evaluación y potenciación de la calidad del e-learning.

c) Adoptar estándares que favorezcan la reutilización de los contenidos de repositorios, tanto propios como ajenos.

d) Diseñar de un plan de incentivos adecuado. 
3) Marketing y ventas
a) Diseñar una estrategia de marketing adecuada al e-learning
b) Establecer una oferta atractiva y ágil.
c) Optimizar el posicionamiento en buscadores.

4) Diseño de materiales educativos
a) Calidad de los contenidos.
b) Control de calidad en los contenidos.
c) Selección de profesorado que elabore los materiales.
d) Elección adecuada del software utilizado.
e) Creación de un grupo de revisores pedagógicos.

5) Servicios educativos
a) Adopción de la filosofía CRM al entorno universitario.
b) Establecimiento de un servicio de atención al alumno.
c) Acceso a los recursos de una biblioteca digital.

6) Gestión de la institución

a) Adoptar un sistema de gestión para poder incorporar el e-learning en la actividad universitaria.

b) Mejorar la infraestructura TIC, sobre todo en seguridad y gestión basada en nuevas tecnologías que soporten aplicaciones como el pago on-line.

7) Gestión de recursos humanos
a) Formación específica del PAS y el PDI en e-learning
b) Creación de nuevas figuras adecuadas al entorno e-learning

8) Gestión académica

a) Evolucionar hacia una ventanilla on-line única para el alumno.

b) Incorporar los pagos on-line con el fin de abarcar todo el ciclo de producto.

9) Servicios de infraestructura de la Universidad
a) Dotar a las infraestructuras de los medios suficientes para un servicio de alta calidad.
b) Acercar el producto al usuario, sobre todo en el ámbito internacional.
c) Dimensionar adecuadamente los servidores para el servicio que se oferte.
d) Garantizar el servicio $365 \times 24 \times 7$.

\subsubsection{Estructura de costes}

La distinción y clasificación de las distintas partidas de costes en costes fijos y costes variables (ver apartado 8.1) permite identificar que entre los primeros destacan los derivados del trabajo especializado y de la platforma tecnológica que, en su mayoría, se engloban en la generación de los contenidos, mientras que entre los variables, destaca el soporte docente on-line.

\subsubsection{Sistema de valor}


En el apartado 7.3 se trató el sistema de valor del e-learning, respectivamente hablando, se demostró que la mayoría de las Universidades son capaces de desarrollar por sí solas todas las actividades de la cadena de valor del e-learning y que, además, pueden aglutinar el sistema de valor completo. Esto, en principio, les permite competir en el mercado sin ningún tipo de atadura o acuerdo con alguna otra organización.

Sin embargo, en algunas ocasiones resulta frecuente encontrar alianzas estratégicas entre universidades o bien entre universidad y empresa. La opción de competir sola o en compañía dependerá, en todo caso, de la estrategia institucional.

A partir de la clasificación de proveedores educativos propuesta por Seufert (2002), se han identificado tres tipos de alianzas estratégicas entre Universidades y proveedores educativos y que tienen sentido en el caso de la UPV:

- Intermediario

La intermediación se basa en que una entidad pone en contacto a otra con el cliente final. Una posibilidad bastante común es la de un intermediario que vende los cursos de una o varias universidades aprovechando el prestigio y la imagen de marca de éstas. Generalmente, la empresa se dedica a los aspectos más relacionados con el marketing y las instituciones educativas se encargan del resto. Este modelo de negocio concede una gran importancia al intermediario y eso conlleva un elevado riesgo para las instituciones educativas que por una mala gestión del intermediario podrían ver comprometido su prestigio.

Un ejemplo de proveedor educativo que sigue este modelo es la OLA (Open Learning Australia), actualmente llamada Open Universities Australia (http://www.open.edu.au). Esta empresa se creó a finales de 1992 y actúa como intermediario en el sector de la Educación Superior australiana. Esta empresa es una asociación de siete universidades australianas y, desde que se fundara en 1993, ha acumulado alrededor de 100.000 matrículas. Los certificados que emite esta organización tienen la misma validez que los que obtienen los estudiantes que acuden a las universidades que forman parte de la asociación.

En el caso concreto de la UPV, debería estudiarse la conveniencia de colaborar con la Fundación VIU (Valencian International University), que recientemente se ha planteado como un proyecto en esta línea y que, por otra parte, contribuiría a proyectar internacionalmente la labor del UPV.

- Alianzas para ofrecer certificados profesionales

Existen empresas que emiten los llamados certificados profesionales, entre las que se encuentran Cisco, Microsoft, Novell, Oracle o el PMI (Project Management Institute). Una posibilidad para aumentar el valor de la oferta del proveedor y de la institución es integrar estos certificados profesionales en la oferta de títulos propios de la Universidad.

En el caso de la UPV uno de los ejemplos es el Máster en Redes Corporativas e Integración de Sistemas que conduce a sus alumnos a una doble titulación: el CCNA o CCNP de Cisco, que caduca a los dos años; y, un título propio de la Universidad, que carece de fecha de caducidad.

Fuera de España, merece la pena nombrar, por ejemplo, la alianza entre la Charles Sturt University australiana y la compañía IT Masters, que siguen una línea similar.

- Alianzas para formación continua

Recientemente, se están fomentando los acuerdos con empresas para la formación continua de trabajadores. Uno ejemplo de iniciativas en este sentido, es el Master en Asesoría Financiera Europea que, recientemente, se ha adaptado a las necesidades particulares de los empleados de Bancaja.

\subsubsection{Estrategias competitivas}

Una vez que se ha definido el negocio y analizada la información recogida en los apartados anteriores, el paso siguiente será establecer con qué estrategia se competirá en el sector. Porter (1980) identificó dos estrategias competitivas genéricas: el liderazgo en costes y la diferenciación. 
Otra opción es la estrategia de nicho, que introduce en las dos opciones anteriores el concepto de ámbito de la estrategia para medir el alcance de la misma, de tal forma que la estrategia de nicho consiste en centrarse en un segmento del mercado, producto o servicio muy concreto y en el que se dispone de algún tipo de ventaja competitiva derivada de un liderazgo en costes o de una diferenciación derivadas, por ejemplo, del dominio de una cierta tecnología.

En el caso de la UPV, y dadas las características del sector del e-learning en el ámbito de la Educación Superior, se recomienda lo que se denomina una estrategia de diferenciación optimizada en costes, resultante de una apuesta decidida por la diferenciación en calidad pero con una control de los costes de la actividad, tal y como se justificará en los párrafos siguientes.

El liderazgo en costes, genéricamente, consiste en conseguir unos costes de producción más bajos que los competidores en un producto o servicio indiferenciado. En el e-learning, algunas estrategias útiles son la limitación de la oferta de cursos a sectores muy específicos, la reducción de la complejidad de los procesos de diseño y producción de material formativo o la disminución del servicio de atención a los estudiantes. Todo ello, complementado un estricto control de costes. Tampoco hay que olvidar los beneficios de las organizaciones virtuales que, entre otras cosas, permiten desarrollar una actividad de negocio sin necesidad de disponer de instalaciones físicas, ahorrándose los gastos y la inversión que ello supone. Un ejemplo de institución que ha apostado por una estrategia de liderazgo en costes en la University of Phoenix (UoP) contrando profesores a tiempo parcial y dedicándolos, única y exclusivamente, a labores de docencia y no otras tareas también propias del personal docente como la investigación y la gestión académica. La UoP también trata de mantener los costes controlados minimizando sus necesidades de infraestructura, por ejemplo, proporcionando multitud de recursos bibliográficos a través de Internet en lugar de disponer de una biblioteca propia.

Por tanto, uno de los puntos clave para conseguir el liderazgo en costes es la optimización del proceso de generación de contenidos. En este sentido, se aconseja la creación de grandes repositorios de objetos de aprendizaje que permitan, por otra parte, aprovecharse de los efectos de las economías de escala en la producción de cursos. Un repositorio de contenidos es un gran almacen de objetos de aprendizaje, es decir, de elementos modulares en los que se empaquetan los contenidos y que permiten la construcción de lecciones, cursos y, en general, cualquier tipo de elemento formativo, a partir del ensamblado "bajo demanda" de dichos objetos de aprendizaje (ver Figura 102):

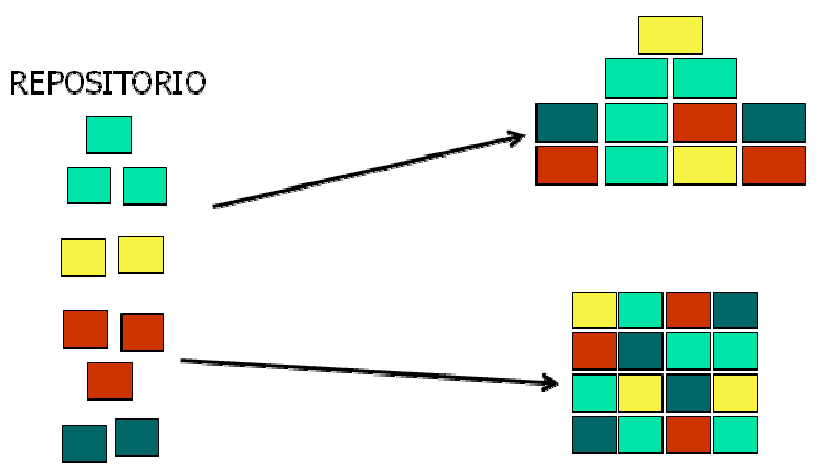

Fuente: elaboración propia.

Figura 102. Construcción de cursos a partir de un repositorio digital.

La UPV ya dispone de un repositorio digital, fruto del Plan Docencia en Red, que pone a disposición de los creadores de contenidos una gran variedad de objetos de aprendizaje que pueden ser empleados en la generación de contenidos para las asignaturas del campus virtual. Se tratará, por tanto, de potenciar esta línea de actuación.

El impacto de un repositorio digital en la estrategia de liderazgo en costes puede verse fácilmente si consideramos el análisis del punto de equilibrio ya introducido en el apartado 8.1.4 y 
que se emplea para determinar el umbral de rentabilidad del producto, servicio, proyecto, estrategia, etc. Como muestra la Figura 103, un repositorio digital se podría traducir en la reducción de los costes fijos asociados a la generación de contenidos, habida cuenta de la posibilidad de la reutilización de los mismos, y, por tanto, en un desplazamiento del punto de equilibrio hacia la izquierda, con la consiguiente maximización de la zona de beneficios que ello supone.

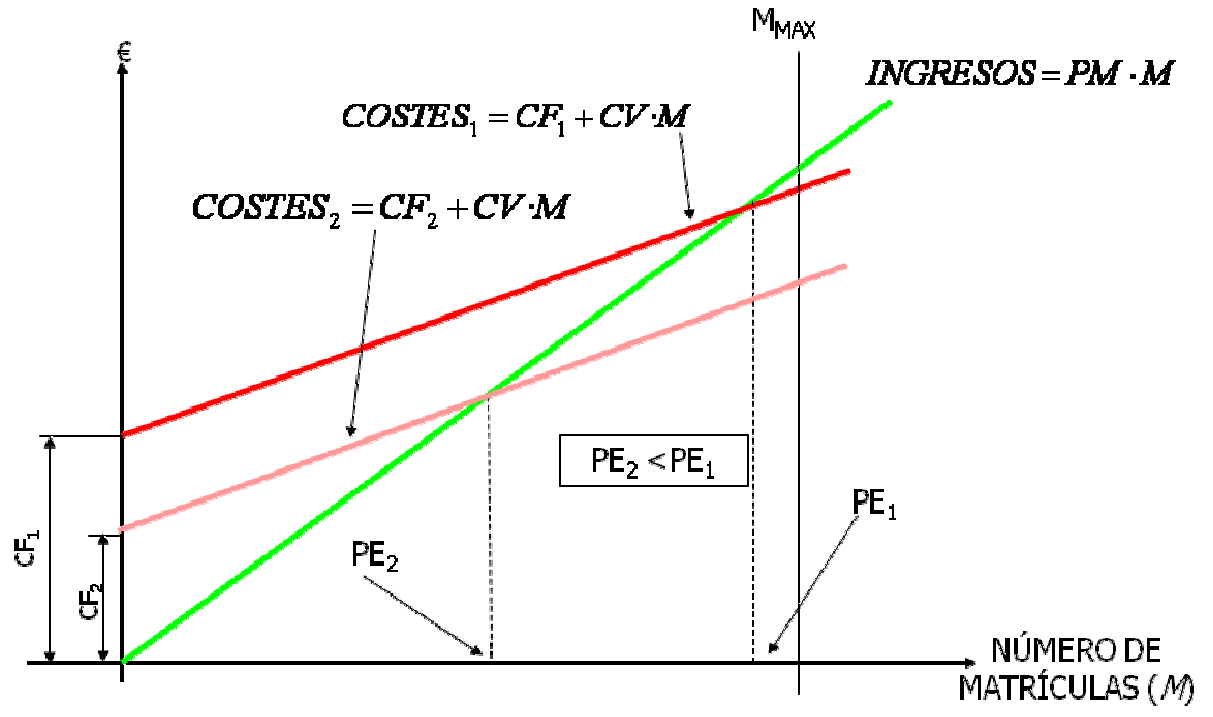

Fuente: elaboración propia.de

Figura 103. Aumento de la rentabilidad por efecto de un repositorio digital.

En cuanto a la diferenciación, consiste en conseguir que el producto o servicio tenga, al menos, una característica única que lo distinga de los productos o servicios de la competencia y de modo que los clientes perciban un mayor valor en él. La esencia de la diferenciación en el elearning es que, en general, un curso en sí mismono proporciona ninguna ventaja competitiva en tanto en cuanto cualquier organización puede duplicarlo, bien comprándolo directamente del proveedor o creándolo ella misma. Sin embargo, cuando al curso se le añaden los servicios prestados por profesores, tutores, etc., se establece un mayor vínculo entre los estudiantes y la organización educativa que se traduce en una ventaja competitiva en cuanto a soporte, servicio, excelencia y calidad. Precisamente, la calidad es el principal factor diferenciador en este sector para la creación de una imagen de prestigio. Esta calidad debe entenderse en dos sentidos: calidad de los contenidos y calidad del servicio.

La calidad de los contenidos puede conseguirse mediante la implicación de un equipo multidisciplinar a la generación de los contenidos, de tal forma que cada miembro del equipo se centre en las tareas en que es especialista y se aprovechen las sinergias del trabajo conjunto. En grupo de trabajo de este tipo deben participar, al menos, un experto en la materia (habitualmente un profesor) que se encargue verter sus conocimientos en los contenidos, un experto multimedia que se encargue de la producción de los contenidos y un revisor pedagógico que asegure que los contenidos en cuestión se rigen por los principios pedagógicos, metodológicos y didácticos que exige la formación virtual. De este modo, se garantiza una elevada calidad didáctica, tecnológica y pedagógica de los contenidos (ver Figura 104), pilares sobre los que puede construirse una imagen de marca. 


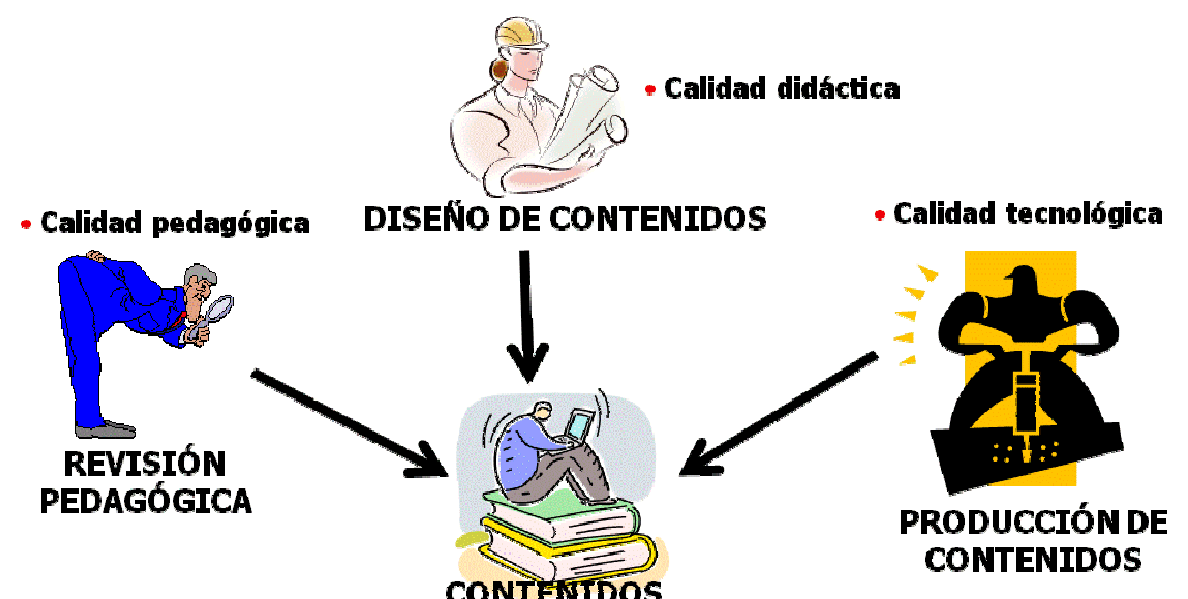

Figura 104. Proceso multidisciplinar de generación de contenidos.

Pero además de unos contenidos de calidad, resulta fundamental también la calidad en la atención de los estudiantes, profesores, etc y que agruparemos, a efectos de los párrafos siguientes bajo la denominación genérica de cliente. Son tres los pasos necesarios para manejar consistentemente la figura del cliente:

- Disponer de medios que permitan identificar a los clientes, ya que así se podrá personalizar la atención en tanto y en cuanto se sea capaz de saber quién se está conectando al portal web de la organización.

- Diseñar indicadores y atributos que permitan diferenciar entre las distintas categorías de clientes y que dependerán el modelo de negocio.

- Integrar los datos de los clientes con el fin de ofrecerles un servicio sin fisuras independientemente del canal seleccionado por éste y enriquecer la información de que se dispone para el análisis de dichos datos.

El beneficio inmediato de un tratamiento consistente del cliente es que se consigue la diferenciación respecto de la competencia ya que facilite que los clientes perciban un mayor valor en el servicio y un trato individualizado. La Figura 105 resume las características de un servicio orientado al cliente comparándola con el enfoque tradicional. 


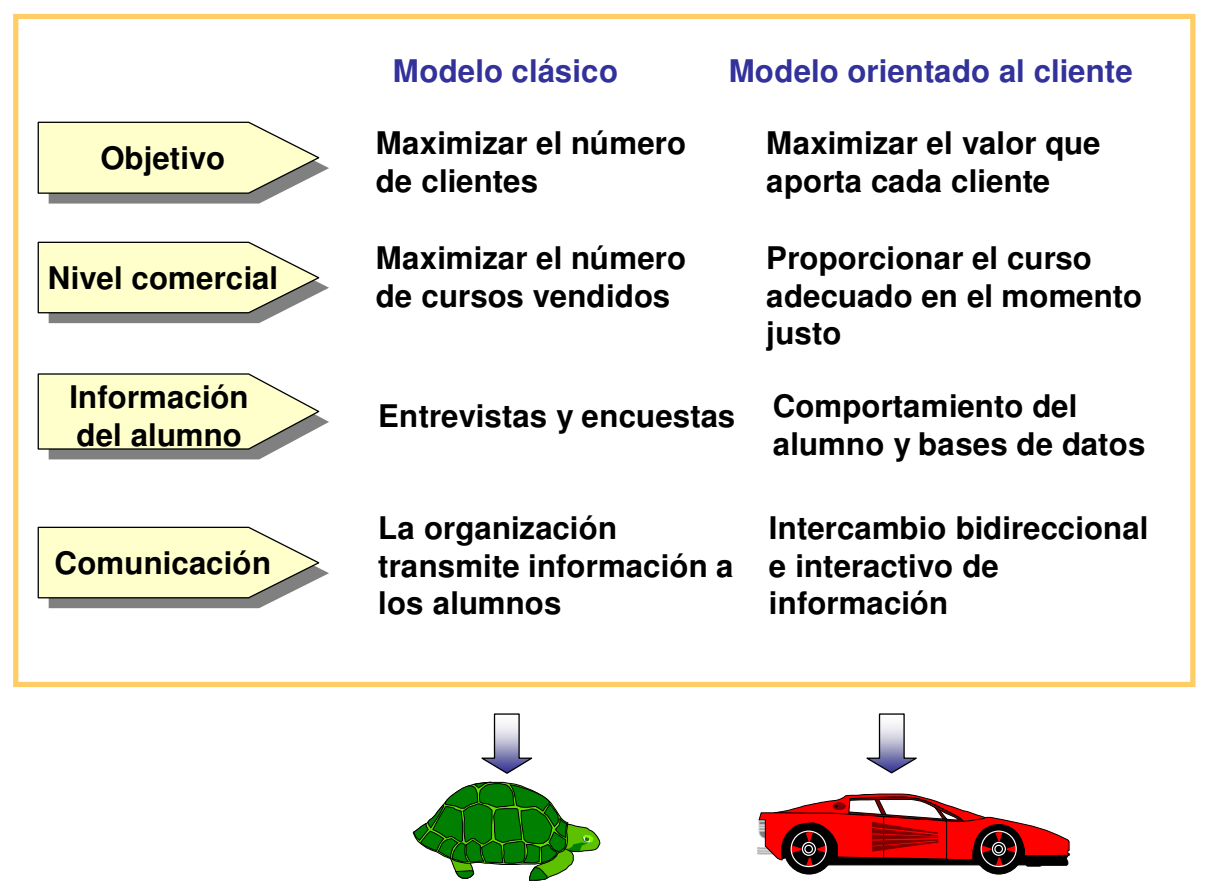

Fuente: elaboración propia.

Figura 105. Modelo clásico vs. Modelo orientado al cliente.

Todo se consigue a través de la organización de la atención al cliente estructurada en nivel de atención (ver Figura 106), en la línea de lo que actualmente se hace en el Centro de Atención a Usuarios (CAU) del ASIC. En un sistema de atención por niveles, los operadores del centro se estructuran en categorías o grupos dependiendo de sus conocimientos y capacitación, de manera que las incidencias son enviadas, en primer lugar, a los operadores de menor nivel y, en caso de que estos no sepan resolverlas, se escalan (reenvían) a los operadores del nivel superior y así sucesivamente. 


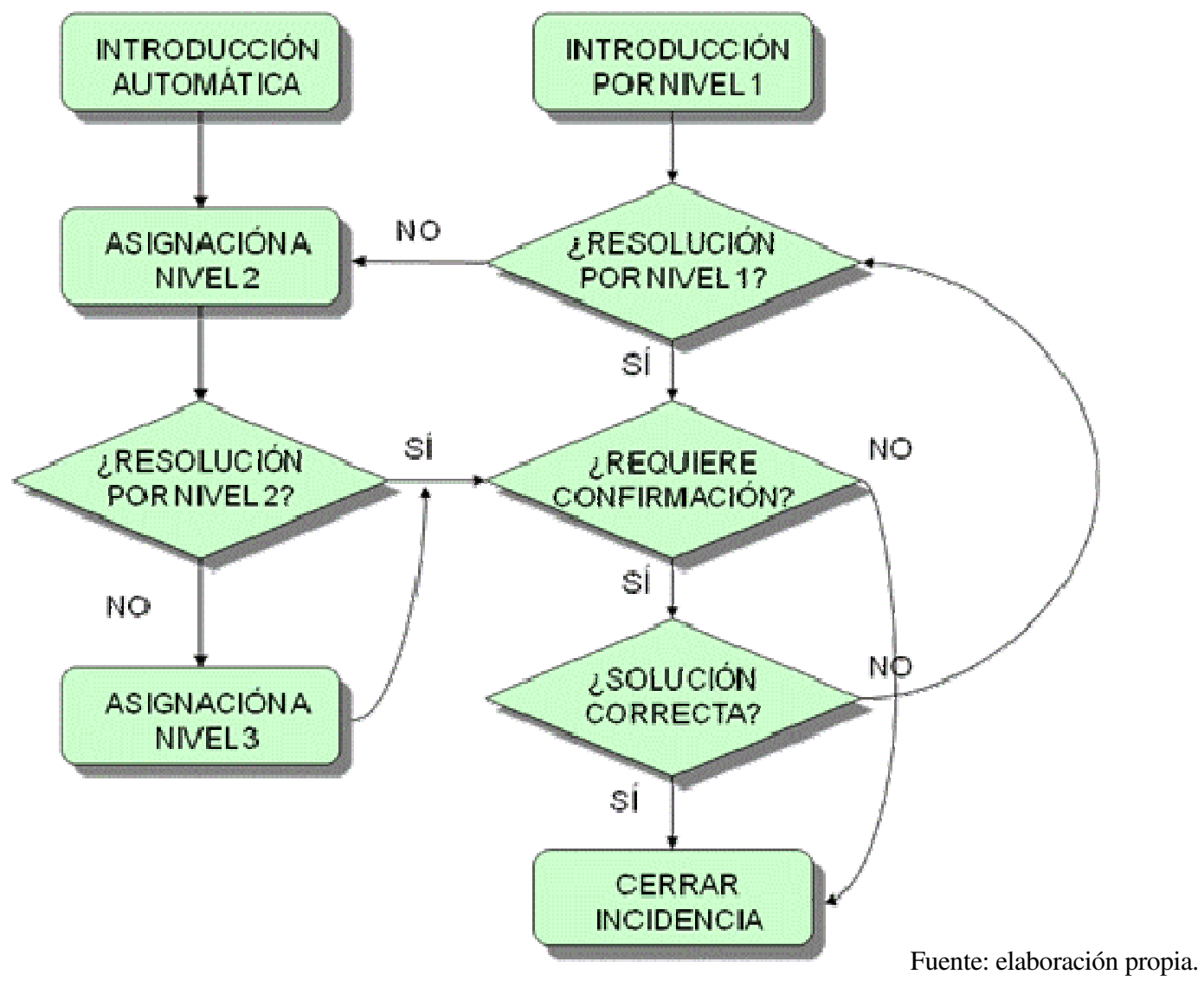

Figura 106. Proceso de atención en niveles.

Para la gestión de las incidencias, los operadores de cada nivel disponen de una aplicación de gestión de las mismas, como es el caso de GREGAL, la herramienta puesta en funcionamiento por el ASIC de la UPV para este efecto. El objetivo de este tipo de soluciones es conseguir que ninguna incidencia se quede sin resolver y, por otra parte, que los clientes puedan saber, en cualquier momento, cuál es el estado de la suyas.

\subsection{LÍNEAS DE INVESTIGACIÓN FUTURAS}

En las cuestiones abordadas en este trabajo de investigación, debido a la utilización de una estrategia de indicios, podría haberse caído en una visión demasiado simplista en algunas ocasiones. Esto demanda la construcción de un modelo que incorpore, en primer lugar, los factores relevantes en el campo de análisis y, en segundo lugar, que explore las relaciones entre dichos factores. Ello conducirá a explicar satisfactoriamente la contribución de cada factor a la estrategia de las Universidades.

La investigación adicional que pueda suscitarse a partir de esta tesis, debería incluir la medición y el grado de influencia de factores como la cultura institucional, el papel del personal clave, la experiencia internacional, factores geográficos, la inversión en TIC, etc., que quizá sean relevantes y cuyo papel debiera ser analizado y tomado en cuenta para investigaciones futuras. Todo ello permitirá la obtención de expresiones matemáticas más compleja de los factores descriptores de la rivalidad que han sido presentados aquí de un modo muy simplificado.

Finalmente, existe gran cantidad de estudios acerca de la Educación Superior presencial, por ser éste el formato tradicional. Sin embargo, la utilización del e-learning en Educación Superior como respuesta a la internacionalización de la misma, está mucho menos analizado y, 
además, carece de sustento empírico por la relativa juventud de este campo de análisis. Por tanto, existen aquí otras líneas futuras de investigación. 


\section{ANEXOS}




\section{LISTA DE PUBLICACIONES}

$-2007$

1. Hervás Jorge, A. y Roldán Martínez, D. (2007).E-learning strategic analysis: the role of HE institutions. Aceptado en FEJ Electronics and Communications. Próxima publicación. Beca FVIU.

2. Roldán Martínez, D. y Hervás Jorge, A. (2007). A framework for on-line learning business models analysis in Higher Education institutions. Proceedings of the ICALT , pp.139-146.

3. Roldán Martínez, D., Hervás Jorge, A. y Monsoriu Flor, M. (2007). Next generation e-learning tools. Sometido a Journal of Online Learning and Teaching. Beca FVIU.

$-2006$

4. Dean, A. y Roldán Martínez, D. (2006). E-Learning: A Value Chain and Business Analisys. Fourth EDEN Research Workshop. Research into Online Distance Education and e-learning. Castelldefels, Spain.

5. Roldán Martínez, D. (2006). El e-learning como estrategia de marketing en Internet. Cámara de Comercio de Valencia.

6. Roldán Martínez, D. y Buendía García, F. (2006). Analizing mobile learning issues in a Higher Education context. Proceedings of the ICALT, pp. 41-48.

7. Roldán Martínez, D., Buendía García, F. y Hervás Jorge, A. (2006). MLF: una arquitectura m-learning basada en el modelo JISC. Actas del II Congreso Iberoamericano sobre Computación Ubicua, pp. 263-270.

$-2005$

8. Roldán Martínez, D. (2005). E-learning: estrategias de formación sin límites, Actas de Mundo Internet, pp.174-179.

9. Roldán Martínez, D. (2005). Formación on-line. Retos y oportunidades. Madrid: ACTA.

10. Roldán Martínez, D. (2005). Tecnologías de negocio electrónico aplicadas a la $E A D$. Virtual Educa 2005. Ciudad de México (México). 


\section{REFERENCIAS}

[1] Aaker, D. (1989). Managing assets and skills: the key to a sustainable competitive advantage. California Management Review, vol. 31, № 2, pp.91-106.

[2] Abell, D.E. (1980). Defining the business: Starting point of strategic planning, Englewood Cliffs, N.J: Prentice-Hall.

[3] AEFOL (2003). El estado del e-learning es España. Obtenido el 4/07/2007 desde http://banners.noticiasdot.com/termometro/boletines/docs/elearning/aefol/2003/aefol_estudio 2003.pdf.

[4] Afuah, A. y Tucci, C. (2001). Internet Business Models and Strategies, New York: Irwin/McGraw Hill.

[5] Alexander, S. (2001). E-learning developments and experiences. Education and Training, Vol. 43, no 4-5, pp.240-248.

[6] Allison, G.T. (1971). Essence of decision: Explaining the Cuban missile crisis, Boston: Little, Brown.

[7] Amit, R. y Zott, C. (2001). Value creation in e-Business. Strategic Management Journal. Vol. 22. pp. 493-520.

[8] Andreu, R., Ricart, J.E. y Valor, J. (1996). Estrategia y Sistemas de Información, Madrid: McGraw-Hill.

[9] Ansoff, H.I. (1965). Corporate Strategy, Nueva York: McGraw-Hill.

[10]ANTA (2003). Flexible Learning Business Planning Framework. Obtenido el 24/02/2007 de http://flexiblelearning.net.au.

[11]Area, M. (dir.) (2002). Los campus universitarios virtuales en España. Análisis del estado actual, II Congreso Europeo TIEC, Barcelona. Obtenido el 28/01/2007 de http://web.udg.es/tiec/orals/c52.pdf.

[12]Arias, F. (1985). Un modelo propositito de planeación estratégica para instituciones educativas privadas de nivel superior. Revista de la Educación Superior, $\mathrm{n}^{\circ}$ 56. Obtenido el 28/01/2007 http://www.anuies.mx/servicios/p_anuies/publicaciones/revsup/res056/txt4.htm.

[13]Arocena, R., Sutz, J. (2001). La transformación de la universidad latinoamericana mirada desde una perspectiva CTS. En: López Cerezo y Sánchez Ron (eds.), Ciencia, Tecnología, Sociedad y Cultura, Biblioteca Nueva-OEI, Madrid.

[14]Arocena, R. y Sutz, J. (2002): La Universidad Latinoamericana del Futuro. Tendencias Escenarios - Alternativas, Revista de la OEI. Obtenido el 27/12/2006 de http://www.campusoei.org/salactsi/sutzarocena04.htm.

[15]Association of European Universities (1998), Restructuring the university: new technologies for teaching and learning: guidance to universities on strategy, $56 \mathrm{p}$. 
[16]Azcorra, A., Bernardos, C.J., Gallego, O. y Soto, I. (2001). Informe sobre el estado de la Teleeducación en España. Universidad Carlos III y Asociación de Usuarios de Internet. Obtenido el $19 / 03 / 2007$ de http://banners.noticiasdot.com/termometro/boletines/docs/consultoras/aui/2001/aui_Informe_t eleeducacion_CarlosIII_2001.pdf.

[17]Ba, S.; Whinston, A.B.; Zhang, H. (1999). Small Business in the Digital Economy: Digital Company of the Future, Conferencia: Understanding Digital Economy: Data, tools and research Washington 25-26 Mayo 1999.

[18]Bain, J.S. (1956). Barriers to new competition. Harvard: Harvard University Press.

[19]Bakos, J.Y. (1991). A strategic analysis of electronic marketplaces. MIS Quarterly, 15, 3, pp. 295-310.

[20]Bakos, J.Y. (1997). Reducing buyer search costs: Implications for electronic marketplaces, Management Science, vol. 43, $\mathrm{n}^{\circ}$ 12, pp. 1676 - 1692.

[21] Bakos, J.Y. (1998). The emerging role of Electronic Marketplaces on the Internet. Communications of the ACM, Vol. 41, $\mathrm{n}^{\circ}$ 8, pp. 35-42.

[22]Bakos, J.Y.; Brynjolfsson, E. (1993). From vendors to partners: information technology and incomplete contracts in buyer-seller relationships. Journal of Organizational Computing, Vol. 3, no 3, pp. 301-328.

[23]Ballarin, E. (1985). Estrategias competitivas para la banca. Barcelona: Ariel, SA.

[24]Barney, J. B. (1986). Strategic factor markets: Expectations, luck, and business strategy. Management Science, Vol. 32, $\mathrm{n}^{\mathrm{o}}$ 10, pp.1231-1241.

[25]Barney, J.B. (1991). Firm resources and sustained competitive advantage. Journal of Management, Vol. 17, pp. 99-120.

[26]Barney, J.B. (2001). Is the resource-based view a useful perspective for strategic management research? Yes. Academy of Management Review, Vol. 26, No 1, pp. 41-56.

[27]Barney, J. B., y Arikan, A. M. (2001). The resource-based view: Origins and implications. En M. A. Hitt, R. E. Freeman, \& J. S. Harrison (Eds.), The Blackwell Handbook of Strategic Management (pp.124-188). Malden, MA: Blackwell Publishers Inc.

[28]Barney, J.B. y Zajac, E.J. (1994). Competitive organizational behaviour: toward an organizationally-based theory of competitive advantage. Strategic Management Journal, Vol. 17, pp. 5-9.

[29]Bartlett, C. y Goshal, S. (2002). Building competitive advantage through people. Sloan Management Review, Winter, pp.34-41.

[30]Bartolic-Zlomislic, S. y Bates, A.W. (1999). Assessing the Costs and Benefits of Telelearning: A Case Study from the University of British Columbia. NCE series of reports. Developing and Applying a Cost-Benefit Model for Assessing Telelearning, Telelarning Networks Centers of Excellence, Canadá. Obntenido el 18/12/2006 de http://det.cstudies.ubc.ca/detsite/framewhat-index.html.

[31]Bates, A.W. (1994). Costing Distance Education Technologies. Developing a Methodology. Open Learning Agency (OLA) paper (abril).

[32]Bates, A.W. (1995) Technology, open learning and distance edutacion. Londres: Routledge.

[33]Bates, A.W. (2001) Cómo gestionar el cambio tecnológico, Barcelona: Gedisa.

[34]Bates, A.W. (2001). National strategies for e-learning in post-secondary education and training, Fundamentals of Education Planning Series 70, United Nations Educational, Scientific and Cultural Organization.

[35]Bates, A.W. (2003) Technology, E-Learning and Distance Education, Londres/Nueva York: Routledge.

[36]Bates, A.W. (2004). La planificación para el uso de TIC en la enseñanza, en Sangrá, A. y Sanmamed, M. (Coordinadores), La transformación de las universidades a través de las TIC: discursos y prácticas (pp.31-51), Barcelona: Editorial UOC.

[37]Baum, J.A.C. y Korn, H.J. (1996). Competitive Dynamics of Interfirm Rivalry, Academy of Management Journal, Vol. 39, $\mathrm{n}^{\circ}$ 2, pg. 255-291. 
[38]Baum, J.A.C. y Korn, H.J. (1999). Dynamics of dyadic competitive interaction, Strategic Management Journal, Vol. 20, 251-278.

[39]Benjamin, R. y Wigand, R. (1995). Electronic Markets and Virtual Value Chains on the Information Superhighway. Sloan Management Review, Vol. 36, nº 2, pp. 62-72.

[40]Benczes, I. (1998). Quasi-market financing in higher education: the case of Great Britain. Obtenido de http://www.uni-corvinus.hu/benczes/HeduGB_English.pdf el 1/05/2007.

[41]Bergen, M.E. y Peteraf, M.A. (2002). Competitor Identification and Competidor Análisis: A Broad-Based Managerial Approach. Managerial and Decision Economics, Vol 23, pp. 157169.

[42]Berndt, E.; Morrison, C. (1995). High-tech capital formation and economic performance En U.S. manufacturing industries: an exploratory analysis. Journal of Econometrics, Vol. 65, pp. 9-43.

[43]Bernheim, B., y Whinston, M. (1990).Multimarket Contact and Collusive Behavior, RAND Journal of Economics, $\mathrm{Vol} 21, \mathrm{n}^{\circ} 1$, pp. 1-26.

[44]Bernroider, E. (2002). Factors in SWOT analysis applied to micro, small-to-medium and large software enterprises: an Austrian study. European Management Journal, Vol. 20, № 5, pp. $562-573$.

[45]Berry, L., Yadav, M. (1997). Capture and communicate value in the pricing of services, Sloan Management Review, Spring.

[46]Bettis, R.A. y Weeks, D. (1987). Financial returns and strategic interaction: the case of instant photography. Strategic Management Journal Vol. 8, nº 6, pp. 549-563.

[47]Blau, F. y Khan, L. (1996). Internacional differences in wage inequality: institutions versus market forces. Journal of Political Economy, Vol. 104, nº 4, pp. 791-837.

[48]Bloom, D. (2005). Raising the pressure: globalization and the need for higher education reform. En Jones, G., McCarney, P. y Skolnik, M. (eds.) Creating Knowledge: Strengthening Nations: The changing role of higher education. University of Toronto Press, Toronto, pp. 2141.

[49]Boeker, W., Goodstein, J., Stephan, H. y Murmann, J.P. (1997). Competition in a multimarket environment: The case of market exit, Organization Science, Vol. 8, pp. 126-142.

[50]Bogner, W.C. y Thomas; H. (1993). The role of competitive groups in strategy formulation: a dynamic integration of two competing models, Journal of Management Studies, Vol. 30, pp. 51-67.

[51]Brandenburger, A.M. y Nalebuff, B.J. (1995) The right game: use game theory to shape strategy. Harvard Business Review, Vol. 73, no 4, pp. 57-71.

[52]Brandtweiner, R., Mahrer, H. (2002), Business models for virtual communities: An explotratory analysis, en Eighth Americas Conference on Information Systems, pp 474-481, Association for Information Systems. Consultado el 16/11/2006 de http://aisel.isworld.org/password.asp?Vpath=/amcis/2002/\&PDFPath=020901.pdf

[53]Bredo, O., Foersom, T. and Laursen, P. F. (1993). Students choice - a model. HE Review, Vol. 26, nº 1, pp. 64-73.

[54]Bricall, J. M. (2000). Informe Universidad 2000. Comisión Europea.

[55]Bricall, J. (2004): La Universidad ante el Siglo XXI. En: Sangrá, A y Sanmamed, M. (Coordinadores) 2004: La transformación de las universidades a través de las TIC: discursos y prácticas, Barcelona: Editorial UOC.

[56]Briz, J. y Laso, I. (2001). Internet y Comercio Electrónico. Madrid: Ediciones Mundi-Prensa.

[57]Brynjolfsson, E. y Hitt, L. (1996). Paradox losst? Firm-level evidence of the returns to information systems spending. Management Science, Vol. 42, $\mathrm{n}^{\mathrm{o}}$ 4, pp. 541-558.

[58]Brynjolfsson, E. y Kahin, B. (eds.) (2000). Understanding the digital economy: data, tools and research. MIT Press, Cambridge.

[59]Brynjolfsson, E. y Smith, M. (2000). Frictionless commerce? A comparison of Internet and conventional retailers. Management Science, Vol. 46, nº 4, pp. 563-585.

[60]Brynjolfsson, E. y Yang, S. (1996). Information Technology and productivity: a review of the literature. Advances in Computers, Vol. 43, pp.179-214. 
[61]Brown, T.H. (2004). The role of m-learning in the future of e-learning in Africa?. En Distance Education and Technology: Issues and Practice. Hong Kong, 2004.

[62]Brunner, J.J. (2001). Globalización y el futuro de la educación: tendencias, desafíos, estrategias. Obtenido de http://mt.educarchile.cl/archives/Futuro_EDU\%25UNESCO2000.pdf el 1/05/2007.

[63]Brunner, J.J. y Tillett, A. (2005). El mercado avanza sobre la educación superior: un Reader dinámico. Obtenido de http://mt.educarchile.cl/mt/jjbrunner/archives/2005/11/el_mercado_avan.html el 1/05/2007.

[64]Brunner, J.J. y Tillett, A. (2007). Higher education in Central Asia; the challenges of modernization - an overview. Report for World Bank.

[65]Bueno Campos, E. (1991). Organización flexible y gestión del cambio, Documento IADE $(U A M), \mathrm{n}^{\mathrm{o}} 28, \mathrm{p} .34$.

[66]Bueno Campos, E. (1996). Dirección estratégica de la empresa. Metodología, técnica y casos. Madrid: Pirámide.

[67]Business Week (1999a) In the ring eBay vs. Amazon.com: the fight you never thought you'd see, Business Week, May 31, pp. 128-140.

[68]Business Week (1999b) Intel is taking no prisoners: it's slashing prices to gain share and blitzkrieg the competition, Business Week, June 12, p. 38.

[69]Bueno, E. (1996). La investigación sobre las empresas turísticas en España: el estado del arte. Estudios Turísticos, $\mathrm{n}^{\circ} 129$.

[70]Cachon, G.P.; Zipkin, P.H. (1999). Competitive and cooperative inventory policies in a twostage supply chain. Management Science, Vol. 45, $\mathrm{n}^{\circ}$ 7, pp. 936-953.

[71]Calvo, B. (2007). Perspectiva europea de la Educación Superior. Carácter transversal y redes universitarias (internacionalización, movilidad, redes). Consultado el 30/04/2007 en http://www.gampi.upm.es/ECTEU-Cap1-BCalvo.pdf.

[72]Camerer, C.F. (1991) Does strategy research need game theory? Strategic Management Journal Vol. 12(Winter Special Issue), 137-152.

[73]Cameron, K y Smart, J. (1998), Maintaining effectiveness amid downsizing and decline in institutions of higher education, Research in Higher Education, febrero.

[74]Canals Margalef, J (2001). La Estrategia de la Empresa en la Era Internet, Información Comercial Española, núm 793, pp.57-75.

[75]Canzer, B (2003), E-Business: Strategic thinking and practice, Boston: Houghton Mifflin.

[76]CAPA (2005). Credit transfers - uniformity in recognition and granting of exemptions. Obtenido de http://www.capa.edu.au/conferenceevents/2005_SCM/CreditTransfers.pdf el $1 / 05 / 2007$.

[77]Capacete, L. (2001). Burocracia. Obtenido de http://www.diezminutos.org/colaboraciones/Burocracia.html el 1/05/2007.

[78]Caparrós, A., Navarro, M.L. y Rueda, M.F. (2005). Determinantes de la formación en la empresa. Jornadas de la Asociación de la Economía de la Educación. Oviedo, España.

[79]Carnoy, M. (1999). Globalization and educational reform: what planners need to know; Paris: IIEP.

[80]Carnoy, M. (2005). Globalization, educational trends and the open society. Obtenido de http://www.soros.org/initiatives/esp/articles_publications/articles/globalization_20060217/car noy_english.pdf el 1/05/2007.

[81]Carnoy, M. (2004). Las TIC en la enseñanza: posibilidades y retos. En: Lección inaugural del curso académico 2004-2005 de la UOC (2004: Barcelona) Consultado el 28/11/2006 de http://www.uoc.edu/inaugural04/dt/esp/carnoy1004.pdf.

[82]Cartwright, S.D. y Oliver, R.W. (2000) Untangling the value web. The Journal of Business Strategy, Vol. 21, no 1, pp.22-28.

[83]Carús Ribalgaygua, L. (2000). Análisis estratégico del segmento turístico recreativo de alta montaña: el caso del Pirineu Lleidata. Tesis doctoral. Departamento de Administración de Empresas y Gestión económica de los Recursos Naturales. Universitat de Lleida. 
[84]Casadesus, R. (2004). Dinámica competitiva y modelos de negocio. Universia Business Review, Cuatro trimestre, pp.8-17.

[85]Castells, M. (1997). La era de la información. Economía, sociedad y cultura. Alianza Editorial, Madrid.

[86]Castillo, D. (2004). Tecnología, economia i universitat: anàlisi dels efectes de les tecnologies de la informació i la comunicació sobre l'eficència econòmica de les universitats virtuals. Tesis doctoral. Universitat Oberta de Catalunya.

[87]Caves, R. y Porter, M.E. (1977). From entry barriers to mobility barriers: Conjectural decisions and contrived deterrence to new competition, Quarterly Journal of Economics, Vol. 91, $\mathrm{n}^{\circ} 2$, pp. 241-262.

[88]Cioffi, J. (1999). The Digital Economy in International Perspective: Common Construction or Regional Rilvary? Analytical Summary and Report. Working Paper N ${ }^{\circ}$ 1. E-Conomy Project. Universidad de Berkeley.

[89]Clark, B.R. (1983). The higher education system: Academic organization in cross-national perspective. Berkeley: University of California press.

[90]Clarke, T. y Hermens, A. (2001). Corporate developments and strategic alliances in elearning. Education and Training, Vol. 43, No 4-5, pp. 256-267.

[91]COCE (2006). Propuesta metodológica para la discussion del Modelo de Universidad. Comisión Operativa del Consejo Estratégico de la Universidad Central de Venezuela. Consultado el 12/11/2006 de http://www.ucv.ve/vradm/Archivos/AnexosPlan\%20Estra/Propuesta\%20metodol\%C3\%B3gi ca\%20para\%201a\%20discusi\%C3\%B3n\%20del\%20Modelo\%2016-2-06.pps.

[92]Collis, D.J. (1991). A resource-based analysis of global competition: the case of the bearing industry. Strategic Management Journal, Special Issue, Summer, pp. 49-68.

[93]Collis, D.J. (1994). Research Note: how valuable are organizational capabilities?. Strategic Management Journal, Vol. 15, pp.143-152.

[94]Collis, B. y Moonen, J. (2001). Flexible learning in a digital world: experiences and expectations. London: Kogan Page.

[95]Comisión de las Comunidades Europeas (1999). Libro Blanco del Comercio, COM (99) 6 final. Consultado el 14/11/2006 de http://www.cordis.lu/esprit/scr/ecomcom.html.

[96]Commision of the European Communities (2003). The role of the Universities in the Europe of Knowledge. Consultado el 4/01/2007 de http://europa.eu.int/eurlex/en/com/cnc/2003/com2003_0058en01.pdf.

[97]Connor, H., Burton, R., Pearson, R., Pollard, E. y Regan, J. (1999). Making the Right Choice: How Students Choose Universities and Colleges. London: Institute for Employment Studies for CVCP.

[98]Cool, K. y Schendel, D., (1987). Strategic group formation and performance: The case of the US Pharmaceutical Industry 1963-1982, Management Science, Vol. 33, pp. 1102-1124.

[99]Cool, K. y Dierickx, I. (1993). Rivalry, strategic groups and firm profitability, Strategic Management Journal, 14, pp. 47-59.

[100] Costa, J. (1999). La comunicación en acción. Barcelona: Editorial Paidós.

[101] Crabb, G. (ed.) (1990) Costing Open and Flexible Learning. A practical guide. Londres: National Council for Educational Technology (NCET).

[102] CRUE (2003a) Hacia un Espacio Europeo de Enseñanza Superior. Boletín de Educación Superior, No. 25, enero.

[103] CRUE (2003b) Políticas de cooperación en la Universidad. Boletín de Educación Superior, No. 27, marzo-abril.

[104] Cunningham, K (1994). Digressions on paradigms. Obtenido el 5/10/2006 de http://capita.wustl.edu/ME567_Informatics/concepts/paradigm.html.

[105] Cunningham, S., Ryan, Y., Stedman, L., Tapsall, S., Bagdon, K., Flew, T. y Coaldrake, P. (2000). The business of borderless education. , Canberra (Australia): Department of Employment Training and Youth Affairs. 
[106] Cunningham, S., Tapsall, S., Ryan, Y., Stedman, L., Bagdon, K. y Flew, T. (1997), New media and borderless education: A review of the convergence between global media networks and higher education provision, Evaluations and Investigations Program, Higher Education Division. Canberra (Australia) Department of Employment Training and Youth Affairs.

[107] Chasco, C., Gonzáles, I. y López, A. (2003): El E-learning en la Universidad Española, Anales de Economía Aplicada, XVII Reunión Nacional ASEPELT, Almería.

[108] Chen, M. (1996). Competitor Analysis and Interfirm Rivalry: Toward a Theoretical Integration. Academy of Management Review, Vol. 21, no 1, pp. 100-134.

[109] Chen, M.J., y Miller, D. (1994). Competitive attack, retaliation and performance: An expectancyvalence framework. Strategic Management Journal, Vol. 15, nº 2, pp. 85-102.

[110] Chen, M.J. (1996) Competitor analysis and interfirm rivalry: toward a theoretical integration. Academy of Management Review. Vol. 21, n 1, pp. 100-134.

[111] Chen, M.J. y MacMillan, I.C. (1992). Nonresponse and delayed response to competitive moves: the roles of competitor dependence and action irreversibility. Academy of Management Journal. Vol. 35, $\mathrm{n}^{\circ}$ 3, pp.539-570.

[112] Chen, M.-J., Smith, K. G., y Grimm, C. M. (1992). Action characteristics as predictors of competitive responses. Management Science, Vol. 38, no 3, pp. 439-455.

[113] Cherry, C. (1998). Processes of a case study methology for postgraduate research in marketing. European Journal of Markeing, Vol. 32, No 9/10, pp.758-802.

[114] Chesbrough, H. y Rosenbloom, R.S. (2002). The role of the business model in capturing value from innovation: evidence from Xerox Corporation's technology spin-off companies", Industrial and Corporate Change, vol. 11, no. 3, pp. 529-555.

[115] Christy, R., Wood, M. (1999). Researching possibilities in marketing. Qualitative Market Research, Vol. 2, No 3, pp.189-196.

[116] D'Antoni, S., ed. (2003). The Virtual University: Models and Messages, Lessons from Case Studies, Paris, UNESCO, International Institute for Educational Planning (IIEP). Obtenido el 5/03/2007 de http://www.unesco.org/iiep/virtualuniversity/index.html.

[117] D'Aveni, R.A. (1994) Hyper-Competition: Managing the Dynamics of Strategic Manoeuvering. The Free Press, New York.

[118] Daniel, J. S. (1999), Mega-Universities and Knowledge Media. Londres: Kogan Page.

[119] Davies, J. (2000). Cultural Change in Universities in the Context of Strategic and Quality Initiatives.

Obtenido

de http://www.eua.be/eua/jsp/en/upload/Strategic_Manag_Uni_institutional_Devlpt.1069322397 877.pdf el 1/05/2007.

[120] Davies, J. (1992) Developing a Strategy for Internationalization in Universities: towards a conceptual framework (pp. 177-190). En C. Klasek (Ed.) Bridges to the future:stratetgies for internationalizing higher education. Carbonale: Association of International Education Administration.

[121] Day, G.S y Wensley, R. (1988a). Assesing advantage: a framework for diagnosing competitive superiority. Journal of Marketing. Vol. 52, Abril, pp.1-20.

[122] Day, G.S. y Fahey, L. (1988b). Valuing Marketing Strategies. Journal of Marketing, Vol. 52, July, pp. 45-57.

[123] Day, G.S. (1999a). Market driven strategy: processes for creating value add. Nueva York: The Free Press.

[124] Day, G.S. (1999b). Market driven organization. Nueva York: The Free Press.

[125] Day, G.S. (1999c). Market driven strategy. Nueva York: The Free Press.

[126] Del Águila, R. (2000). Comercio Electrónico y Estrategia Empresarial. Madrid: RA-MA.

[127] Del Águila, R., Padilla, M. y Serrarlos, C. (2006). Análisis de la creación de valor en el ebusiness. Una aplicación al sector de distribución de noticias on-line. Boletín Económico de ICE, $\mathrm{n}^{\mathrm{o}} \quad 2885, \quad 48$ Obtenido el 30/10/2006 de http://www.revistasice.com/Estudios/Documen/bice/2885/BICE28850204.PDF. 
[128] De Núñez y Lugones, F.A. (2001). Modelos de negocio en Internet. Una visión poscrisis. Madrid, McGrawHill.

[129] De Wit, H. (2002). Internationalization of Higher Education in the United States and Europe: A Historical, Comparative, and Conceptual Analysis. WestPort, CT: Greenwood Press.

[130] Dill, D.D. (1997). Higher education markets and public policy. Higher Education Management.

[131] Dixit, A.K. y Nalebuff, B.J. (1991) Thinking Strategically: The Competitive Edge in Business, Politics, and Everyday Life. Nueva York: W.W. Norton and Company.

[132] DMR Consulting/SEDISI (2002). Las Tecnologías de la Sociedad de la Información en la Empresa Española 2001. SEDISI DMR Consulting, Dirección Académica: Cátedra UCMDMR Consulting de Administración de Negocios en Internet. Madrid, marzo 2002.

[133] Docampo, D, (2001). La Declaración de Bolonia y su repercusión en la estructura de las titulaciones. CRUE. Madrid.

[134] Downes, R. y C. Mui (1999), Aplicaciones Asesinas: Estrategias Digitales para Dominar el Mercado. Boston (Massachussets, EEUU): Harvard Business School Press.

[135] Doyle, P. y Wong, V. (1998). Marketing and competitive performance: an empirical study. European Journal of Marketing. Vol. 32, No 5/6, pp. 514-535.

[136] Duart, J.M. (2002). ROI y e-learning: más allá de beneficios y costes. Obtenido el 10/10/2006 en http://www.uoc.edu/duart0902/esp/duart0902/duart0902.html.

[137] Duart, J.M., Lupiáñez, F (2005). E-strategias en la introducción y uso de las TIC en la universidad. En: Duart, J.M. y Lupiáñez, F. (coords.). Las TIC en la universidad: estrategia y transformación institucional. Revista de Universidad y Sociedad del Conocimiento (RUSC). Vol. 2, núm. 1. UOC. Obtenido el 15/11/2006 de http://www.uoc.edu/rusc/dt/esp/duart0405.pdf.

[138] Duarte, J.L. (2004). Factores determinantes y críticos en empresas de servicios, para la obtención de ventajas competitivas sostenibles y transferibles a estrategias de globalización: un análisis de la industria del software. Tesis doctoral. Departamento de Economía de Empresa. Universidad Autónoma de Barcelona.

[139] Duderstadt, J., Atkins, D. y Van Houweling, D. (2003). The development of institutional strategies. Educause Review. Vol. 38, núm. 3, pp. 48-58.

[140] Dutton, J.E. y Jackson, S.B. (1987) Categorizing strategic issues: Links to organizational action. Academy of Management Review, 12, pp. 76-90.

[141] Edwards, C.D. (1955). Conglomerate bigness as a source of power. En Business concentration and price policy (National Bureau of Economic Research conference report): 331-352. Princeton, NJ: Princeton University Press.

[142] Eisenhardt, K. (1989). Building theories from case study research. Academy of Management Review, Vol. 14, No. 4, pp.532-550.

[143] EITO (2006). ICT markets. Consultado el 1/1/2007 de http://www.eito.com/download/EITO\%202006\%20-

\%20ICT\%20market\%20March\%202006.pdf

[144] Elloumi, F (2004), Value chain analysis: A strategic approach to online learning, en Theory and practice of online learning (pp.61-92) Canadá: T Anderson y F Elloumi (eds), Athabasca University.

[145] Encyclopaedia Britannia - Vol 6 1962, Cuneiform, London.

[146] Esteve, M., Hervás, A., Del Blanco, D., Tarazona, A. C., Villanueva, R.J. (2002). El sistema de teleevaluación del VUPA. Terceras Jornadas de Innovación Docente del DMA

[147] Esteve, M., Hervás, A., Palau, C. y Guerri, J.C. (2001). Open distance over the Internet. Symposion Sprachen \& Medien

[148] Esteve, M., Gómez-Senent, E., Hervás, A., Tarazona, A.C. (2003). Pre-University students projects. International Conference on Engineering Education.

[149] Ethiraj, S.; Guler, I.; Singh, H. (2000). The impact of electronic technologies on firms and its implications for competitive advantage, Working Paper, The Warthon School, pp. 1-40. 
[150] European Commission (2003). eLearning. Better eLearning for Europe. Luxemburgo: Office for Official Publications of the European Communities.

[151] European Commission (2004). Studies in the Context of the E-Learning Initiative: Virtual Models of European Universities, Draft Final Report to the European Commission, DG Education and Culture, February 2004, 228 p. European Commission, Directorate-General for Education and Culture and European Universities Association (2003), Trends III: Learning structures in European higher education, 153 p. (EUA Graz Convention 29/31 May 2003)

[152] Evans, W. y Kessides, I. (1994) Living by the "Golden Rule": Multimarket Contact in the U.S. Airline Industry. Quarterly Journal of Economics, Vol. 109, nº 2, pp. 341-366.

[153] Fan, M; Stallaert, J.; Whinston, A.B. (1999). A web-based financial trading system. IEEE Computer (Abril).

[154] Fernández, E. (2001). Algunos conceptos sobre la utilización de tecnologías en la educación. Presentado en el Seminario Educación a Distancia: Metodología Pedagógica, Medios Técnicos y Tutorías, Montevideo, Universidad de la República; AECI.

[155] Fernández, F. (2004). La reingeniería de Campus Virtual a partir de elementos pedagógicos, en Actas del IV Congreso Internacional Virtual Educa. Barcelona.

[156] Fernández, S. y Ruzo, E. (2004): Los procesos de internacionalización y regionalización en la educación superior: un análisis de los países OECD, Revista de Educación, no 335 (Septiembre - Diciembre).

[157] Finquelievich, S. y Prince, A. (2006). Universidades y TICs. Las universidades argentinas en la Sociedad del Conocimiento. Buenos Aires: Telefónica de Argentina.

[158] Flavián, C. y Polo, Y. (2001). Diversidad estratégica y resultados en la distribución, Revista de Economía Aplicada, Vol. 26, pp. 29-56.

[159] Foskett, N. (2001). Choosing Futures : Young People's Decision-Making in Education, Training and Careers Markets. Londres, Reino Unido: Routledge.

[160] Frederick, H.H. (1993). Global communication and international relations. Belmont, Canadá: Wadsworth Publishing.

[161] Freeman, B., Routen, T., Ryan, S., Patel, D. y Scott, B. (eds.) (2000). The Virtual University: The Internet and Resource-Based Learning. Londres: Kogan Page.

[162] Fruhan, W.I., Jr. (1972) The Fight for Competitive Advantage. Division of Research, Graduate School of Business Administration, Harvard University, Boston.

[163] Fuentelsaz, L., Gómez, J. y Lucea, V. (2002). Identificador del competidor y rivalidad en el sector bancario español. Departamento de Economía y Dirección de Empresas. Universidad de Zaragoza.

[164] Fuentes, S.I. (2005). Comunicación: eje estratégico para la gestión del cambio educativo. Revista Académica del Foro Iberoamericano sobre Estrategias de Comunicación. Año 1, No 2, pp. 1-15.

[165] Fundación Auna (2003). eEspaña 2003. Informe anual sobre el desarrollo de la Sociedad de la Información en España. Madrid: Fundación Auna.

[166] Fundación Auna (2004). eEspaña 2004. Informe anual sobre el desarrollo de la Sociedad de la Información en España. Madrid: Fundación Auna.

[167] Fundación Auna (2005). eEspaña 2005. Informe anual sobre el desarrollo de la Sociedad de la Información en España. Madrid: Fundación Auna.

[168] Fundación Auna (2006). eEspaña 2006. Informe anual sobre el desarrollo de la Sociedad de la Información en España. Madrid: Fundación Auna.

[169] Funk, K. (2003). Sustainability and Performance. Sloan Management Review, Winter, pp.65-69.

[170] Furrer, O. y Thomas, H. (2000). The rivalry matrix: understanding rivalry and competitive dynamics. European Management Journal, vol. 18, nº 6, pp. 619-637.

[171] Galbraith, J. (1973). Designing Complex Organizations. Reading, EEUU: AddisonWesley. 
[172] García del Junco, J. et al. (1998). Casos prácticos de economía de empresa. Madrid: Ediciones Pirámide, SA.

[173] García del Junco, J. y Castellanos, M. (1998). El método del caso y de las situaciones: herramientas de diagnóstico y de decisión. Dirección y Organización, Vol. 19, Enero, pp.95105.

[174] Garvin, D.A. (1980). The Economics of University Behavior; New York: Academic Press.

[175] Gavirneni, S.; Kapuscinski, R. y Tayur, S. (1999). Value of information in capacitated supply chains. Management Science, Vol. 45, $\mathrm{n}^{\mathrm{o}}$ 1, pp. 16-24.

[176] Geuna, A. (2000). The Economics of Knowledge Production. Funding and the Structure of University Research. Cheltenham, Reino Unido: Edward Elgar.

[177] Ghazanfar, A., McGee, J. y Thomas, H. (1987) The impact of technological change on industry structure and corporate strategy: the case of the reprographics industry in the United Kingdom. En The Management of Strategic Change (pp. 166-191), Basil Blackwell, Oxford: ed. Andrew M. Pettigrew.

[178] Gilmore, A. y Carson, D. (1996). Management competences for service marketing. The Journal of Services Marketing, Vol. 10, № 3, pp. 39-57.

[179] Gimeno, J. (1999). Reciprocal threats in multimarket rivalry: Staking out 'spheres of influence' in the U.S. airline industry. Strategic Management Journal, Vol. 20, no 2, pp. 101128.

[180] Gimeno, J. (2002). The Performance Effects of Unintended and Purposive Multimarket Contact. Managerial and Decision Economics, Vol. 23, pp. 209-224.

[181] Gimeno, J. y Jeong, E. (1999). Multimarket contact: meaning and measurement at multiple levels of analisys, Advances in Strategic Management, Vol. 18, pp. 357-408.

[182] Gimeno, J. y Woo, C. (1996). Hypercompetition in a multimarket environment: The role of strategic similarity and multimarket contact in competitive de-escalation. Organization Science, Special Issue, pp. 322-341.

[183] Glennerster, H. (1991). Quasi-Markets for Education?. The Economic Journal, Vol. 101, No. 408.

[184] Goig, R. (2006). Radiografía de los centros de e-learning. Expansión \& Empleo, edición del 30 septiembre y 1 de octubre de 2006, p. 25.

[185] Goodhue, D.L., Wybo, M.D. y Kirsch, L.J. (1992). The impact of data integration on the cost and benefits of information systems. MIS Quarterly, Vol. 16, n 3, pp. 293-312.

[186] Gornitzka, A. y Maassen, P. (2000). Hybrid steering approaches with respect to European higher education, Higher Education Policy 13.

[187] Gouldner, A. (1973). La Crisis de la Sociología Occidental; Buenos Aires: Amorrortu.

[188] Greenstein, S. (2000). Framing empirical research on the evolving structure of commercial Internet markets. En Brynjolfsson, E. y Kahin, B. (eds.). Understanding the digital economy: data, tools and research. MIT Press, Cambridge.

[189] Gruca, T.S. y Sudharshan, D. (1995). A framework for entry deterrence strategy: the competitive environment, choices, and consequences. Journal of Marketing, Vol. 59, $\mathrm{n}^{\mathrm{o}} 3$, pp.44-55.

[190] Gurbaxani, V.; Whang, S. (1991). The impacts of information systems on organizations and markets. Communications of the ACM. Vol. 34, 1, 59-73.

[191] Haddad, W. D. y Draxler, A., eds. (2002). Technologies for Education: Potentials, Parameters and Prospects, Paris, UNESCO, Washington, Academy for Educational Development, $202 \mathrm{p}$.

[192] Haltiwanger, J. y Jarmin, R.S. (2000). Measuring the digital economy. En Brynjolfsson, E. y Kahin, B. (eds.).-Understanding the digital economy: data, tools and research. MIT Press, Cambridge.

[193] Hamel, G. (1999). The strategos manifesto. Obtenido el 4/04/2007 de http://www.stategosnet.com/about/manifesto.html.

[194] Hamel, G. y Prahalad, C.K. (1985). Do you really have a global strategy?. Harvard Business Review, Julio-Agosto, pp. 139-148. 
[195] Hamel, G. y Prahalad, C.K. (1990). El propósito estratégico. Harvard Deusto Business Review, Primer trimestre.

[196] Hamel, G. y Prahalad, C.K. (1991). Corporate imagination and expeditionary marketing Harvard Business Review, Vol. 69, Julio-Agosto, pp. 81-92.

[197] Hamilton, S. (2003). Culture's complications: the problem of global data collection in a world of difference, New Library World, Vol. 104, No 1187/1188, pp.149-155.

[198] Hannan, M.T. y Freeman, J. (1977). The population ecology of organizations, American Journal of Sociology, Vol. 82, n 5, pp. 929-964.

[199] Hansmann, H. B. (1980). The Role of Nonprofit Enterprise, Yale Law Journal, Vol. 89, $\mathrm{n}^{\circ}$ 5.

[200] Hansmann, H. B. (1990), Why Do Universities Have Endowments?; The Journal of Legal Studies, Vol. 19, No. 1.

[201] Hatten, K.J. y Hatten, M.L. (1987). Strategic groups, asymmetrical mobility barriers and contestability, Strategic Management Journal, Vol. 8, $\mathrm{n}^{\circ}$ 4, pp. 329-342.

[202] Haveman, H. y Nonnemaker, L. (2000). Competition in Multiple Geographic Markets: The Impact on Growth and Market Entry. Administrative Science Quarterly, vol. 45, pp. 232267.

[203] Hax, A.C. y Majluf, N.S. (1984). Stategic Management: an integrativa perspective. Englewood Cliffs, Nueva York: Prentice-Hall.

[204] Hedges, A. (1985). Group interviewing. En Walker, A. ,Applied Qualitative Research (pp.71-91). Brookfield, VT: Gower.

[205] Held, D. McGrew, A. Goldblatt, D. y Perraton, J. (1999). Global Transformations: Politics, economics and culture. Standford: Stanford University Press.

[206] Helfat, C.E. y Peteraf, M.A. (2003). The dynamic resource-based view: capability life cycles, Strategic Management Journal, Vol. 24, nº 10, pp. 997-1010.

[207] Henderson, R. y Cockburn, I. (1994). Measuring competence? Exploiting firm effects in pharmaceutical research, Strategic Management Journal. Vol. 15, pp. 63-84.

[208] Hernández, J. (2003). VII Curso sobre Régimen Jurídicos de las Universidades Públicas. 9-11 Abril de 2003. Universidad de Alicante.

[209] Hertz, D.B. y Thomas, H. (1982) Evaluating the risk in acquisition. Long Range Planning. Vol. 15, $\mathrm{n}^{\mathrm{o}}$ 6, pp. 38-44.

[210] Hervás, A. (2002). El proyecto Universidad Politécnica Abierta de la U.P.V. VIRTUAL EDUCA 2002

[211] Hervás, A., Capilla, R., Collado, V. (2002). La información y orientación al futuro estudiante universitario. X Congreso de Innovación Educativa en las Enseñanzas Técnicas

[212] Hervás, A., De Miguel, E., Tarazona, A.C., Villanueva, R.J. (2003). Training teachers for a experience in University mixed-distance learning. International Conference on Engineering Education.

[213] Hervás, A., Esteve, M., Tarazona, A.C. (2001), IFTA: Una herramienta de generación de materiales de teleformación. Intermedia 2001

[214] Hervás, A., Montesinos, P., Lacruz, J., Villanueva, R.J. (1999). A Project of Developments of Engineers. The 4th. European Forum for Continuing Engineering Education.

[215] Hervás, A., Tarazona, A.C., Esteve, M. (2002). HAUPA: Herramienta de Autor de la Universidad Politécnica de Valencia. VIRTUAL EDUCA 2002

[216] Hervás, A., Villanueva, R.J., Lorente, J.J. (1995). Un curso de Teoría de Grafos mediante Enseñanza Asistida por Ordenador. TEMU-95, Jornadas Tecnológicas sobre Enseñanza de las Matemáticas en la Universidad.

[217] Hervás, A., Villanueva, R.J., Lorente, J.J. (1996). Mathematica como herramienta para la enseñanza asistida por ordenador. Mathematica 96, I Congreso de Mathematica en España

[218] Hervás, A., Villanueva, R.J., Monforte, C. (1998). A project of Computer Aided Learning. 7th World Conference on Continuing Engineering Education.

[219] Hervás, A., Villanueva, R.J., Monforte, C. (1999). Technology versus Pedagogy. The 19th ICDE World Conference on Open Learning and Distance Education 
[220] Hervás, A., Villanueva, R.J., Rodríguez, M. (2000). ¿Pueden las nuevas tecnologías olvidar la "viejas" metodologías?. Revista de nuevas tecnologías en la educación. Quaderns Digitals.NET. Vol. 20, pp.1-13

[221] Hervás, A., Villanueva, R.J., otros (200). El proyecto InterF@D (Internet aplicado a la formación a distancia). Jornadas de investigación y fomento de la multidisplinaridad, Septiembre 1999-Mayo 2000.

[222] Hess, C.M. y Kemerer, C.F. (1994). Computerized loan organization system: an industry case study of the electronic markets hypothesis. MIS Quarterly, Vol. 18, $\mathrm{n}^{\mathrm{o}} 3$, pp. 251-274.

[223] Hirsh, W. y Weber, L.E., eds. (2002), As the Walls of Academia are Tumbling Down, Paris: Economica.

[224] Hitt, M. et al. (2003). Administración estratégica: competitividad y conceptos de globalización. México: Thompson.

[225] Hitt, L. y Brynjolfsson, E. (1997). Information Technology and internal firm organization: An exploratory analysis. Journal of Management Information Systems, Vol. 14, no 2, pp. 81101.

[226] Hollins, C.S. (1992). Where do we go from here?. New Directions for Institutional Research, $\mathrm{n}^{\circ} 75$.

[227] Hoppe, G., Breitner, M.H. (2003). Business models for e-learning. Multikonferenz Wirtschaftsinformatik 2004, Essen Germany.

[228] Hoque, F. (2000). e-Enterprise, Business Models, Architecture and componets. Nueva York: Cambridge University Press.

[229] Huisman, J. y van der Wende, M.C. (eds.) (2004). On Cooperation and Competition. National and European policies for internationalisation of higher education. ACA Papers on International Cooperation. Bonn: Lemmens.

[230] Huisman, J. y van der Wende, M.C. (eds.) (2005). On Cooperation and Competition II. Institutional responses to internationalisation, Europeanisation and Globalisation. ACA Papers on International Cooperation. Bonn: Lemmens.

[231] Hülsmann, T. (2000) The costs of open learning: a handbook. Bibliotheks- und Informationssystem der Universität Oldenburg.

[232] Hunt (1993). Quality in America: How to Implement a Competitive Quality Program. Homewood, Illinois, EEUU: Technology Research Corporation.

[233] Hunt, S.D. y Morgan, R.B. (1995). The comparative advantage theory of competition. Journal of Marketing. Vol. 59, Abril, pp.1-15.

[234] Hunt, S.D. y Morgan, R.B. (1996). The resource-advantage theory of competition: dynamic, path dependencies and evolutionary dimensions. Journal of Marketing. Vol. 60, Octubre, pp.107-114.

[235] Hunt, S.D. y Morgan, R.B. (1997). Resource-advantage theory: the snake swalloging its tail or a general theory of competition. Journal of Marketing. Vol. 61, Octubre, pp.74-82.

[236] Instituto Universitario de Postgrado (2006). Estudio de la demanda internacional de másters y formación de postgrado on-line en lengua española. Obtenido de http://www.santillanaformacion.com/v2.0/sala_informes.html el 1/05/2007.

[237] Internacional de la Educación (2006). El Acuerdo General sobre el Comercio de Servicios. ¿Qué es y qué significa para la Educación?. Obtenido de http://www.eiie.org/gats/file/(2006)\%20EI\%20GATS\%20Information\%20Kit\%20\%20What\%20does\%20it\%20mean\%20for\%20education\%20es.pdf el 14/05/2007.

[238] Jackson, P. y Eckersley, P.M. (2003), Organizations in the electronic age. En Jackson, P., Harris, L. y Eckersley, P.M., e-Business fundamentals (pp.3-10). Routledge E-Business, Routledge, London.

[239] Jayachandran, S.; Gimeno, J. y Varadarajan, P.R., (1999). The theory of multimarket competition: A synthesis and implications for marketing strategy, Journal of Marketing, Vol. 63, pp. 49-66.

[240] Jochems, W., Van Merriënboer, J. Y Koper, R. (2004). Integrated e-learning. Implications for pedagogy, technology \& organization. Londres: Routledge-Falmer. 
[241] Jofre, L. y Suárez, B., (2002). La convergencia hacia el Espacio Europeo de Educación Superior en el ámbito de las Ingenierías, 19, Debats Tecnològics, Revista del Col-legi d'Enginyers Tècnics Industrials de Barcelona.

[242] Johnston, W.J., Leach, M.P., Llu, A.H. (1999). Theory testing using case studies in Business to business review, Industrial Marketing Management, Vol. 28, pp.201-213.

[243] Johnstone, Sally M. y Witherspoon, John (2002), Open Educational Resources Emerge on the Web, IAU Newsletter, Vol. 5, no 8 , pp.1-2.

[244] Jonbloed, B. (2004). Funding Higher Education: options, trade-offs and dilemmas. Obtenido de http://www.utwente.nl/cheps/documenten/engpap04fundinghe.pdf el 1/05/2007.

[245] Jongbloed, B. (2004). Regulation and competition in higher education. En Teixeira, P., Jongbloed, B., Dill, D. y Amaral, A. (Eds.) Markets in Higher Education. Rethoric or Reality?, pp. 99-104.

[246] Jones, G. (1998). Globalisation and internationalism: democratic prospects for world education. Comparative Education, vol. 34, n 2, pp. 143-155.

[247] Jones, G. (2001). Bridging the challenges of transnational education and accreditation, Higher Education in Europe, vol. XXVI, n 1 , pp. 107-116.

[248] Jorgenson, D. y Stiroh, K. (1995). Computers and growth. Economics of Innovation and New Technology, vol. 3, Mayo, pp. 295-316.

[249] Kalakota, R. y Robinson, M. (1999). e-Business Roadmap for Success. Reading: Addison Wesley Longan.

[250] Kalakota, R. y Whinston, A.B. (1997), Electronic commerce: A manager's guide, Reading: Addison Wesley Longman, Inc.

[251] Kaplan, S.; Shawhney, M. (2000). E-hubs: The new B2B marketplaces. Harvard Business Review, Vol. 78, n 3, pp. 97-103.

[252] Kaplún, G. (2005). Aprender y enseñar en tiempos de Internet. Formación profesional a distancia y nuevas tecnologías. Montevideo: CINTERFOR/OIT.

[253] Karelis, C. (1999). Education technology and cost control: four models. Syllabus. Vol. 12, No 6, pp. 20-28.

[254] Karnani, A. y Wernerfelt, B., (1985). Multiple point competition, Strategic Management Journal, Vol. 6, pp. 87-96.

[255] Katz, R. (1999). Dancing with the devil. Information technology an the new competition in higher education. San Francisco: Jossey-Bass Publishers.

[256] Kay, J. (1993). The structure of strategy. Business Strategy Review, Vol. 4, No 2, pp.3444.

[257] Kay, J. (1994). Fundamentos del éxito empresarial. Barcelona: Editorial Ariel, S.A.

[258] Keegan, M. (2000). E-learning. The engine of the knowledge economy. Obtenido en 17/02/2006 de http://internettime.com/itimegroup/morgankeegan.pdf.

[259] Kenney, M. y Curry, J. (2001). Beyond transaction costs: E-commerce and the power of internet dataspace. En Leinbach, T. y S.Brunn, eds. Worlds of E-Commerce: Economic, Geographical and Social Dimensions (pp.45-65), Nueva York: Wiley.

[260] Kiesler, S. y Sproull, L. (1982). Managerial response to changing environments: Perspectives on problem sensing form social cognition, Administrative Sciencie Quarterly, Vol. 27, pp. 548-570.

[261] Knight, J. (1997) Internationalization of Higher Education: a conceptual framework. In: J. Knight \& H. de Wit (Eds) Internationalization of Higher ducation in Asia Pacific Countries. European Association for International Education, Amsterdam. 5-19.

[262] Koh, C.E. y Nam, K.T. (2005). Business Use of the Internet: A Longitudinal Study from a Value Chain Perspective. Industrial Management \& Data Systems, Vol. 105, $\mathrm{n}^{\mathrm{o}}$ 1, pp.82-95.

[263] Kotler, P.; Fox, K. (1995). Strategic marketing for educational institutions. Englewood Cliffs, NJ, EEUU: Prentice Hall Inc.

[264] Kotler, P. y Achrol, R.S. (1984) Marketing strategy and the science of warfare. En Boyden, R. Competitive Strategic Management (pp. 94-133). Englewood Cliffs, NJ, EEUU: Prentice-Hall. 
[265] Kwiek, M. (2003). The University, Globalization, Central Europe;. Frankfurt a/Main and New York: Peter Lang.

[266] Langlois, C. (1998). Universities and New Information and Communication Technologies: Issues and Strategies", European Journal of Engineering Education, Vol. 3, n 23.

[267] Langlois, C. (2003) "Facilitating lifelong learning in Universities: the role of ICTs", Round Table "Education and knowledge societies", World Summit on the Information Society, Geneva, 10-12 December 2003.

[268] Lant, T.K., Milliken, F.J. y Batra, B. (1992) The role of managerial learning and interpretation in strategic persistente and reorientation, Strategic management Journal, Vol. 13 , pp. 585-608.

[269] Larsen, K. y Vincent-Lancrin, S. (2002). International trade in educational services: good or bad?. Higher Education and Management Policy, Vol. 14, $\mathrm{n}^{\circ} 3$.

[270] Lawrence, E., Corbitt, B., Fisher, J., Lawrence, J. y Tidwell, A. (2000). Internet commerce: Digital models for business. Brisbane, Australia: John Wiley \& Sons Australia, Ltd..

[271] Lee, H.L., Padmanabhan, V. y Whang, S. (1997). Information distortion in a supply chain: The bullwhip effect. Management Science, Vol. 43, no 4, pp. 546-558.

[272] Leirner, B. et al. (2003). A brief history of the Internet. Obtenido el 5/05/2006 en http://www.isoc.org/internet/history/brief.shtml.

[273] Lengnick-Hall, C.A. y Wolff, J.A. (1999). Similarities and contradictions in the core logic of three strategy research streams. Strategic Management Journal, Vol. 20, no 12, pp. 11091132.

[274] Levy, D. C. (2006). An Introductory Global Overview: The Private Fit to Salient Higher Education Tendencies. Obtenido de http://www.albany.edu/dept/eaps/prophe/publication/paper/PROPHEWP07_files/PROPHEW P07.pdf el 1/05/2007.

[275] Lincoln, Y.S. y Guba, E.G. (1994) Paradigmatic controversies, contradictions and emerging conflucences, en Senzin, N.K., Lincoln, Y.S., Handbook of Qualitative Research (pp.163-188). Thousand Oaks, Canadá: Sage.

[276] Lindblom, C. E. (1977). Politics and Markets: The World's Political-Economic Systems. New York: Basic.

[277] Lipman, S. y Rumelt, R. (1982) Uncertain imitability: An analysis of interfirm differences in efficiency under competition, Bell Journal of Economics, Vol. 13, pp. 418-438.

[278] Llodrà Riera, Bel (2000): Aprendizaje constante y formación continua. en.red.antes, $\mathrm{n}^{\circ}$ 78, 20/6/2000. Obtenido el 30/8/2006 de http://www.nonopp.com/ar/filos_educ/00/apred_constante.htm.

[279] Llonch, J. (1993). La orientación al mercado y competitive de la empresa. Barcelona: Ediciones Gestión, 2000.

[280] López Sánchez, J.I. y Carretero Díaz , L.E. (1999). Las empresas de suministro de información, una nueva forma de coordinar las transacciones comerciales. Economía Industrial, Vol. 326, pp. 33-50.

[281] López Sánchez, J.I. y Sandulli, F.D. (2001). Líneas de Investigación en la Administración de Negocios en Internet. Una Aproximación al Estado de la Cuestión, comunicación presentada al XI Congreso Anual de ACEDE.

[282] Lub, A., van der Wende, M. y Huisman, J. (2005). On cooperation and competition: A comparative analysis of national policies for internationalization of higher education in seven Western European countries, Journal of Studies in Higher Education, Vol 9, $\mathrm{n}^{\circ}$ 2, pp. 147163.

[283] Lub, A., Huisman J. y van der Wende, M.C. (2005). Conclusions, reflections and recommendations. In .J. Huisman and M. C. van der Wende (eds.). On Cooperation and Competition II. Institutional responses to internationalisation, Europeanisation and Globalisation. ACA Papers on International Cooperation. Bonn: Lemmens. 
[284] Lub, A., van der Wende, M. y Witte, J. (2003). The implementation of the bachelormaster system in Germany and the Netherlands, TEAM, 9, pp. 249-266.

[285] Luce, R.D. y Raiffa, H. (1957). Games and Decisions. Nueva York: Wiley.

[286] Luque, T. (1997). Investigación de marketing. Madrid: Ariel.

[287] Lynch, M. (1989). Private sector training and its impact on the earnings of young workers. NBER WP n 2872.

[288] Ma, H. (1999a). Creation and pre-emption for competitive advantage. Management Decision, Vol. 37, № 3, pp.256-266.

[289] Ma, H. (1999b). Constellation of competitive advantage: Components and dynamics. Management Decision, Vol. 37, $\mathrm{N}^{\mathrm{o}}$ 4, pp.348-355.

[290] Ma, H. (1999c). Anatomy of competitive advantage: A select framework. Management Decision, Vol. 37, № 9, pp.709-718.

[291] Machado, S. (2000). Introduction to the Theme of Transnational Education, presentado en Conference of the Directors General for Higher Education and the Heads of the Rector's Conferences of the EU. Aveiro, 2000.

[292] Mahadevan, B (2000). Busienss Models for Internet-Based E-Commerce: An Anatomy, California Management Review, Vol. 42, no 4, pp. 55-69.

[293] Makadok, R. (2001). Toward a synthesis of the resource-based and dynamic-capability views of rent creation. Strategic Management Journal, Vol. 22, n ${ }^{\circ}$, pp. 387-401.

[294] Malhotra, N. K. (1997). Investigación de mercados: un enfoque práctico. México: Pearson Educación.

[295] Malhotra, Y. (1993). Role of Information Technology in Managing Organizational Change and Organizational Interdependence. Obtenido el 28/02/2007 de http://www.brint.com/papers/change/ index.htm.

[296] Malone, T.; Yates, J.; Benjamin, R. (1987). Electronic Markets and Electronic Hierarchies. Communications of the ACM, vol. 30, nº 6, pp. 484-497.

[297] Malott, M. (2001). Paradoja del Cambio organizacional. México: Editorial Trillas.

[298] Manucci, M. (2004). Comunicación corporativa estratégica. Colombia: SAF Grupo.

[299] Marginson, S. y Rhoades, G. (2002). Beyond national states, markets, and systems of higher education: A glonacal agency heuristic. Higher Education, no 43, pp. 281-309.

[300] Marginson, S. y Van Der Wende, M. (2006). Globalisation and higher education. Obtenido de http://www.oecd.org/dataoecd/20/4/37552729.pdf el 1/05/2007.

[301] Matsushima, H. (2001). Multimarket Contact, Imperfect Monitoring and Implicit Colusion. Journal of Economic Theory, vol. 98, pp. 158-178.

[302] McAfee, A. (2000a). Economic impact of the Internet revolution: Manufacturing. Conferencia The E-business transformation: sector developments and policy implications, Universidad de California en Berkeley.

[303] McAfee, A. (2000b). The napsterization of B2B. Harvard Business Review, Vol. 78, $\mathrm{n}^{\circ}$ 6, pp.18-29.

[304] McGee, J. y Thomas, H. (1992). Strategic groups and intra-industry competition. International Review of Strategic Management, Vol. 3, pp. 77-98.

[305] McGrath, R.G., Chen, M.-J. y MacMillan, I.C. (1998). Multimarket manoeuvring in uncertain spheres of influence: resource diversion strategies. Academy of Management Review, Vol. 23, no 4, pp. 724-740.

[306] Merrilees, B., Tiessen, J.H. (1999). Building generalizable SME International marketing models using case studies. International Marketing Review, Vol. 16, No 4/5, pp. 326-344.

[307] Michavila, F. (2005). Cinco ideas innovadoras para la europeización de la educación superior. Revista de Universidad y Sociedad del Conocimiento, Vol 2, $\mathrm{n}^{\circ} 1$, UOC. Obtenido el 15/02/2007 de http://www.uoc.edu/rusc/dt/esp/michavila0405.pdf.

[308] Miguel Peris, S., Caplliure Giner, E.V., García Sastre, M.A. (2002). El fenómeno de la compra interactiva en España. Esic Market, Revista Internacional de Economía y Empresa, num. 112. 
[309] Miles, R.E; Snow, C.C. (1978). Organizational Strategy. Structure and Process. Nueva York: McGraw Hill.

[310] Milgrom, P.; Roberts, J. (1988). Communication and inventory as substitutes in organizing production. Scandinavian Journal of Economics, vol. 90, $\mathrm{n}^{\circ} 3$, pp. 275-289.

[311] Miller, R. (2003). The future of the tertiary education sector: Scenarios for a learning society. Obtenido de http://www.mext.go.jp/a_menu/kokusai/forum/04022701/004/001.pdf el $1 / 05 / 2007$.

[312] Miller, D. y Shamsie, J. (1996). The resource-based view of the firm in two environments: The Hollywood studios from 1936 to 1965, Academy of Management Journal, Vol. 39, $\mathrm{n}^{\circ} 3$, pp. 519-543.

[313] Milliken, J. y Barnes, L. P. (2002). Teaching and technology in higher education: Student perceptions and personal reflections. Computers \& Education, Vol. 39, $\mathrm{n}^{\mathrm{o}} 3$, pp.223-35.

[314] Mintzberg. H. (1990). The design school: reconsidering the basic premises of strategic management. Strategic Management Journal, Vol. 11, № 3, March-April, pp. 171-195.

[315] Mitchell, J. (2000), E-Competent Australia: report on the impact of e-commerce on the national training framework, Melbourne, Austrilia: Australian National Training Authority.

[316] Mitchell, J (2000). The implications of e-commerce for online learning systems. Obtenido el 21/01/2007 de http://www.flexiblelearning.net.au/nw2000/talkback/p71.htm.

[317] Moingeon, B.; Ramantsoa, B.; Métasis, E y Orton, J.D. (1998). Another look at strategystructure relationships: the resource-based view. European Management Journal, Vol. 16, $\mathrm{N}^{\circ}$ 3, Junio, pp.297-304.

[318] Mora, J.G. (2005). El proceso de Bolonia: la necesidad de dar respuesta a las nuevas demandas sociales. En Informe CYD 2005, pp. 163-164.

[319] Morecroft, J.D.W. (1984) Strategy support models. Strategic Management Journal. Vol $5, \mathrm{n}^{\mathrm{o}} 3$, pp. 215-229.

[320] Mora, J. G. (1999): La Universidad: una empresa al servicio de la sociedad del conocimiento, Cuadernos IRC, Revista de Evaluación, Planificación y Gestión Universitaria, Vol. $\mathrm{n}^{\circ} 1$, pp. 41-55.

[321] Moreno, A. (2004). Conciliación, una oportunidad en la Sociedad en red. En Telefónica, Trabajar y vivir la red (pp.31-33). Obtenido el 17/02/2007 de http://www.telefonica.es/sociedaddelainformacion/pdf/publicaciones/teletrabajo/teletrabajo.p df.

[322] Moreno, J. L. (1998). Economía de la Educación. Madrid: Pirámide.

[323] Morgan, B. M. (2002) Is Distance Learning Worht It? Helping to Determine the Costs of Online Courses, Research Project, Marshall University.

[324] Nelson, R. R., y Winter, S. G. (1982). An Evolutionary Theory of Economic Change. Cambridge, MA: The Belknap Press of Harvard University Press.

[325] North, D. (2005). Understanding the Process of Economic Change. Princeton: Princeton University Press.

[326] OECD (1996). The Knowledge-based economy. Paris: OECD.

[327] OECD (1998a). Open markets matter: The benefits of trade and investment liberalization. Paris: OECD.

[328] OECD (1998b) Redefining Tertiary Education. París: OECD.

[329] OECD (2003) Education at a Glance, OECD Database. Obtenido de http://www.oecd.org.

[330] Oyarzún, R. (2003). Educación superior y globalización. Alcances críticos sobre el caso chileno. Intervención en el Taller "Educación en las Américas: ¿servicio público o mercancías?" , 28 de Julio de 2003.

[331] Ortega, E. (1994). Manual de investigación comercial. Madrid: Editorial Pirámide.

[332] Osiakwan, C. y Wright, D. (2001) Distance Training for Operating Equipment: A CostBenefit and Return-on-Investment Analysis. American Journal of Distance Education, Vol. $15, \mathrm{n}^{\circ} 1$, pp. 155-161. 
[333] Oster, S.M. (1999) Modern Competitive Analysis, 3rd edn. Nueva York: Oxford University Press.

[334] Panda, S. (2003). Planning and management in distance education, Londres: Kogan Page.

[335] Parker, P. y Röller, L. (1997). Collusive Conduct in Duopolies: Multimarket Contact and Cross-Ownership in the Mobile Telephone Industry. Journal of Economics, vol. 28, $\mathrm{n}^{\circ}$ 2, pp. 304-322.

[336] Parkhe, A. (1993). Strategic alliance structuring: a game theoretic and transaction cost examination of interfirm cooperation. Academy of Management Journal, Vol. 36, $\mathrm{n}^{\mathrm{o}} 4$, pp. 794-829.

[337] Penn, A. (2003): Globalizing online education through partnership and networks, International Conference on Network Universities and E-learning. Valencia.

[338] Perranton, H. (2004). Handbook B3: costs and economics of open and distance learning. The Commonwealth of Learning. Obtenido el 12/4/2007.

[339] Perraton, H. y Hülsmann, T. (2000). Planning and Evaluating Systems of Open and Distance Learning, Report to the Department for Education and Employment by the International Research Foundation for Open Learning. Obtenido el 26/11/2006 de http://www.col.org/irfol/planeval.doc.

[340] Perry, C. (1998). Processes of a case study methodology for postgraduate research in marketing, European Journal of Marketing, Vol. 32, No 9/10, pp. 785-802.

[341] Peteraf, M.A. (1993a). The cornerstones of competitive advantage: a resource based view, Strategic Management Journal, Vol. 14, pp. 179-191.

[342] Peteraf, M.A. (1993b). Intra-industry structure and the response towards rivals, Managerial and Decision Economics, vol. 14, pp. 519-528.

[343] Peteraf, M.A. y Bergen, M.E. (2003). Scanning dynamic competitive landscapes: a market-based and resource-based framework, Strategic Management Journal, Vol. 24, $\mathrm{n}^{\mathrm{o}} 10$, pp. 1027-1041.

[344] Phelps, R.H., Wells, R.A., Ashworth, R.L., Hahn, H.A., (1991) Effectiveness and Costs of Distance Education Using Computer-Mediated Communication. American Journal of Distance Education, vol. 5, $\mathrm{n}^{\mathrm{o}}$ 3, pp.7-19.

[345] Plasencia, A., Hervás, A. (2002). Sociedad e información. A distancia. Vol. 20, no 1, pp.210-215.

[346] Porac, J.F, Thomas, H., Wilson, F. Paton, D. y Kanfer, A. (1995) Rivalry and the industry model of Scottish knitwear producers, Administrative Science Quarterly, Vol. 40, pp. 203228.

[347] Porter, M.E. (1976). Interbrand choice, strategy and bilateral market power. Cambridge: Harvard University Press.

[348] Porter, M.E. (1979) The structure within industries and companies' performance, The Review of Economics and Statistics, Vol. 61, n 2, pp. 214-227.

[349] Porter, ME. (1980). Competitive strategy, New York: Free Press.

[350] Porter, M.E. (1990). The competitive advantage of Nations. Nueva York: Free Press.

[351] Porter, M.E. (1991). Toward a dynamic theory of strategy. Strategic Management Journal, Vol. 12(Winter Special Issue), pp. 95-117.

[352] Porter, M y Millar, V (1985). How information gives you competitive advantage, Harvard Business Review, vol. July-August, pp. 1-13.

[353] Priem, R.L. y Butler, J.E. (2001). Is the Resource-Based 'View' a Useful Perspective for Strategic Management Research? Academy of Management Review, Vol. 26, no 1, pp. 22-41.

[354] Quinn, J.B, Baruch, J.J. y Zien, K.A. (1996). Software based innovation. The Mackinsey Quartely, No 4, pp.94-119.

[355] Rappa, M. (2005). Business models on the Web. Obtenido el 28/01/2007 de http://digitalenterprise.org.

[356] Rapoport, A. y Chammah, A.M. (1965). Prisoner's Dilemma: A Study in Conflict and Cooperation. Ann Arbor, MI: University of Michigan Press. 
[357] Rayport, J.F.; Sviokla, J.J. (1996). Aprovechar la Cadena de Valor Virtual, Harvard Deusto Business Review, núm. 74, Septiembre-Octubre, pp. 6-16.

[358] Rhoades, G. y Slaughter, S. (2004). Academic Capitalism in the New Economy: Challenges and Choices. Obtenido de http://www.aft.org/pubsreports/american_academic/issues/june04/Rhoades.qxp.pdf el 1/05/2007.

[359] Rialp, A. (1998). El método del caso como técnica de investigación y su aplicación al estudio de la función directiva. Universitat Autónoma de Barcelona. Ponencia presentada en el IV Taller de Metodología ACEDE, Arnedillo (La Rioja). 23-25 Abril.

[360] Ries, A. y Trout, J. (1986). Marketing Warfare. Nueva York: Plume.

[361] Ritzen, J.M.M. (2006). Scenarios for Higher Education, 2020 or When Will China Invade Iran?. Obtenido de http://www.oecd.org/dataoecd/25/33/37051349.pdf el 1/05/2007.

[362] Rodríguez, M.J., Hervás, A., Gallego, E. (2001). Un curso de Enseñanza Asistida por Ordenador de Introducción al Cálculo Simbólico: Las herramientas del profesor. Jornadas de Innovación Docente: Las enseñanzas y el Proyecto Europa.

[363] Rogers, E. (1995). Difussion of innovations. Nueva York: The Free Press.

[364] Rorty, R. (2000). El Pragmatismo, Una Versión. Barcelona: Ariel Filosofía.

[365] Rosa, M.J. y Amaral, A. (2005). A Self-Assessment of Higher Education Institutions from the Perspective of the EFQM Excellence Model. Obtenido de http://www.fup.pt/admin/cipes/docs/eventos/Rosa\&Amaral.pdf el 1/05/2007.

[366] Rosenberg, M.J. (2001). E-learning. Strategies for Delivering Knowledge in the Digital Age. New York: McGraw-Hill.

[367] Rothschild, M. y White, L. (2003). The University in the Marketplace: Some Insights and Puzzles. En Belfield, C.R. y Levin, H. M. (Eds.) The Economics of Higher Education, The International Library of Critical Writings in Economics; Cheltenham, UK: An Elgar Reference Collection.

[368] Ruíz-Rivas, C., (2002). El ámbito europeo de la enseñanza superior: informe de situación y programa piloto de la Comunidad de Madrid. Madrid.

[369] Rumble, G. (1986). The planning and management of distance education. Londres: Croom Helm.

[370] Rumble, G. (1989). The management of distance learning systems. Paris: UNESCO International Institute for Educational Planning, Fundamentals of Educational Planning.

[371] Rumble, G. (1997). The Costs and Economics of Open and Distance Learning. Londres: Kogan Page.

[372] Rumble, G. (2001) Just How Relevant is E-education to Global Educational Needs. Open Learning, Vol. 16, $\mathrm{n}^{\circ} 3$, pp.223-232.

[373] Rumelt, R. (1984). Toward a strategic theory of the firm. Competitive Strategic

Management. Englewood Cliffs, N.J: Prentice Hall.

[374] Ryan, S, Scott, B,, Freeman, H, y Patel, D. (2000). The virtual university: the Internet and resourcebased learning. London: Kogan Page.

[375] Salmi, J. (2001). Tertiary Education in the 21st Century: Challenges and Opportunities, Higher Education Management, Vol. 2, $\mathrm{n}^{\circ} 13$.

[376] Sáez Vacas, F., García, O., Palao, J., Rojo, P., (2003). Temas Básicos de Innovación Tecnológica en las Empresas. Documentación de la asignatura Innovación Tecnológica. Obtenido el 3/04/2007 de http://www.dit.upm.es/ fsaez/innovaciontecnologica.html.

[377] Salerno, C. (2006). Financing higher education: The economics of options, trade-offs and dilemmas. Obtenido de http://www.utwente.nl/cheps/documenten/sls2006/background/slssalerno.pdf el 1/05/2007.

[378] Sánchez, C. (2005). Las Universidades españolas incrementan sus recursos TIC, Revista Sociedad de la Información, Número mayo 2005, pp. 38-53. Obtenido el 15/02/2007 de http://www.socinfo.info/contenidos/pdf15/p38-52universidades.pdf.

[379] Sangrá, A. (2001). La calidad en las experiencias virtuales de educación superior. Obtenido el 16/01/2007 de http://www.uoc.edu/web/esp/art/uoc/0106024/sangra_imp.html. 
[380] Sangrá, A; Sanmamed, M.G. (2004). El profesorado universitario y las Tic. Redefinir roles y competencias, en: Sangrá, A, y Sanmamed, M.G. (Coordinadores) La transformación de las universidades a través de las TIC: discursos y prácticas (pp. 73-97). Barcelona: Editorial UOC.

[381] Sarabia, F.J. (1999). Metodología para la investigación en marketing y dirección de empresas. Madrid: Editorial Pirámide.

[382] Sarabia, J.M. (1992). Dirección empresarial en Cantabria: un análisis crítico. Santander: Cámara de Comercio, Industria y Navegación de Cantabria.

[383] Sawhney, M., Prandelli, E., y Verona, G. (2003). The Power of Innomediation. MIT Sloan Management Review, Winter, pp. 77-82.

[384] Serrano (2002) Indicadores de E-learning. Indicadores de la sociedad de la información. Fuentes Estadísticas, $\mathrm{n}^{\circ} 67$.

[385] Seufert, S. (2007). E-learning business models: framework and best practices. Obtenido de http://www.scil.ch/seufert/docs/elearning-business-models.pdf el 14/01/2007.

[386] Schelling, T.C. (1960). The strategy of conflict. Cambridge, MA: Harvard University Press.

[387] Scherer, F.M. (1980). Industrial market structure and economic performance. Boston, MA: Houghton Miffin.

[388] Scherer, F. M. y Ross, D. (1990). Industrial market structure and economic performance. Chicago, EEUU:Rand McNally.

[389] Schmalensee, R. (1978) Entry deterrence in the ready-to-eat breakfast industry. Bell Journal of Economics. Vol. 9, no 2, pp. 305-327.

[390] Schneider, G. (2002), Electronic commerce. Boston: Course Technology, Thomson Learning.

[391] Schoemaker, P.J.H. (1991). When and how to use scenario planning: a heuristic approach with illustration. Journal of Forecasting. Vol. 10, nº 6, pp. 549-564.

[392] Schoemaker, P.J.H. (1993). Multiple scenario development: its conceptual and behavioral foundation. Strategic Management Journal. Vol. 14, nº 3, pp. 193-213.

[393] Schoemaker, P.J.H. (1995). Scenario planning: a tool for strategic thinking. Sloan Management Review, Vol. 36, n 2, pp. 25-40.

[394] Schumpeter, J.A. (1934). The Theory of Economic Development: An Inquiry into Profits, Capital, Credit, Interest, and the Business Cycle. Cambridge, MA: Harvard University Press.

[395] Scott, J.T. (1982). Multimarket Contact and Economic Performance. The Review of Economics and Statistics, vol. 64, $\mathrm{n}^{\circ} 3$, pp. 368-375.

[396] Scott, J.T. (2001). Designing multimarket-contact hypothesis tests: Patent citations and multimarket contact in the chemicals industry, Advances in Strategic Management, Vol. 18, 175-203.

[397] Scott, P. (1998) Massification, internationalization ands globalization. En Peter Scott (ed.) The Globalization of Higher Education. The Society for Research into Higher Education/ Open University Press, Buckingham, pp. 108-129.

[398] Slater, S.F. (1996). The challenge of sustaining competitive advantage. Industrial Marketing Management, Vol. 25. pp.79-86.

[399] Shattock, M. (2003). Managing Successful Universities; Maidenhead, England: Society for Research into Higher Education \& Open University Press.

[400] Shank, J.K. y Govindarajan, V. (1989). Strategic Cost Analysis: The Evolution from Managerial to Strategic Accounting. Homewood, IL: Irwin.

[401] Shaw, M., Blanning, R., Strader, T. y Whinston, A. (1996). Handbook on Electronic Commerce. Springer.

[402] Skilbeck, M. (2002). The University Challenged: A Review of International Trends and Issues with Particular Relevance to Ireland. Dublin: Higher Education Authority, 2001, p.7. 
[403] Slaughter, S. y Rhoades, G. (2004). Academic Capitalism and The New Economy. Markets, State, and Higher Education; Baltimore and London: The Johns Hopkins University Press.

[404] Smith, K.G., Ferrier, W., y Ndofor, H. (2001). Competitive dynamics research: Critique and future directions. En M. Hitt, R. Freeman, \& J. Harrison (eds.). Handbook of Strategic Management (pp. 315-36). London: Blackwell Publishers.

[405] Smith, F.L, Grimm, C.M. y Gannon, M.J. (1992) Dynamics of competitive strategy. Newbury Park. CA: Sage.

[406] Smith K.G., Grimm, C.M. y Wally, S. (1997). Strategic groups and rivalrous firm behaviour: Towards a reconciliation. Strategic Management Journal, Vol. 18, $\mathrm{n}^{\circ}$ 2, pp. 149157.

[407] Smith, K.G., Grimm, C.M., Gannon, M.J. y Chen, M.J. (1991). Organizational information processing, competitive responses, and performance in the U.S. domestic airline industry. Academy of Management Journal, Vol. 34, $\mathrm{n}^{\mathrm{o}}$ 1, pp. 60-85.

[408] Smith, F.L. y Wilson, R.L. (1995). The predictive validity of the Karnani and Wernerfelt model of multipoint competition. Strategic Management Journal, Vol 16, nº 2, pp. 143-160.

[409] Spagnolo, G., (1999). On interdependent supergames: multimarket contact, concavity, and collusion, Journal of Economic Theory, Vol. 89, pp. 127-139.

[410] Standing Stones Consulting Ltd (2000). Strengthening the Alberta advantage: Business models for distributed learning. Calgary: The Council of Presidents of the Public Universities, Colleges and Institutes of Alberta.

[411] Stonich, P.J. (1982). Cómo implementar la estrategia. Madrid: Editorial Instituto de Empresa.

[412] Su Hu, Y. (1995). The Internacional Transferability of the firm's advantages. California Management Review, Vol. 32, No. 4, pp. 72-78.

[413] Sun-Tzu (1963) The Art of War. Oxford: Oxford University Press.

[414] Sun-Tzu (1993). The Art of Warfare. Nueva York: Ballantine Books.

[415] Tang, C. (1990). The impact of uncertainty on a product line. Management Science, Vol. $36, \mathrm{n}^{\mathrm{o}} 12$, pp. 1518-1531.

[416] Tarazona, J.M., Hervás, A., Esteve, M., Palau, C., Guerri, J.C. (2002). Diseño de un curso básico prototipado. Un modelo integrador. X Congreso de Innovación Educativa en las Enseñanzas Técnicas

[417] Tarazona, J.M., Hervás, A., Esteve, M.(2002). Un enfoque metodológico aplicado a HAUPA. Herramienta de apoyo desarrollada para producir materiales de teleformación. II Congreso de Aplicación de las Nuevas Tecnologías en la Docencia Presencial y e-learning.

[418] Taylor, R.G. y Osorio, J. (2005). Economías del e-learning en la enseñanza superior: estrategias de implantación. En Duart, J.M. y Lupiáñez, F. (2005). Las TIC en la Universidad: estrategia y transformación (pp.85-99). Revista de Universidad y Sociedad del Conocimiento, Vol. $2, \mathrm{n}^{\circ} 1$.

[419] Teece, D. J., Pisano, G., y Shuen, A. (1997). Dynamic capabilities and strategic management. Strategic Management Journal, Vol. 18, nº 7, pp. 509-533.

[420] Teichler, U. (2004). The changing debate on internationalization of higher education, Higher Education, $\mathrm{n}^{\circ}$ 48, pp. 5-26.

[421] Teichler, U.y Jahr, V. (2001). Mobility during the course of study and after graduation, European Journal of Education, Vol. 36, nº 4, pp. 443-458.

[422] Telefónica (2006). La sociedad de la información en España 2006. Madrid: Telefónica.

[423] Temperini, M. (2004). Model for a European Networked University for e-learning, Work Package $2 d$. Obtenido el 4/04/2007 de http://www.hsh.no.

[424] Temple, H. (1995). Cost Effectiveness of Open Learning for Small Firms. A study of first experiences of open learning. Londres: Department for Education and Employment. 
[425] Thomas, H. (1984). Strategic decision analysis: applied decision analysis and its role in the strategic management process. Strategic Management Journal, vol. 5, no 2, pp. 139-156.

[426] Thomas, H. y Pollock, T. (1999). From I-O economics S-C-P paradigm through strategic groups to competencebased competition: reflections on the puzzle of competitive strategy. British Journal of Management, Vol. 10, pp. 127-140.

[427] Thorsby, D. (1991). The financial impact foreign student enrolments. Higher Education, $\mathrm{n}^{\circ} 21$, pp. 351-258.

[428] Thorsby, D. (1998). Financing and effects of internationalisation of higher education. Paris, OCDE.

[429] Tschang, F.T. y Della Senta, T., eds. (2001), Access to Knowledge: New Information Technologies and the Emergence of the Virtual University, Paris: International Association of Universities.

[430] Tünnermann, C. (1996) La educación superior en el umbral del siglo XXI. CRESALC/UNESCO, Colección Respuestas NO. 1, Caracas, Venezuela.

[431] Turban, E., Lee, J., King, D. y Chung, M. (2000). Electronic commerce: a managerial perspective. Upper Saddle River, New Jersey: Prentice Hall.

[432] Turban, E., McLean, E. y Wetherbe, J. (2004). Information technology for management: Transforming organizations in the digital economy. Nueva York: John Wiley \& Sons.

[433] UNESCO (1998), Higher Education in the Twenty-First Century: Vision and Action, World Conference on Higher Education, Paris, 5-9.

[434] UNESCO (1998) World Conference on Higher education: From Traditional to virtual: the New Information technologies.

[435] UNESCO - Educación (2004). Educación Superior en una sociedad mundializada. Documento de orientación. Obtenido de http://unesdoc.unesco.org/images/0013/001362/136247s.pdf el 1/05/2007.

[436] UNESCO - OECD (2005). Guidelines for Quality Provision in Cross-border Higher Education. Obtenido de http://www.unesco.org/education/guidelines_E.indd.pdf el 1/05/2007.

[437] van Vught, F. (1999). Governmental Strategies and Innovation in Higher Education; London: Jessica Kingsley Publishers.

[438] Villanueva, R.J., Hervás, A. (1997). Internet by Internet. APICS'97

[439] Villanueva, R.J., Hervás, A. (1999). A project of Computer Aided Learning: A Course of Computer Algebra in the Web. Tambov University Reports, Vol. 4, № 4, pp.441-418

[440] Villanueva, R.J., Hervás, A. (2000). Un curso de Enseñanza Asistida por Ordenador de Introducción al Cálculo Simbólico en la web. Segundas Jornadas de Investigación y Fomento de la Interdisciplinariedad.

[441] Vincent-Lancrin, S. (2004). Building futures scenarios for universities and higher education. An international approach. that was published in Policy Futures in Education, Vol. $2, n^{\circ} 2$.

[442] Vincent-Lancrin, S. (2006). Globalisation, market forces and the future of Higher Education. Presentado en CERI Expert meeting, Lisboa, 4-5 mayo de 2006.

[443] Vincent-Lancrin, S. (2004). Six Scenarios for Universities. Obtenido de http://www.oecd.org/dataoecd/50/46/36758932.pdf el 1/05/2007.

[444] von Clausewitz, C. (1911). On War, new and revised edition. Londres: Kegan Paul, Trench, Tru" ber and Co.

[445] Von Neuman, J. and Morgenstern, O. (1944). The Theory of Games and Economic Behavior. Nueva York: Wiley.

[446] Vossensteyn, H. (2004). Fiscal stress: Worldwide trends in higher education finance. Obtenido de http://www.nasfaa.org/annualpubs/journal/Vol34n1/Vossensteyn.pdf el $1 / 05 / 2007$. 
[447] VV.AA. (2003). Challenges to University governance structures. Governance in the twenty-first-centuryuniversity: approaches to effective leadership and strategic management. Vol. 30.

[448] Wack, P. (1985a). Scenarios: uncharted waters ahead. Harvard Business Review, Vol. 63, no 5 , pp. 73-89.

[449] Wack, P. (1985b) Scenarios: shooting the rapids. Harvard Business Review, Vol. 63, $\mathrm{n}^{\circ}$ 6, pp. 139-150.

[450] Walker, O.C, Boyd, H.W., Mullins, J. y Larréché, J.C. (2005).Marketing estratégico. Enfoque de toma de decisiones. México: McGraw-Hill.

[451] Ward, J. y Peppard, J. (2002), Strategic planning for information systems. Chichester: John Wiley \& Sons Ltd.

[452] Warner, G. (1992) Internationalization Models and the Role of the University. International Education Magazine, 21.

[453] Warren, K. (1995). Exploring competitive futures using cognitive mapping. Long Range Planning, Vol. 28, $\mathrm{n}^{\mathrm{o}}$ 5, pp. 10-21.

[454] Warren, K. (1999). The dynamics of strategy. Business Strategy Review, Vol. 10, no 3, pp. $1-16$.

[455] Watts, A. G. (1972). Diversity and Choice in Higher Education. London: Routledge Kegan Paul.

[456] Weigel, V. B. (2002). Deep learning for a digital age: technology's untapped potential to enrich higher education. San Francisco: Jossey-Bass.

[457] Weiler, H. N. (2001). States and Markets: Competing Paradigms for the Reform of Higher Education in $\quad$ Europe. Obtenido de http://firgoa.usc.es/drupal/filestore2/download/4986/850_OP16.pdf el 1/05/2007.

[458] Wernerflet, B. (1984). A resource-based view of the firm. Strategic Management Journal, Vol. 5, $\mathrm{N}^{\circ}$ 2, pp.171-180.

[459] Whalen, T. y Wright, D. (1999) Methodology for Cost-Benefit Analysis of Web-Based TeleLearning: Case Study of the Bell Online Institut", American Journal of Distance Education, vol. 15, $\mathrm{n}^{\circ}$ 1, pp. 24-44.

[460] Williams, G. (1993). Total Quality Management: Panacea or Placebo?, Higher Education, $\mathrm{n}^{\circ} 25, \mathrm{p} .229$

[461] Winston, G. C. (2000). Economic Stratification and Hierarchy among U.S. Colleges and Universities. Williams Project on the Economics of Higher Education, Williams College, Discussion Paper No. 58, 2000.

[462] Winston, G. C. (2003). Toward a Theory of Tuition: Prices, Peer Wages, and Competition in Higher Education. Williams Project on the Economics of Higher Education, Williams College, Discussion Paper No. 65, 2003.

[463] Woodrow, M. (1998). From Elitism to Inclusion: A Guide to Good Practice in Widening Access to Higher Education. London: CVCP.

[464] Yang, R. (2002). University internationalisation: its meanings, rationales and implications, Intercultural Education, vol. 13, n 1, pp. 81-95.

[465] Yarzábal, L. (2004). Internacionalización de la Educación Superior: de la cooperación académica al comercio de servicios. Obtenido de http://www.ilaedes.org/documentos/Conferencia\%20UPR\%2004\%20editada.pdf $\quad$ el $15 / 05 / 2007$.

[466] Yin, R.K. (1993). Applications of Case Study Research, Applied Social Research Methods Series, Vol. 34. Newbury Park, Ca: Sage.

[467] Yin, R.K. (1994). Case Study Research-Design and methods", Applied Social Research Methods Series, Vol. 5. Newbury Park, Ca: Sage.

[468] Yin, R.K. (1998). The abridged version of case study research. En Bickman, L., Rog, D.J. (Eds): Handbook of Applied Social Methods (p.229-259). Thousand Oaks: Sage Publications. 
[469] Young, G., Smith, K., y Simon, D. (2000). Multimarket Contact and Resource Dissimilarity: A Competitive Dynamics Perspective. Journal of Management, vol. 26, $\mathrm{n}^{\circ} 6$, pp. 1217-1236.

[470] Zott, Ch. (2000). Strategies for value creation in e-commerce: Best practice in Europe, European Management Journal, Vol. 18, nº. 5; pp. 462. 